
2/ Perspectivas Metodológicas /19/Vol. II /Año 2017

ISSN: 1666-3055

Perspectivas Metodológicas forma parte del Portal de Revistas Científicas de la UNLa "Arturo Peña Lillo" a través del cual se puede acceder a su publicación digital.

(C) Los autores

(C) Ediciones de la UNLa / 2017

29 de setiembre 3901

Remedios de Escalada - Partido de Lanús

Pcia. de Buenos Aires - Argentina

Tel. +54 11 5533-5600 int. 5686 


\section{Perspectivas Metodológicas}




\section{Perspectivas Metodológicas}

ISSN 1666-3055 / Año 17 / Nro. 19 / mayo de 2017

Publicación semestral del Departamento de Humanidades y Artes de la Universidad Nacional de Lanús

\section{Universidad Nacional de Lanús \\ Rectora \\ Ana Jaramillo \\ Vicerrector \\ Nerio Neirotti \\ Departamento \\ de Humanidades y Artes \\ Director \\ Daniel Bozzani \\ Comité Editorial \\ Ana Farber \\ Héctor Muzzopappa \\ Oscar Tangelson \\ Hugo Spinelli}
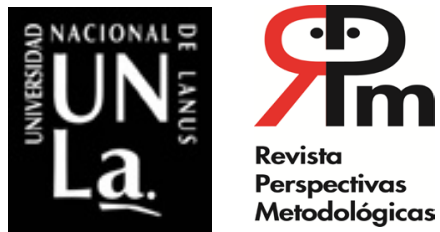

Revista

Perspectivas

Metodológicas

Servicio de indización/service:

EBSCO:

Latindex Sistema Regional de Información en Línea para Revistas

Científicas de AméricaLatina,

El Caribe, España y Portugal

CAICYT - CONICET

Edición digital http://revistas.unla. edu.ar/epistemologia del Portal de

Revistas Científicas de la UNLa "Arturo Peńa Lillo", bajo Open Journal Systems
Staff de la Revista

\author{
Directora \\ Cristina Ambrosini \\ Editor Responsable \\ Andrés Mombrú Ruggiero
}

Comité Editorial

Cristina Ambrosini

Andrés Mombrú Ruggiero

Pablo Martín Méndez

Cecilia Pourrieux

Traducciones

Claudia Bértolo

Comité Asesor

Javier Echeverría

(Universidad Complutense de Madrid)

Ricardo Gómez

California State University)

Manuel Barrios Casares

(Universidad de Sevilla - España)

Massimo Desiato

Universidad Católica Andrés Bello -

Veneruela)

Julio De Zan

(Universidad Nacional de Entre Ríos)

Alfonso Galindo Hervás

(Universidad de Murcia- España)

Daniel Dei

(Universidad Nacional de Lanús)

Mónica Cragnolini

(Universidad de Buenos Aires)

Rodrigo de Paiva Duarte

(Universidad Federal de Minas Gerais -

Brasil)

Roxana Ynoub(Universidad de Buenos Aires (Universidad Nacional de Lanús)

(C) Ediciones de la UNLa

29 de Septiembre 3901 - Remedios de Escalada

Provincia de Buenos Aires - Argentina

Tel.: 5533-5600, int. 5686

Email: metodologia@unla.edu.ar - Sitio web: www.unla.edu.ar 


\section{Índice}

Editorial

\section{Artículos}

Clase, cultura y desigualdad en la perspectiva de los Estudios Culturales británicos y la Sociología de la Cultura de Pierre Bourdieu

Javier Andrés Pińeiro

Aspectos Epistemológicos de la Infoesfera

Mariana Olezza

Propiedad, apropiación y robo en torno a la autoría

Andrés Mombrú

Una técnica de las ciencias sociales: Escritura y auto observación en la investigación en artes

Guadalupe Arqueros .55

"Nosotros: el público ilustrado". Para una breve genealogía de los modos contemporáneos de critica

Pablo Martín Méndez

\section{Perspectivas}

Un perfil de Foucault: Notas a partir de una lectura arqueológica del archivo foucaulteano Iván Gabriel Dalmau 79

Por qué las herramientas juridicas actuales tornan innecesaria una modificación del plexo normativo en materia de Derecho de Autor

Cintia Caserotto Miranda

Aproximaciones analiticas al campo estadístico de la violencia. Avances de investigación

María Belén Muñiz y Cristian Tibaldi . 


\section{Dossier}

Presentación

Esther Díaz; Cristina Ambrosini 103

Bendita tesis: tribulaciones personales e institucionales

Cristina Ambrosini; Andrés Mombrú

La tesis imposible

Horacio Potel

¿Cómo investigar un problema que involucra a distintas disciplinas? (propuestas para la investigación en bioética)

Cecilia Pourrieux

La escritura académica y su evaluación (una experiencia con estudiantes de ingeniería a partir de un tema de geometría analitica)

Vicente Messina; Gloria Cittadini; Carlos Pano

\section{Reseñas}

MOMBRÚ, ANDRÉS. Metodologías y Epistemologías de la Investigación. Fundamentos epistemológicos y técnicas de investigación de algunas de las propuestas metodológicas de las ciencias en general y de las ciencias sociales en particular

Javier Andrés Piñeiro

ALONSO, MANUEL; AMBROSINI, CRISTINA; BERALDI, GASTÓN: Bestiario epistemológico. Metáforas zoomórficas y de otras entidades en la enseñanza de las ciencias y la epistemología

Cecilia Pourrieux 


\section{Editorial}

En Perspectivas Metodológicas estamos -como siempre- abiertos a la recepción de artículos, perspectivas y reseńas que se encuentren relacionados con temas de las metodologías y de las epistemologías de las ciencias, así como de trabajos que pongan en juego estos conceptos vinculados con la investigación y con las problemáticas sociales y culturales que afectan nuestras prácticas como investigadores y docentes comprometidos con la educación pública y de calidad.

En este número y en el próximo de noviembre, queremos poner el énfasis en los temas que hacen a dos proyectos de investigación relacionados con la Maestría en Metodología de la Investigación Científica y el Centro de Investigaciones en Teorías y Prácticas Científicas: Supuestos epistemológicos en la formación de posgrado y su relación con politicas educativas y sociales en Argentina, dirigida por la Dra. Cristina Ambrosini y codirigida por el Dr. Andrés Mombrú, y El concepto de autoría y sus implicancias éticas. Las normativas vigentes, imaginarios y conflictos de interés en universidades argentinas, dirigida por el Dr. Andrés Mombrú y codirigida por el Dr. Hugo Alazrraqui, en el contexto del Departamento de Humanidades y Artes y del Instituto de Cultura, de la Universidad Nacional de Lanús.

Ambas propuestas, plantean líneas de investigación que tienen por cometido tratar la incidencia de problemas que atraviesan, tanto a los contextos teóricos epistemológicos y metodológicos, en los que se reflexiona sobre los fundamentos disciplinares como de aquellas instancias que imbricadas con las anteriores, son determinantes de políticas públicas en investigación y educación, pero también de la conformación de subjetividades que hacen a las prácticas de los docentes-investigadores de nuestras universidades.

Continuamos con la publicación de nuestra sección Dossier, en la que, por el momento, se rescatan publicaciones de los Cuadernos de Trabajo de la Especialización en Metodología de la Investigación Científica y del Centro de Investigación en Teorías y Prácticas Científicas, en sus ediciones pasadas y se intercalan con las producciones recientes. Como se ha señalado en números anteriores, los Cuadernos tienen la intención de permitir que se visualicen las producciones de trabajos de investigación más específicos que son el fruto tanto de investigadores y docentes como de estudiantes de los posgrados del Departamento de Humanidades y Artes de la Universidad Nacional de Lanús.

En el editorial del número 18 se hacía referencia a la imposibilidad de sostener económicamente la publicación de Perspectivas Metodológicas en soporte papel y de las ventajas que - por suerte- nos daba la tecnología, para realizar una propuestas superadora mediante el soporte digital a través del Open Journal System y el Public Knowledge Project. Entende- 


\section{8/ Perspectivas Metodológicas /19/Vol. II /Año 2017}

mos que el hecho de que podamos sostener nuestros proyectos en el plano de la docencia, la investigación y la extensión, a pesar de las cada vez más adversas situaciones que atraviesa el país, y de la que de ningún modo pueden sustraerse las universidades públicas, debe hacernos reflexionar sobre el hecho de que no son posibles las tareas cotidianas que docentes-investigadores llevamos adelante sin las condiciones básicas de sustento material. No hacemos referencia sólo a la problemática de los salarios docentes y de los magros incentivos de investigación, queremos que se tenga en cuenta el significado de la reducción de un $70 \%$ en gastos de infraestructura y equipamiento, la disminución del número de becas para estudiantes de bajos recursos.

Cuando el presupuesto de las universidades baja, lo primero que se trata de garantizar es el salario docente, ya que se trata de un "insumo" imprescindible y el que de mayor modo impacta socialmente. Del mismo modo y proporcionalmente, lo que más se reciente es la investigación y esta actividad, tan importante como la docencia, ya que es la que garantiza la formación de científicos e investigadores comprometidos con las problemáticas de la comunidad. El desfinanciamiento de la investigación atenta contra la autonomía política y genera la dependencia de los centros de producción del primer mundo, muy distantes de nuestras particularidades y necesidades.

Durante la Segunda Guerra Mundial, en la antigua Unión Soviética, en la Oficina de Botánica Aplicada, luego Intituto Vavílov de Industria Genética, los científicos murieron, -como miles de soviéticos- a causa de las hambrunas que la guerra y las pésimas políticas científicas del estalinismo habían producido, sin embargo, resguardaron los bancos de semillas que eran objeto de sus investigaciones y reserva biológica. Dieron con sus vidas, testimonio de que la investigación científica no es un lujo, un gasto, o una simple práctica que busca satisfacer la curiosidad, sino que representa la diferencia entre la vida y la muerte y la continuidad de la especie.

Los debates acerca del lugar que ocupa la producción científico tecnológica en nuestras sociedades ha recrudecido a la luz de nuevos escenarios políticos. Las alertas acerca de los recortes presupuestarios tienen el sentido de evitar retrocesos y evitar nuevas "fuga de cerebros" como los ocurridos en el pasado y que tanto costó reparar. Esta situación no es exclusiva de Argentina sino que se corresponde con el mismo fenómeno registrado en países de la Región y contrasta con los indicadores de desarrollo científico-tecnológico de los países centrales. La existencia de esta disparidad indica la necesidad de seguir consolidando el vínculo entre formación universitaria y políticas científicas puesto que, como todos sabemos, no se trata de aumentar la inversión sin más sino de orientar este esfuerzo que hace el conjunto de la sociedad, en vista al mejoramiento de la calidad de vida de los ciudadanos. Esta alianza de intereses, requiere repensar los modos de reproducción de saberes en el ámbito de las Universidades públicas que es donde se concentra la mayor parte de la inversión en investigación científica, ya que, como dijo Jorge Sábato "[...] los países como los nuestros no pueden darse el lujo de no producir ciencia”.

La ciencia es hoy por hoy la estrategia dominante en lo que refiere a las formas de instalación del hombre en el mundo. Si se desfinancia la educación, la ciencia, la investigación se generará un futuro de pobreza, miseria y muerte, como el que produjo el ingeniero agrónomo Trofim Lysenko en la Unión Soviética. 
La defensa de la educación pública gratuita y de calidad no puede estar separada de la defensa de la investigación científica, tanto en las ciencias naturales y aquellas en el campo de la ingeniería, que brindan beneficios tecnológicos y económicos de interés del Estado, sino de las ciencias sociales, de las humanidades y de la filosofía, cuyo ojo crítico resulta imprescindible a la hora de reflexionar sobre las implicancias y las consecuencias de los desarrollos científicos-tecnológicos.

En este difícil momento para la educación pública, pero también para la investigación y los proyectos de autonomía y emancipación de modelos "regresivos", reivindicamos las luchas de todos los trabajadores de la educación, de la investigación, de las ciencias y de las humanidades que bregan por una sociedad más equitativa y ponen todo su empeño en favor de la comunidad.

Cristina Ambrosini, Andrés Mombrú, Pablo Méndez, Cecilia Pourrieux Miembros del Comité Editor 



\section{Artículos}


12/ Perspectivas Metodológicas /19/Vol. II /Año 2017 


\title{
Clase, cultura y desigualdad en la perspectiva de los Estudios Culturales británicos y la Sociología de la Cultura de Pierre Bourdieu
}

Javier Andrés Piñeiro ${ }^{1}$

javaeiro@hotmail.com

\section{Resumen}

El presente trabajo se propone problematizar la dimensión cultural en la formación de las clases sociales, la delimitación de las fronteras de clase y la legitimación de la desigualdad en la vida cotidiana a partir de una lectura metateórica de dos de las tradiciones que más han influido en los últimos cincuenta años en el análisis de la relación cultura-sociedad: los Estudios Culturales y la Sociología de la Cultura de Pierre Bourdieu. Nuestro interés por estas dos corrientes supone no solamente la voluntad de hacer explícitos los planteos fundamentales que ellas postulan en el plano de la teoría, sino también un intento de indagar aquellos supuestos más generales a partir de los cuales estas teorías se posicionan frente a lo social, y a partir de los cuales construyen una serie de aparatos conceptuales y de categorías para darle sentido a la complejidad del mundo que estudian.

Palabras clave: Estudios Culturales, Sociología de la Cultura, Desigualdad Social.

\begin{abstract}
The following article intends to problematize the cultural dimension in the formation of social classes, the delimitation of class frontiers and the legitimation of inequality in daily life by means of a metatheoric reading of two of the traditions that in the last fifty years have most influenced the analysis of the relation between culture and society: the Cultural Studies and Pierre Bourdieu's Sociology of Culture. Our interest in these two currents implies not only the will to make explicit the fundamental propositions that they postulate at the level of the theory, but also an attempt to investigate those
\end{abstract}

1 Licenciado en Ciencias de la Comunicación (FSOC-UBA). Maestrando en Investigación en Ciencias Sociales (FSOC-UBA). Docente Universitario (FSOC-UBA, CBC-UBA). 


\section{4/ Perspectivas Metodológicas /19/Vol. II /Año 2017}

more general assumptions from which these theories stand in front of the social world, and from which they construct a series of conceptual devices and categories to give meaning to the complexity of the world they study.

Keywords: Cultural Studies, Sociology of Culture, Social Inequality.

\section{Introducción}

El presente trabajo se propone problematizar la dimensión cultural en la formación de las clases sociales, la delimitación de las fronteras de clase y la legitimación de la desigualdad en la vida cotidiana a partir de una lectura metateórica de dos de las tradiciones que más han influido en los últimos cincuenta años en el análisis de la relación cultura-sociedad: los Estudios Culturales y la Sociología de la cultura de Pierre Bourdieu. Nuestro interés por estas dos corrientes supone no solamente la voluntad de hacer explícitos los planteos fundamentales que ellas postulan en el plano de la teoría, sino también un intento de indagar aquellos supuestos más generales a partir de los cuales estas teorías se posicionan frente a lo social, y a partir de los cuales construyen una serie de aparatos conceptuales y de categorías para darle sentido a la complejidad del mundo que estudian. Es por este motivo que, como señalamos más arriba, el abordaje y la puesta en relación de la Sociología de la cultura bourdieuana y de los Estudios Culturales que nos proponemos reviste una intencionalidad metateórica o epistemológica.

A modo de aproximación preliminar a la cuestión, intentaremos hacer un esbozo de caracterización general forzadamente sintético de las dos corrientes teóricas que serán objeto de nuestra indagación.

\section{Birmingham: la heterodoxia marxista}

La fundación del Center for Contemporay Cultural Studies de la Universidad de Birmingham en 1964, viene a darle cauce institucional a la búsqueda de renovación del pensamiento marxista que desde fines de los años cincuenta habían emprendido autores como Richard Hoggart en The uses of literacy (1957), Raymond Williams en Culture and Society (1958) y The Long Revolution (1961), y Edward Palmer Thompson en The Making of the English Working Class (1963). ${ }^{2}$ Uno de los elementos centrales que caracteriza a estas obras es el profundo interés que ponen en el mundo de la cultura, de las experiencias, y de las prácticas de las clases populares, a cuyo estudio están consagradas. Esta reivindicación de la cultura popular como un auténtico espacio de resistencia a las transformaciones del orden capitalista, y la visión de una historia construida a partir de la interacción entre la cultura y la economía, que se pone en juego en las luchas sociales, marca una ruptura epistemológica radical entre el pensamiento birminghamiano y el marxismo ortodoxo que desprecia lo cultural tal como si fuera un mero reflejo especular del único dominio social relevante capaz de darle forma a la auténtica realidad de los hombres: el económico. ${ }^{3}$

2 Nombres como los de Stuart Hall, Perry Anderson y David Morley merecen también ser destacados por la decisiva influencia que su obra ha tenido en el desarrollo de los estudios culturales.

3 En este intento de dar lugar a una teoría materialista de la cultura, fue fundamental la incorporación de los desarrollos de dos importantes teóricos marxistas: el italiano Antonio Gramsci (quien planteo 
Javier Andrés Pińeiro/ Clase, cultura y desigualdad en la perspectiva de los[...]/15

La idea de resistencia al orden cultural, y la convicción de que es imposible abstraer la cultura de las relaciones de poder y de las estrategias de cambio social, es consustancial con la diversidad de dominios explorados por los Estudios Culturales, y con su carácter fuertemente transdisciplinar.

\section{Bourdieu: elementos para un constructivismo estructuralista}

El pensamiento de Pierre Bourdieu se destaca como una de las contribuciones más originales e influyentes para la renovación de la teoría sociológica y de la epistemología de las ciencias sociales de la segunda mitad del siglo XX. Ya sea para acordar con sus postulados o para disentir con ellos, es tanto el reconocimiento y la influencia que la teoría social bourdieuana ha alcanzado en las últimas décadas que el autor ha logrado convertirse en un clásico de las ciencias sociales.

La concepción del pensador francés sobre lo social se constituye como una propuesta de superación de la dicotomía objetivismo-subjetivismo, ${ }^{4}$ como una teoría sociológica capaz de articular los elementos subjetivos y los elementos estructurales que se juegan en la tarea de producir y reproducir cotidianamente el mundo social. En su intento de evitar la Escila del fisicalismo y la Caribdis hermenéutica, la piedra de toque del pensamiento de Bourdieu es la construcción de las categorías analíticas de campo y de habitus.

El concepto de campo -que, al poder ser caracterizado como un subespacio social en el cual un conjunto de individuos desarrollan su praxis, en los que ocupan posiciones diferenciadas, y en los que confrontan por la apropiación y maximización de los diferentes tipos de capital valorados como necesarios para ocupar una posición dominante dentro de ellos (y en relación a otros campos), se ubica del lado de lo estructural- encuentra su complemento en la idea de habitus - conjunto de disposiciones estructuradas y estructurantes que orientan la acción práctica y, por lo tanto, se vinculan directamente con el mundo de la subjetividad y de la agencia humana-. Habitus y campo son, entonces, conceptos dinámicos -que tienen su historia, y que en su interrelación se van transformando- y siendo plenamente relacionales -no se puede pensar a las estructuras y a los sistemas de valores como instancias separadas, sino que sólo tiene sentido pensarlas de manera conjunta-.

que en la sociedad capitalista el dominio no se da por la fuerza sino que es consensuado. Esa forma de dirección social a la que llamó "hegemonía" es siempre dominante pero no de modo exclusivo ni excluyente, de modo tal que supone un campo dinámico de luchas y la existencia de formas de contrahegemonía) y el ruso Valentin Voloshinov (quien estudió los fenómenos discursivos mediante los cuales las clases luchan por la construcción del sentido dentro de la sociedad. El signo, de acuerdo a este lingüista, es el lugar en el que se dirime la lucha de clases. Uno de los principales aspectos sobre los que los de Birmingham pusieron énfasis fue precisamente el estudio de la riqueza comunicativa que implica la dimensión de la discursividad). Para sintetizar diremos que lo que plantean los estudios culturales es la necesidad de concebir a la comunicación como un campo en el que se manifiestan aquellas relaciones de fuerza que dan forma al entramado de lo social, y a la recepción como un proceso complejo (no lineal) mediado por la cultura (así, un mismo mensaje será decodificado de manera muy distinta por diversos sectores sociales, algunos de los cuales podrán aceptarlo sin más mientras que en otros es posible que genere un importante rechazo).

4 Y, más en general, de superar las parejas de conceptos dicotómicos que la sociología ha heredado de la vieja filosofía social, como las oposiciones entre idealismo y materialismo, entre sujeto y objeto, y entre lo colectivo y lo individual. 
El lugar que los sujetos ocupan en los diferentes campos de la estructura social -determinado fundamentalmente por el nacimiento y la crianza, y a partir de ello por el éxito que consigan los individuos a la hora de llevar adelante estrategias que les permitan acumular el capital que otorga reconocimiento en aquellos campos donde se desarrolla su praxis- condiciona los sistemas de ideas, de valores y de representaciones (habitus) a partir de los cuales perciben y actúan sobre el mundo. Partiendo de esta idea, se hace patente en la mirada de Bourdieu un constructivismo estructuralista, vale decir, una concepción de la agencia humana, si bien activa, fuertemente constreñida, acotada, formateada por los componentes estructurales ${ }^{5}$ de la sociedad.

La postura de Bourdieu se reivindica constructivista porque, por un lado, pretende trascender el "sociologismo" -que valoriza lo colectivo a expensas de lo individual- y el "individualismo metodológico" -que valoriza al individuo a expensas de lo colectivo y estructural-, y por el otro, porque trata de aprehender las realidades sociales como construcciones históricas y cotidianas de actores individuales y colectivos, construcciones que tienden a sustraerse a la voluntad y al control de estos mismos actores. Es este reconocimiento explícito de que existen en el mundo social estructuras objetivas independientes de la conciencia y de la voluntad de los agentes, capaces de orientar o de restringir sus prácticas y sus representaciones, la que le pone al constructivismo bourdieuano el carácter estructuralista que lo caracteriza.

\section{Clase, cultura y desigualdad en la mirada teórica de los estudios culturales británicos}

\section{La construcción del concepto de clase social en los Estudios Culturales}

Tal como adelantáramos en la introducción, los Estudios Culturales surgen con la intencionalidad manifiesta de renovar profundamente el pensamiento marxista, liberándolo de sus lastres más dogmáticos. Uno de estos lastres es, precisamente, la dualidad estructura-superestructura, que condena a pensar la cultura como una variable dependiente de la estructura económica. Aun cuando los autores birminghamianos reconocen en todo momento el peso decisivo que tiene sobre la conformación de lo social el condicionamiento material -no hacerlo supondría ya salirse del marxismo-, ven en los fenómenos culturales una especificidad y un grado de autonomía que los hace irreductibles. El determinismo economicista es percibido como un verdadero obstáculo epistemológico para la construcción de una teoría materialista de la cultura, por lo que esta no puede desarrollarse sin operar una ruptura con aquel.

Para los Estudios Culturales una clase social es, por lo tanto, una formación tanto económica como cultural. En este sentido, E. P. Thompson critica a aquellas posturas que separan artificiosamente ser social y conciencia social, o que reducen una de estas instancias a la otra. La propuesta de Thompson consiste en reducir tanto como sea posible -y por la vía de la mediación del concepto clave de experiencia de clase- la distancia entre

5 Porque se originan en un orden social dado del cual son un producto, los habitus son sistemas de disposiciones estructuradas. Y porque estas disposiciones, al hacerse carne en los sujetos, orientan una praxis que se vuelca sobre ese orden social que los posibilitó, es que son estructurantes. 
Javier Andrés Piñeiro/ Clase, cultura y desigualdad en la perspectiva de los[...]/17 los dos polos de la dualidad, de modo tal que aquello que entiende por clase termina siendo, en gran medida, conciencia de clase. ${ }^{6}$ Sobre la experiencia de clase se conforma su conciencia, de ahí la pertinencia de abordar ser y conciencia conjuntamente, sin perder nunca de vista que el ser social condiciona de manera unilateral ${ }^{7}$ y constriñe fuertemente las formas de conciencia, pero sin desconocer que la conciencia no es una simple reproducción simbólica de la lógica que signa las relaciones en las que los hombres incurren en la tarea de producir sus vidas. ${ }^{8}$

En La formación de la clase obrera en Inglaterra, Thompson se propone dar lugar a una historia social fuertemente reivindicatoria de las experiencias, las tradiciones, los usos y costumbres, los hábitos, las diversiones, las canciones populares, las doctrinas políticas, la religiosidad, la alimentación, las estrategias de lucha, las formas de sociabilidad, los mitos, leyendas y valores, vale decir, del imaginario que orienta, da sentido y constituye la praxis de la clase obrera. En franca oposición a los estructuralismos (de izquierda y de derecha) que en su intento de reconstruir la historia se dan el lujo de prescindir de las vicisitudes de los hombres concretos -o que entienden que los sujetos hacen las veces de marionetas cuyos hilos mueve la inercia de las estructuras ${ }^{9}-$, Thompson busca recuperar

6 "La clase cobra existencia cuando algunos hombres, de resultas de sus experiencias comunes (heredadas o compartidas), sienten y articulan la identidad de sus intereses a la vez comunes a ellos mismos y frente a otros hombres cuyos intereses son distintos y habitualmente opuestos a los suyos". (Thompson, 1989, p. 14)

$7 \mathrm{Si}$ bien el concepto de experiencia de clase pone de manifiesto la enorme voluntad que manifiesta Thompson de reducir en su análisis histórico la distancia entre ser y conciencia, el ser social sigue siendo para el autor el factor determinante. Thompson reniega del dogmatismo materialista que caracteriza al marxismo más ortodoxo, pero no así del materialismo ni de la tradición marxista que adopta convencidamente en su mirada. Pensar en una relación más abierta entre los elementos estructurales y la experiencia subjetiva de la agencia humana -de manera que ambos polos resulten alcanzados y modificados por las transformaciones que produce este tipo de interrelaciones- supondría para Thompson salirse completamente del marxismo, algo de lo cual (al menos en La formación de la clase obrera en Inglaterra) no parece tener intención.

8 "La experiencia de clase está ampliamente determinada por las relaciones de producción en que los hombres nacen o en las que entran de manera involuntaria. La conciencia de clase es la forma en que se expresan estas experiencias en términos culturales: encarnadas en tradiciones, sistemas de valores, ideas y formas institucionales". (Thompson, 1989, p.14)

9 En su crítica tanto del estructuralismo marxista como del estructural-funcionalismo parsoniano, Thompson entiende que ambas corrientes -aún desde veredas ideológicas opuestas- terminan por coincidir en la negación de la conciencia de clase, unos tachándola de representación falsa y mistificadora de lo real, y los otros de artificio ideológico disruptivo del orden social. En este sentido, el estructuralismo de inspiración althusseriana entiende que si la clase se define en virtud de la posición que el individuo ocupa en relación a la propiedad de los medios de producción, es posible deducir mecánicamente de esta relación qué conciencia de clase deberían tener estos hombres si tuviesen una real dimensión de sus condiciones de existencia y de sus intereses reales. Si la superestructura cultural distorsiona la percepción al punto de ser fuente de alienación y de falsa conciencia en el obrero, la tarea del partido o del intelectual crítico debe orientarse precisamente a desvelar la conciencia no como es, sino como debería ser. El estructural-funcionalismo, por su parte, cuestiona la propia entidad teórico/ontológica del concepto de conciencia, al que achaca ser "un invento de intelectuales desplazados" con intencionalidades manifiestas de generar perturbaciones innecesarias en la coexistencia armoniosa de los grupos que desempeñan diferentes papeles en la estructura social. Para esta corriente, el mejor aporte que la sociología está en condiciones de hacerle a la praxis social no pasaría, entonces, por contribuir a correr el velo de la falsa conciencia, sino en determinar cuál es la mejor forma de condicionar a los trabajadores para que acepten su papel social, y cuál es el mejor 


\section{8/ Perspectivas Metodológicas /19/Vol. II /Año 2017}

la subjetividad y las condiciones de vida de aquellos hombres que se fueron constituyendo en la clase obrera inglesa a fines del siglo XVIII. De esta manera, a la historia muerta, deshumanizada e inercial de las estructuras, le opone una búsqueda de reconstrucción del mundo de la vida, objetivamente vivido y subjetivamente experimentado por un grupo humano histórica, cultural y socialmente situado. ${ }^{10}$ Lo decisivo en una investigación sobre la formación de la clase del tipo de la que Thompson propone son todos aquellos elementos subjetivos, todas las múltiples experiencias y vivencias, que propician la formación de la conciencia autónoma de clase.

Es por ello que la crítica de Thompson se dirige también hacia aquellas concepciones teóricas que abordan el concepto de clase social en términos esencialistas, ${ }^{11}$ inmanentistas, mecanicistas y/o ahistóricos. ${ }^{12} \mathrm{El}$ autor entiende que es imprescindible tener presente cómo determinados individuos llegaron a desempeñar aquellos roles que juegan en una estructura social, y cómo esta estructura llegó a tener las cualidades que le son características. Lo cual implica la necesidad romper el inmanentismo ahistórico de la mirada estructuralista para pensar lo social como un conjunto de relaciones dinámicas que se van conformando más o menos conflictivamente a lo largo de la historia, y que en el fluir de este tiempo se van transformando y modificando:

Si detenemos la historia en un punto determinado, entonces no hay clases, sino simplemente una multitud de individuos con una multitud de experiencias. Pero si observamos a esos hombres a lo largo de un período suficiente de cambio social, observaremos pautas en sus relaciones, sus ideas y sus instituciones. La clase la definen los hombres mientras viven su propia historia, y al fin y al cabo ésta es su única definición. [...] Estoy convencido de que no podemos comprender la clase a menos que la veamos como una formación social y cultural que surge de procesos que sólo pueden estudiarse mientras se resuelven por si mismos a lo largo de un periodo histórico considerable. (Thompson, 1989, pp. 15-16. El subrayado es mío)

modo de 'manejar y canalizar' sus quejas. Contra el pensamiento estructuralista Thompson nos invita a recordar "que la clase es una relación, y no una cosa" y que, como tal, no existe "ni para tener un interés o una conciencia ideal, ni para yacer como paciente en la mesa de operaciones del ajustador". (Thompson, 1989, p. 15)

10 Thompson denuncia, por idealista y contraria al ejercicio de la historia, la estrategia intelectual que compara el caso inglés con algún tipo de referente que se encarga de dictaminar su excepcionalidad, e insiste en que la experiencia histórica es "en cierto sentido" siempre única. De acuerdo a la mirada thompsoniana la tarea es hacer la historia real de la clase y del movimiento obrero y sus luchas atendiendo a las tradiciones y las condiciones específicas del país en el que surge.

11 "Hoy día existe la tentación, siempre presente, de suponer que la clase es una cosa. No fue tal el sentido que le dio Marx en sus propios escritos de tipo histórico, aunque el error vicia muchos de los recientes escritos 'marxistas'. Se supone que "ella", la clase obrera, tiene una existencia real, que se puede definir de una forma casi matemática: tantos hombres que se encuentran en una determinada relación con los medios de producción" (Thompson, 1989, p. 14)

12 "La noción de clase entraña la noción de relación histórica. Como cualquier otra relación, es un proceso fluido que elude el análisis si intentamos detenerlo en seco en un determinado momento y analizar su estructura. [...] La relación debe estar siempre encarnada en gente real y en un contexto real. Además no podemos tener dos clases distintas, cada una con una existencia independiente, y luego ponerlas en relación la una con la otra". (Thompson, 1989, pp. 13-14) 
Javier Andrés Piñeiro/ Clase, cultura y desigualdad en la perspectiva de los[...]/19

\section{Hacia una concepción dinámica de los procesos históricos}

La cita de Thompson con la que cerramos el apartado anterior hace explícito un elemento característico del pensamiento birminghamiano sobre las clases: considerarlas como formaciones sociales y culturales cuyo ser social y formas de conciencia relacionadas sólo resultan aprehensibles en sus interrelaciones con las otras clases y a lo largo de la historia. A los efectos de indagar las relaciones dinámicas internas que se juegan en el interior de los procesos históricos, Raymond Williams propone tres categorías analíticas que serán las fundamentales en su abordaje materialista de la cultura: lo "dominante", lo "residual" y lo "emergente". Según el autor, todo proceso histórico tiene su orden simbólico dominante, sus características culturales hegemónicas, y este orden se relaciona conflictivamente con elementos culturales -residuales y emergentes- que no han podido ser incorporados, cooptados, asimilados o eliminados por la cultura dominante. ${ }^{13}$ Para Williams, el cambio en las formaciones sociales se genera a partir de las modificaciones que resultan de la dialéctica entre lo dominante y lo residual/emergente a lo largo de la historia. Y en esta confrontación, se destaca la fundamental importancia que tiene el papel activo de los hombres al crear sus condiciones históricas.

Williams entiende por residuales a aquellos elementos que a pesar de haberse formado en el pasado $-\mathrm{y}$, por lo tanto, provenir de órdenes simbólicos anteriores- aún siguen teniendo plena vigencia en el proceso cultural actual, no como una mera pervivencia histórica $-\mathrm{y}$ en esto se diferencian de lo arcaico, de los elementos culturales del pasado o bien perimidos, o bien reconvertidos y asimilados plenamente por el orden dominante actual-, sino como parte viva del presente en el que actúa y sobre el cual produce efectos. Lo residual puede presentar "una relación alternativa e incluso de oposición con respecto a la cultura dominante" (Williams, 2000, p. 144), motivo por el cual la conquista de una cierta autonomía y el avance de estos elementos sobre prácticas, instituciones y formaciones sociales es vista con recelo por el orden simbólico hegemónico.

Un elemento cultural residual se halla normalmente a cierta distancia de la cultura dominante efectiva, pero una parte de él, alguna versión de él -y especialmente si el residuo proviene de un área fundamental del pasadoen la mayoría de los casos habrá de ser incorporada si la cultura dominante efectiva ha de manifestar algún sentido en estas áreas. Por otra parte, en ciertos momentos la cultura dominante no puede permitir una experiencia y una práctica residual excesivas fuera de su esfera de acción, al menos sin que ello implique algún riesgo. Es en la incorporación de lo activamente residual -a través de la reinterpretación, la disolución, la proyección, la inclusión y la exclusión discriminada- como el trabajo de la tradición selectiva se torna especialmente evidente. [...] En la ausencia subsecuente de una fase particular dentro de una cultura dominante se produce entonces

13 "La complejidad de una cultura debe hallarse no solamente en sus procesos variables y en sus definiciones sociales -tradiciones, instituciones y formaciones-, sino también en las interrelaciones dinámicas, en cada punto del proceso que presentan ciertos elementos variables e históricamente variados. [...] En el auténtico análisis histórico es necesario reconocer en cada punto las complejas interrelaciones que existen entre los movimientos y las tendencias, tanto dentro como más allá de una dominación efectiva y específica. Es necesario examinar cómo se relacionan con el proceso cultural total antes que, exclusivamente, con el sistema dominante selecto y abstraído" (Williams, 2000, p. 143) 
la remisión hacia aquellos significados y valores que fueron creados en el pasado en sociedades reales y en situaciones reales, y que todavía parecen tener significación porque representan áreas de la experiencia, la aspiración y el logro humanos que la cultura dominante rechaza, minusvalora, contradice, reprime, o incluso es incapaz de reconocer. (Williams, 2000, pp. 145-146 subrayado es mío)

Por emergente, Williams se refiere a "los nuevos significados y valores, nuevas prácticas, nuevas relaciones y tipos de relaciones que se crean continuamente" (Williams, 2000 , p. 145). Así como el autor remarcó, según vimos, la necesidad de no confundir lo "residual" y lo "arcaico", resalta también la importancia para el análisis materialista de la cultura de distinguir lo auténticamente "emergente" de lo meramente "nuevo". Para ello -y a pesar de las dificultades analíticas que esto involucra -, el desafío es saber diferenciar entre "los elementos que constituyen efectivamente una nueva fase de la cultura dominante" (lo nuevo) y "los elementos que son esencialmente alternativos o de oposición a ella" (lo emergente).

La formación de una nueva clase, tanto en lo que respecta a su ser social -esto es, en la posición objetiva en la que un grupo humano aparece ubicado en la estructura productiva de una sociedad, y en las relaciones asimismo objetivas que lo vinculan con otros grupos humanos- como, fundamentalmente, en las formas de conciencia que esta nueva clase va constituyendo, es fuente generatriz de prácticas y valores culturales emergentes. Buena parte del interés de Thompson, en su estudio sobre la formación de la clase obrera inglesa entre fines del siglo XVIII y comienzos del XIX, pasa por poner de manifiesto cómo en el proceso histórico mediante el cual la clase obrera se va haciendo como clase, los elementos social y culturalmente emergentes -para expresarlo en términos de Williams-, se relacionan en la experiencia vivida de esta clase con los elementos residuales y, sobre todo, con los dominantes, produciendo modificaciones en la formación sociocultural.

\section{La cultura popular como bastión de resistencia}

Apoyándose en sus conceptos de residual y emergente, Williams señala que en la estructura de toda sociedad real "existe siempre una base social para los elementos del proceso cultural que son alternativos o de oposición a los elementos dominantes" (Williams, 2000, p. 146). Resulta, entonces, de fundamental importancia en la propuesta teórica del autor destacar que: "ningún modo de producción y por lo tanto ningún orden social dominante y por lo tanto ninguna cultura dominante verdaderamente incluye o agota toda la práctica humana, toda la energía humana y toda la intención humana" (Williams, 2000, p. 147. En itálica en el original).

En la medida en que los elementos emergentes sean percibidos por la cultura dominante como opuestos al orden legítimo, más bien que como alternativos, lo dominante echará mano de sus habituales estrategias de cooptación intencionada. En este sentido, Williams señala que:

[...] la incorporación franca se ensaya más directamente contra los elementos de clase visiblemente alternativos y de oposición: los sindicatos, los 
Javier Andrés Piñeiro/ Clase, cultura y desigualdad en la perspectiva de los[...]/21 partidos políticos de la clase obrera, los estilos de vida de la clase obrera (incorporándolos al periodismo "popular", a la publicidad y al entretenimiento comercial. En tales condiciones el proceso de emergencia es un movimiento constantemente repetido y siempre renovable que va más allá de una fase de incorporación práctica. (Williams, 2000, p. 147)

En la consideración de la lucha por la hegemonía, hay un rasgo distintivo que merece tenerse en cuenta, todo orden social dominante pasa por considerar qué ese orden debe afianzarse dentro de la escala total de las prácticas y experiencias. Aquello que persigue en definitiva la intensión dominante de lo social es confundirse con el sentido común, embozar su condición de producto social interesado, volverse conciencia práctica.

Entendemos que esta convicción en que la cultura es una arena de luchas por la hegemonía y que, por lo tanto, la lucha de clases es tanto material como simbólica, en que lo dominante no lo es nunca de un modo absoluto, capaz de reprimir completamente lo residual y lo emergente, y en los que estos últimos elementos juegan un papel clave como movilizadores del cambio en la dinámica histórica de las formaciones sociales, constituyen el corazón teórico del pensamiento birminghamiano, aquello que mejor caracteriza su manera de pensar la historia, y de concebir la relación cultura-sociedad.

\section{Clase, cultura y desigualdad en la mirada teórica de la sociología de la cultura de Pierre Bourdieu}

\section{La construcción del concepto de clase social en la teoría bourdieuana}

Uno de los aspectos que los Estudios Culturales y la Sociología de la cultura de este autor comparten -más allá de que luego difieran en varios puntos que más adelante expondremos- es el de considerar que la clase social es una formación tanto económica como cultural. Según la mirada de Bourdieu, la clase social "no se define sólo por una posición en las relaciones de producción, sino también por el habitus de clase que 'normalmente' -es decir, con una fuerte probabilidad estadística- se encuentra asociado a esta posición". La propuesta bourdieuana no es, por tanto, ni una sociología de estructuras sin sujetos ni, mucho menos, una sociología de sujetos sin estructuras.

Hay en Bourdieu, desde el inicio, un reconocimiento explícito de la dimensión del poder como principio rector de las relaciones sociales. El autor plantea que en toda sociedad existe un único orden simbólico dominante del cual las distintas clases participan de manera desigual. Este orden legítimo es el que organiza las posiciones que los individuos ocupan en la estructura social, el que le da sentido a las relaciones de las que los individuos participan en aquellos campos en los que interactúan, y el que legitima la desigual distribución de las diferentes formas de capital que otorgan reconocimiento -fundamentalmente de tipo económico, social y cultural-. Clase dominante es, entonces, aquel colectivo humano que mejor posicionado se encuentra relativamente en su capacidad de apropiamiento de los recursos materiales, simbólicos y sociales que otorgan legitimidad de acuerdo a los valores consagrados por la cultura dominante. 
Lo dominante no es, sin embargo, un todo homogéneo. Muy por el contrario, Bourdieu señala que las disposiciones por medio de las cuales las diferentes fracciones de la clase dominante orientan su conducta y buscan distinguirse son muy dispares, e incluso pueden suponer marcados antagonismos en el interior de la clase. ${ }^{14}$ En este sentido, entendemos que uno de los puntos más interesantes que plantea el autor es el de poner en relación directa los diferentes estilos de vida a los que da lugar la búsqueda de la distinción con un conjunto de elecciones que son tanto estéticas como éticas, correlativas a trayectorias sociales diferentes.

El fin último que persigue la lucha por la dominación entre las facciones dominantes pasa por darse los medios para imponerle al orden simbólico legítimo aquel principio dominante de dominación que más funcional resulte al reconocimiento y valorización del tipo de capital que se posee, vale decir, a los propios intereses. A pesar de no adscribir a posiciones decididamente materialistas, Bourdieu reconoce que, frente al capital económico, el capital cultural es un principio dominado de dominación. En este sentido, si los profesores, intelectuales, o cuadros medios, encuentran serias dificultades para acceder de la pequeña-burguesía a la burguesía, es precisamente por el desbalanceo que caracteriza a su alta capacidad de acumular capital simbólico y a su capacidad relativamente menor de acumular capital económico. ${ }^{15}$

Así, aquellas facciones de origen social pequeño-burgués que deben su ascenso a la clase dominante a una empresa de acumulación de credenciales educativas -y cuyo capital económico está desfasado desfavorablemente respecto de su capital simbólicotenderán a desarrollar un estilo de vida ascético orientado a incrementar y maximizar los recursos culturales de que disponen, y fuertemente crítico de lo que perciben en los sectores genuinamente burgueses como banalidad, derroche, frivolidad, lujo u ostentación. Los miembros de las profesiones liberales - próximos a los profesores y cuadros medios en lo que respecta a capital simbólico, pero de origen mayormente burgués y, por tanto, mucho mejor dotados de capital social y económico- tenderán a llevar, en cambio, un estilo de vida abundante en reuniones sociales plenas de pompa y exhibición de símbolos de la riqueza, porque lo que los intelectuales perciben como un "despreciable derroche" constituye para estos sectores no simplemente un modo de ver y de sentir la vida, sino una necesaria inversión, condición de posibilidad de potenciar su mundo de relaciones, y con ello su imagen, y con ello su capital social, y con ello su capital económico. Cada quien busca hacer de sus necesidades virtudes, para así condenar como arbitrarias las "virtudes" que se corresponden con las necesidades de los otros. Disposiciones éticas y estéticas van en la postura de Bourdieu, como quedo dicho, juntas a la par.

Un aspecto fundamental de la manera en que Bourdieu piensa la agencia es, enton-

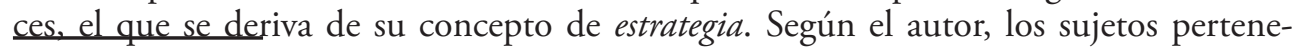
14 "El antagonismo entre estilos de vida correspondientes a los polos opuestos del campo de la clase dominante es, en efecto, tajante, total, y la oposición entre los profesores y los patronos [...] evoca la que separa dos 'culturas' en el seno de la etnología" (Bourdieu, 2006, p.258).

15 De ahí la propensión que manifiestan estos sectores hacia la impugnación de un orden social que no termina de reconocer plenamente sus méritos porque reconoce otros principios de enclasamiento que los del sistema escolar al que le deben su trayectoria social ascendente. Es a este malestar de los sectores intelectuales pequeño-burgueses a lo que Bourdieu denomina "rebelión meritocrática". 
Javier Andrés Piñeiro/ Clase, cultura y desigualdad en la perspectiva de los[...]/23 cientes a los grupos más favorecidos -aquellos a los que el orden social otorga la parte del león en la distribución de los diferentes tipos de capital-, tanto como aquellos que conforman los sectores medios o pequeño-burgueses, así como los más desfavorecidos, implementan estrategias con la finalidad de optimizar y maximizar su participación en los diferentes tipos de capital, de modo tal de poder darle a sus vidas trayectorias sociales ascendentes. No obstante, los sectores dominantes y dominados no se valen -ni podrían valerse, ya que sus posiciones sociales son diferentes, sus recursos son diferentes, y sus habitus son asimismo diferentes- de las mismas estrategias, lo que determina que la búsqueda burguesa esté orientada hacia la distinción, la pequeño-burguesa guiada por la pretensión, y la de los sectores socialmente más postergados signada por la privación.

La distinción propiamente dicha es un asunto exclusivo de dominantes, un lujo que solamente pueden darse aquellos que no viven constreñidos por el imperio de la necesidad. La pretensión marca la paradójica relación pequeño-burguesa con un orden que los incluye favorablemente, aunque nunca tan favorablemente como quisieran. Lo que pretenden los sectores medios es, precisamente, recorrer aquel camino que los lleve a ser cada vez menos pequeño-burgueses y cada vez más burgueses. Bourdieu destaca cómo para conseguir su objetivo ${ }^{16}$ la estrategia característica del habitus pequeño-burgués es la disposición ética hacia la ascesis -reducir el consumo y otras gratificaciones, reducir voluntariamente la natalidad, orientar una parte creciente del ingreso hacia el ahorro, o bien hacia la inversión en servicios educativos, etc.-. Bourdieu pinta de cuerpo entero su mirada sobre la estrategia de movilidad ascendente propia de los sectores medios cuando afirma que un pequeño-burgués no es otra cosa que un proletario que elige hacerse pequeño para poder ser burgués. ${ }^{17}$

La privación es, finalmente, aquello que moldea el habitus de los sectores populares. La cultura popular se rige mediante un principio de necesidad. La estética de las clases populares, según Bourdieu, es funcionalista, pragmática, responde a la necesidad y a la carencia. Por ende, el gusto de los dominados está condenado a ser un no-gusto, un gusto adaptativo o, lo que es lo mismo, un gusto de necesidad.

\section{La dinámica del cambio social en el pensamiento de Bourdieu}

La conceptualización que Bourdieu hace de lo popular es que lo popular no existe como tal, no tiene una entidad propia, sino que es simplemente un producto de aquello único que resulta ontológicamente relevante: lo dominante. ${ }^{18}$ De acuerdo a lo que

16 Objetivo que bien puede ser intergeneracional, es decir, para que los frutos del esfuerzo en pos de una trayectoria social ascendente sean recogidos por hijos o nietos, mucho más que por quien realiza ese esfuerzo.

17 En este sentido, el autor señala que aquellos agentes que desarrollan trayectorias sociales ascendentes suelen guiar sus prácticas según los principios del habitus del lugar social destino de sus trayectorias, más bien que según el habitus de origen.

18 "Los que creen el la existencia de una 'cultura popular', verdadera alianza de palabras mediante la cual se impone, quiérase o no, la definición dominante de la cultura, no deben esperar encontrar, si van a ver lo que hay ahí, otra cosa que los dispersos fragmentos de una cultura erudita más o menos antigua [...] seleccionados y reinterpretados evidentemente con arreglo a los principios fundamentales del habitus de clase e integrados en la visión unitaria del mundo que éste engendra, y no la contracultura que ellos reclaman, cultura enfrentada a la cultura dominante, reivindicada con todo 


\section{4/ Perspectivas Metodológicas /19/Vol. II /Año 2017}

Bourdieu denomina el "principio de buena voluntad cultural" (Bourdieu, 2006, pp. 321-322), lo que la investigación empírica pone de manifiesto es que aquellos sectores que menos conocen la cultura legítima -dado el lugar marginal que el orden social les asigna- son, paradójicamente, los que más la reconocen. No ve el autor en las disposiciones que orientan las prácticas de los dominados nada que se asemeje a alguna forma de impugnación o de resistencia frente a la cultura oficial, sino más bien una finalidad adaptativa y acomodaticia, así como resignación y vergüenza por la propia ignorancia. ${ }^{19}$ Y no solamente esto: ni siquiera hay lugar para el "alternativismo".

Si para Bourdieu, como vimos, hay un solo orden social legítimo y lo popular aparece negado, se hace evidente que el cambio social solamente puede producirse desde arriba. A diferencia de Thompson y de Williams -que ven en las prácticas, experiencias y luchas de los sectores populares un suelo fértil para la emergencia de nuevos valores y de nuevas formaciones sociales-, el dominocentrismo que singulariza a la mirada de Bourdieu lo lleva a postular que ninguna genuina "emergencia" puede provenir de las prácticas de los dominados, sino que la dinámica del cambio social se da por medio de transformaciones y rearticulaciones propias de las relaciones de fuerza de los dominantes. ${ }^{20}$

conocimiento como símbolo de estatus o profesión de existencia separada" (Bourdieu, 2006, p.325).

19 En este sentido, Bourdieu afirma que los miembros de las diferentes clases sociales "se distinguen menos por el grado en que reconocen la cultura que por el grado en que la conocen: son excepcionales las declaraciones de indiferencia y más excepcionales son aún las repulsas hostiles. [...] Uno de los más seguros testimonios de reconocimiento de la legitimidad reside en la propensión de los más desposeídos a disimular su ignorancia o su indiferencia y a rendir homenaje a la legitimidad cultural". Asimismo, sostiene que sería fácil "enumerar las características del estilo de vida de las clases dominadas que encierran, a través del sentimiento de incompetencia, de fracaso o de indignidad cultural, una forma de reconocimiento de los valores dominantes. [...] Tanto como por la ausencia de todos los consumos de lujo, el estilo de vida de las clases populares se caracteriza por la presencia de sustitutivos en rebaja de muchos de esos bienes especiales, índices de una carencia en segundo grado que se deja imponer la definición de los bienes dignos de ser poseídos" (Bourdieu, 2006). El enorme crecimiento que han tenido en los últimos años las ferias del estilo "La salada", en las que se venden prendas de vestir que son réplicas de segunda perfectamente logradas en su carácter imitativo de las que diseñan las grandes marcas, parece se un fenómeno en consonancia con el planteo bourdieuano. Es también significativa la predisposición que manifiestan los sectores populares -al menos los de la zona metropolitana de Buenos Aires y sus suburbios- a la compra de zapatillas y ropa deportiva "de marca", así como de dispositivos de alta tecnología, cuyos altos precios aparecen desfasados respecto de unos ingresos económicos relativamente bajos. Lejos de pretender rebelarse contra los símbolos de estatus de ese orden que los condena a la subalternidad, los dominados parecieran querer buscar una mayor inclusión en él por medio de la práctica del consumo. En la utilización del sociolecto dominante que los dominados realizan en sus lugares de trabajo frente a sus patronos o a sus clientes también parece ponerse de manifiesto el reconocimiento de la legitimidad cultural. Las jergas, los vocativos, los giros lingüísticos y otras formas del habla que caracterizan a los modos de comunicación mediante los cuales los dominados se relacionan entre sí cotidianamente, y que funcionan para estos sectores como marcas identitarias, son puestas en suspenso en beneficio de las formas de habla legítimas a la hora de ir a golpear la puerta de la fábrica para buscar trabajo.

20 Una de las críticas más interesantes a esta postura de Bourdieu es la que le hace Michel De Certeau en La invención de lo cotidiano. A diferencia de Bourdieu, De Certeau descree de una cultura dominante que impone sus preceptos a los dominados sin que estos opongan resistencia, y de unos dominados que se conformen con estar situados culturalmente hablando en los intersticios que le deja la cultura dominante. Sí afirma, en cambio, que las reglas de juego -las estrategias- las imponen los dominantes. Los dominados apelan a prácticas de desvío -tácticas- para hacer frente a esta dominación. Así, el sujeto popular se muestra siempre dispuesto a contradecir el camino que pretende imponérsele. Las tácticas son propias de los débiles (el arte de los débiles), las estrategias sólo de los dominantes 
Javier Andrés Piñeiro/ Clase, cultura y desigualdad en la perspectiva de los[...]/25

Un ejemplo de emergencia que da Bourdieu es la formación de una nueva facción de la clase dominante a la que denomina "nueva burguesía", y que se caracteriza principalmente por su oposición a la vieja burguesía industrial y comercial. Estos burgueses de la nueva ola -que suelen llegar más jóvenes a posiciones de poder, cuentan con credenciales educativas, y se desempeñan en las empresas más modernas y pujantes del sector privado-, buscan distinguirse de la burguesía tradicional -y de sus "vacaciones en balnearios, sus recepciones y sus obligaciones mundanas" - llevando adelante un estilo de vida más "modernista" y más "joven". La nueva burguesía condensa además la posesión de atributos que solían marcar polarizaciones en el interior de la clase dominante: por un lado capital cultural en alto grado, bastión tradicional de los intelectuales y los miembros de las profesiones liberales, y por el otro el estilo de vida lujoso y cosmopolita que solamente puede otorgar un capital social y económico muy alto, bastión tradicional de la vieja burguesía.

Bourdieu señala que la nueva burguesía debe su conquista de las posiciones más altas del poder al haber sabido ponerse a la vanguardia de las transformaciones que en el ámbito de la economía y de la cultura marcaron la transición desde el capitalismo ascético basado en la moralidad protestante, a un capitalismo basado en la moral hedonista del consumo. En este sentido, la nueva burguesía se constituye como la punta de lanza "de la transformación de las disposiciones éticas y de la visión del mundo que se realiza en el seno de la burguesía, que a su vez se encuentra en la vanguardia de una transformación general del estilo de vida" (Bourdieu, 2006, p. 270).

\section{A modo de conclusión}

\section{Entre la dialéctica aceptación/resistencia y la buena voluntad cultural de los dominados}

La negación que Bourdieu hace de lo popular ${ }^{21}$ es un punto de su postura sumamente controversial que, como tal, ha despertado enormes polémicas. Al contrastar la mirada bourdieuana sobre lo popular con aquella que caracteriza a la de los Estudios Culturales, el contrapunto que se genera es evidente.

Como vimos en la primera parte de este artículo, en la lectura de los procesos sociales que realizan los intelectuales de Birmingham desempeña un papel central el concepto de gramsciano de hegemonía. Pensar en términos de hegemonía supone concebir un orden social dominante que no puede serlo nunca de un modo total o exclusivo, que está atravesado por una dialéctica de aceptación y resistencia, que debe convivir conflictivamente con elementos residuales y emergentes disruptivos y potencialmente contrahegemónicos. En este sentido, Williams afirma que la hegemonía:

(De Certeau, 2000).

21 Y no sólo de lo popular, sino también de la llamada "cultura media". Bourdieu sostiene que "no existe cultura media como no existe lenguaje medio. Lo que constituye la cultura media es la relación pequeño-burguesa con la cultura, error de objeto, equivocación, creencia mal situada, alodoxia" (Bourdieu, 2006). 
[...] debe ser continuamente renovada, recreada, defendida y modificada. Asimismo, es continuamente resistida, limitada, alterada, desafiada por presiones que de ningún modo le son propias. Por tanto, debemos agregar al concepto de hegemonía los conceptos de contrahegemonía y de hegemonía alternativa, que son elementos reales y persistentes de la práctica. [...] La realidad de toda hegemonía, en su difundido sentido político y cultural, es que, mientras que por definición siempre es dominante, jamás lo es de un modo total o exclusivo. [...] Esto significa que las alternativas acentuaciones políticas y culturales, y las numerosas formas de oposición y lucha son importantes no sólo en sí mismas, sino como rasgos indicativos de lo que en la práctica ha tenido que actuar el proceso hegemónico con la finalidad de ejercer su control. [...] Por lo tanto, el proceso cultural no debe ser asumido como si fuera simplemente adaptativo, extensivo e incorporativo". (Williams, 2000, pp. 134-136)

Ninguno de estos argumentos le resultan convincentes a Bourdieu, quien se muestra mucho más proclive a afirmar que es el mismo orden social legítimo aquel que produce y limita sus propias "formas de contracultura" (para expresarlo en términos birminghamianos). La "contracultura" sería también, de esta manera, un producto de lo dominante.

La conceptualización que Bourdieu hace de lo popular no solamente ha entrado en disputa con el abordaje de los Estudios Culturales, sino que ha recibido también críticas y objeciones desde el propio seno mismo de la Sociología de la Cultura francesa. En Lo culto y lo popular (1992), Claude Grignon y Jean-Claude Passeron cuestionan lo que ellos ven en Bourdieu como una sociología de cuño legitimista, y postulan que lo propio de la sociología de la cultura no es definir lo popular por la negativa, como un conjunto de carencias con respecto a la cultura dominante, sino tratar de reponer su densidad simbólica. La postura de Bourdieu, afirman, no hace más que abolir todas las propiedades en la indiferenciación de las carencias. Lo que Grignon y Passeron se proponen, entonces, es operar distinciones y establecer variaciones donde el dominocentrismo bourdieuano no ve sino uniformidad, vacío y homogeneidad.

Grignon y Passeron concluyen que las clases dominadas, al igual que las dominantes, tienen un estilo para sí -más allá de los estilos de las otras-, echan por la borda el concepto de habitus, al afirmar que los individuos no ejecutan mecánicamente una partitura o un programa, y proponen como método la interpretación de las prácticas. Asimismo, señalan que el relativismo cultural que lleva implícito reconocer la igual dignidad que tiene lo popular frente a lo culto no debe hacer olvidar que la dominación existe, y que se hace patente en la cotidianeidad de los dominados. Es por esto que para superar el etnocentrismo bourdieuano aplicando categorías dominomórficas -las únicas herramientas de análisis de las que disponen- plantean como metodología la ambivalencia y la alternancia entre el relativismo y el dominomorfismo (Grignon, Claude; Passeron, Jean-Claude, 1992). 
Javier Andrés Piñeiro/ Clase, cultura y desigualdad en la perspectiva de los[...]/27

\section{Bibliografía}

— Bourdieu, Pierre (2006). "El sentido de la distinción", "La buena voluntad cultural" y "La elección de lo necesario". En La distinción. Criterio y bases sociales del gusto. Taurus, Barcelona.

— De Certeau, Michel (2000). "Valerse de: usos y prácticas". En La invención de lo cotidiano I. Artes de hacer. Universidad Iberoamericana, Instituto Tecnológico y de Estudios Superiores de Occidente, México.

- Grignon, Claude; Passeron, Jean-Claude (1992). "Relaciones de fuerza y dominación simbólica", y "Alternancia y ambivalencia". En Lo culto y lo popular. Ediciones de La Piqueta, Madrid.

— Thompson, Edward Palmer (1989). "Prefacio". En La formación de la clase obrera en Inglaterra., Critica, Barcelona.

- Williams, Raymond (2000). "Dominante, residual y emergente", y "Hegemonía". En Marxismo y literatura. Península, Barcelona. 
28/ Perspectivas Metodológicas /19/Vol. II /Año 2017 


\title{
Aspectos Epistemológicos de la Infoesfera
}

\author{
Mariana Florencia Olezza ${ }^{1}$ \\ marianaolezza@gmail.com
}

\section{Resume}

El objetivo de este artículo es analizar críticamente desde un punto de vista epistemológico la "Infoesfera": Entendemos como Infoesfera a Big Data junto con los agentes que operan en ella procesando información. A modo introductorio se definirán estos conceptos. En la primera parte del trabajo se explorarán los conceptos de Niveles de Abstracción y Realismo Estructural Informacional, y se explicará su utilidad. En la segunda parte, se expondrá lo importante que es la recolección de datos para el poder dominante: El caso a analizar será la vigilancia masiva con algunas de sus metodologías. En la tercer parte se debatirá acerca de dos casos de control de masas de población: Marketing (político) y Algocracia. Finalmente se mostrará un diagrama general de la Infoesfera, este nuevo panóptico digital, como cierre.

Palabras clave: Algocracia Big Data, Filosofía de la Información, Sociedad del Conocimiento, Vigilancia Masiva, Simulaciones, Poder.

\section{Abstract}

In this article we will discuss from an epistemic point of view the "Infosphere": We understand Infosphere as Big Data plus the agents which operate in it, processing information. On the introduction we will define and categorize this two concepts in detail. The article consists in three parts. On the first part, the concepts of Levels of Abstraction and Informational Structural Realism will be explored and their utility will be explained. On the second part, how important is the collection of data for the dominant power is explained: The study case will be mass surveillance with some of its methodologies. Finally we will analyze two cases of mass control: Political marketing and algocracy. Adiagram of this new "digital panoptic", the Infosphere, will be displayed.

Keywords: Algocracia, Big Data, Philosophy of Information, Knowledge Society, Mass Surveillance, Simulation, Power. 


\section{Introducción}

Un dato acerca de los datos: Aproximadamente la humanidad acumuló 180EB entre la invención de la escritura y el 2006. Solo entre el 2006 y el 2011, el total creció 10 veces y llegó a 1600EB. (1 Exabyte $=2^{60}$ byte).

En esta sociedad del conocimiento, comienzan a ser cada vez más difusos los límites entre la realidad-"real" y la realidad-virtual, a través de distintas tecnologías que recién están dando sus primeros pasos, como Realidad Aumentada, Web Semántica e Internet de las Cosas, por mencionar algunas. La ubicuidad cada vez es mayor, y lo que fusione lo virtual con lo "real" estará probablemente en forma de dispositivos no solo embebidos en los agentes artificiales (como displays en sistemas embebidos de todo tipo, o computadoras, smartphones, etcétera), sino como en forma de extensiones a nuestros sentidos (como con lentes para la realidad virtual, por ejemplo).

Con respecto al área de Internet de las Cosas, el desarrollo viene en una escalada exponencial: Se calcula que para 2020 habrá en el mundo 50.000 millones de dispositivos de todo tipo, conectados a Internet. Generarán $44 \mathrm{ZB}$ de datos aproximadamente anuales, o lo que es lo mismo, 44.000 millones de terabytes (TB).

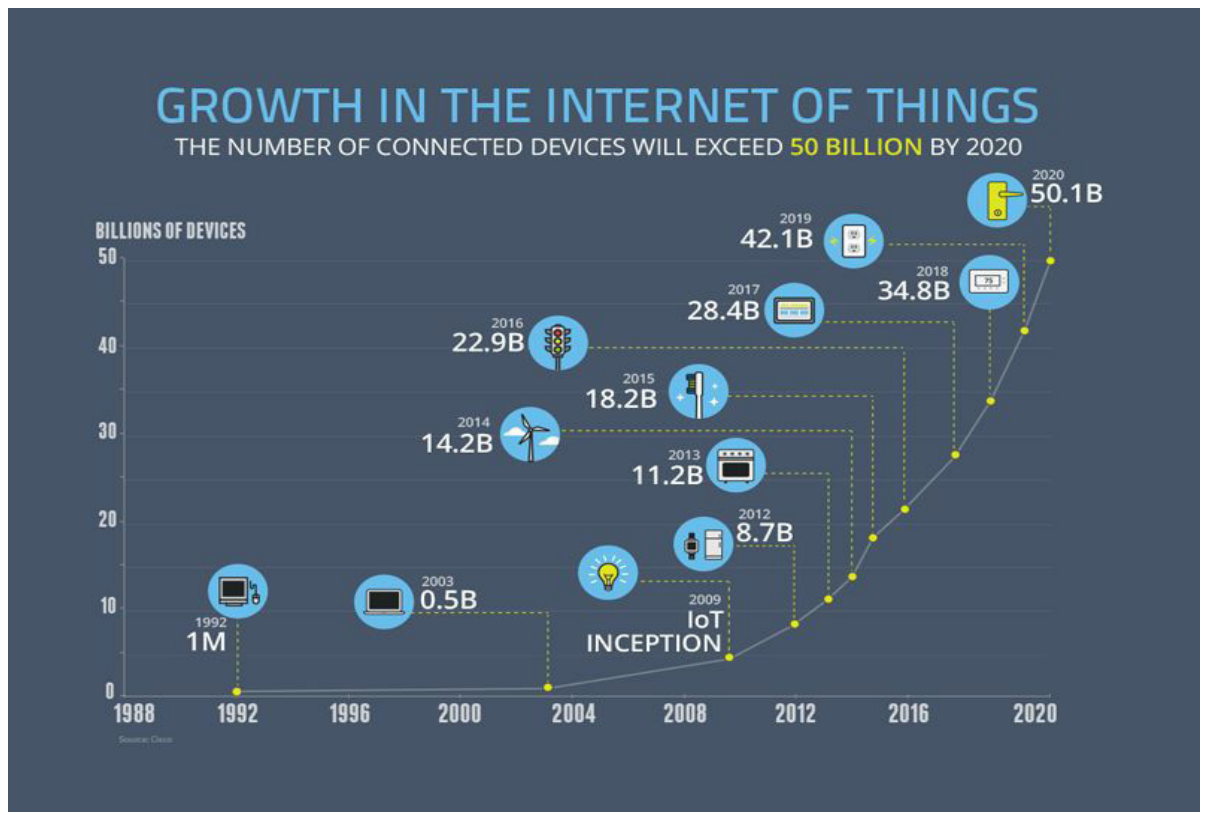

Gráfico 1. Evolución del Internet de las Cosas

La noción de Big Data muchas veces se presta a confusión, y de hecho en una rápida indagación "socrática" se llega a la conclusión de que pocos saben bien el significado del concepto de Big Data (incluyendo a los que "trabajan con Big Data"). Su descripción oficial en la página de la NSF (National Science Foundation) tampoco aclara mucho las cosas. ¿¿ué dice exactamente? 
Mariana Olezza/ Aspectos Epistemológicos de la Infoesfera/31

Big Data: Sets de datos distribuidos, complejos, diversos, grandes, longitudinales, generados de: Instrumentos, sensores, transacciones por Internet, email, video, streams de clics, y/o cualquier fuente digital hoy y en el futuro.

Consideremos Big Data a todos los datos almacenados en algún tipo de base de datos, o en flujo, extraídos de diferentes fuentes -sea de:

1. Internet en general, pasando por todas sus capas de aplicaciones, como las redes sociales (en forma de comentarios, fotos, videos, likes).

2. Datos científicos producidos por estaciones meteorológicas, nucleares, etc.

3. Datos de cualquier organización en bases de datos como hospitales, empresas de ventas.

4. Aplicaciones para usuarios individuales enfocados a celulares/tablets que registran variaciones en el tiempo de alguna actividad del usuario (actividad física, comida, libros que leyó, etc.).

5. Datos de sensores, como cámaras (de los cuales se prevé un crecimiento exponencial debido al área de Internet de las Cosas).

Los datos también pueden ser datos en sí (semánticos, como el contenido de una conversación), o metadatos (duración de la llamada). Los metadatos son extremadamente importantes como veremos en la modelización de objetos informacionales, ya que brindan información como:

$>$ Duración de una llamada

$>$ Frecuencia entre llamadas

$>$ Conexión entre agentes, es fácil ver cómo se puede armar una red y un tendido.

Con respecto a los agentes, con "entelequia", pudiendo transmitir, recibir y procesar información, plantean también complejidad en su multiplicidad y es interesante para el análisis tener en cuenta los diversos tipos que coexisten en la Infoesfera, e ir más allá de la mirada antropocéntrica, hacia la ontocéntrica. Podríamos hacer la siguiente clasificación:

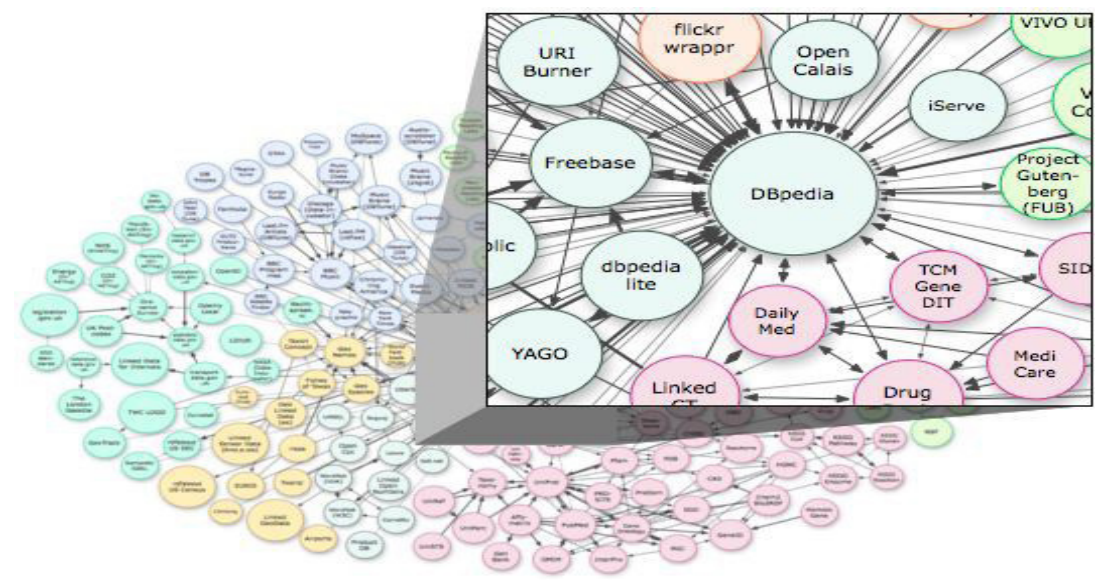

Gráfico 2. Web Semántica. Hace uso de los metadatos 
32/ Perspectivas Metodológicas /19/Vol. II /Año 2017

1. Vivientes:
a. Humanos
b. No humanos

2. No vivientes:

a. Organizaciones. Compuestos por humanos y bases de datos + capacidad de cómputo (científicas, gubernamentales, corporativas)

b. Autómatas a cualquier nivel, con o sin hardware (por ejemplo computadoras, inteligencia artificial de distintos niveles de complejidad, etc. El área de Internet de las Cosas muy involucrada aquí)

c. Autómatas sin hardware: Bots en la red.

Hay que notar que actualmente el lugar privilegiado del conocer humano es por lo menos parcialmente cuestionado no sólo a través de los esfuerzos para explicar científicamente el emerger de la conciencia, sino con proyectos tecnológicos de Inteligencia Artificial. De acuerdo a Capurro "ni la ciencia ni la tecnología de la información han tenido un rol de peso en la discusión filosófica. Esto se puede interpretar como un signo de la alienación mutua entre el discurso filosófico y esta disciplina así como con el proceso tecnológico" (Capurro, 2003).

En el área de las ciencias de la información creemos que estamos en los umbrales de una nueva crisis, o mejor dicho en el comienzo de una revolución de la que hay que tomar plena conciencia, más allá de las diversas posturas optimistas/pesimistas. Es un punto de inflexión.

Así como pasamos de la prehistoria a la historia cuando obtuvimos medios materiales para dejar registros de nuestras sociedades, hoy estamos en un nuevo nivel de la historia produciendo registros con base material, pero de formato inmaterial, en... "la nube". ¿Qué es la nube? ¿Es una buena idea tener nuestros datos en servidores en cualquier lugar del mundo?¿Están en "cualquier lugar" o mayormente concentrados en determinados lugares geográficos? Estas sociedades con sus redes digitales (y sus estructuras, que permiten la distribución one-to-many de los mensajes) ha provocado una revolución mediática y epistémica, y el surgimiento de nuevos problemas a resolver.

Actualmente hay una tendencia a un "sistema de memoria transactivo", donde recordar hechos y conceptos se comparte en un grupo social. Y la mente humana individual representa un tope del almacenamiento de la información. Nuestras mentes funcionan como un límite en esta gran nube por donde circula información y se arman mapas mentales, creando ideas (sugerencias de Google, por ejemplo). Y sin embargo, a pesar de ser nosotros transparentes, entregando nuestros datos "en bandeja", gran parte de la maquinaria permanece en total oscuridad para nosotros. Ese debate ético informacional está en puerta.

Y por otro lado es curioso, porque nos encaminamos hacia una fase de "era digital oscura", ya que la creación de dispositivos de almacenamiento no puede seguirle el paso a la creación de procesadores. Desde el 2007 tenemos una falta de capacidad para guardar datos debido a este desfase. Entre la obsolescencia tecnológica, las leyes de copyright, y el deterioro de los datos, nuestra memoria digital, va seleccionando "naturarficialmente" qué recordar y qué olvidar. 
Mariana Olezza/ Aspectos Epistemológicos de la Infoesfera/33

No es la de Funes, ${ }^{2}$ evidentemente.

A la Infoesfera, que pretendemos analizar, al mezclar agentes de tan diversas características que comparten en común su entorno informacional, ya sea virtual o real, es muy interesante pensarla por medio del Realismo Estructural Informacional (REI) de Floridi.

Se analizará lo que los agentes conocen en el medio informacional, a través de REI que deriva del Realismo Estructural (RE) y de sus corrientes Realismo Estructural Epistémico (REE) y Realismo Estructural Óntico (no-eliminativista) (REON). En esta entrega por motivos de simplicidad no entraremos en detalles acerca de REE y REON pero si entendemos que es necesario explicar el concepto de Niveles de Abstracción (NdAs).

\section{Los Niveles de Abstracción y el Realismo Estructural Informacional}

El método de los Niveles de Abstracción deriva de técnicas de modelado en el área de las Ciencias de la Computación. En Matemática Discreta se usa para especificar y analizar el comportamiento de sistemas de información.

Los NdAs son Sets no vacíos finitos de observables. Los sistemas a modelar pueden ser enteramente ficticios, de modo que los observables no siempre son "empíricamente observables". Al ser una abstracción, un observable no es necesariamente el resultado de una medida cuantitativa o percepción. Podemos pensar en una simulación, donde muchos observables pueden ser variables internas de la misma, y otras venir de datos recogidos empíricos.

A continuación se expondrá un breve ejemplo de $\mathrm{NdA}$. Un NdA es discreto si y sólo si todos sus observables son discretos, de modo contrario se llama híbrido.

Consideremos un ejemplo de NdA, en un semáforo. Supongamos que deseamos describir el estado del tráfico. Consideramos un vector observable, llamado:

color $=\{$ rojo, amarillo, verde $\}$.

que corresponde con el color indicado por la luz. Esta opción abstrae:

- Tiempo de duración para color

- Longitud de onda exacta

- Altura a la que se exhibe

- Etcétera.

Si quisiéramos considerarlo, sería:

color=

$\left[\left\{t_{\text {rojo }}\right\},\left\{t_{\text {am }}\right\},\left\{t_{\text {verde }}\right\}\right.$;

$\{\lambda$ rojo $\},\{\lambda$ am $\},\{\lambda$ verde $\}$;

$\{h$ rojo\}, $\{h$ am $\},\{h$ verde $\} ;]$

2 El memorioso, JL Borges (Ficciones, 1944). 
Como se puede observar, no existe un límite superior, le podemos seguir agregando dimensiones ad infinitum teóricamente.

Para un agente que está en el proceso de diseño o construcción del semáforo, o para el agente mismo semáforo como entidad ${ }^{3}$ (objeto informacional como veremos más adelante), el NdA mas detallado probablemente en el que estaría situado. Para un peatón el $\mathrm{NdA}$ más abstracto, es con el que se relacionará.

Ser explícito acerca del NdA adoptado, evita ambigüedades, falacias y errores que se pueden dar si dos agentes discuten acerca de un mismo fenómeno pero analizandolo desde distintos NdA (refiriéndose a lo mismo con diferente nivel de granularidad, por ejemplo).

Desde Newton y Leibniz, los comportamientos de los observables analógicos, estudiados en la ciencia, se han descripto por medio de ecuaciones diferenciales. El uso de predicados para demarcar el comportamiento de un sistema es esencial en cualquier análisis no trivial de sistemas discretos o híbridos, y los informacionales son de este tipo, o sea los procesos desarrollándose en el espaciotiempo tienen saltos de discontinuidad entre el adentro y el afuera de sistemas, sea entre el adentro y el afuera de un agente, el cambio de estado de un fluido, etc.) porque en estos no se mantiene la continuidad: El cambio de un observable en un solo valor puede llevar al cambio radical del comportamiento del sistema. Los comportamientos aproximados son descritos exactamente, por un predicado, en un determinado Nivel de Abstracción. Este formalismo provisto por el método de abstracción puede ser visto como haciendo para los sistemas discretos, los que el cálculo diferencial ha hecho tradicionalmente para los sistemas analógicos.

Para terminar de conceptualizar los NdA, podemos hablar de los Gradientes de Abstracción (GdAs). Para un sistema dado (empírico o conceptual) distintas NdA corresponden a distintas representaciones o vistas. Un GdA provee un mecanismo de variar los NdA para hacer observaciones en diferentes NdA relacionados. $G d A=\{N i / 0$ $\leq i<n\}$, siendo $N i=\mathrm{NdA}$ Nivel de Abstracción moderado ${ }^{4}$ y una familia de relaciones $\mathrm{R} i, j \ldots$ para $0 \leq i \neq j<n$ relacionando los observables de cada par de Niveles de Abstracción $\mathrm{Ni}$ y $\mathrm{Nj}$ de forma tal que:

1. Las relaciones son inversas: Para i distinto de j, $R i, j$ es la inversa de $R j, i$

2. El comportamiento moderando cada Nivel de Abstracción inferior es consistente con lo que está especificado por un nivel superior. (Sucede "lo mismo" en todos los NdAs... solo que a mayor nivel de granularidad se ven más detalles).

Un GdA (Gradiente de Abstracciones) anidado es ideal para describir un sistema complejo exactamente a cada Nivel de Abstracción:

3 Es un agente $2 \mathrm{~b}$ : Un autómata, máquina de Moore.

4 Un NdA moderado se define como el NdA junto con el comportamiento de ese NdA (por ejemplo la restricción de que el observable " $x$ " se mantenga entre determinados límites). 


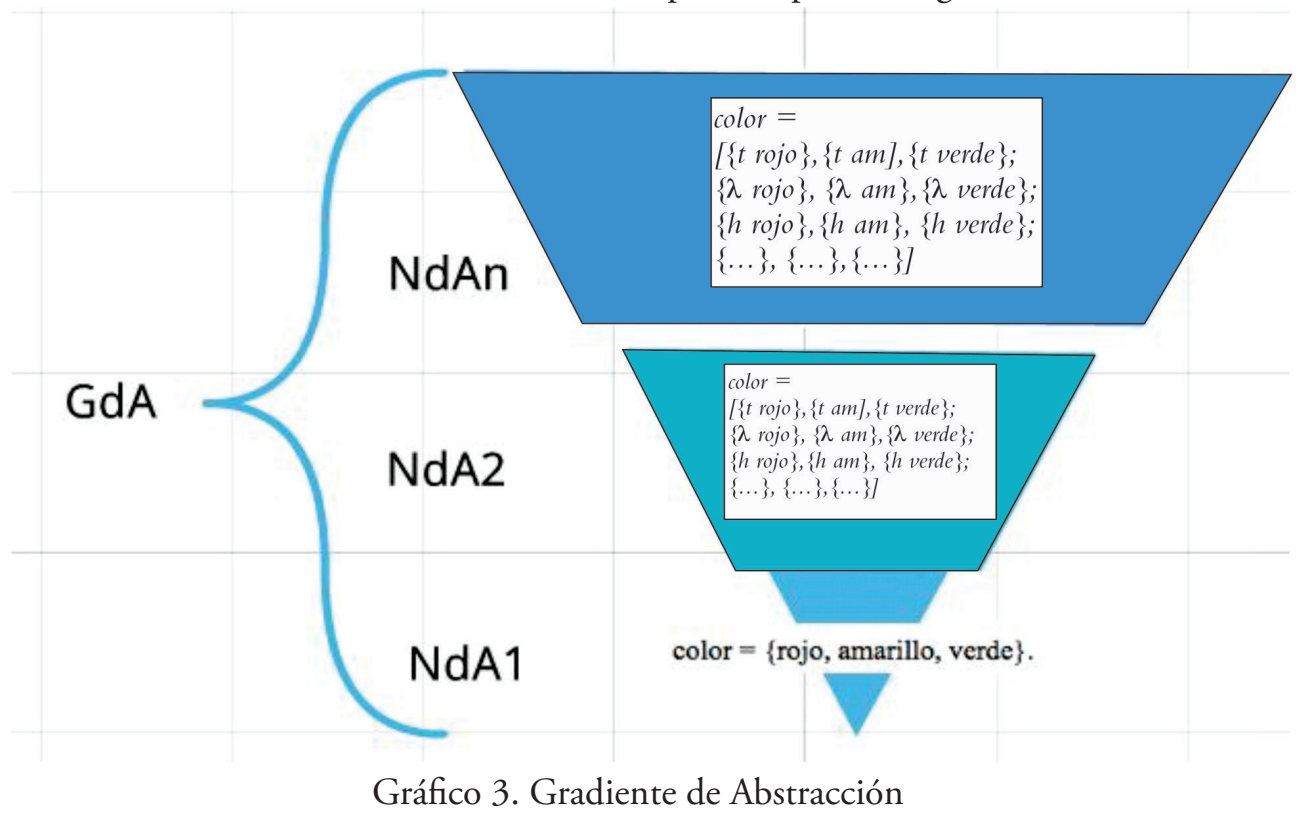

Dada la naturaleza anidada de los $\mathrm{NdA}$ y la posibilidad de construir supersets de sets de observables, los agentes pueden agregar incrementalmente espacios informacionales. Estando la adquisición y evolución de NdAs garantizada ( Como las pieles de la serpiente!). Pueden moverse de un NdA a otro, si bien no todos: Algunos tienen su NdA "embebido". Como en el caso del semáforo. (A menos que tenga memoria reprogramable y sea actualizado con más datos por un agente externo a él). Pensemos en un cambio de NdA en los seres vivientes no humanos: Se basan mucho en los ritmos circadianos y los ciclos día/noche. Pensemos en un felino que adquiere para su visión una superior NdA (más refinada) de noche.

Volviendo a ejemplos tecnológicos: Usando lentes de Realidad Virtual claramente se incorporan NdAs disjuntos entre sí (no anidados) que son las aplicaciones que se usen (no diríamos que una aplicación como un Editor de Textos LibreOffice está anidada con el Navegador Web, por ejemplo. Son disjuntas. Pero son anidadas con respecto al sistema operativo, están "dentro de él"), y anidadas con respecto al NdA del agente, y anidadas también con respecto al $\mathrm{NdA}$ del sistema operativo que lleven los lentes.

Mencionemos brevemente el Realismo Estructural, del cual deriva el Realismo Estructural Informacional:

RE) Modelos explicativos, instrumentales, predictivos exitosos, (especialmente pero no solo dentro del ámbito de teorías científicas) pueden ser incrementalmente informativos acerca de las relaciones que obtenemos entre los (objetos posiblemente sub-observables) que constituyen el sistema bajo investigación (a través de fenómenos observables) (Floridi, 2003, p. 17). 
En esta definición no está involucrada la noción de gradiente de niveles de Abstracción. El Realismo Estructural lidia con dos principales problemas en la filosofía de la ciencia, a saber, el argumentos de los no milagros (a favor): "El argumento positivo para el realismo es que es la única filosofía que no hace de la ciencia, un milagro" (Hillary Putman,1975, p. 73), y el argumento pesimista de metainducción (en contra): Debido a que muchas teorías científicas que predecían correctamente han sido descartadas en el pasado, hay una evidencia inductiva que las teorías actuales sean desechadas también, a pesar de su incremental éxito.

Éste último se puede transformar en un argumento optimista de metainducción:

Debido a que muchas teorías falsas han sido descartadas en el pasado, más allá de ser predictivamente exitosas, hay evidencia inductiva de que si las teorías actuales también son falsas, serán descartadas también, a pesar de su éxito. (Floridi, 2003, p. 9)

Hay obviamente más argumentos a favor y en contra en la comunidad. Ahora bien, el argumento de los no milagros junto con el optimista/pesimista están relacionadas con otros problemas epistemológicos de justificarnos al menos parcialmente en algún punto con nuestros compromisos ontológicos a pesar de que no tenemos acceso directo a la realidad en si. Esto muestran las raíces Kantianas de el RE. El problema epistemológico diferencia el $\mathrm{RE}$ del realismo ingenuo, ${ }^{5}$ mientras que la meta de $\mathrm{RE}$, lo diferencia de formas de instrumentalismo. ${ }^{6}$ Ahora incorporaremos la noción de NdA's y surge la versión del Realismo Estructural Informacional:

REI) Modelos explicativos, instrumentales, y productivamente exitosos (especialmente, pero no solo, en teorías científicas) en un determinado Nivel de Abstracción pueden ser, en las mejores circunstancias, incrementalmente informativos acerca de las relaciones que obtienen entre el (posiblemente subobservable) objeto informacional que constituye el sistema bajo investigación (a través de fenómenos observables). (Floridi, 2008, p. 32)

\section{Ontología REI, computación y bases de datos}

Un corolario del REI es que la naturaleza última de la realidad es informacional: Tiene sentido adoptar NdAs que comprometen nuestras teorías a una visión de la realidad independiente de la mente y constituida por objetos estructurales que no son materiales (podrian serlo, pero no tenemos porque suponerlo), sino informacionales. Esto permite reconciliar dos visiones metafísicas en la filosofía de la información: de (Wiener, 1961) (la información es información, no materia ni energía), y la de (Wheeler, 1990) "it from bit".

5 Actitud filosófica desprovista de toda reflexión crítica acerca del conocimiento, que considera que las cosas son tal como las percibimos.

6 Varias formas de instrumentalismo evitan riesgos al evitar cualquier compromiso ontológico específico más allá de lo mínimo aceptado de la realidad externa independiente de la mente. De esta manera puede un instrumentalista argumentar ser realista. 
Mariana Olezza/ Aspectos Epistemológicos de la Infoesfera/37

"It from bit": Esta tesis dice que cada partícula, campo de fuerza, el mismo espaciotiempo ("it") deriva su función, su sentido, su existencia misma incluso (si en algunos binarias, bits. Simboliza la idea de que cada ítem del universo físico tiene un "fondo" fuente inmaterial y explicación; que lo que llamamos realidad surge en el último análisis del planteo de las preguntas silno y el registro de las respuestas; que todas las cosas físicas son informacionalmente-teoréticas de origen y este es un universo participatorio.

Por un lado Wiener del lado de la epistemología sistémica. Y con la estructura de los sistemas que surgió como resultado de un quiebre paradigmático que ocurrió en la década de 1950, después de la Segunda Guerra Mundial y afectó a disciplinas varias. Con el concepto de REI y a través de las NdA's tenemos a el acceso a la realidad en forma de capas, de un gradiente.

Primero tomemos REE que impone la restricción epistemológica de conocimiento con un límite inferior, creando una "bifurcación Kantiana". Si embargo, a través de la unión con REON, se logra concebir ontológicamente a los objetos como los necesitamos, con finalmente una estructura informacional interior (concibiendo todo informacionalmente, el "fondo" de Wheeler, aunque sea indirectamente, a través de estímulos.

La generalidad de una ontología suele depender de su portabilidad, escalabilidad e interoperabilidad. La ontología más portable podría "ejecutarse" en cualquier mundo posible. La escalabilidad se refiere a cuán bien una solución a un problema funciona a medida que aumenta la complejidad. La interoperabilidad se refiere a la habilidad, por ejemplo en hardware y software de múltiples marcas de comunicarse mutuamente.

Una de las ventajas de REON, de la que deriva REI, es su portabilidad entre las teorías físicas y matemáticas. Es de esperar, ya que tiene una conexión con la filosofía de la física cuántica. Sin embargo REON puede ser metafísicamente local con poca capacidad de escalabilidad. ${ }^{7}$ Aquí es cuando un enfoque informacional es de peso. Una ontología de objetos estructurales es portable a las ciencias de la computación también, y mientras que la matemática garantiza la consistencia, la ciencia de la computación garantiza la escalabilidad. Tanto los micro como macro objetos son analizables en términos informacionales.

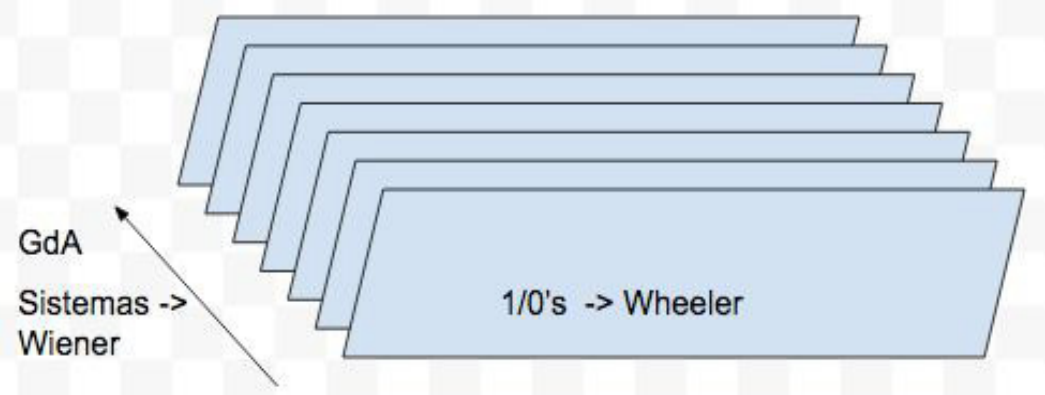

Gráfico 4. Ontología muy fácilmente de manipular computacionalmente

7 Por ejemplo a las monadas de Leibinz no son fácilmente escalables: Es difícil explicar objetos macroscópicos en sus términos. 
38/ Perspectivas Metodológicas /19/Vol. II /Año 2017

Podemos inspirarnos en la metodología de la Ingeniería del Software para testeo de caja negra: Se focaliza en el comportamiento de los requerimientos del programa, sin tener en cuenta su funcionamiento interno. El acercamiento a la realidad es de acuerdo a el REI "gris" (El gradiente GdA hace variar la aproximación a la "caja a ser develada"). Existen objetos informacionales que son "cajas negras" no directamente cognoscibles, pero con los que se puede interaccionar empíricamente, y de esta forma modelarlos más detalladamente.

Resumiendo: Puede que un agente (del tipo que sea) nunca se conozca por dentro al $100 \%$, pero mientras más estímulos se le presenta y mas respuestas al estímulo da, más certeramente es modelado. Este modelado ocurre al recibir datos y responder a ellos, tanto de forma individual como en forma colectiva. Tanto los micro como macro (masas poblacionales, por ejemplo) objetos pueden ser simulados y predicciones pueden ser hechas con mucha eficacia. En las simulaciones se pueden mezclar datos recogidos empíricamente con datos inventados y analizar la salida del sistema.

\section{Recogida masiva de datos: PRISM}

Tomemos para la vigilancia masiva electrónica el emblemático caso de PRISM, uno de los programas de vigilancia electrónica que el exanalista de la NSA y la CIA y experto en seguridad Edward Snowden denunció. En éste, la NSA trabaja en conjunto con las empresas: Microsoft, Yahoo, ${ }^{8}$ Google, Facebook, ${ }^{9}$ PalTalk, AOL, Skype, YouTube y Apple con dos tipos de recogida de datos:

1. Alto nivel: Directamente de los servidores de los mencionados proveedores en donde los datos están guardados.

2. Bajo nivel: A medida que los datos fluyen por los cables de fibra e infraestructuras.

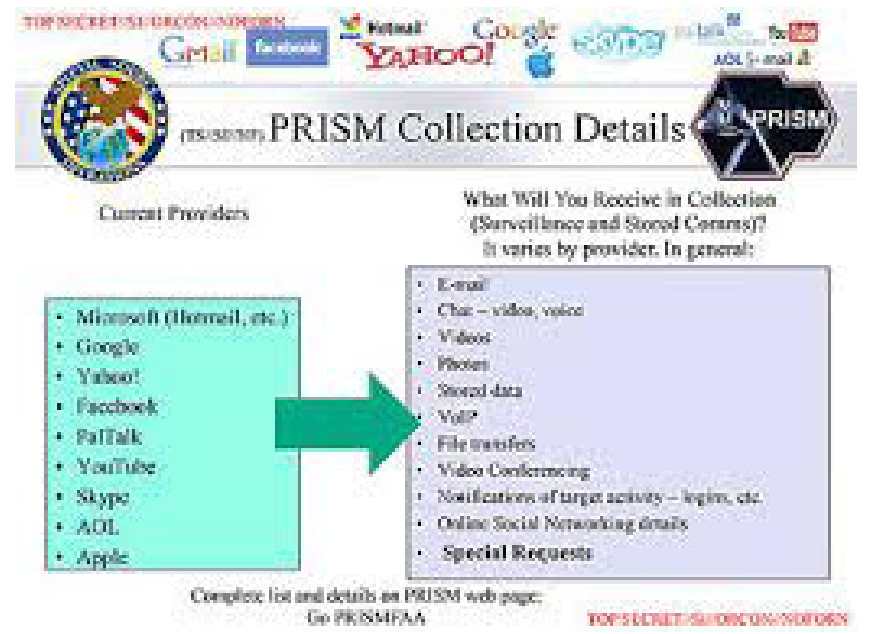

Gráfico 5. Entrega de datos de distinto tipo, de las empresas a NSA

8 Yahoo se opuso en tribunales enérgicamente a participar en PRISM y fue obligado por el tribunal EISA.

9 Facebook y Google sostenían que sólo brindaban información si la NSA tenía una orden judicial y describían PRISM como "un detalle técnico insignificante". 
Mariana Olezza/ Aspectos Epistemológicos de la Infoesfera/39

Recogen contenido y metadatos. Los metadatos revelan patrones, relaciones y comportamientos. Son importantísimos porque justamente con estos datos es con los que mejor se puede clasificar y procesar a los Objetos Informacionales, incluyendo a los agentes la, es decir a los seres humanos.

Circula actualmente una comparación de los grandes centros de datos, con las grandes centrales eléctricas. Pensamos que hay una diferencia fundamental: Los primeros tienen contenido y forma del contenido (metadatos), mientras que las segundas son señales (sólo forma). El gráfico 6 muestra un esquema sólo a partir de los metadatos de una casilla de correo. ¿No afecta a la privacidad mostrar metadatos?

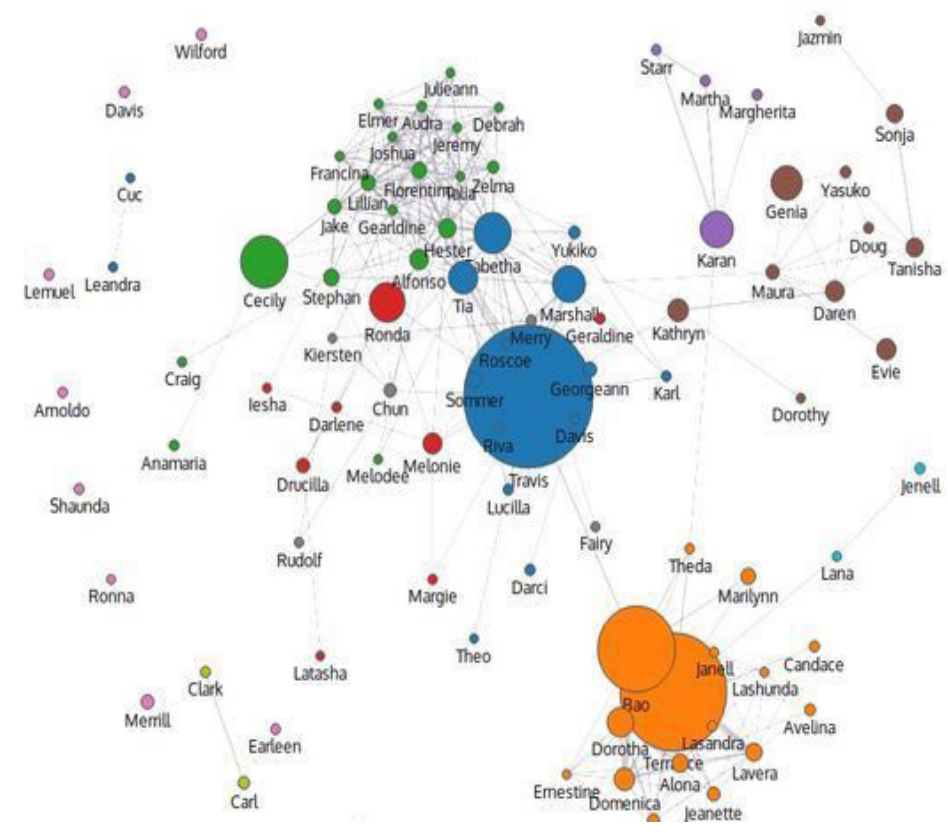

Gráfico 6. Gráfico a partir de metadatos de casilla de correo

\section{4. ¿Qué debemos hacer? Información y Poder}

En esta segunda parte, habiendo visto cómo se toman los datos de los agentes, se mostrará como a los agentes se les induce determinados a comportamientos, a través del bombardeo informacional en el caso del marketing y el alambre de púas invisible en el caso de la algocracia.

Como veníamos analizando, para un agente, la Realidad Informacional está compuesta por un NdA que varía a lo largo del contexto (al pasar el tiempo, al cambiar el lugar), e interactúa con otros "objetos informacionales" o cajas negras que puede abrir. Con la información que sintetiza se genera conocimiento de diversos tipos. Ahora bien, ¿Se puede abrir "abrir" un agente? Justamente contra ésto critica el filósofo coreano Byung-Chul Han. 
40/ Perspectivas Metodológicas /19/Vol. II /Año 2017

Ningún otro lema domina hoy el discurso público tanto como la transparencia. [...] La transparencia estabiliza y acelera el sistema por el hecho de que elimina lo otro o lo extraño. Esta coacción sistémica convierte a la sociedad de la transparencia en una sociedad uniformada. En eso consiste su rasgo totalitario: Una nueva palabra para la uniformación: transparencia. (Byung-Chul, 2013, pp.1-5)

\section{a. Marketing Político}

Por otro lado, en el artículo "Big Data and Their Epistemological Challenge", Floridi analiza algunas cuestiones fundamentales acerca de Big Data, como el a veces denominado "infoglut": Sobreabundancia de datos. Menciona con acierto, que la solución no pasa por seguir agregando memoria (capacidad de almacenamiento), "agrandar el sistema digestivo", sino por la búsqueda, en esa marea de datos, de los llamados pequeños patrones.

Explica cómo es la nueva frontera de competencia de empresas y en ciertos rubros "hambrientos" de datos que también son científicos (menciona a la genética y a las neurociencias), y acerca de el problema ético que surge, cuando se pasa de predecir fenómenos naturales, a fenómenos sociales. ${ }^{10}$ Esto es lo que hace riesgosos a los pequeños patrones. Los agentes que están a cargo de esto, son en general de la categoría 2a, compuestos y de gran tamaño. Técnicas como data analytics son usadas para obtener tendencias.

Pensemos en el "bombardeo informacional":

$z$, porque $w$, debido a que $h->$ (se puede discutir)

w.w.w.w.w.w.w.w.w.w.w.w.w. $\rightarrow$ (bombardeo informacional/ slogans)

¿Qué posibilidades tiene un agente potencia media de enfrentarse a ese contexto informacional? Si no tiene la suficiente energía o no sabe dirigir el foco de su atención correctamente (y esto es difícil en muchos casos si es perturbado por el medio) se presenta la situación:

1. Creer: La parte lógica del agente cede a la información estructurada de la fuente. Absorbe la creencia impuesta.

2. "Reventar": Ataque emocional. La parte emocional del agente cede. No acepta creencia pero se desestabiliza internamente. Sobre este punto habría que tener más atención ya que es muy utilizado y no tan advertido. Es la famosa "indignación" no canalizada adecuadamente. Los políticos que salen a decir cosas solo para generar sentimientos de indignación por parte de la población y que esta pierda tiempo en indignarse en cosas que no forman parte del debate esencial.

10 Menciona el ya conocido caso de la chica embarazada que recibió cupones de descuento a su casa en base a su historial de s por su familia (que desconocían la situación). 


\section{b. Algocracia}

Definimos Algocracia como el proceso se lleva a cabo por medio de la eliminación de la privacidad y el procesamiento masivo de información personal por parte de los gobiernos y las corporaciones que tiende a un gobierno algorítmico de procesos automatizados, en los que los ciudadanos pierden poder de decisión o sólo simulan tenerlo. Se observa en algunas democracias ricas en información que han llegado a un punto en el que quieren resolver los problemas sin tener que explicarse o justificarse ante los ciudadanos.

Es el "alambre de púas invisible" que tienen a su alrededor los agentes, formado a raíz de Big Data y la vigilancia masiva. De acuerdo al analista Morozov, en su artículo "The Real Privacy Problem"

"Google y Facebook se basan en recolectar la mayor cantidad de datos para impulsar su efectividad en los avisos que venden. Las agencias de gobierno necesitan los mismos datos -ellos pueden recolectarlos por si mismos o en cooperación con compañías tecnológicas- para seguir sus propios programas. El gobierno Italiano, por ejemplo, usando una herramienta llamada redditometro o calculadora de ingresos, que analiza las recibos y patrones de gastos para señalar a la gente que gasta más de lo que declara como ingresos, como potenciales evasores de impuestos a futuro. Una vez que los pagos por móvil reemplacen la mayor cantidad de las operaciones monetarias, con Google y Facebook como intermediarios, los datos coleccionados por estas compañías serán indispensables para los recolectores de impuestos."

Vemos varios problemas de base a debatir a futuro:

1. ¿Por qué las intermediarias y no el Estado hacerse cargo de los datos?

2. ¿Y hasta qué punto entregamos nuestros datos a cambio de confort o mejora en calidad de ciertos procesos?

3. El Derecho aparece desfasado del avance tecnológico. ¿Debería regular conductas a futuro de las personas?`¿Dejar sellada una persona como potencial a "X"? ¿Y si es así, no debería esta persona saberlo?

4. El Estado puede detectar conductas que sean virtuosas pero vayan en contra de alguna creencia base que ponga en riesgo la estabilidad social. ¿Entonces qué se eliminarían dichos agentes? ¿Cómo comenzarían las revoluciones entonces? ¿Pasaríamos a una época de hielo informacional en que se puede detectar de antemano cualquier perturbación excesiva para eliminarla de antemano?

5. Si los Estados delegan en empresas privadas con sus algoritmos privados (como vienen haciendo en los países "desarrollados"), nosotros como agentes somo deberíamos pensar en cambiar esta dinámica.

6. Big Data y provee los datos y ciertas técnicas los mecanismos para que cada vez se necesite "menos gente en la cúpula", a través del proceso de automatización. En 


\section{2/ Perspectivas Metodológicas /19/Vol. II /Año 2017}

lo que respecta a las leyes esto deriva en situaciones como la mencionada algocracia, donde las decisiones se saltean al debate ciudadano, (o hay un falso debate como una "cortina de humo", no desarrollado en profundidad aquí) comandas por un muy reducido número de personas que no conocemos.

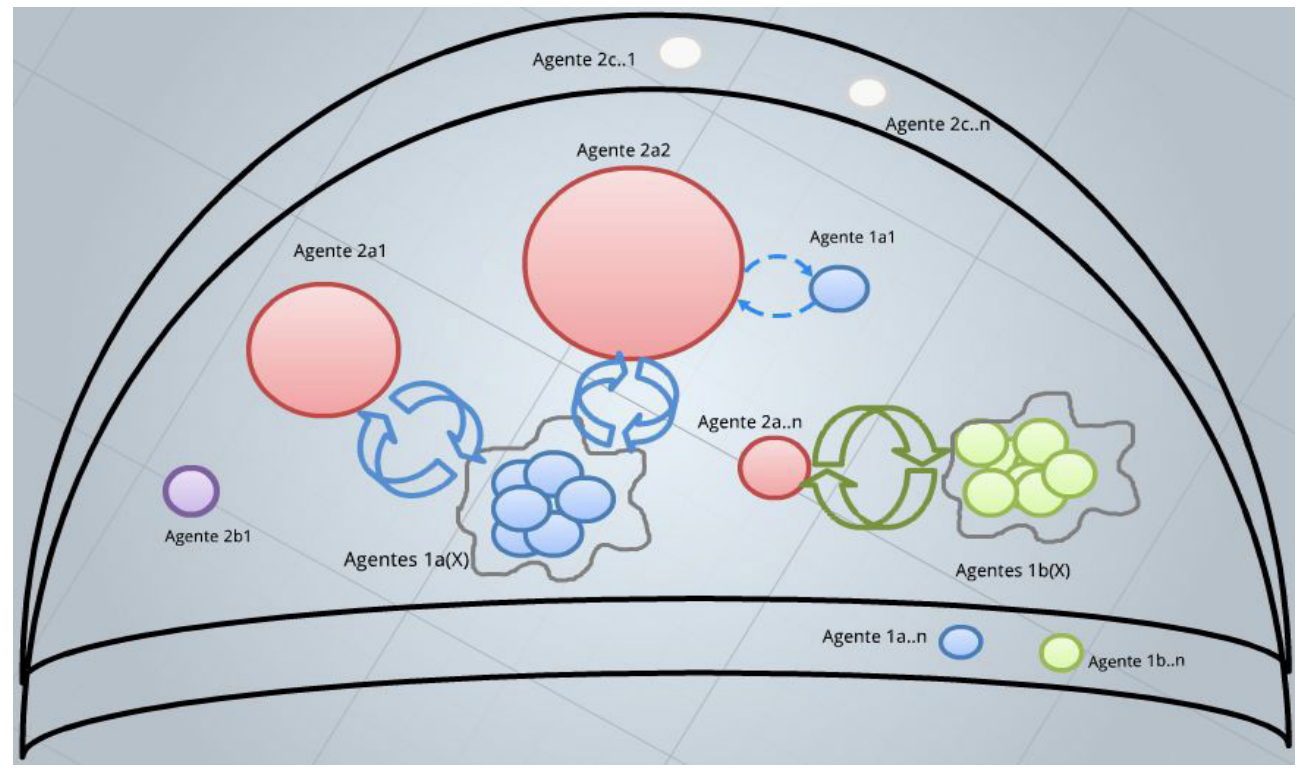

Gráfico 7. La Infoesfera

En el gráfico 7 se puede observar la interacción en la Infoesfera de diversos agentes:

1. Agente 2a2, corporación:

a. Con agente 1a1: Toma datos específicos y le muestra publicidad en base a sus búsquedas (mucha gente nota esto pero es lo menos nocivo).

b. Con masa de agentes $1 \mathrm{a}(\mathrm{X})$ : Toma grandes cantidades de datos y con eso sabe cómo orientar marketing. Entrega de datos a programas como PRISM.

2. Agente 2a1, gubernamental:

a. Con masa de agentes $1 \mathrm{a}(\mathrm{X})$ : Toma grandes cantidades de datos y con eso sabe cómo tomar ciertas decisiones. Acá tenemos algocracia.

3. Agente 2a..n, científico:

a. Con masa de agentes $2 \mathrm{a}(\mathrm{X})$ : Toma grandes cantidades de datos y con eso genera modelos científicos. Organismos generados artificialmente en la realimentación, por ejemplo.

4. Agente 2b1: Con interfaz de hardware y software

5. Agentes c1...n: Agentes que viven en la Infoesfera pero solo en el software (en la red)

6. Agente 1a...n y agente $1 \mathrm{~b} . . . \mathrm{n}$ : No alcanzados por ningún medio tecnológico, no participan de la Infoesfera ni pasiva, ni activamente. 


\section{Conclusión}

A lo largo de este artículo se desarrolló la realidad informacional estructural (REI), dependiente del concepto de niveles de abstracción (NdAs). Se observó que para un agente determinado su conocimiento de la realidad puede ser vista en estos términos, y por otro lado que funciona muy bien en término de analizar la realidad y manejarla computacionalmente (donde escala muy bien).

En la simulaciones: Ontológicamente podemos analizar las estructuras, y epistemológicamente el comportamiento dentro de estos millones de millones de datos, que no son meros datos, que tienen su estructura, algunos datos son empíricos y otros invenciones para ver la respuesta del sistema simulado. Al escalar bien, se pueden simular masas de Objetos Informacionales (como una sociedad). Una vez modelados se pueden generar simulaciones de consumidores en el ámbito privado, o de ciudadanos en el ámbito público, de todo tipo.

Ahora bien, alguien podría pensar, que a los que les corresponde pensar en estas cuestiones, son los que denostan el poder suficiente como para poder llevar a cabo estas cuestiones, y no podríamos estar más en desacuerdo. Debe surgir un nuevo nivel de conciencia a nivel mundial. Y eso nos incluye en el ámbito de la filosofía Latinoamericana. La privacidad de nuestros datos es el eje principal de los problemas ya que con ellos nos moldean como Objetos Informacionales. Siguiendo la línea de REI se ve muy claro.

Saber cómo nos piensan nos da una ventaja. No le hacemos una propaganda a la forma de pensar de tratar a los agentes 1a como objetos, deshumanizar no lo es, pero bajo un control y una transparencia total de nuestros datos se llega a ese límite, y si es lo que está ocurriendo, entonces la filosofía está muy implicada y no debería ser la última en llegar a la sentarse en la mesa del debate.

En este mundo de tantas "respuestas", podríamos empezar por sembrar más preguntas.

\section{Fuente de Gráficos}

- Gráfico 1: https://www.ncta.com/platform/broadband-internet/behind-the-numbers-growth-in-the-internet-of-things/

— Gráfico 2: http://blog.classora.com/2012/10/10/describiendo-el-conocimiento-en-un-formato-estandar-para-la-web-semantica-rdf/

- Gráfico 3: Propio

— Gráfico 4: https://laicismo.org/2013/el-espionaje-y-analisis-de-tus-metadatos-puede-descubrir-tus-creencias-y-convicciones-tus-relaciones-vulnerando-tu-intimidad-aunque-no-vea-su-contenido/55357

— Gráfico 5: https://www.google.com.ar/search?q=Gr\%C3\%A1fico+5.+Entrega+de+datos + de+distinto +tipo, +de+las + empresas + a + NSA\&source $=\ln m s \& t b m=i s-$ ch\&sa=X\&ved=0ahUKEwiD1 K6lw5rTAhWHIJAKHXBHAtYQ_AUICCgB\&biw=1536\&bih=774\#imgrc=QhsPTngFlY6h3M: 
44/ Perspectivas Metodológicas /19/Vol. II /Año 2017

- Gráfico 6: http://www.dailymail.co.uk/news/article-2342200/Revealed-YahooFOUGHT-NSAs-warrantless-spying-program-lost-forced-secret-court-joinPRISM.html

\section{Bibliografía}

- AAVV. (2010). Core Techniques and Technologies for Advancing Big Data Science \& Engineering (BIGDATA). Recuperado de https://www.nsf.gov/pubs/2012/ nsf12499/nsf12499.h tm

- Blanché, R. (1973). La Epistemología. Barcelona, España. Editorial oikos-tau, s.a.

- Byung-Chul, H. (2013). La Sociedad de la Transparencia. Barcelona, España. Editorial Herder.

- Byung-Chul, H. (2012). La Sociedad del Cansancio. Barcelona, España. Editorial .

- Herder. Carr, N. (2010) ¿¿Qué Está Haciendo Internet Con Nuestras Mentes? Superficiales. Editorial Taurus.

- Capurro, R. (2003). Epistemología y Ciencias de la Computación. Conferencia (keynote speaker) presentada en el V Encontro Nacional de Pesquisa em Ciência da Informação, Belo Horizonte (Brasil). Recuperado el 18 de enero de http://www. capurro.de/enancib.htm

- Floridi, L. (2012). Big Data and Their Epistemological Challenge. Springer Link, Philosophy and Technology, Volume 25, Issue 4, pp 435-437.

- Floridi, L. (2008). A Defense of Informational Structural Realism. Springer Link, Synthesis, Volume 161, Issue 2, pp 219-253.

- Floridi, L. (2008). The Method of Levels of Abstraction. Springer Link, Minds and Machines, Volume 18, Issue 3, pp 303-329.

- Floridi, L. (2001). Philosophy and Computing. An Introduction. New York, USA. Editorial Taylor \& Francis.

- Greenwald, G. (2014). Sin un Lugar Donde Esconderse. Barcelona, España. Editorial Ediciones B.

- Llanes, G. (2016). La utopia de una sociedad de la empresa. Entrevista a Pablo Méndez. Recuperado de Iniciativa Sur el 10 de febrero de 2017 de http://iniciativasur.org/pablo-mendez-la-utopia-de-una-sociedad-de-la-empresa/NSF-12499 Morozov, E. (2013). The Real Privacy Problem. Recuperado de The MIT Technology Review el 13 de marzo de 2017 de https:/www.technologyreview.com/s/520426/ the-real-privacy-problem/ 


\title{
Propiedad, apropiación y robo en torno a la autoría
}

\author{
Andrés Mombrú ${ }^{1}$ \\ amombru56@yahoo.com.ar
}

\section{Resumen}

El tema de la autoría no solamente plantea temas éticos y legales, también afecta de modo muy determinante las prácticas de docencia e investigación. Este trabajo trata de analizar la relación entre los conceptos de autoría, de propiedad, de lo propio -que es parecido pero no es lo mismo-y de las diferentes formas de "robo", legal e ilegal que se perpetran en torno a la producción intelectual en el campo de las ciencias sociales y de las humanidades. Indaga sobre el modo en que ciertas tradiciones operan reproduciendo prácticas instituidas a nivel educativo y de la producción de conocimiento de modo asimétrico entre instituciones y docentes e investigadores, quienes suponen sustraerse de las relaciones de producción y las formas de dominio establecidas y sin embargo son atravesados por ellas.

Palabras clave: Autoría, derechos de autor, docencia e investigación

\begin{abstract}
The subject of authorship not only involves ethical and legal issues, it also affects the practices of teaching and researching in a very determinant way. This paper intends to analyze the relationship among the concepts of authorship, of ownership, of one's own -which is similar but is not the sameand of the different ways of "theft", legal and illegal, that are committed regarding intellectual production in the field of social sciences and humanities. It inquires into the way in which certain traditions operate reproducing instituted practices concerning education and knowledge production in an asymmetrical way among institutions, teachers and researchers, who believes to be subtracted from the relations of production and from the established forms of domination but, nevertheless, they are crossed by them.
\end{abstract}

Keywords: Autoría, derechos de autor, docencia e investigación

Una vieja canción del músico Moris, de la década del 60, Pato trabaja en una carnicería, decía en sus primeros versos: "Todo empezó con el chiste que decía, lo tuyo es mío y lo mío es mío, no comprendimos que eso sería, lo que algún día nos heriría." ¿Qué es fica. Docente e investigador en la Universidad de Buenos Aires y en la Universidad Nacional de Lanús. 
mío?, ¿qué es tuyo?, ¿qué es nuestro? El tema de lo propio y de la propiedad, es decir, de lo que es propio en un sentido personal y en un sentido colectivo, el de la apropiación indebida y el de la propiedad como un derecho, atraviesa el problema de la autoría. Lo propio y la propiedad parecen referir a cosas similares y sin embargo distan mucho de ser lo mismo. Lo que consideramos nuestro puede ser compartido o no y en diferentes términos. Podemos prestar un libro, sin que deje de ser nuestro, pero no podemos prestar algo que, siendo nuestro, no vaya a ser devuelto, por ejemplo un riñón. En este caso decimos que donamos o regalamos algo que nos pertenece, que nos es propio y que pasará a pertenecer, a ser propio de otro. Ese otro puede ser individual o colectivo. Un cepillo de dientes puede ser prestado, pero nadie sería calificado de egoísta porque no lo quiera compartir, se lo considera propio y privativo. Se hace entonces necesario distinguir la diferencia entre lo que es propio y lo que es propiedad.

Lo propio es personal, lo que pertenece a la propia persona porque hace a su posibilidad de ser. Nuestros órganos nos son propios y en un sentido extensivo se podría decir que nuestras ropas, nuestras herramientas, el lugar que habitamos, etcétera; es decir, todo aquello que se encuentra en función de nuestra existencia y es requerido para que sea garantizada de acuerdo a un principio de equidad. Al mismo tiempo, eso que es propio puede ser al mismo tiempo compartido colectivamente, como por ejemplo, compartir un techo, o una comida o una prenda. Por otro lado están aquellas cosas que nacen como propias de un colectivo: un país, un barrio, una calle, una plaza, una institución. Los espacios y las entidades públicas no tienen dueño; cualesquiera de ellas que no sean pasibles de libertad de tránsito, de uso, se torna privada. La defensa de lo propio personal implica un legítimo sentido de dignidad y en consecuencia, esa defensa, o ese reclamo, de respeto por lo propio siempre es justo. De igual modo sucede con lo propio colectivo, que puede pertenecer a una comunidad específica: un territorio, un patrimonio cultural, entidades físicas o morales. Cuando el valor que adquieren trasciende a la comunidad en la que tiene origen, puede convertirse en "bienes" de la humanidad. Y preferimos decir "bienes", ya que ese concepto tiene una acepción más laxa, más ambigua, en la que se incluye la connotación que también tiene el término "patrimonio", pero que no la reduce a una dimensión económica.

Aquellas entidades que son consideradas "patrimonio" de la humanidad, pierden la posibilidad de ser compradas o vendidas, pertenecen a la humanidad presente y futura; pero el lenguaje siempre deja traslucir la matriz ideológica de la que surge, y entonces caemos en la contradicción de llamar "patrimonio" que remite originariamente a lo que es propio del "pater" de raigambre netamente patriarcal y qué, al poder mensurarse económicamente, puede ser comprado o vendido, con algo que se coloca en un ámbito de excepción, precisamente porque se lo sustrae de la dimensión de lo mercantil. Más allá de estas contradicciones, el sentido de propiedad, difiere del de lo propio, personal o colectivo, ya que -paradójicamente- tiene un valor jurídico que no necesariamente está emparentado con la justicia. En otras palabras, las leyes pueden ser justas o estar orientadas a promover justicia, pero en sí misma no sólo no son garantía de justicia, sino que incluso pueden ser garantía de iniquidad. La dificultad para advertir esto es que en la sociedad capitalista, "justo" se ha tornado en un sinónimo de legal. Muchas veces la justicia no radica en el cumplimiento de la ley, sino en su incumplimiento. Pero si ese incumplimiento no va acompañado de una modificación en la correlación de fuerzas y 
Andrés Mombrú /Propiedad, apropiación y robo en torno a la autoría /47 en la instauración de otra escala de valores en lo que refiere al concepto y las prácticas de justicia, entonces las normas vigentes establecerán los criterios de justicia y se aplicarán de modo discrecional las penas. Los Estados, y muchos poderosos, incumplen con las leyes sin que esto genere -en buena cantidad de casos- castigo; pero esas mismas leyes se aplican de manera implacable a los más débiles. En nuestra sociedad hay incumplimientos que son considerados contravenciones y otros delitos. Ambos implicarían una violación de las leyes o normas establecidas, la diferencia radica en la pena. No entraremos aquí en tecnicismos jurídicos, pero hay acciones que son catalogadas como criminales, en ellas se encuentra en un lugar destacado los llamados "delitos" contra la propiedad.

Ser propietario, tener un título de propiedad, no es indicativo, per se, de que aquello que se encuentra registrado a nombre de un propietario le sea propio. La conquista del desierto otorgó títulos de "propiedad" de enormes extensiones de tierra a los conquistadores, legalmente son sus dueños y esa es su propiedad por derecho, sin embargo esos territorios son "propios" de aquellos que los habitaban y a los que les fueran arrebatados. He aquí una apropiación sujeta a derecho, pero realizada sobre una criminal injusticia. Injusticia porque viola lo que es justo, imponiendo por sobre ello lo que establecen las instituciones encargadas de impartir justicia como "derecho".

La autoría, por otra parte, tiene un sentido que muchas veces se torna ambiguo en lo que hace a "lo propio" y a la "propiedad". Preguntando una vez a un grupo de estudiantes de arte de quién era la obra "Los girasoles" -que en realidad es una serie de cuadros-, todos respondieron obviamente que de Vincent Van Gogh. Cuando les dije que se equivocaban, que "Los girasoles" no pertenecían a Van Gogh, todos quedaron desconcertados, como si esa declaración estuviera revelando alguna última novedad sobre el carácter apócrifo de la obra -cosa que ha ocurrido no pocas veces en el arte-. ¿Y, a quién pertenece?, preguntaron; en ese momento respondí que pertenecía al empresario japonés Yasuo Goto, quien la había comprado por cerca de 75 millones de dólares. Agregué que Yasuo era el propietario, pero que aquella obra pertenecía y pertenecería por siempre al pintor holandés. No sería tan triste la historia si Van Gogh no hubiera vivido y muerto en la más absoluta pobreza. A pesar de haber sido autor y de haberle sido propias sus obras como producto de su creatividad y maestría, los criterios de mercantilización de una sociedad en la que todo puede convertirse en mercancía, amparándose por lo tanto en un título de "propiedad", produjeron la "enajenación" de lo que era "propio". Es verdad también que el artista produce una obra que "dona" a la sociedad. El señor Yasúo Goto no podía hacer con ella otra cosa que la que puede hacer cualquier persona, aunque no haya pagado un centavo por ella, contemplarla. Luego las exhibiciones públicas o privadas pueden "socializar" la obra o seguir sacando dividendos como fruto de su apropiación.

Los conceptos de autoría y propiedad, presentan dificultades en su consideración, pues son asuntos que van por senderos diferentes. La suma de 75 millones de dólares pagada por el empresario japonés parece escandalosa, sin embargo, es una cifra insignificante en relación a los cientos y hasta miles de millones de dólares que grupos particulares obtienen mediante los derechos de patentes sobre producciones tales como desarrollos tecnológicos, medicamentos, producciones literarias, etcétera. Por ejemplo, producir medicinas cuyo enorme costo se desvanece cuando se la puede poner al alcance de millones de personas, 
producen, sin embargo, cientos de millones de dólares cuando se las comercializa por sumas enormes y para un mercado al que tienen acceso sólo sectores privilegiados de la sociedad. Menor costo mayor ganancia, es la lógica subyacente. La consecuencia es que la propiedad de las patentes, que las leyes y el Estado amparan, genera millones de personas sin acceso a ellas, que sufrirán y morirán. El criterio que gobierna todas estas producciones es el más alto y sagrado principio de nuestra sociedad, la "propiedad privada". La pregunta que nos hacemos aquí es, ¿̇de dónde han salido los insumos y los recursos materiales y humanos que permiten el conocimiento y la creatividad?

En general estos son bienes sociales, de producción colectiva, son el resultado del conocimiento acumulado por generaciones, del lenguaje del que nadie es dueño, de los recursos naturales sobre los que podemos servirnos con respeto por la naturaleza, o apropiarnos en base a "derecho" en provecho propio y en detrimento de la misma naturaleza y de la sociedad. Ahora bien, juntar todas esas cosas y convertirlas en algo de provecho tiene su mérito y merece su reconocimiento y su recompensa, pero, ¿cuál es el límite? ¿Cuál es el derecho a lucrar con algo al costo del sufrimiento, la destrucción y la muerte de muchos?

Entre "autoría" y "propiedad privada" se produce una tensión que no siempre es claramente visualizable. La autoría reclama sus "derechos", pero los únicos "derechos" que regulan la relación con las producciones es el "derecho de propiedad". El primero queda sometido al segundo. El autor puede "ceder", "vender", "donar" lo producido y esto cuando no ha trabajado desde el comienzo en condiciones en las que, eso producido, queda "enajenado" por las condiciones mismas de producción. Siempre hay una relación de asimetría entre quién "cede" y quien usufructuará los beneficios de la cesión. Cuando se trabaja para una institución, empresa u organismo que financia esa producción, el resultado pertenece al financista. Ahora bien, ese financista puede ser una entidad que puede socializarlo sin lucro, como los resultados de algunas investigaciones científicas que se producen por investigadores individuales o equipos de investigación, como sucede en algunas universidades, o en determinados y muy limitados centros de investigación. En otros casos, la principal meta del financista es el lucro y las ganancias que derivan de su comercialización, que no tienen como fin mejorar la vida de las personas, contribuir al interés colectivo, sino el lucro como un fin en sí mismo. En este sentido el autor puede ver al fruto de su autoría como una creación, como un bien que surge a través de él, pero que es el resultado de un proceso histórico y social, o puede pensar también que ésa es su propiedad y que tiene el derecho de lucrar con ella.

¿Hasta dónde se extiende el "derecho de autor" y de una "retribución económica" por el mismo? ¿En qué consisten esos "derechos”? En áreas como las artes -música, pintura, literatura, cine- los derechos de autor están medianamente regulados, aunque en relación a un contexto que en las últimas décadas ha cambiado enormemente y que no se ajusta a los tiempos actuales en el que las nuevas tecnologías han modificado sustancialmente el escenario.

En el campo de la investigación científica en ciencias naturales, los derechos de autor suelen estar "conculcados" por las instituciones financiadoras y por los sistemas de patentes. En el campo de la investigación en ciencias sociales la situación es similar en 
Andrés Mombrú /Propiedad, apropiación y robo en torno a la autoría /49 lo que refiere a investigaciones de campo y al lucrativo negocio de las consultoras. Pero en buena parte de las ciencias sociales y en las humanidades en general, la "autoría" es algo que no suele quitar el sueño en relación con los posibles beneficios económicos que se podrían obtener (insignificantes en general). Las entregas sistemáticas de la producción que surge de su seno suele ser a cambio -en el mejor de los casos- de algún tipo de "recompensa moral", de la posibilidad de obtener un prestigio o un reconocimiento que permita colocar al autor en otro orden de consideración, y/o le permita aspirar indirectamente a mejores oportunidades de trabajo, o premios y galardones si hay fortuna. Muchos no sólo son capaces de ceder "derechos", sino que estarían dispuestos a pagar para que sus producciones sean publicadas y sus nombres aparezcan junto a otros nombres prestigiosos. Aquí las tensiones no suelen ser, en general, por la obtención de recursos económicos; las disputas suelen darse más bien en el delicado juego de plagiarios y plagiados.

La apropiación indebida puede producir un beneficio que se obtiene con el esfuerzo o el talento de otro. Puede ser tan pequeño como el de los estudiantes que plagian trabajos de sus compañeros, o de otros autores, con el interés de aprobar un examen o una materia; incluso se puede llegar al punto de plagiar una tesis, ya sea por no tomarse la molestia de trabajar o por la falta de capacidad para hacerlo. La falta de rigor de muchos docentes en las correcciones hace que esos plagios circulen con mayor o menor impunidad y que esa clase de estudiantes hagan de la práctica su modus operandi durante los años de formación. Aunque sus consecuencias económicas inmediatas son prácticamente nulas, esta no deja de ser una situación grave, que viola la autoría, y de consecuencias nefastas al largo plazo, ya que una carrera cimentada en la mentira, el oportunismo y el plagio tiene como resultado a profesionales, académicos y científicos de pésima formación y de muy escaso conocimiento. En el mejor de los casos, estos "delincuentes" quedarán excluidos de las funciones a causa de su propia incapacidad. Si logran infiltrarse las consecuencias son más graves; de hecho, pueden producir "mala praxis" en cualquier disciplina que se trate. Pero el peligro más grande es cuando alcanzan cargos que implican responsabilidades y compromisos para los que no sólo están poco preparados, sino en los que el ejercicio de su función produce efectos de amplio impacto negativo y con consecuencias devastadoras en muchos casos.

Ahora bien, queremos referirnos exclusivamente a la producción intelectual que se expresa a través de la publicación -por medio de cualquier soporte disponible- de artículos y libros. Excluimos de estas consideraciones a la llamada "propiedad industrial", que refiere a las invenciones, marcas o patentes, comunes en los campos de la industria, y de desarrollos industriales a partir de investigaciones científicas. Entre las llamadas producciones que dan lugar al derecho de autor, también queremos dejar de lado en esta consideración a las producciones estéticas: pintura, escultura, o literarias, como novelas, cuentos, etcétera; o musical: partituras, letras, danza, etcétera. Nos referiremos solamente a libros, artículos y distintos "papers" como el producto final de la tarea de investigadores, sobre todo en el campo de las ciencias sociales. En algunos casos, los artículos científicos son sólo un modo de presentación de una autoría subyacente, por ejemplo: un desarrollo biomédico, algún tipo de dispositivo o incluso una teoría científica. En otros casos, vinculados a la producción intelectual -y quizá más próximos a la producción literaria-, el mismo artículo o libro es "la obra"; esto es, 


\section{0/ Perspectivas Metodológicas /19/Vol. II /Año 2017}

el objeto de autoría no radica en aquello a lo que la obra remite, (una vacuna), sino a la obra misma, el libro, el artículo, etcétera. En la República Argentina, el Registro Nacional de Propiedad Intelectual se realiza mediante una declaración con todos los datos que hacen a la datación de la obra y el depósito de ejemplares que deberán ir a parar a Biblioteca Nacional, Biblioteca del Congreso, Archivo General de la Nación y Dirección Nacional del Derecho de Autor.

El registro y el depósito de las obras a través de la Cámara Argentina del Libro parece estar destinado a proteger a los autores de abusos realizados sobre sus obras, que puede ser llevado adelante por editoriales o instituciones de investigación, y que se perpetra mediante el incumplimiento de las normas establecidas. El apartado "De las Penas", de la ley 11.723 de propiedad intelectual, en todos sus artículos refiere a las penalizaciones que se aplicarán a quienes incumplan lo dispuesto con penas de distinta duración y multas de diverso valor monetario. Pero lo establecido por la ley no logra impedir la situación de indefensión de los autores frente a los abusos, muchas veces difíciles de probar, que las propias editoriales o el negocio de la fotocopia infringen constantemente. Ahora bien, cuando se consultan los juicios llevados adelante en lo que refiere a propiedad intelectual, se puede advertir que en su mayoría pertenecen a reclamos sobre obras musicales o literarias, pero es casi inexistente la demanda sobre violaciones a las normativas referidas a la obra de intelectuales o científicos de las ciencias sociales. En los ámbitos universitarios, quienes suelen verse más perjudicadas son aquellas editoriales, en general pequeñas, que publican materiales de cátedra frente a fotocopiadoras externas o internas a las facultades que venden descaradamente materiales que le son ajenos. Es vergonzoso ver cómo, en la mayoría de las universidades, las fotocopiadoras autorizadas a funcionar en su interior violan con total impunidad todas las normas legales sobre autoría y sobre propiedad intelectual. En ocasiones los docentes-investigadores son víctimas cuando se publican sus producciones sin autorización, en otros casos son cómplices, -por ignorancia o por desconocimiento- del negocio ilícito de la fotocopia, cuando ellos mismos entregan a las fotocopiadoras materiales fotocopiados de libros que violan abiertamente los derechos de autoría y propiedad intelectual. Esta situación pone al descubierto instancias que revelan nuestras pobrezas intelectuales e institucionales en muchos aspectos.

Algunas gestiones universitarias han tenido una auténtica preocupación por facilitar el acceso a los estudiantes a obras de calidad y a costos muy accesibles. El ejemplo más trascendente corresponde a lo que fuera en otros tiempos la gestión de EUDEBA por Boris Spivacow entre 1958 y 1966, pero que dejará marcada su impronta por un tiempo más prolongado. EUDEBA no solamente publicaba los libros clásicos de todas las disciplinas que correspondieran a todas las carreras de la Universidad de Buenos Aires y también a autores de vanguardia, sino que además daba lugar, en su colección Manuales, a la publicación de muchos trabajos de docentes, investigadores, intelectuales, que desarrollaban sus actividades en esa Universidad. En aquellos tiempos, los modos de producción editorial eran mucho más costosos que hoy, y sin embargo se podía ver claramente que el lema "Libros para todos" se sostenía en ofrecer libros que todos podían comprar. Lo cual revela que no se trata de un problema de costos, sino de una decisión política. Aquellos años de esplendor fueron opacados por "La noche de los bastones largos" y por dictaduras y también por gobiernos "democráticos" que 
Andrés Mombrú /Propiedad, apropiación y robo en torno a la autoría /51 avasallaron a la educación pública, a la comunidad científica, a los intelectuales, muchos de los cuales fueron perseguidos y tuvieron que emigrar o pasaron a engrosar la lista de los asesinados y desaparecidos. La educación y la ciencia argentina, que habían alcanzado niveles de excelencia a escala mundial, tenían que ser desmanteladas, propiciando condiciones de insuficiencia que sólo fue remontada por la inquebrantable voluntad de los trabajadores de la educación.

La falta de financiamiento de políticas editoriales era parte del estado a que había sido sometida la educación superior, la que durante décadas ha contado con los recursos mínimos para sostener los gastos básicos y el sueldo a los docentes, amén de algunas gestiones que supieron usar muy discrecionalmente los recursos públicos llenando sus propios bolsillos. Por motivos que no viene a cuento analizar aquí, la educación primaria y secundaria no suele tener producciones propias, aunque ambas se convirtieron rápidamente en uno de los negocios editoriales más lucrativos de todos los tiempos a través de los monopolios de dos o tres editoriales que concentraban con un público cautivo todo el mercado. La multiplicidad y diversidad del mundo universitario hacía más difícil producir un manual para varios millones de estudiantes. Así y todo, siempre hubo editoriales que ofrecían textos a bajo costo. En ese clima, donde los mejores docentes e investigadores se encontraban en el exilio o expulsados de la universidad, y donde además los "libros baratos" no existían ni tampoco los apuntes de cátedra (mimeografiados) de autoría del profesor a cargo de la materia, se produce un reemplazo de autoridades y cuerpo docente de escasos dotes intelectuales. Los refritos y pastiches se convirtieron en el material de estudio de los alumnos universitarios. Estaba naciendo la cultura de la fotocopia, que se extendería hasta nuestros días y que se ha instalado de tal modo que no puede ser desplazada ni por los "libros baratos" ni por los soportes digitales. En los países "del primer mundo", que tanto se admiran por sus adelantos y avances en el campo de la educación, la titularidad de una cátedra no se alcanza si no se posee por lo menos una publicación propia del área disciplinar. Las mismas autoridades universitarias parecen desentenderse de este tema y, dentro de las propias instituciones, el negocio ilegal de las fotocopias se desarrolla con toda libertad por parte de concesiones y principalmente de los centros de estudiantes que, con la excusa de facilitar los materiales a los estudiantes, se valen de recursos como locales, energía, instalaciones, insumos, que pertenecen a la universidad y cuyo provecho se traduce, en ocasiones, o en parte, en ganancia propia y en financiamiento de sectores políticos de los que ganaron el centro. Ninguna de estas cosas es desconocida, no es ni siquiera "un secreto a voces", es algo a la vista de todos. Esta dinámica se ha convertido en el modus operandi ya internalizado y aceptado en las comunidades universitarias. La lucha por los centros es, al mismo tiempo, la lucha por la caja, en la que se encuentran involucrados miembros de la comunidad académica.

El doble carácter de docente-investigador impone la producción y publicación de las investigaciones y su acceso a la práctica docente. En 1993, a través de la Secretaria de Políticas Universitarias, se implemente el sistema de incentivos para docentes investigadores.

Si bien el objetivo declarado fue aumentar la investigación y desarrollar una carrera académica integrada -docencia junto a investigación-, las características del Programa (plus salarial, escalafón jerárquico, sistema de 


\section{2/ Perspectivas Metodológicas /19/Vol. II /Año 2017}

evaluación) muestran que el verdadero sentido fue transformar las relaciones entre el Estado y las universidades a través de una injerencia directa en las actividades que debía realizar un docente universitario. Mediante la introducción del Programa se buscó que los docentes realizaran más investigación científica, pero también se intentó tener un mayor control por parte del Estado a través de la SPU, de lo sucedido en las universidades en materia de investigación y respecto al conjunto de las actividades de los investigadores universitarios. En los considerandos del decreto de creación del Programa se le asignó, asimismo, un rol destacado a las universidades en la producción de conocimiento. El Programa declaró como objetivo: "promover el desarrollo integrado de la carrera académica en las Universidades Nacionales", entendiendo por ello la realización conjunta de actividades de "docencia, investigación, extensión y gestión", como respuesta a una serie de circunstancias:

- La baja proporción de docentes universitarios que participan en actividades de investigación científica y tecnológica (15\% del total de docentes).

- La importancia del desarrollo científico y tecnológico para el crecimiento económico y la justicia social, en el marco de un nuevo paradigma científico-tecnológico dominante a escala mundial, basado en la microelectrónica, la biotecnología y los nuevos materiales, que ubica a las Universidades como destacados protagonistas en la investigación científica y en el desarrollo de nuevas tecnologías de productos y procesos.

- La necesidad de aumentar las tareas de investigación y desarrollo a nivel nacional y de fomentar la reconversión de la planta docente, motivando una mayor dedicación a la actividad universitaria y a la creación de grupos de investigación.

- La simultánea contribución del Programa al mejoramiento de los ingresos de los docentes universitarios durante el período en que participen en proyectos de investigación, en el marco de asignación de recursos a las Universidades en función de programas específicos basados en criterios objetivos que favorezcan el rendimiento del trabajo académico. (Sarthou, Araya, 2015).

La creación de una Secretaría de Políticas Universitarias hubiera supuesto un contrasentido en otros períodos históricos, donde la competencia del Estado se limitaba al financiamiento y el funcionamiento de las mismas estaba basado en el gobierno autónomo. Dotar a una Secretaría con poder de intervención suponía el primer paso hacia la mayor regulación y orientación de las actividades docentes y de investigación de las universidades. (Gordon, 2011, p. 173, en Sarthou, Araya, 2015)

Más allá de las delicadas situaciones que plantean los autores citados, la situación de los docentes se ve modificada en sus prácticas cotidianas. Los docentes nunca tuvieron buenas remuneraciones y su papel, en general, se reducía a ser trasmisores de conocimientos, pero no a ser productores de los mismos. Aquí se produce una nueva tensión que dejaremos de lado pero que no conviene perder de vista; la mayoría de los docentes universitarios carecen de formación pedagógica, ya que las universidades han privilegia- 
Andrés Mombrú /Propiedad, apropiación y robo en torno a la autoría /53 do durante décadas a sus propios egresados con perfil académico o profesional pero no instrucción para la docencia, la que sí poseen los docentes formados en los profesorados, aunque careciendo de la formación necesaria para la investigación.

La nueva figura que aparece del docente-investigador, si no renguea de una pata renguea de la otra. Ahora bien, de pronto, la mayoría de los docentes que no ven la oportunidad de mejorar sustancialmente sus ingresos mediante los incentivos económicos personales, pero sí de la necesidad de participar de la carrera docente con nuevas reglas, se encuentran, sin embargo, muy poco preparados para encarar eso que se denomina "investigación". Sólo las camadas de docentes más jóvenes, que comenzaron sus actividades con los programas y las convocatorias ya en funcionamientos, pudieron encajar mejor en el nuevo sistema. Pero este nuevo rol de docente-investigador implicaba la suma de nuevas tareas; a las ya agobiantes de la docencia en universidades de ingreso irrestricto, o más abiertas a la comunidad, con las tareas habituales de planificación y preparación de clases y contenidos frente a cursos muy numerosos, a cientos de exámenes que corregir y a las nuevas necesidades de preparación y de aplicación de otros fenómenos que imponía también nuevas exigencias, el uso de las Tecnologías de la Información y la Comunicación y sus aplicaciones educativas, se sumaban las ignotas actividades de investigación. Ante esto no había muchas opciones, más que concentrar esfuerzos en todos esos frentes unificando los temas docentes con los de investigación y aplicación.

¿De qué modo inciden todos estos elementos en las prácticas de la docencia y la investigación, y en la exteriorización y divulgación de la producción académica e intelectual? ¿En qué medida lo que el esfuerzo -y los recursos- de los proyectos de investigación y la formación de nuestros docentes e investigadores producen, repercute en las condiciones de realización de la docencia? ¿Cómo las instituciones reconocen y estimulan esas producciones, protegiendo el trabajo intelectual que dinamiza la práctica docente y que va mucho más allá de cumplir un horario, dar un programa y atender a todas las instancias burocráticas? Cuando se observan programas y bibliografías que han permanecido inalteradas durante más de 20 y a veces 30 años, se puede concluir que, en no pocos casos, la investigación no ha aportado nada a la docencia, pues ella se ha convertido en una tarea enajenada donde el único interés del docente es cobrar su salario y la del investigador continuar manteniendo esa categoría. En el caso de muchos investigadores, esa situación se hace patente cuando su única actividad es solicitar que se los incluya como "investigador" dentro de un proyecto y comunicar si mandó alguna ponencia a un congreso o publicó algún artículo -que muchas veces no tiene ninguna relación con la investigación- para incluir en los informes de avances o en el informe final.

Esta situación generó dos categorías de docentes: los docentes y los docentes-investigadores. Los primeros parecen quedarse a la saga de promociones mediante concursos e incentivos económicos, miran con desdén a sus compañeros investigadores contando los días para la jubilación. Los segundos, con aparentemente más opciones, también pueden dividirse en dos: los que hacen como sí y los que corren desesperados detrás de plazos, vencimientos, solicitudes perentorias; los que le quitan horas al sueño para entregar el artículo, el "paper", el informe, la solicitud de convocatoria en los malditos sistemas que se caen todo el tiempo. Ninguno de ellos parece muy afortunado. 


\section{4/ Perspectivas Metodológicas /19/Vol. II /Año 2017}

Se podría decir que la publicación de libros y artículos, la participación en congresos, el desarrollo de la carrera docente y de investigador, tiene una recompensa moral, al sentir que se cumple con la tarea, y una recompensa institucional a la hora del puntaje que se puede obtener en un concurso, o cuando se pretende una beca; pero si los contenidos son "ficcionales" y la calidad de la producción es mediocre, entonces los puntos pueden llegar, pero la calidad como docente y como investigador se ve severamente desmerecida. $\mathrm{Si}$ a esto se le suma que los incentivos por investigación son míseros, que en muchas universidades los concursos son escasos, que muchos docentes se encuentran durante años, y a veces durante décadas, en carácter de contratados o interinos, con cargas horarias abrumadoras y demandas burocráticas absurdas - por ejemplo, mantener al día tres o cuatro sistemas de información curricular- entonces el problema no radica solamente en los aspectos legales que hacen a la autoría, sino en los contextos materiales y en las condiciones de posibilidad de la docencia, la investigación y la extensión; principalmente esta última, que es la que permite la transferencia de producciones y de conocimientos al conjunto de la sociedad y que para un docente-investigador, sobre todo en el área de las ciencias sociales, se expresa como publicaciones.

Ahora bien, cuando los esfuerzos legítimos de la actividad de docencia e investigación se traducen en publicaciones que tienen alcance en las áreas de la docencia donde hay un público cautivo -el conjunto de los estudiantes que no eligen comprar un material, sino que no tienen más remedio- entonces la asimetría entre las editoriales grandes y los autores, entre las editoriales pequeñas y las fotocopiadoras, entre los comerciantes y el público, reproduce la enajenación del trabajo intelectual, que deja de estar incentivado como una producción social de conocimiento y se convierte en el lucro de unos pocos.

¡Cómo se equivocan los que piensan que las condiciones del trabajo intelectual se encuentran por encima, o sustraídas, de las vicisitudes de expoliación y robo que se ciernen sobre el trabajo manual!

\section{Bibliografía}

- Sarthou, N. y Araya, J. M. (2015). "El Programa de Incentivos a Docentes Investigadores en Argentina: a dos décadas de su implementación”. Ciencia docencia y tecnología, 26(50), pp. 1-34. 


\section{Una técnica de las ciencias sociales: Escritura y auto observación en la investigación en artes}

Guadalupe Arqueros ${ }^{1}$

gimenarqueros@yahoo.com.ar

\section{Resumen}

¿Cuáles son los sentidos de la investigación cuando es artística? ¿Cómo resolver la narración de la producción? ¿Es narrable el proceso creativo? ¿Qué significa textualizar? ¿Podrían las metodologías de investigación de las ciencias sociales aportar y vincularse con la textualidad del proceso? Con que técnica específica podría resolverse esta narración?

En la creación artística, la función de la escritura (memoria reflexiva) es considerada un instrumento central para la toma de distancia y contemplación, a la vez que la observancia del estilo posibilita leer el resonar de la obra, como una reconstrucción desde palabras de un proceso que es el de la creación misma.

La reelaboración del proceso a través de su escritura, constituye un esfuerzo consciente y guiado a la manera de una auto observación que completa el sentido de un recorrido y presenta otra especificidad en el aporte final del trabajo. La siguiente reflexión busca establecer un vínculo teórico entre las características de la técnica de la auto observación y la explicitación del proceso creativo a través de la escritura en la investigación en artes. Para ello retomamos una experiencia particular de formación en investigación de un Ciclo de Articulación en una Carrera de Artes de una facultad pública, donde el trabajo final incluye la posibilidad de una producción artística conjunta con una narración del proceso creativo. Consideramos que los matices de la auto observación como técnica, aportan a la escritura en artes (textualidad del proceso creativo) y dotan de una dimensión resonante socialmente, a las obras y al trabajo de quienes las producen.

Palabras clave: proceso, auto observación, creación, escritura.

\section{Abstract}

What are the meanings of artistic research? How to solve the narrative of production? Could research methodologies of social sciences contribute and connect with that textuality of the process?

1 Lic.en Filosofía, profesora de enseñanza superior y de enseñanza media, Especialista y maestranda en Metodología de la Investigación científica NEDIM.IIGHI-CONICET/UNNE. 
In creation, the function of writing (reflective memory) is considered a main instrument for taking distance and contemplation, while adherence to style it facilitates reading the resound of artwork, as a reconstruction from words of a process which is the creation itself. Despite the fact that who research isn't researching him or herself, writing constitutes a guided and conscious effort after a self-observation which completes the meaning of a journey, and it makes another contribution quality.

The following text seeks to establish a theoretical link between the features of methodological technique of self-observation and the explanation of creative process through writing at research in Arts.

Keywords: process, method, self observation, creation, writing.

\section{Introducción}

La discusión sobre el progreso en las artes tiene nuevas traducciones concentradas en interrogantes tales como: ¿En qué sentidos se habla de investigación artística? ¿Cuáles son los elementos para considerar que el trabajo ha expandido las fronteras de representación o aportó variables de construcción diferentes? Algunos autores consideran que el desarrollo de las artes visuales (como paradigmáticas) no viene dado por la investigación de datos contextuales (historia de los períodos artísticos, semiótica de las imágenes) sino por la producción de obra y las innovaciones que en este campo puedan aportarse. El arte sería un espacio donde no existe progreso acumulativo al modo científico, sino que su devenir se asemeja a saltos cualitativos diferenciados, no rigurosamente predecibles ni lineales. Consecuentemente la tarea de la investigación no parece aplicable sin más en el campo artístico, como tampoco los conceptos de la epistemología científica.

Distinguimos para continuar, la investigación sobre el arte, de la investigación artística propiamente dicha, reservando para esta última los sentidos de un tipo de indagación estética creativa en la constitución de nuevos lenguajes y obras. La investigación sobre arte seria la indagación teórica regular donde los objetos son obras, producciones, etc. o tópicos vinculados al mundo del arte. En la actividad de creación la función de la escritura como reelaboración del proceso y traducción a una textualidad, es considerada un instrumento central para la toma de distancia y en el ejercicio del estilo de la misma, resuena el hacer de la obra (Arias, 2010, p. 7). Pese a que quien investiga no está investigándose a si mismo se trata de un esfuerzo plenamente autoconsciente y guiado a la manera de una auto-observación. Es decir que el trabajo no finaliza con la producción, sino con la narrativa del proceso que la originó y completa su sentido en un recorrido experimental que es científico y que constituye un aporte diferente y enriquecedor. Para otros autores la escritura colabora en establecer el puente instrumental que aúna práctica artística y reflexión como un proceso y un resultado (Durán Castro, 2011, p.12), es decir que tiene un sentido no complementario sino constitutivo en la creación.

El presente texto indaga sobre un vínculo entre la técnica de la auto observación, proporcionada por la metodología de las ciencias sociales, y la explicitación de la instancia creativa a través de la escritura en la investigación en artes. Recorreremos la idea con 
Guadalupe Arqueros / Una técnica de las ciencias sociales: Escritura y auto [...]/57 un caso que analiza los requerimientos del Reglamento de Tesinas de una carrera de la Universidad Nacional (UNNE) que otorga títulos de Licenciados en Artes. Luego desarrollamos apuntes e ideas propias sobre la auto observación como técnica proveniente de las ciencias sociales, enriquece y contribuye cualitativamente al proceso creativo.

\section{Tesinas de la licenciatura en artes}

Como especialista en metodología y profesora en una Facultad de Artes de Universidad Nacional me encuentro integrando una Comisión de Tesina encargada de evaluar proyectos finales de la carrera de Licenciatura en Artes de la Facultad de Artes, Diseño y Ciencias de la Cultura de la Universidad Nacional del Nordeste con sede en la ciudad de Resistencia, ${ }^{2}$ Provincia del Chaco, República Argentina. Esta institución inicia sus actividades ofreciendo un Ciclo de Articulación para profesionales que posean un título de nivel terciario o universitario.

Los llamados ciclos de articulación son carreras que no tienen un dictado regular y continuo como las tradicionales de una unidad académica, sino que se cursan por única vez y por lo general presentan contenidos y ejes curriculares comprimidos. Son trayectos especiales que complementan la formación de profesionales dedicados al trabajo en el área hace tiempo. En su mayoría ofrecen títulos de investigación, como la licenciatura que analizamos, pero no de posgrado y sus bacantes son cubiertas por adultos que simultáneamente, en sus trayectos vitales, están trabajando. El ciclo educativo de tres años comenzó como carrera a término, otorgando certificaciones de Licenciatura en Artes, en tres ramas: visuales, musicales y escénicas. El dictado de asignaturas allí y el trabajo junto a la directora de la articulación en la Comisión de Tesinas, fue el motor de la reflexión del presente artículo.

Según el reglamento aprobado en el Ciclo de Articulación, las tesinas de finalización de carrera podrían tener dos modalidades; de investigación teórica, en este caso serían trabajos individuales; o bien de producción artística (teórico-práctica) trabajos grupales que además van acompañados de una memoria del proceso. El Reglamento de tesinas de la facultad explicita para las tesinas individuales:

Investigación: su formato seguirá los lineamientos de la investigación básica. Consistirá en un trabajo individual que refleje las capacidades teórico-críticas logradas por el alumno a lo largo de la carrera. El tema elegido por el alumno deberá referirse a aspectos que hagan a la teoría, historia, crítica, técnica o aspectos relacionados que constituyan una profundización y un aporte original e inédito en el campo en el que se inserta. (Res. $\mathrm{N}^{\circ} 016 / 12$ D. del 23 de febrero de 2012) ${ }^{3}$

Resaltamos tres detalles importantes en la extracción previa:

a) la limitación en la modalidad individual del trabajo, que descarta una construcción colectiva del conocimiento que resulta como aporte;

2 F.A.D. y C.C./UNNE. http://www.artes.unne.edu.ar/ y http://www.artes.unne.edu.ar/artes-combinadas.html [consulta: 25-7-2015]

3 Resolución de la Facultad de Artes, Diseño y Ciencias de la Cultura, de la Universidad Nacional del Nordeste, Resistencia Chaco, Argentina. Anexo: Reglamento de tesina. 
58/ Perspectivas Metodológicas /19/Vol. II /Año 2017

b) el concepto teórico de investigación básica, sin desarrollar sus matices epistémicos, aplicado al campo de la teoría sobre artes,

c) el reglamento muestra conocimiento prediciendo las orientaciones de los trabajos, en consonancia con lo explicado por los autores citados.

Cuando los cursantes optan por la investigación teórica coincidimos con el análisis de Tolosa para el caso de España: las tres líneas de investigación universitaria se agrupan en confluencias interdisciplinares por un lado, trabajos históricos por otro y temas específicos (Tolosa, 1998, p. 64). Las investigaciones de tipo teóricas (sobre artes) representan las elecciones mayoritarias de los futuros graduados, concentrándose en tópicos de historia y educación artística. Las preferencias resultan ser la teoría estética, historia del arte, crítica y materiales e instrumentos. Elaboramos un gráfico [Figura 1] que puntualiza los contenidos hallados en las tesinas individuales con orientación teórica:

Figura 1: Recorridos temáticos de las tesinas del Ciclo de Articulación en Artes de la UNNE. (Datos de la Comisión de Tesina, al mes de marzo de 2015)

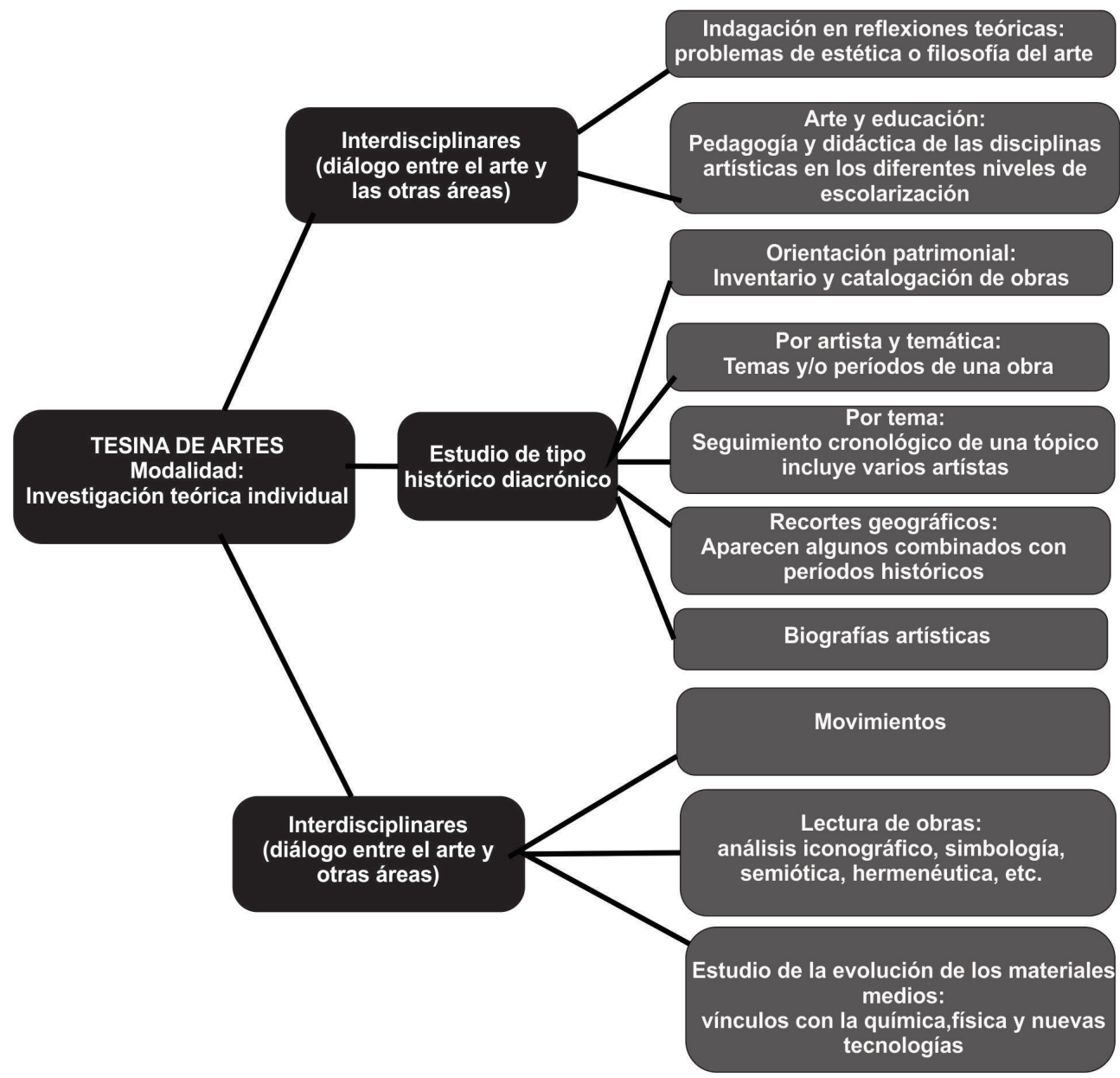

En las investigaciones teóricas se destacan en especial los estudios históricos, referidos a la historia del arte y artistas, locales y regionales en especial. También encontramos que 
Guadalupe Arqueros / Una técnica de las ciencias sociales: Escritura y auto [...]/59 los tópicos se solapan pese a nuestro afán analítico, por ejemplo en las biografías, donde aparecen estudios pormenorizados de un recorte de obras o en la confluencias disciplinares específicas y el desarrollo de una ciencia (como en la química y los análisis de los materiales). También hay conjunción en los recortes históricos y geográficos (aparecen títulos como el arte de la región en el periodo... por ejemplo).

\section{Egresar con una producción artística}

En las tesinas de realización (llamadas teórico-prácticas según el reglamento) a la hora de acompañar desde la dirección de las mismas, nos encontramos con la dificultad de dilucidar: ¿Qué tipo de saber específico otorga a un creador o productor un grado académico de investigación, como supone el de licenciado? ¿Qué pide el reglamento para la obtención del título en el caso de esta modalidad de tesina? ¿Qué género de escritura y que metodología acompaña la producción, traducida a texto? ¿Es posible describir un proceso creativo?

Si tomamos la letra, nos dice para la realización de una obra como producción artística:

a) en el campo de las artes visuales: se permitirá la presentación de los resultados de una obra o serie con la explicitación escrita que partirá de una reflexión teórica sobre la creación de la misma, investigación del tema, objetivos y público al que va destinada, y que dé cuenta de los procedimientos técnico/procedimentales aplicados.

b) en el campo de las artes escénicas: podrá consistir en una obra dramática original que deberá ser acompañada por una memoria en la que se desarrolle la metodología de trabajo, la problemática abordada y los recursos artísticos y técnicos utilizados en su producción.

c) en el campo de las artes musicales: [...] una Memoria que contenga los elementos estéticos y conceptuales como también tecnológicos utilizados. ${ }^{4}$

Analizando los requerimientos del reglamento para los egresos con producción hallamos una restricción al trabajo individual. Para la obtención del título la producción debe ser grupal, la introspección será entonces grupal. El reglamento estipula que los trabajos teóricos sean hechos por un solo estudiante y los de producción sean colectivos, sin embargo no prevé una actividad artística individual y se muestra condicionante en este sentido. La producción sería un tipo de trabajo de experimentación con nuevos lenguajes junto con el complemento de un escrito que continúa la obra original.

Con respecto al texto que debe acompañar las obras, es denominado explicitación escrita y reflexión teórica sobre la creación, para las artes visuales; memoria para las escénicas y musicales y se refiere a un trabajo usualmente de no más de quince carillas donde se describe el proceso, los antecedentes, las técnicas, el nivel de innovación, etc., que 4 Op. cit., p 1. 


\section{0/ Perspectivas Metodológicas /19/Vol. II /Año 2017}

trae aparejada la obra que se presenta. Este pedido de manifiesto resulta un requisito al menos interesante para aquellos que sean también creadores y que culminando el proceso de formación deben realizar una explicitación autoconsciente y porque no una auto observación, del proceso mismo. En el reglamento sin embargo falta especificidad sobre la composición del escrito y es en el caso de los licenciados en artes visuales donde únicamente aparece una reflexión teórica sobre la creación, ya que en las restantes ramas solo se solicita metodología de trabajo, problemática abordada y recursos artísticos y técnicos utilizados para las artes escénicas y un escueto elementos estéticos y conceptuales como también tecnológicos utilizados para los licenciados en artes musicales.

Las mayores dificultades se presentan cuando hay que destacar la producción como un trabajo original, en vinculación con los antecedentes en el campo y cuando hay que observar-describir un proceso creativo grupal, operación que hemos llamado arbitrariamente textualizar. Tal vez sea de ayuda en este punto recordar que para referirse a la instancia que aúna investigación y producción desde la Universidad de Granada Marín Viadel utiliza el término IENA (Investigación en Artes) en las llamadas tesis prácticas (con obra original) estipulando sus características. (Marín Viadel, 1998, p. 87)

\section{Investigación artística y académica}

Expedir un título de licenciatura es para la institución superior otorgar una certificación inicial en investigación, por eso es fundamental establecer las posibles modalidades cada vez que se menciona la investigación en artes. Tomando arbitrariamente como paradigma las artes visuales el desarrollo de las mismas, como actividad cultural humana no viene dado a través de la investigación de datos contextuales (historia de los períodos, semiótica de las imágenes, etc., que sí corresponderían a la investigación teórica) sino por la producción de obra y las innovaciones que en este campo puedan aportarse.

La confusión surge cuando se asume que la producción sin más es una tarea de investigación. En un artículo clásico escribe Tolosa al respecto:

$\mathrm{Al}$ estatus que puede adquirirse como artista, legitimado por el campo del arte, viene a añadirse el de investigador en Arte legitimado por la Universidad. Las cualidades que se necesitan para obtener estas dos legitimaciones, son complementarias. Se trataría de saber cómo pueden interaccionarse o, incluso, superponerse. De qué manera esta noción de investigación en Arte, asumida por los criterios de investigación en la Universidad, plantea de forma inédita, una cierta aproximación a la práctica del arte y su explicitación. (Tolosa, 1998, p. 59)

Las carreras que articulan estas trayectorias se enriquecen con la presencia de artistas y productores de obras entre sus estudiantes y sus programas por lo general, aprovechan esta instancia, brindando un tipo de especulación teórica y sobre la práctica misma. Esta reflexión es diferente en calidad y profundidad a la recibida en los centros de formación docente, de donde egresaron en general los inscriptos. Por otro lado Tolosa menciona como la investigación en artes puede echar luz sobre los procesos más internos de la crea- 
Guadalupe Arqueros / Una técnica de las ciencias sociales: Escritura y auto [...]/61 ción. Nos preguntamos entonces ¿¿Cuál es el instrumento como conjunto de pasos, o la técnica que pueda ser usada y enseñada para este vínculo, para textualizar este proceso?

Avanzando, conviene deslindar dimensiones. Borgdorff (2004) diferencia los planteos hacia adentro de la investigación en artes y clasifica tres enfoques. Los inclinados a la ontología resultan en visiones sobre la naturaleza de los objetos de investigación. Abarcarían desde los comienzos de la reflexión estética, cuando con Platón el artista copiaba los eidos primeros del topos uranos. Hasta las modernas teorías de la ficción, en literatura, por ejemplo y los contratos con lectores (Pozuelo Yvancos, 1993). La escala metafísica de los objetos producidos por el arte discuten los parámetros de una realidad intersubjetivamente compartida. Además el arte contemporáneo en especial, se muestra esquivo y plagado de ambigüedades que imposibilitan un análisis esencialista y esquemático (Oliveras, 2009). En el grafico [Figura 1] las indagaciones ontológicas se corresponden con las filosóficas y estéticas propiamente dichas (reflexiones teóricas).

Las cuestiones epistemológicas sin embargo versarían sobre el tipo de conocimiento discursivo que se produce y sus vínculos con otros campos del saber humano. Si bien el análisis completo es de carácter epistémico, las observaciones se centran en el alcance y la envergadura del contenido producido, como conocimiento sobre los campos del arte analizados.

Y por último los métodos adecuados y las técnicas seleccionadas y sus relaciones con las ciencias naturales, las humanidades y en especial las ciencias sociales y la historia. Estos últimos se llamarían análisis metodológicos. Como los puntos de contacto son diferentes, las técnicas y métodos también lo serán. En el ejemplo que analizamos de las tesinas de la Carrera de Articulación, prevalece la metodología historiográfica ya que hay búsqueda heurística y de fuentes sobre biografías de artistas y trayectos profesionales que se corresponden en especial con los recorridos históricos y diacrónicos. Sin embargo existe otro sector temático vinculado al estudio y evolución de materiales y medios que usan las técnicas de las ciencias naturales, por ejemplo la química y la física. ${ }^{5}$ En un cuadro ordenamos las posibilidades [Figura 2].

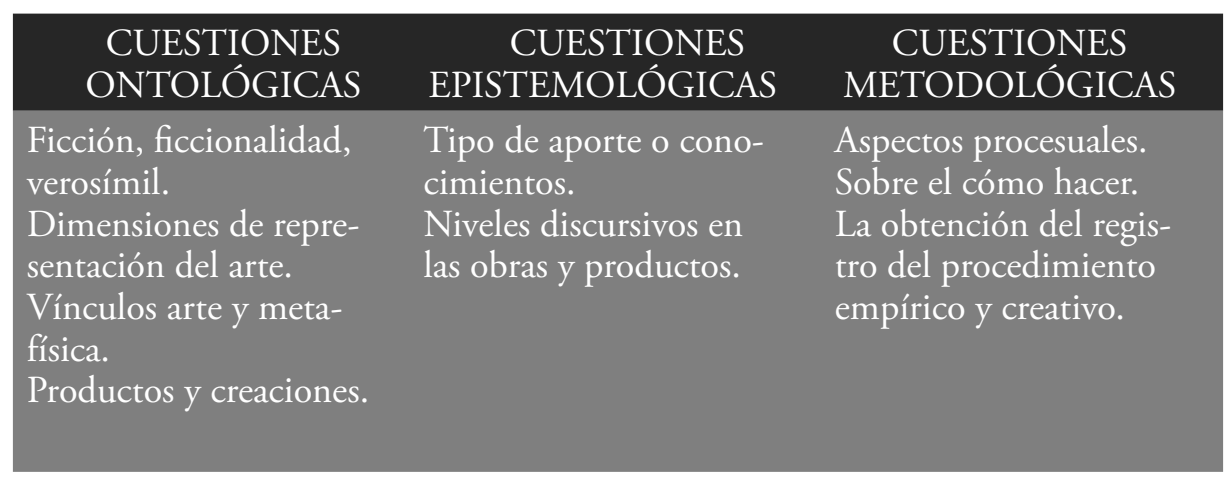

Figura 2: Clasificación de los principales aspectos según (Borgdorff, 2004, pp.15-18)

5 En este caso se habla también de una investigación para el arte. 


\section{2/ Perspectivas Metodológicas /19/Vol. II /Año 2017}

Hasta el momento se discutieron las tesinas teóricas, aquellas donde la investigación es sobre objetos vinculados al mundo del arte. Pero el nudo comienza cuando aparece la urgencia de la memoria descriptiva de las tesinas de producción: ¿¿Cuál es el género de esta narración? ¿Qué le recomendamos al grupo cuando tiene que narrar compulsivamente su proceso para la obtención del título? Dirimiendo los puntos de vista de la discusión y contraponiéndose a quienes impugnan esta modalidad de egreso, Marin Viadel considera que:

[El rechazo a las tesis prácticas] lo que discute es la conveniencia de que el dibujo, la pintura, la escultura, la fotografía o el diseño, sean un campo universitario. De otro modo no encuentro qué pueda ser una aportación original al dibujo que no sea el dibujo. Lo que rige en arte son las obras de arte. El método iconológico no es una aportación a la pintura sino a la disciplina de la historia del arte. Para desarrollar la pintura no hay más remedio que pintar buenos cuadros. Este es el objetivo fundamental de las tesis prácticas. (Marin Viadel, 1998, p. 91)

Este punto de vista puede sonar radical si no se comprende que el autor piensa en las grandes revoluciones estéticas principalmente pero no solamente, también científicas, que modificaron y hasta multiplicaron las subjetividades y formas de ver el arte como manifestación humana, diversificando la sensibilidad de una realidad nunca única.

\section{Auto observación}

En cualquier proceso creativo hay un pensamiento reflexivo, que no coincide con el mitema de la inspiración o en su extremo la habilidad mecanizada. Es el momento del tema, el asunto, los materiales, las decisiones expresivas y de comunicación en la obra, los posibles efectos en los espectadores, etc. (Duran Castro, 2011, p. 7) Frente a la posibilidad de que un texto refleje la lógica misma de este tipo de proceso Arias va más allá, pregunta y contesta:

¿Cómo tomar distancia de los procesos de creación y reflexión teórica de las obras para delimitarlas como objetos de investigación? Dicha distancia es posible en la escritura, no simplemente como elaboración teórica sino como ejercicio de un estilo en el que:

[...] resuena el hacer de la obra. [...] el objetivo de toda investigación en artes, es ante todo construir ese método comprendido no en el sentido tradicional de un sistema de pasos a seguir con el fin de ampliar el ámbito del conocimiento, sino como la construcción de una dinámica en la que se hagan posibles diversas replicas en las que el movimiento creativo encuentre cierta distancia sobre sí mismo. (Arias, 2011, pp. 7-8)

Pese a no coincidir con el subsiguiente posicionamiento que Arias deriva de las precedentes afirmaciones, cuando considera que a través del texto se unifica una separación que supone entre teoría y práctica; en algo si coincidimos y es que la escritura posibilitaría hacer explícito un sentir de quien crea, y que como recurso de auto observación puede conducir a una teoría o a la conceptualización del proceso. ${ }^{6}$

6 Tomando el término teoría como lo entendía Ladriere de modelización de un tipo de realidad que 
Guadalupe Arqueros / Una técnica de las ciencias sociales: Escritura y auto [...]/63

Habría variables frecuentes (en un sentido no específico) en el proceso creativo de los individuos, que pueden rastrearse, serian estas las réplicas mencionadas en la cita. Se justifica de esta manera el registro escrito en código de auto observación, buscando líneas comunes y desalojando definitivamente la estética kantiana del genio creativo único, falo-logocéntrico retomada por la teoría especulativa del arte. Aunque al decir de Tolosa: "Existen también sectores que cultivan el mito del puro creador, que no necesita ejercitar su modestia, ni contrastar su obra de una manera crítica" (Tolosa, 1998, p. 61).

Si tomamos a Delgado y Gutiérrez, (1999, p. 165) discutiendo la auto observación como un tipo de metodología que refleja y propicia el cambio social conversacional, veremos que hay una serie de rasgos que podrían ser aplicables a la escritura del proceso creativo como exigen las memorias académicas. Analizando sus rasgos hay que delimitar que observador y observado son posiciones y no personas o compartimentos inamovibles, el término con el que se denominarán será sistema observador y sistema observado y sucederán en el mismo individuo. En este marco la auto observación es una forma derivada de la relación nosotros en orientación otro, es decir es una reflexividad con base en dicha orientación, (Delgado y Gutiérrez, 1999, p. 163).

En la investigación empírica tradicional (pensamos en la sociología cualitativa) el sistema observado es objeto de observación externa directa o indirecta con registros cuantitativos y cualitativos. Pero en la auto observación tal como la sugerimos para este campo, el sistema observador se escinde en estado observador y estado observado. Remarcan los autores para las ciencias sociales, la necesaria prioridad en los roles, de tal manera de que la configuración sea actor - observador y no a la inversa (¿podríamos traducir en creador-observador?).

En la auto observación se da el proceso inverso al de la observación participante, donde se aprende a ser nativo de una cultura extraña; aquí sin embargo se extraña de la propia cultura o del proceso tomando distancia y ordenando. Partiendo de la noción de sistema observador y sistema observado, los autores recuerdan que la necesaria prioridad la tiene el orden que desdobla el sistema en actor y luego observador. Esto nativo próximo inundado (Flick 2004, p. 176) con orientación otro (¿sí mismo?) se convierte en constructor y autor del mundo de percepción lo que hace de la metodología una arqueología vivencial, al decir de Delgado y Gutierrez (1999, p. 168). También es fundamental que el observador sea un nativo próximo y no un nativo remoto, lo que implica que el sujeto debe abandonar, o debe haber dejado su condición de participante, para constituirse en estado observador del sistema y este movimiento de giro el que trae la distancia autoreflexiva.

La posición auto observadora es dependiente de una teoría de la fractalidad social en la medida en que es relacional y existen núcleos de complejidades comunes en los niveles y escalas de observación. La hipótesis de base radica en que no es el individuo aislado quien piensa e interpreta, sino que es siempre producido y reproductor de esas instituciones y discursos de tipo abstracto. En este sentido la metodología cualitativa entiende el sistema como una unidad holística, donde tanto quien investiga como los sujetos se encuentran atravesados por los rasgos de cultura y educación que son los del uso de su comunidad. ${ }^{7} \mathrm{Y}$ estos rasgos componen la complejidad de la interpretación misma.

se está analizando, y no en el sentido rígido omniexplicativo que conserva para la ciencia positiva (Ladriere, 1977)

7 Recordamos una frase importante de la historia de la sociología que puede ejemplificar el caso: La 
Frente al desboblamiento en sistemas de observación, resulta pertinente aquí una cita de Hammersley y Atkinson referida al método etnográfico:

El etnógrafo en su dinámica de inmersión y distanciamiento simultáneos, puede vivir una especie de esquizofrenia. Pero ese sentimiento, $\mathrm{u}$ otros equivalentes, deberían ser tomado por lo que realmente es. No es algo que necesariamente tenga que evitarse o ser sustituido por sensaciones más agradables de bienestar. (Hammersley y Atkinson 1994, p. 118)

Escribir es reconstruir el mundo a través de la experiencia del sujeto y usufructuar de la fractalidad social, análoga y no equivalente en cada uno, que aúna complejidades comunes ${ }^{8}$. El núcleo entonces es que en la memoria explicativa de los trabajos que dan cuenta de las producciones artísticas, asoma un tipo de narración que sobrepasa la dinámica de la creación individual. En la memoria se cruzan los tipos diferentes de enfoque que puntualizara Borgdorff (2004). Conocer es entonces tener experiencia de y experiencia en, más la conceptualización obligatoria del proceso que lo convierte en transferible, a la vez que le quita idealización romántica y elitismo falo-logocéntrico a los creadores. Esta visión se impregna más con las presentaciones emergentes del arte contemporáneo que se autodefine como desdefinido.

La posibilidad de enseñar la narratividad y la distancia del propio proceso creativo en alumnos y estudiantes adultos de artes que conllevan sus propias experiencias vitales de artistas, implicó la adaptación de una técnica para la recreación de un proceso y también un aporte al conocimiento de la educación en artes.

El dilema seguirá siendo ¿Cuánto tarda el proceso y si es posible transformar artistas y docentes en investigadores?

\section{Bibliografía}

- Arias, J. C. (2010). "La investigación en artes: el problema de la escritura y el método”. Cuadernos de Música, Artes Visuales y Artes Escénicas, 5(2), pp. 5-8.

- Arqueros, G. (2014). "Explicitar el proceso. Auto-observación y escritura en la investigación en artes”. En Actas I Post Congreso ICQI, I Congreso de Investigación Cualitativa en Ciencias Sociales. IIQI, CIECS CONICET/UNC. Universidad Siglo 21. Recuperado de http://www.21.edu.ar/investigacion-ponencias-congreso-investigacion-cualitativa-ciencias-sociales.html

— Borgdorff, H. (2007). El debate sobre la investigación en las artes. Recuperado de: http://gabrielabarrionuevo.com.ar/lenguajeeinvesticacion/el-debate-sobre-la-investigacion-en-las-artes/.

historia del individuo, no es más que una especie de concreción de la historia colectiva de su grupo o clase social. Bourdieu, Pierre. Esbozo de una teoría de la práctica. 1977.

8 Aquí vendría a coincidir la llamada tarea política asignada por Feliu y Jaunesse (Feliu y Jaunesse 2007) a la autoetnografía contemporánea. El descentramiento de quien escribe hecha raíces en lo particular e intransferible del proceso creativo, pero también vincula posibilidades de expandir y si no reproducir, reconocer uniformidades que des-hegemonizan el genio falo-logocéntrico. 
Guadalupe Arqueros / Una técnica de las ciencias sociales: Escritura y auto [...]/65

— Delgado, J. M. y Gutierrez, J. (1999). "Teoría de la observación”. En Métodos y técnicas cualitativas de investigación en ciencias sociales. Madrid: Síntesis.

— Della Porta, D. y Keating, M. (Eds.) (2013). Enfoques y metodologías de las ciencias sociales. Una perspectiva pluralista. Madrid: AKAL.

- Duran Castro, M. (2011). "La escritura en las disciplinas artísticas". Cuadernos de Música, Artes Visuales y Artes Escénicas, 6(2), pp. 5-12.

— Feliu, J. y Lajenusse, S. (2007). "Nuevas formas literarias para las ciencias sociales: el caso de la autoetnografía". Athenea Digital, (12), pp. 262-271.

— Fernández Arenas, J. (1982). Teoría y metodología de la historia del arte. Barcelona.: Antrophos.

— Gallart, M. A. (1992). La integración de métodos y la metodología cualitativa. Una reflexión desde la práctica de la investigación. En Vasilachis de Gialdino, I. y otros, Métodos cualitativos I y II (pp. 107-119). Buenos Aires: Centro Editor de América Latina, (pp. 107-119).

- Hammserley, M. y Atkinson, P. (1994). Etnografía. Métodos de investigación. Buenos Aires: Paidós.

— Ladrier, J. (1997). El reto de la racionalidad. Salamanca: Sígueme.

- Marin Viadel, R. (1998). El espacio de la 'IENA': ¿Qué es la investigación en arte y cuál es su función entre las investigaciones de bellas artes? En La investigación en bellas artes. Tres aproximaciones a un debate. Granada: Grupo Editorial Universitario.

- Mendioca, G. (2003). Sobre tesis y tesistas. Lecciones de enseñanza-aprendizaje. Buenos Aires: Espacio.

- Montoya López, A. (2006). "La investigación en arte. Como acceder a nuevas formas de expresión”. Artes. La Revista, 12(6).

- Oliveras, E. (2009). La metáfora en el arte. Retórica y filosofía de la imagen. Buenos Aires: Emecé.

— Pozuelo Yvancos, J. M. (1993). Poética de la ficción. Madrid: Síntesis.

- Rodríguez Gómez, G., Gil Flores, J. y García Jiménez, E. (1999). Metodología de la investigación cualitativa. Málaga: Aljibe.

— Tolosa, J. L. (1998). "Modelos de investigación en bellas artes". En La investigación en bellas artes. Tres aproximaciones a un debate. Granada: Grupo Editorial Universitario. 
66/ Perspectivas Metodológicas /19/Vol. II /Año 2017 


\title{
"Nosotros: el público ilustrado". Para una breve genealogía de los modos contemporáneos de crítica
}

\author{
Pablo Martín Méndez ${ }^{1}$ \\ pablomartinmendez@hotmail.com
}

\section{Resumen}

Entre los años 1978 y 1979, en un breve pasaje de sus trabajos e investigaciones, Michel Foucault advierte el pronto advenimiento de un "nuevo orden interior". Se trata de un pasaje fugaz, que hasta ahora no ha sido explorado en todos sus alcances. Este artículo retoma los interrogantes allí abiertos, poniendo especial atención en el surgimiento histórico del "publico" como sujeto crítico. De alguna manera, es el público y sus modalidades de subjetivación lo que el nuevo orden interior pone en juego. ¿Cómo se constituye hoy en día el público?, ¿cuáles son sus relaciones y tensiones con el poder? Foucault esboza algunas respuestas en el curso Naissance de la Biopolitique, sobre todo en las clases que abordan las condiciones de emergencia del "neoliberalismo". Más que una simple ideología económica, habría que concebir al neoliberalismo como una forma de diferenciación ante el poder, un posible modo de constituirse como público crítico. La pregunta por el nuevo orden interior debe considerar este último punto, advirtiendo, tal y como Foucault habría advertido en su momento, que nuestras actuales críticas contra el Estado tienen en gran parte una oscura procedencia neoliberal.

Palabras clave: racionalidad de gobierno - crítica moderna - liberalismo neoliberalismo - fobia al Estado

\section{Abstract}

Between the years 1978 and 1979, in a passage of his works and research, Michel Foucault warns the advent of a "new inner order". It is a fleeting passage, which until now has not been explored in all its scope. This article takes up the questions opened by Foucault, paying special at-

1 Doctor en Filosofía por la Universidad Nacional de Lanús. Licenciado y Profesor en Ciencia Política por la Universidad de Buenos Aires. Becario Postdoctoral CONICET (2017-2019). Profesor adjunto en la Maestría en Metodología de la Investigación Científica, profesor titular de Fundamentos de Ciencia Política de la Licenciatura en Ciencia Política y Gobierno, y en el área "Ética" de la Universidad Nacional de Lanús. 
tention to the historical emergence of the "public" as a critical subject. In some way, it is the public and its modes of subjectivation which the new order brings into play. How is the public configured today? What are their relationships and tensions with power? Foucault outlines some answers in the course Naissance de la Biopolitique, especially in classes where he analyzes the conditions of emergency "neoliberalism". More than a simple economic ideology, neoliberalism should be conceived as a form of differentiation vis-à-vis power, a possible way of establishing itself as a critical public. The question of the new internal order must consider this last point, warning, as Foucault would have warned in his moment, that our current criticisms of the state have in some points a dark neoliberal legacy.

Key words: governmental rationality - modern criticism - liberalismneoliberalism - State phobia

\section{Introducción}

¿Qué somos hoy?, ¿cómo pensar el presente en el cual vivimos y desde el cual hablamos?, ¿de qué manera ser otros? He aquí algunas de las preguntas que Michel Foucault planteaba poco antes de su muerte; para nosotros, los que hablamos actualmente con Foucault y a partir de Foucault, son también un modo específico de continuar haciendo filosofía, de llevar al pensamiento hasta sus propios límites.

Existen diferentes formas de contestar aquellas preguntas, todas lícitas y sin duda necesarias. Así por ejemplo, bien podríamos reconstruir y profundizar las investigaciones foucaultianas sobre las tecnologías políticas de normalización, prestando especial atención a lo que el texto La voluntad de saber dio en llamar "biopolítica". Esto resultaría importante para comprender el modo en que el poder nos ha constituido como sujetos; de hecho, sería una de las tantas vías que nos conduciría de lleno hasta la problematización del presente. Otra vía a seguir, también importante e imprescindible en nuestros días, consistiría en ampliar las investigaciones de Foucault sobre las prácticas de sí greco-romanas, particularmente aquellas que se explayan en los textos El uso de los placeres y La inquietud de sí. No se trataría de hacer una simple descripción histórica, sino más bien, y como ya advirtiera Foucault, de problematizarnos a nosotros mismos; más concretamente, se trataría de analizar las prácticas mediante las cuales hemos llegado a constituirnos como sujetos de nuestra propia conducta moral. Hay sin embargo un camino adicional, y es el que nosotros querríamos proponer a lo largo de este escrito.

Luego de abordar la biopolítica, y un poco antes de internarse definitivamente en el estudio de las prácticas de sí greco-romanas, Foucault se preguntará por las especificidades y las diferencias constitutivas de nuestro actual "orden interior". Nos referimos a la conferencia titulada como "Nuevo orden interior y control social" (1991 [1978]), pero además a la segunda parte del curso Nacimiento de la biopolitica (2008a [1979]). De alguna manera, allí Foucault entrevé la alteración de la actual dimensión pública; precisamente aquella donde Kant encontraba la posibilidad de ilustrarse a sí mismo, usando la propia razón sin relación de obediencia o de autoridad. Pues bien, el camino que proponemos ahora consiste en reto- 
Pablo Martín Méndez / "Nosotros: el público ilustrado”. Para una [...] /69 mar las interrogaciones de Foucault sobre el actual orden interior, preguntándonos concretamente cómo, a través de qué prácticas y relaciones, se constituye hoy en día el "público".

\section{Dentro y fuera del liberalismo}

Conviene hacer una aclaración de entrada: el público del que aquí hablamos, y del que también parecería hablar Foucault en diferentes ocasiones, puede pensarse de varias maneras menos como un grupo de individuos expectantes, a la espera de ser conducidos y hasta manipulados por alguien, sin ninguna iniciativa y capacidad de reacción. El público no es, o acaso no ha sido siempre, un mero objeto de estudio y de análisis; de hecho, tampoco alcanza con ver allí la superficie de innumerables sondeos estadísticos. Hay que pensar la cuestión desde otra perspectiva: más que un objeto aislable y perfectamente manejable, el público se define siempre en relación. Diríase que el público está relacionado con tres cuestiones complementarias: en primer lugar, con una coyuntura histórica bien precisa: la Europa de fines del siglo XVIII, signada por una ola de revoluciones políticas, económicas y culturales de diferente alcance; en segundo lugar, con el modo en que, durante ese mismo período histórico, el poder no sólo es ejercido, sino además cuestionado e incluso resistido; y finalmente, con la emergencia de lo que ha dado en llamarse la "crítica moderna". Genealogía, poder y crítica: si realmente el público nos indica algo acerca de nosotros mismos, lo hace siempre en relación a todo esto.

Cuando Foucault habla sobre el público se sitúa en un contexto histórico concreto, un campo de emergencia que, por muchas razones, resulta de enorme importancia para entender nuestro presente. Estamos refiriéndonos a las últimas décadas del siglo XVIII. ¿Qué sucedía en aquél momento? Desde fines del siglo XVIII, y hasta bien entrado el siglo XX, va desarrollándose y cobrando cada vez más fuerza una "racionalidad" específica de gobierno. Se trata de un entramado de procedimientos, análisis y cálculos políticos; es toda una manera de percibir y de resolver problemas conforme a ciertos fines de gobierno. El objeto de intervención principal de esa racionalidad emergente estaría en la población, su forma de saber en la economía política, mientras que sus instrumentos técnicos más fundamentales serían los dispositivos de seguridad. Sin duda alguna, resuenan aquí muchas de las cuestiones por las cuales Foucault se ha interesado en otros momentos: como las tecnologías biopolíticas y disciplinarias, también el biopoder, e igualmente, o quizá ya en el límite, la red de dispositivos inmanentes a las sociedades de normalización.

Ahora bien, los cursos Seguridad, territorio y población y Nacimiento de la biopolítica dejan entrever una cuestión adicional, y es que todo ese entramado de tecnologías, cálculos y saberes está atravesado por el "liberalismo" como racionalidad gubernamental específica. Precisamente allí, más que en ningún otro lugar, debe situarse al público:

La palabra no es nueva, aunque sí su uso. El público, noción capital del siglo XVIII, es la población considerada desde el punto de vista de sus opiniones, sus maneras de hacer, sus comportamientos, sus hábitos, sus temores, sus prejuicios, sus exigencias: el conjunto susceptible de sufrir la influencia de la educación, las campañas, las convicciones. (Foucault, 2006, p. 102) 
El público aparece en el extremo de la población misma; de alguna manera, es la población considerada desde un punto de vista a-orgánico, no necesariamente biológico. Al menos así lo daría a entender Foucault: "De la especie al público tenemos todo un campo de nuevas realidades" (Foucault, 2006, p. 102).

Maurizio Lazzarato, un filósofo italiano que intenta profundizar las problemáticas abiertas por Foucault, parecería ir todavía más lejos:

El "público" no es un hecho social estático reducible a un organismo, sino una variación, una tendencia, un devenir. [...] La multiplicidad, en el público, tiende a volverse simultáneamente molecular e inmediatamente colectiva y a asumir la forma del flujo, de la variación, de la velocidad [...]. El público, en efecto, es un acontecimiento. (Lazzarato, 2006, p. 74)

Nosotros diríamos también que el público se ubica en el límite de las tecnologías liberales de gobierno; es el acontecimiento que las disciplinas y la biopolítica nunca logran encauzar y ni regular del todo. Ciertamente, el público no cabe en los reducidos espacios de la disciplina, aunque tampoco se lo puede situar sin más en los espacios abiertos de la biopolítica; no puede gobernarse de igual manera en que se gobierna a los organismos individuales, ni regularse como se regulan habitualmente las poblaciones. Para la racionalidad liberal de gobierno, hay aquí todo un desafío, un acontecimiento, y en última instancia un límite.

¿Por qué decimos que el público está en el límite del liberalismo? Volvamos brevemente al siglo XVIII; o en otros términos, a aquello que dio en llamarse l'âge des Lumières [la época de las Luces]. Foucault ha sostenido que esa época estuvo marcada por una profunda obsesión, prácticamente un miedo:

Un miedo obsesivo recorre el siglo XVIII: el espacio oscuro, la pantalla de oscuridad que impide la visibilidad de las casas, las gentes, las verdades. Disolver los fragmentos de noche que se oponen a la luz, hacer que no existan más espacios oscuros en la sociedad, demoler esas cámaras negras en las que se fomenta la arbitrariedad política, los caprichos del monarca, las supersticiones religiosas, los complots de los tiranos y los frailes, las ilusiones de ignorancia, las epidemias. (Foucault, 1980, p. 16)

La racionalidad liberal tiene un problema de fondo, que consiste en disolver cualquier punto donde se acumulen la superstición y la ignorancia, cualquier estrato demasiado oscuro que sirva de apoyo para la arbitrariedad y el despotismo. ${ }^{2}$ A la ignorancia y la superstición se les debe anteponer entonces una mayor "libertad"; más específicamente, hay que contrarrestarlas dejando que las ideas y las creencias circulen libremente, sin formar estratificaciones o complots potencialmente peligrosos.

2 Vale recordar aquí las palabras de Mercier de la Rivière, un fisiócrata francés del siglo XVIII: "El despotismo arbitrario, producción propia de la ignorancia, es una fuerza física que se sirve de su superioridad para oprimir. Esta fuerza no existe por sí misma, ni en un solo individuo, sino que es el resultado de una asociación; y esta asociación se forma precisamente de un concurso de pretensiones y de intereses arbitrarios unidos a éste efecto (de la Rivière, 1823, p. 314). 
Pablo Martín Méndez / "Nosotros: el público ilustrado". Para una [...] /71

Los gobiernos liberales sólo funcionan bien cuando existen y quedan aseguradas una serie de libertades concretas, incluyendo no únicamente la libertad de mercado o de circulación de bienes, sino a la larga la libertad de ideas:

[...] libertad de mercado, libertad del vendedor y el comprador, libre ejercicio del derecho de propiedad, libertad de discusión, eventualmente libertad de expresión. [...] la nueva razón gubernamental tiene necesidad de libertad. [...] Está obligado a producirla y está obligado a organizarla. (Foucault, 2008a, p. 84)

Si la gubernamentalidad liberal produce libertad, es porque encuentra en ella un contra-efecto para las supersticiones y las arbitrariedades políticas que de allí se siguen. Hecho curioso, y quizá más importante de lo que perecería a primera vista -sobre todo cuando se trata de pensar los alcances y las limitaciones de una determinada práctica de gobierno-. Según Foucault, desde cierto momento histórico los "dispositivos liberógenos", los saberes y las tecnologías productoras de libertad, redundaron en efectos opuestos a los que se esperaban. Así sucedió con la libertad de producción y de comercio, que desde finales del siglo XIX, y tal como pudo percibirse aquí y allá, reportaron un enorme peligro para la libertad económica y política de los trabajadores industriales; pero así también con las libertades de trabajo, cuyos mecanismos de protección fueron a su vez percibidos como una amenaza para la libertad de producción y de comercio. No otra es la encrucijada del liberalismo, donde los dispositivos de producción y promoción de las libertades ponen en peligro a las libertades mismas: "Ése es el equívoco de todos los dispositivos [...] 'liberógenos', todos esos dispositivos destinados a producir liberad y que, llegado el caso, corren el riesgo de producir exactamente lo contrario". (Foucault, 2008a, p. 91)

De más está decir que el público emerge en relación con los dispositivos liberógenos, especialmente con aquellos destinados a garantizar la libertad política y la libertad de expresión. Bajo el objetivo de contrarrestar los focos de arbitrariedad, o por necesidad de disolver los puntos de ignorancia y de superstición, el gobierno estimula la mayor circulación posible de ideas y creencias; en simples palabras, permite que poco a poco vaya conformándose un nuevo espacio público. Ahora bien, tal vez no sea demasiado aventurado sostener, como nosotros sostendremos en adelante, que la libre circulación de ideas y creencias tuvo un efecto sumamente inesperado. Lo que en principio debía servir al sostenimiento de los gobiernos liberales, se vuelve eventualmente en su contra. Y es que, en el límite, el público no sólo critica los focos de arbitrariedad, sino además las incongruencias y los peligros provocados por la propia racionalidad liberal de gobierno. De hecho, muchos descubrirán que los gobiernos liberales bien pueden conducir hacia la arbitrariedad y el exceso mismo de poder.

\section{Diferenciarse del poder}

A fines del siglo XVIII, en aquel interesante artículo titulado Was ist Aufklärung? [¿Qué es la Ilustración], Kant solicitaba a los príncipes dejar al público en libertad de ilustrarse a si mismo; esto es, usando la propia razón sin relación de obediencia o de autoridad: "resulta posible que el público se ilustre a sí mismo, algo que es casi inevitable 


\section{2/ Perspectivas Metodológicas /19/Vol. II /Año 2017}

si se le deja en libertad" (Kant, 2005, p. 22). Cabe remarcar aquí un par de cuestiones complementarias: la primera está explicitada por Kant, mientras que la otra aparece de una manera más implícita.

Tal y como se desprende del texto Was ist Aufklärung?, existen dos usos posibles de la razón, a saber: el "uso público" y el "uso privado". Así pues, el uso público nos constituye como sujetos universales; o en los términos de Kant, como "doctos" capaces de atener nuestro propio juicio a la razón total de la humanidad: "Entiendo por uso público de la razón el que alguien hace de ella en cuanto docto (Gelehrter) frente al gran público del mundo de los lectores" (Kant, 2005, p. 23). El uso privado de la razón se ubicará en un terreno distinto: no es el que hacemos como miembros del público, en cuanto doctos que hablan ante la razón total de la humanidad, sino más bien como miembros pasivos del Estado. Por un lado el uso público de la razón, y por el otro el uso privado; aquí la crítica y allá la obediencia. No es que ambos usos sean contradictorios o excluyentes; en todo caso, funcionan en dimensiones distintas: justamente en la dimensión pública y la dimensión privada, o también en el espacio de la crítica y en el de la obediencia.

La segunda cuestión aparece en forma más implícita, y es en realidad Foucault quien después se encargará de remarcarla. Ocurre que el uso público de la razón implica o supone en el límite todo un trabajo de sí sobre sí mismo: "Los hombres salen gradualmente del estado de rusticidad por su propio trabajo, siempre que no se los intente mantener, adrede y de modo artificial, en esa condición" (Kant, 2005, p. 27). Para salir de la rusticidad o la pasividad en la cual nos encontramos inmersos, para abandonar lo que Kant llamará igualmente como "minoría de edad", hace falta un trabajo de sí sobre sí. Se trata de asumir otra "actitud", otro modo de relación consigo mismo y con los demás. Foucault hablará sobre la voluntad de no ser gobernado de determinada manera, o también del intento de "diferenciarse" ante los poderes existentes: "una cierta voluntad decisoria de no ser gobernado, una voluntad decisoria como actitud a la vez individual y colectiva de salir, como decía Kant, de la minaría de edad. Cuestión de actitud" (Foucault, 1995, p. 17). La especificidad de la crítica moderna reside justamente allí: en el cambio de actitud alrededor del gobierno. Ser moderno equivale a asumir una actitud crítica, mientras que actuar críticamente resulta propio de todo aquel que ya no quiere ser gobernado de esta manera, bajo estos fines y por medio de estas técnicas: "no de esa forma, no para eso, no por ellos" (Foucault, 1995, p. 7). La actitud moderna estará presente tanto en Kant como en el Aufklärung; así también, marcará el horizonte de emergencia del público.

El público emerge de un juego de diferenciaciones con el poder; más aún, es todo un espacio de crítica contra las extralimitaciones y los abusos de las autoridades instituidas. Foucault señalará que las diferentes maneras de usar la razón, donde se obedece al poder en cuanto ciudadano y se lo critica en cuanto docto, abren una nueva labor para la actividad filosófica:

[...] desde Kant el papel de la filosofía ha sido el de impedir que la razón sobrepase los límites de lo que está dado en la experiencia; pero desde esta época -con el desarrollo de los Estados modernos y la organización política de la sociedad- el papel de la filosofía también ha sido el de vigilar los abusos del poder de la racionalidad política. (Foucault, 2008b, p. 96). 
Pablo Martín Méndez / "Nosotros: el público ilustrado". Para una [...] /73

La crítica moderna ya no consiste únicamente en marcar los límites legítimos del conocimiento, aquellos a partir de los cuales la razón se torna heterónoma o queda a merced de una autoridad externa; además de eso, o junto con eso, aparece poco a poco la cuestión del poder. En otras palabras, y aquí habría que inscribir toda una rama del pensamiento moderno, se plantea la sospecha o la interrogación sobre las relaciones entre la razón y el poder, el uso de la razón y los efectos de poder que ésta conlleva. Durante la primera mitad del siglo XX, varios serán los participen de semejante sospecha; no sólo Max Weber y después la Escuela de Frankfurt, sino igualmente una parte nada menor del público alemán de izquierda:

[...] esta sospecha de que hay algo en la racionalización y quizá incluso en la razón misma que es responsable del exceso de poder, pues bien, esta sospecha se ha desarrollado especialmente en Alemania y, digamos, para ser aún más breves, que se ha desarrollado en lo que podríamos llamar una izquierda alemana. (Foucault, 1995, p. 10)

Muchas cosas han trascurrido desde entonces; varios acontecimientos de los cuales también Foucault fue testigo.

¿Cómo se ejerce hoy la crítica?, ¿de qué manera nos diferenciamos ante el poder y sus excesos? En el curso Nacimiento de la biopolítica, Foucault otorga algunos indicios sobre el caso; de hecho, sostiene que la crítica moderna ha devenido en toda una sospecha antiestatal, una intensa y diseminada fobia al Estado:

[...] lo que se pone en cuestión en la actualidad, y a partir de horizontes extremadamente numerosos, es casi siempre el Estado; el Estado y su crecimiento indefinido, el Estado y su omnipresencia, el Estado y su desarrollo burocrático, el Estado con los gérmenes de fascismo que conlleva, el Estado y su violencia intrínseca debajo del paternalismo providencia. (Foucault, 2008a, p. 218)

Aquí se habla de intervenciones autoritarias, allí de fascismo e incluso de totalitarismo, en última instancia: la mayor parte del público supondría hoy que el Estado, ya sea por derecha o por izquierda, ya por defecto o por omisión, se encuentra siempre presto a degenerar en lo peor.

Sin importar cuál sea su orientación económico-política, el Estado irá indefectiblemente para peor. Tan es así que nuestros actuales modos de crítica terminarían percibiéndolo como una gran sombra vertida sobre la sociedad civil; o, en términos de Foucault, como un "fantasma paranoico y devorador": "en nombre del dinamismo del Estado, siempre se puede encontrar un parentesco o un peligro, algo así como el gran fantasma del Estado paranoico y devorador. En este sentido, poco importa en definitiva qué influjo se tiene sobre lo real o qué perfil de actualidad presente éste" (Foucault, 2008a, p. 220). De un lado estaríamos nosotros, el público capaz de constituirse y de actualizarse a sí mismo mediante la crítica, y del otro el Estado, que por defecto intrínseco resulta demasiado inactual o poco adaptado a estos tiempos. Ahora bien, mientras más inactual es el Estado, mientras más dificultad encuentra para adaptarse a las exigencias de nuestro presente, más omnipresente 


\section{4/ Perspectivas Metodológicas /19/Vol. II /Año 2017}

y avasallante se torna. De manera tal que el problema no residiría en la simple avidez de poder, sino en algo peor: en la completa ineptitud de las estructuras estatales.

\section{La oscura procedencia}

Ya en la década de 1970, Foucault advertía que ese modo de crítica -el cual es también, cabe recordarlo siempre, un modo de relación consigo mismo y de diferenciación ante el poder- estaba difundido en casi todas partes, tanto como para obturar cualquier otro tipo de análisis y de problematización sobre la actualidad: "Basta con encontrar, a través de la sospecha y (...) de la denuncia, algo parecido al perfil fantasmático del Estado para que ya no sea necesario analizar la actualidad" (Foucault, 2008a, 220-221). De ahí lo que nosotros entendemos como una de las apuestas más importantes de Foucault. Para pensar el presente a fondo y hasta las últimas consecuencias, tenemos que preguntar de dónde nos llega la crítica antiestatal: "la crítica por el dinamismo del Estado (...) no busca saber de dónde viene esa especie de sospecha antiestatal, esa fobia al Estado que circula hoy en tantas formas diversas de nuestro pensamiento" (Foucault, 2008a, p. 221). Apuesta importante aunque inclusa; en realidad, sólo la segunda parte del curso Nacimiento de la Biopolitica se dedicará a brindarle cierta atención. El resto nos corresponderá a nosotros, los que hablamos hoy desde Foucault y también más allá de Foucault.

Preguntemos entonces de dónde procede -o mejor aún: a través de qué acontecimientos nos viene- la sospecha antiestatal. La respuesta de Foucault dirigirá nuestra mirada hacia un lugar y un momento histórico concreto: la Alemania de las décadas de 1930 y 1940. Fue en ese momento cuando un grupo de doctos quiso diferenciarse ante los poderes existentes; fue especialmente allí, más que en ningún otro lugar, donde se percibió al Estado como una entidad polimorfa, omnipresente y avasallante. El hecho fundamental, y quizá impensado para los actuales modos de crítica, consiste en que aquellos doctos solían definirse a sí mismos con una divisa o un distintivo; esto es, el "neoliberalismo":

[...] en la escuela neoliberal alemana hallamos el análisis de los parentescos necesarios entre las diferentes formas estatales y la idea de que el Estado tiene una dinámica propia por la que jamás puede detenerse en su ampliación y en su cobertura de la totalidad de la sociedad civil. (Foucault, 2008b, p. 221).

Así como hemos intentado pensar al público desde una perspectiva diferente, así también deberíamos proceder con el neoliberalismo. En efecto, no se trata de una simple ideología económica, sino más bien de toda una manera de diferenciarse del poder y de constituirse a la par como público crítico. El neoliberalismo sería el lugar de donde procede gran parte de las actuales críticas contra el Estado; o inversamente, el oscuro fondo desde el cual recibimos y heredamos nuestra actual racionalidad de gobierno. Foucault sostenía que el neoliberalismo alemán elabora otro modo de percibir, de calcular y de resolver problemas: otra racionalidad gubernamental. Si ello fuera cierto, convendría añadir enseguida que el gobierno neoliberal no sólo actúa a través de la represión y la violencia -tal y como muchos críticos señalan con frecuencia-, sino además a través del consenso público; vale decir, a través de nosotros mismos, mediante nuestras propias creencias y deseos. 
Pablo Martín Méndez / "Nosotros: el público ilustrado”. Para una [...] /75

Gobernar según la racionalidad neoliberal implica producir conceso sobre ciertas cuestiones o problemas: sólo en este sentido, la fobia antiestatal juega un papel más que fundamental; y sólo así se entienden además las palabras que Foucault pronunciaba a fines de la década de 1970: "Todos los que participan en la gran fobia al Estado, sepan que están siguiendo la corriente y que por doquier se anuncia desde hace ańos y años una disminución efectiva del Estado, de la estatización y de la gubernamentalidad estatizante y estatizada" (Foucault, 2008a, p. 225). La cuestión no consiste sencillamente en reducir el ámbito de injerencia del gobierno, sino en ejercerlo de una manera diferente, en nuevos espacios y con otras tecnologías. Son las tecnologías de control que hacen al nuevo orden interior, aquellas que favorecen la autorregulación de los conflictos y de los peligros sociales (Foucault, 1991, p. 166). Sin lugar a duda, aquí entran en juego los medios masivos de comunicación -incluyendo la prensa, la radio, el cine y la televisión, como también las más recientes "redes sociales"-. No es que los gobiernos neoliberales intervengan directamente sobre los medios; antes que recurrir a semejante aseveración, y a contramano de lo que habitualmente se piensa, decimos más bien que los medios de comunicación pueden ser en si mismos un elemento gubernamental.

Toda una racionalidad atraviesa las tecnologías neoliberales de gobierno. Se trata de solucionar los conflictos y las diferencias a través de la responsabilidad y la iniciativa individual. Es también la creación de un extenso ambiente de competencia donde los individuos sean continuamente incitados a asumir y sopesar los riesgos y los beneficios de sus respectivas acciones; donde la implementación de planes, proyectos y tácticas aparezca como la única forma valedera de comportamiento. Al abordar las cosas con más detenimiento, vemos que el objetivo consiste en disminuir la necesidad de protecciones y de seguridades estatales. Ello nos indica algo bastante importante sobre nuestra propia actualidad, y es que el neoliberalismo no debe pensarse en absoluto como la mera continuación del liberalismo; por el contrario, el neoliberalismo emerge como la respuesta ante las incongruencias de la racionalidad liberal; en el límite, es un intento diferente de gobernar la libertad.

\section{Breves conclusiones}

Hace casi cuarenta años que Foucault planteaba la necesidad de comprender la singularidad histórica del neoliberalismo. Esta tarea sigue aún vigente -especialmente hoy, cuando las críticas neoliberales se han diseminado y generalizado hasta tal punto que ya ni siquiera las percibimos como aquello que fueron en un comienzo-. Si queremos comprender la novedad y la diferencia de nuestro actual orden interior, si en verdad queremos saber quiénes somos hoy, tenemos que pasar en algún momento por el neoliberalismo. Acaso quedaría por ver que allí no hay únicamente una doctrina económica aplicada por derecho, por ideología o por simple imposición, sino también una nueva manera de articular el gobierno de los otros y el gobierno de sí mismo. Tal vez así, con la problematización del neoliberalismo como relación consigo mismo y como racionalidad de gobierno, llevemos todavía más lejos las apuestas de Foucault. Porque una cosa resulta cierta: si Foucault tiene una apuesta de fondo, consiste sin duda en la posibilidad de ser otro, en trabajarse y transformarse constantemente, hasta devenir en algo diferente de lo que ya se es. Para nosotros, el problema pasará entonces por ser distintos a nosotros mismos, o al menos en no ser lo que ahora estamos siendo: unos sujetos atravesados por el neoliberalismo. 


\section{Bibliografía}

— de la Rivière, M. (1823). El orden natural y esencial de las sociedades politicas. Valencia: Benito Monfort.

— Lazzarato, M. (2006). "Para una redefinición del concepto 'biopolítica”. Brumaria. Arte, Máquinas, trabajo inmaterial (7), pp. 71-81.

- Foucault, M. (2008a). Nacimiento de la biopolítica. Curso en el Collège de France (1978-1979). Buenos Aires: Fondo Cultura Económica.

— Foucault, M. (2008b). "Omnes et singulatim: hacia una crítica de la 'razón política”. En Tecnologias del yo y otros textos afines (pp. 95-140). Paidós: Buenos Aires.

- Foucault, M. (2006). Seguridad, territorio, población. Curso en el Collège de France (1977-1978), Buenos Aires: Fondo de Cultura Económica.

— Foucault, M. (1995). “QQué es la crítica [Crítica y Aufklärung]”. Daimwn. Revista Internacional de Filosofia, (11), pp. 5-25.

— Foucault, M. (1991). "Nuevo orden interior y control social". En Saber y Verdad (pp. 163-166). Madrid: La piqueta.

— Foucault, M. (1980) "El ojo del poder”. En Bentham, J., El Panóptico (pp. 9-26). Madrid: La Piqueta.

— Kant, I. (2005). “¿Qué es la ilustración?”. En Ensayos sobre la paz, el progreso y el ideal cosmopolita (pp. 21-31). Madrid: Cátedra. 
Perspectivas 



\title{
Un perfil de Foucault: Notas a partir de una lectura arqueológica del archivo foucaulteano
}

\author{
Iván Gabriel Dalmau ${ }^{1}$
}

\section{A modo de introducción ${ }^{2}$}

\begin{abstract}
En retrospectiva, los trabajos publicados aparecen como fotografías, como recortes momentáneos de un proceso [...]. Sin embargo, la lectura de las lecciones del Collège de France provee un antídoto eficiente para esto. En dichas conferencias vemos a Foucault trabajando, volviendo constantemente sobre cuestiones previas, retomándolas y reformulándolas.
\end{abstract}

Wallenstein, Foucault, Biopolitics and Governmentality

En el presente trabajo recuperamos una serie de discusiones abordadas tangencialmente en el marco de nuestra Tesis Doctoral (Dalmau, 2016), realizada en torno a la problematización del saber que el filósofo francés Michel Foucault elaborara en el marco de su genealogía de la biopolítica. En este artículo pondremos el foco en una cuestión que, si bien escapa al eje de dicha investigación, consideramos nodal a la hora de aproximarnos al discurso foucaulteano y, de hecho, ha sido fundamental para el desarrollo de la citada indagación. Nos referimos específicamente a lo que podría denominarse como "un perfil" de la manera foucaulteana de puesta en práctica del trabajo filosófico. En ese sentido, retomando la cita que hemos colocado como epígrafe, nos ocuparemos de revisar el gesto foucaulteano de recuperación y reelaboración de sus trabajos precedentes desde la perspectiva de sus indagaciones en curso, cuestión que se ha tornado palpable tras la publicación de los cursos dictados por el filósofo en el Collège de France (Raffin, 2015). Al mismo tiempo, buscando problematizar la constitución de dicho "perfil filosófico", nos ocuparemos de dar cuenta de la profunda ligazón que articula al mentado gesto foucaulteano con su posicionamiento en torno a la filosofía crítica.

1 Doctor en Ciencias Sociales (FSOC-UBA). Becario Postdoctoral CONICET. Docente de Epistemología de las Ciencias Sociales (Humanidades-UNSAM) y de Introducción al Pensamiento Científico en el Ciclo Básico Común de la Universidad de Buenos Aires (UBA).

2 Hemos privilegiado el trabajo sobre las fuentes primarias y secundarias en idioma original, razón por la cual las traducciones nos corresponden, excepto que se indique lo contrario. 
Por otra parte, desde un punto de vista formal, sería pertinente remarcar que dividiremos al presente escrito en tres parágrafos. En el primero explicitaremos el modo en que nos apropiamos de las herramientas arqueológicas foucaulteanas para la puesta en práctica de nuestra investigación. Tras lo cual, habiendo explicitado las denominadas "cuestiones de método", en los apartados siguientes nos detendremos en una serie de documentos que constituyen el "archivo Foucault" para dar cuenta del mentado perfil que caracterizaría una faceta del modo en que Michel Foucault ha practicado el trabajo filosófico. Específicamente, en el segundo parágrafo nos detendremos en el modo en que el filósofo buscó ubicarse en torno a una de las "posteridades críticas" erigidas alrededor del legado kantiano; luego, en el último apartado, buscaremos dar cuenta del mencionado gesto foucaulteano de recuperación y reelaboración recurrente de las herramientas fraguadas en sus trabajos precedentes desde el prisma de sus trabajos en curso.

\section{Punto de partida: notas para una lectura arqueológica del archivo Foucault}

A lo largo de las líneas que se despliegan a continuación se pretende llevar a cabo una lectura filosófica de carácter problemático de fragmentos de la discursividad foucaulteana, en torno a lo cual se impone la realización de una serie de aclaraciones, puesto que son varias las aristas implicadas. En términos generales, sería pertinente destacar que el abordaje problemático de los trabajos de Michel Foucault se encuentra jalonado por la búsqueda de herramientas que habiliten a la interrogación respecto de nuestro presente y, por lo tanto, no se encuentra alentado por el intento de elaboración de "la lectura", original e irrecusable, que clausuraría todo tipo de discusión, contribuyendo a la desactivación de la potencia crítica de las herramientas filosóficas foucaulteanas. De hecho, sería más que paradójico proponer un abordaje del discurso foucaulteano erigido a partir de una estrategia metodológica análoga a la que el filósofo francés cuestionara en el marco de sus clásicas reflexiones respecto del método arqueológico (Foucault, 1969). Es decir, que partiendo foucaulteanamente de la base de que la noción de "autor" no remite a una "subjetividad psicológica", con sus "intenciones", ni a su presunta inscripción dentro de una determinada "tradición", sino más bien a una función del discurso (Foucault, 1994a), interrogarnos acerca del "sentido de sus textos" sería comportarnos como investigadores de modo similar al retratado por la clásica metáfora del "perro que se muerde la cola".

Por otra parte, en lo que respecta a las referencias de Michel Foucault a otros filósofos u otras corrientes filosóficas, las consideraremos relevantes en función de la economía del discurso foucaulteano y no como un "problema en sí mismo", cual si sus trabajos fueran los de un comentarista. Por lo tanto, no tomaremos las referencias foucaulteanas, explícitas o no, a la fenomenología o a la filosofía de Immanuel Kant, por ejemplo, como si el suyo fuera un trabajo de historia de la filosofía. En contraposición, distinguiremos lo sugerente que dichas referencias resultan para presentar a su propio registro de interrogación frente al análisis respecto de la plausibilidad filológica de las mismas. En cierto modo, podría decirse que revisaremos al discurso foucaulteano de manera análoga a la que el propio Foucault implementara en su abordaje de los trabajos configurados a partir de mediados del siglo XVI que tenían a la crítica de Maquiavelo como punto de partida. Trabajos en torno a los cuales el filósofo francés explicitó que no se preocuparía respecto 
Iván Gabriel Dalmau/ Un perfil de Foucault: Notas a partir de una lectura [...] / 81 de lo ajustado o no de la lectura que hacían de los textos del clásico pensador político florentino, sino del modo en que en dichos discursos se ponía en juego la contraposición entre los "consejos del príncipe" y el ejercicio del gobierno, que era justamente el problema cuya constitución pretendía abordar (Foucault, 2004).

Declinando levemente las precisiones esbozadas en las líneas precedentes, querríamos mencionar que queda por fuera de nuestros objetivos la puesta en discusión de la caracterización de los trabajos foucaulteanos en tanto presuntamente alineados en una "tradición”. En ese sentido, si bien en el próximo apartado nos detendremos en la búsqueda foucaulteana de inscripción de su propio trabajo en una de las posteridades abiertas en torno a la Crítica kantiana, no es a partir del par categorial "autor"-"tradición" que abordaremos la misma.

\title{
Michel Foucault frente a las posteridades de la Crítica
}

\author{
El objetivo de las investigaciones arqueológico-genealógicas \\ de Foucault no es solamente describir problematizaciones histó- \\ ricas, sino además desenmascararlas y desafiarlas por medio del \\ cuestionamiento de la inevitabilidad y necesidad racional de prác- \\ ticas, instituciones, técnicas y funciones que han sido construidas \\ como respuestas suyas. \\ Mascaretti, \\ "Michel Foucault on Problematization, Parrhesia and Critique"
}

Múltiples son los ejes que se podrían tomar en consideración para brindar un perfil de la manera en que Michel Foucault concibió a la práctica filosófica, por lo tanto, este breve parágrafo no parte de un intento de "unilateralización" del problema, sino más bien de un recorte realizado en función de los objetivos previamente explicitados. Someramente, en tanto antesala de la lectura que propondremos a continuación, querríamos detenernos en la primera clase del curso dictado en el Collège de France durante el ciclo lectivo 1982-1983, es decir, la clase del 5 de Enero de 1983 por medio de la que el filósofo francés diera inicio a su curso titulado Le gouvernement de soi et des autres. De más está aclarar que la revisión de los matices y tensiones que podrían encontrarse entre el conjunto de documentos agrupados en torno al nombre de Michel Foucault que se ocupan del problema de la Crítica queda por fuera de los objetivos y las posibilidades del presente trabajo.

En la mentada clase, Foucault se vale de una presentación del modo en que Immanuel Kant respondió a la pregunta Was ist Aufklärung? para inscribir su propia labor en una modulación de la Crítica. En sus propios términos:

Me parece que la elección filosófica a la que nos encontramos confrontados actualmente es ésta. Hay que optar por una filosofía crítica que se presentará como una filosofía analítica de la verdad en general, o por un pensamiento crítico que tomará la forma de una ontología de nosotros mismos, de una ontología de la actualidad. Y es esta forma de filosofía la que, de Hegel a la Escuela de Frankfurt, pasando por Nietzsche, Max 
Weber, etc., ha fundado una forma de reflexión a la cual, desde luego, me vinculo en la medida en que puedo. (Foucault, 2008, p. 22)

Sería pertinente destacar, entonces, que la filosofía foucaulteana no pretende erigirse como una "analítica de la verdad" preocupada por las posibilidades del conocimiento y sus límites infranqueables, sino que más bien se enmarca en el proyecto de dar cuenta de la constitución histórica de focos de experiencia para poder desentrańar ontológico-politicamente la actualidad y problematizar la contingencia y las posibilidades de franqueamiento de lo presuntamente "universal y necesario". Justamente, por foco de experiencia Foucault concibe la articulación entre las formas de saber, las matrices normativas de comportamiento y los modos de existencia virtual para sujetos posibles (Foucault, 2008); imbricación cuyo desmonte constituye el blanco de la problematización respecto de la actualidad, tal como Foucault lo explicitara en sus trabajos. De lo que se trata, entonces, es de una inflexión del gesto crítico, que desanclado de todo viso de universalidad se desliga a su vez de una pretensión fundadora-normativa. En lugar de configurarse como una gnoseología que dé cuenta de las condiciones de posibilidad del conocimiento, normando las formas adecuadas de conocer, y una ética orientada por la búsqueda de imperativos categóricos, que permita normar las formas moralmente buenas de actuar, la crítica foucaulteana opera por medio del cuestionamiento del pretendido carácter necesario de las formas de pensamiento y de los modos de acción de los sujetos en sus relaciones consigo mismos y con los otros.

\title{
Recuperación y reelaboración recurrente Un perfil filosófico que emerge a partir de los documentos
}

\begin{abstract}
Foucault, en un procedimiento que le era propio, no ha cesado hasta el final de su vida de "releer", de resituar y de reinterpretar sus antiguos trabajos a la luz de los últimos, en una suerte de reactualización incesante.
\end{abstract}

Fontana y Bertani, "Situation du Cours" de Foucault Il faut défendre la société

Hemos decidido dar comienzo a este último apartado remitiéndonos brevemente a una serie de señalamientos realizados por Michel Foucault al inicio de sus conferencias dictadas en la Universidad de Vermont en el año 1982 (Foucault, 1994b), en las cuales desarrollará una problematización de las relaciones entre subjetividad, gobierno y verdad en el marco del abordaje de las denominadas técnicas de sí en la cultura y la filosofía greco-romana. Prácticas a las que en el devenir de las clases contrapondrá tanto a las del "examen de sí mismo" desarrolladas en el ámbito del "cristianismo primitivo" como a las formas de producción de la verdad sobre los sujetos propias de las modernas ciencias humanas. Sin más preámbulos, entonces, partiremos de la inclusión del siguiente fragmento con que Foucault busca contextualizar el tópico a abordar en las conferencias dentro el marco de sus investigaciones precedentes:

Mi objetivo, desde hace más de 25 años, ha sido bosquejar una historia de las diferentes maneras por medio de las que los hombres, en nuestra cultura, elaboraron un saber acerca de sí mismos: la economía, la biología, la 
Iván Gabriel Dalmau/ Un perfil de Foucault: Notas a partir de una lectura [...] / 83 psiquiatría, la medicina y la criminología. Lo esencial, no consiste en tomar este saber como criterio, sino analizar esas pretendidas ciencias como "juegos de verdad" que están ligados a las técnicas específicas que los hombres utilizan con el fin de comprender quiénes son. (Foucault, 1994b, p. 784)

Por otro lado, volviendo nuevamente sobre la relación de las investigaciones en curso con sus trabajos previos, planteará que:

He querido hacer una historia de la organización del saber tanto en lo que respecta a la dominación como en lo que concierne al sí mismo. Por ejemplo, no estudié la locura en función de los criterios de las ciencias formales, sino con el fin de mostrar qué tipo de gestión de los individuos, al interior y al exterior de los asilos, había hecho posible este extraño discurso. Llamo "gubernamentalidad" al punto de encuentro entre las técnicas de dominación ejercidas sobre los otros y las técnicas de sí. [...] Puede que haya insistido demasiado sobre las técnicas de dominación y de poder. Me intereso cada vez más en la interacción que se produce entre sí mismo y los otros, y las técnicas de dominación individual, el tipo de acción que un individuo ejerce sobre sí mismo por medio de las técnicas de sí. (Foucault, 1994b, p. 785)

En torno a lo cual, resulta sumamente sugerente el seńalamiento introducido por el reconocido especialista Gary Gutting, quien en el marco de su clásico trabajo sobre la arqueología foucaulteana, enfatizó en los siguientes términos la relevancia de las indagaciones respecto de "la locura" realizadas por Foucault en su Tesis Doctoral:

Con respecto a los trabajos posteriores de Foucault, Historia de la locura posee un fundamental carácter germinal. Sus tópicos críticos y metodológicos fueron llevados adelante por todo lo que Foucault escribió. [...] A través de todos estos desarrollos, [...] Foucault permanece fiel al objetivo fundamental del método arqueológico tal como apareciera por primera vez en Historia de la locura: entender las estructuras que caen por debajo de aquellas elucidadas por las técnicas estándar de la historia del pensamiento. De modo similar, el objetivo crítico preciso de los posteriores trabajos de Foucault cambia de libro a libro [...]. Pero, a través de ellos, el proyecto continúa siendo el de Historia de la locura: usar la historia para cuestionar la auto-comprensión del conocimiento actual de los seres humanos. (Gutting, 1989, pp. 109-110)

Por otra parte, en un clásico artículo publicado ese mismo año, planteó Foucault que:

Las ideas de las que querría hablar aquí no tienen carácter de teoría ni de metodología. [...] Querría decir, primero, cuál ha sido la finalidad de mi trabajo estos últimos veinticinco años. Ésta no ha sido analizar los fenómenos del poder ni sentar las bases para tal análisis. He buscado más bien producir una historia de los diferentes modos de subjetivación del ser humano en nuestra cultura; me he ocupado, desde esta óptica, de tres modos de objetivación que transforman a los seres humanos en sujetos. [...] Por lo tanto, no es el poder, sino el sujeto, lo que constituye el tema general de mis investigaciones. (Foucault, 1994c, pp. 222-223) 
Ahora bien, en tanto que buscamos trazar un perfil del modo de trabajo foucaulteano, la citada referencia de Gutting al método arqueológico nos permite introducir un pequeño desplazamiento dentro del "archivo Foucault", de modo tal de problematizar distintas aristas que configuran a dicho "perfil filosófico". Nos apropiamos aquí de una caracterización que introdujera el pensador francés Maurice Blanchot en su clásico Michel Foucault tel que je l'imagine (Blanchot, 1986), con respecto a la estrategia de que Foucault se vale para definir el enunciado, y que hacemos extensiva a la estrategia implementada por nuestro "autor" para delimitar el análisis arqueológico. En ese sentido, planteamos que tanto la definición del enunciado, como así también de la metodología arqueológica que lo toma por objeto, se constituye en la prosa foucaulteana por medio de una suerte de "teología negativa". De hecho, podría aseverarse que parte de la dificultad que presenta la lectura de dicho libro, así como todo intento de reconstrucción de sus aspectos fundamentales, radica en que resulta difícil despegarse de dicha estrategia argumental puesta en práctica por Foucault. Pareciera casi imposible sustraerse a dicho juego del discurso foucaulteano, ya que se torna muy difícil la posibilidad de reponer qué entender por arqueología o por enunciado sin reproducir la mentada estrategia: "la arqueología no es..., ni esto, ni aquello, ni esto otro", "el enunciado no es tal o cual cosa...".

En cierto modo, podría plantearse que esta forma de argumentación resulta característica de la economía del discurso foucaulteano. Más allá de las nociones mencionadas, y acorde al registro ensayístico del presente artículo, nos permitimos arriesgar la hipótesis de que el recurso a la "teología negativa" es estructurante del conjunto de trabajos articulados en torno al nombre de Michel Foucault, casi como una suerte de contracara de su reticencia frente al planteamiento de teorías de alcance general. Cuestiones que podrían ser remitidas, a su vez, al modo en que Foucault concibió al ejercicio de la Crítica. El recurso a la "teología negativa" podría ser pensado, entonces, como el reverso del mentado gesto foucaulteano de proposición de hipótesis, que luego son retomadas y reelaboradas en el marco del devenir de sus investigaciones. Podría decirse que la "aproximación por oposición" resulta más lábil y, por lo tanto, abierta a reactualizaciones frente al entorpecimiento con respecto a dicho estilo de trabajo que traería aparejado la utilización de precisas y cerradas definiciones "por la positiva".

¿No podría plantearse, acaso, que el modo en que Foucault buscó inscribir su trabajo en una posteridad de la Crítica, su reticencia con respecto a la propuesta de teorías generales y acabadas, su tendencia a la recuperación y reelaboración de sus trabajos previos desde la perspectiva de sus investigaciones en curso, y el recurso a la "teología negativa", constituyen una cadena, una trama en torno a la que podría trazarse su perfil filosófico?

\section{Bibliografía:}

- Blanchot, M. (1986). Michel Foucault tel que je l'imagine. Paris: Fata Morgana.

- Dalmau, I. G. (2016). (BIO)SABER-(BIO)PODER. Reflexiones en torno a la densidad epistemo-ontológico-politica que vertebra a la problematización del saber elaborada por Michel Foucault en el marco de su genealogía de la biopolítica [Tesis de Doctorado]. 
Iván Gabriel Dalmau/ Un perfil de Foucault: Notas a partir de una lectura [...] / 85 Facultad de Ciencias Sociales, Universidad de Buenos Aires: Buenos Aires.

— Fontana, A., Bertani, M. (1997), "Situation du Cours". En Foucault, M., Il faut défendre la société. Cours au Collège de France. 1976-1977. Paris: Gallimard/SEUIL.

— Foucault, M. (1969). L'archéologie du savoir. Paris: Gallimard.

— Foucault, M. (1994a). "Qu'est-ce qu'un auteur ?”. En Dits et écrits I (1954-1969) (pp. 789-821). Paris, Éditions Gallimard.

— Foucault, M. (1994b). "Les techniques de soi". En Dits et écrits IV (1980-1988) (pp. 783-813). Paris: Gallimard.

— Foucault, M. (1994c). "Le sujet et le pouvoir". En Dits et écrits IV (1980-1988) (pp. 222-223). Paris: Gallimard.

- Foucault, M. (2004), Sécurité, Territoire, Population. Cours au Collège de France (1977-1978), Paris: Gallimard/SEUIL.

- Foucault, M. (2008). Le gouvernement de soi et des autres. Cours au Collège de France (1982-1983). Paris: Gallimard.

- Gutting, G. (1989). Michel Foucault's archaeology of scientific reason. Cambridge: Cambridge University Press.

- Mascaretti, G. M. (2014). "Michel Foucault on Problematization, Parrhesia and Critique". Materiali Foucaultiani, 3(5-6).

- Raffin, M. (2015). "La verdad y las formas políticas: la lectura temprana de la tragedia de Edipo en Michel Foucault". Anacronismo e Irrupción. Revista de Teoría y Filosofía Política Clásica y Moderna, 5(8).

- Wallenstein, S.-O. (2013). "Introduction: Foucault, Biopolitics and Governmentality”. En Nilsson, J., Wallenstein, S.-O. (Eds.). Foucault, Biopolitics and Governmentality. Stockholm: Södertörn University The Library. 



\section{Por qué las herramientas jurídicas actuales tornan innecesaria una modificación del plexo normativo en materia de Derecho de Autor}

Cintia Caserotto Miranda

caserottomiranda_cintia@live.com.ar

\section{Introducción}

Este trabajo tiene por objeto dejar asentada cuál es mi postura en torno al plexo normativo actualmente vigente en materia de lo que doctrinariamente se diera a conocer como el Derecho de Autor.

Así las cosas, adelanto que, en sentido contrario a lo mayoritariamente sostenido, soy de la opinión de que la solución para el abordaje de los diversos conflictos (ej. copyright) que se suscitan en torno a esta temática no reside, precisamente, en una pronta y urgente modificación a la Ley No 11.723 y a su respectivo Decreto Reglamentario No 41.233/34. No reside, al menos, a nivel Nacional.

\section{Desarrollo}

Si bien es cierto que su oportuna sanción se corresponde con aquélla idea inicial, según la cual el beneficio de la exclusividad para el autor encontraba fundamento en el incentivo político a la producción de obras literarias y/o científicas, no debe por ello menospreciarse el contenido de sus soluciones normativas dispuestas oportunamente.

Es cierto que todo texto normativo cuya aplicabilidad pretenda ser eficiente y eficaz requiere ajustarse a las necesidades actuales que la sociedad -como ámbito de aplicación personal de la Ley- requiera. Sin embargo, esto no debe entenderse -al menos esta es mi opinión-como óbice para la resolución de casos que se presenten en esta materia. Ello es así porque, desde el punto de vista jurídico, el Juez cuenta -más aún con la reciente sanción del Código Civil y Comercial de la Nación- con diversas herramientas jurídicas que no podrá dejar de observar y menos aún tildar de anacrónica a la Ley Especial.

Sobre esto último, el Código Civil y Comercial de la Nación trajo, en buena hora, una oportuna solución en materia interpretativa, a la luz de la supuesta hipótesis de con- 


\section{8/ Perspectivas Metodológicas /19/Vol. II /Año 2017}

flicto entre las disposiciones contenidas en una Ley Especial (plexo normativo nacional correspondiente al Derecho de Autor) y las disposiciones contenidas en una Ley General (Código Civil y Comercial de la Nación).

Sobre este punto, el Artículo que resulta de interés es el 963, donde se estable: "ARTÍCULO 963: Prelación normativa. Cuando concurran disposiciones de éste código y de alguna ley especial, las normas se aplican con el siguiente orden de prelación:

a) Normas indisponibles de la ley especial y de este código;

b) Normas particulares del contrato;

c) Normas supletorias de la ley especial;

d) Normas supletorias de éste Código".

Como puede observarse, el Código Civil y Comercial de la Nación reafirma la aplicación en primera instancia de las normas indisponibles de la Ley Especial por sobre las normas indisponibles del Código Civil y Comercial de la Nación. Siendo así, no resulta difícil advertir que, pese a que la Ley Especial ha sido publicada en el Boletín Oficial con fecha 30 de septiembre del año 1933, se le da prioridad a la Ley Especial en su parte pertinente. Esto es: en sus normas con carácter indisponible.

Destacado sector de la Doctrina tiene dicho que "La norma de orden público se vincula con el fundamento de interés social y general de la imperatividad mientras que la mera imperatividad atiende al carácter no disponible de la norma” (Lorenzetti, 2015, p. 559). Asimismo, este autor afirma lo siguiente:

Quizá el concepto que se opone a supletoria no sea indisponible, sino imperativa. Si bien el texto del artículo 963 emplea la palabra indisponible, lo hace como sinónimo de imperativa. Es imperativa la norma que de ser aplicable al caso dado, no puede ser dejada de lado por las partes. También se ha dicho que es imperativa la norma cuando por mandato legal asume carácter de regla preferente en la escala de valores sobre el precepto privado. (Lorenzetti, 2015, p. 556)

Por otra parte, vinculado con este Artículo -más precisamente con su inciso b) - se encuentra el Artículo 1512 del Código Civil y Comercial de la Nación mediante el cual, por primera vez, se ha consagrado en una norma de alcance general, una definición con relación al contrato de franquicia. ${ }^{1}$ Contrato, por cierto, dentro de cuyo objeto se encuentra, entre otros tantos, el derecho de autor.

Sentado lo que antecede, conviene ahora poner énfasis en lo que respecta a las diversas herramientas jurídicas de las que dispone el Juez. En tal sentido, puede señalarse que el Artículo $1^{\circ}$ del Código Civil y Comercial de la Nación, el cual recepta la consagración normativa que obtuvieron los Tratados Internacionales con la reforma Constitucional de 1994 -a diferencia del entonces Código Civil-

1 "Artículo 1512: Concepto. Hay franquicia comercial cuando una parte, denominada franquiciante, otorga a otra, llamada franquiciado, el derecho a utilizar un sistema probado, destinado a comercializar determinados bienes o servicios bajo el nombre comercial, emblema o la marca del franquiciante, quien provee un conjunto de conocimientos técnicos y la prestación continua de asistencia técnica o comercial, contra una prestación directa o indirecta del franquiciado". 
Cintia Caserotto Miranda / Por qué las herramientas jurídicas actuales [...] / 89 propugna que la solución de los casos que se presenten a nivel nacional guarden estricta concordancia con lo normado a nivel internacional.

La necesidad de adecuar la solución brindada por los instrumentos jurídicos internos a la que ofrecen los instrumentos jurídicos internacionales ha sido marcada desde antaño por la Jurisprudencia a través de diversos fallos. Recordemos tan sólo algunos de ellos: Corte Interamericana de Derechos Humanos a) Caso Mendoza y otros vs. Argentina. Sentencia del 14 de mayo de 2013 (Excepciones preliminares, fondo y reparaciones); b) Caso Bueres Alves vs. Argentina. Sentencia del 11 de mayo de 2017 (Fondo, reparaciones y costas), y c) Caso Barrios Altos vs. Perú. Sentencia del 14 de marzo de 2001 (fondo).

De hecho, lo antedicho encuentra sustento incluso en el ámbito de la Organización de las Naciones Unidas; más específicamente, en lo atinente al campo de los derechos humanos. Al punto tal que cualquier particular se encuentra facultado para presentar una denuncia ante el Comité de un Tratado que verse sobre Derechos Humanos, en tanto y en cuanto se sienta vulnerado en los derechos que dicho Tratado protege. Sin embargo, el particular deberá observar - previo a su presentación- el cumplimiento de los siguientes requisitos:

1) Que el Estado al que pertenece haya vulnerado los Derechos consagrados en un Tratado que ese mismo Estado ya había ratificado, y

2) Que el Estado al que pertenece hubiese reconocido, más no sea de forma expresa, la competencia de ese comité para analizar las denuncias presentadas por cualquier particular en torno a un Tratado en particular.

Ahora bien, si bien es cierto que el plexo normativo que, a nivel internacional, aborda la temática del Derecho de Autor no se circunscribe - dada la especificidad de la materiaa Instrumentos que guardan estricta relación con los Derechos Humanos, no por ello éstos pierden su carácter vinculante. Recuérdese que en tal sentido siempre es posible acudir al argumento del control de convencionalidad; esto es, que la Constitución no se encuentre en discordancia con las disposiciones del plexo normativo existente a nivel internacional en una determinada materia.

Con respecto a los Instrumentos específicos que resultan aplicables a la materia, puede consultarse el link correspondiente a la Dirección Nacional del Derecho de Autor, ${ }^{2}$ dependiente del Ministerio de Justicia y Derechos Humanos.

Queda claro entonces que estos instrumentos jurídicos se ciñen a la protección del autor, más no al de la sociedad en general; todo lo cual camina por un carril diferente. Así pues, se tornan primordialmente efectivos los Tratados existentes en materia de Derechos Humanos; más específicamente, la Declaración Universal de Derechos Humanos, la Convención Americana sobre Derechos Humanos, el Pacto Internacional de Derechos económicos, sociales y culturales y la Declaración Americana sobre los Derechos y Deberes del Hombre. 
Por otro parte, en lo atinente a la protección de los intereses de la sociedad, también pueden señalarse: 1) la Ley del Fomento del Libro y la Lectura (Ley No 25.446); 2) la Ley de Protección de datos personales (Ley Nro. 25.326); y 3) la Ley de acceso a la Información pública (Ley No 27.275). Esta última se encuentra vinculada con el derecho que tiene toda persona, sin ningún tipo de discriminación mediante, al acceso a la información pública que se encuentre en manos de los sujetos que se hallan comprendidos en el artículo No 7 de dicha Ley.

En cambio, en relación a los intereses de las Editoriales, puede citarse -más no sea a modo ejemplificativo- la Ley de Defensa de la Actividad Librera (Ley No 25.542).

Con lo cual, como puede observarse, estamos frente a una tensión existente entre los diversos actores en juego: autores, editorial y sociedad. Circunstancia fáctica que será resuelta por el Juez en el caso concreto, atendiendo a sus particulares características (circunstancia de tiempo, modo y lugar) con la debida observancia de la Ley Especial, La Ley General y el plexo normativo internacional actualmente aplicable en la materia.

\section{Conclusión}

Finalmente, en sentido concordante con la postura que adelanté en la introducción de este escrito, soy de opinión que resulta innecesaria una modificación actual en la materia Derecho de Autor, más aún disponiendo el Juez de amplios Instrumentos jurídicos que podría emplear para la resolución del caso concreto.

\section{Bibliografía}

- Arduino, A. H. L. y Azeves, A. H. (2007). "La obra jurídicamente protegida por el derecho de autor". El Derecho Online [No 225-860].

— Butler, A. T. (2012). "Una impostergable reforma a las leyes 11.723 sobre derecho de autor y 24.446 sobre fomento del libro y la lectura". El Derecho Online [No 248980].

— Lorenzetti, R. L. (2015). Código Civil y Comercial de la Nación Comentado, Tomo V. Buenos Aires: La Ley. 


\title{
Aproximaciones analíticas al campo estadístico de la violencia. Avances de investigación
}

\author{
María Belén Muñiz y Cristian Tibaldi \\ belumuniz@hotmail.com
}

\section{Presentación}

Desde múltiples lugares nos llegan a diario las voces que denuncian, lamentan y señalan un aumento de la violencia "callejera" que atraviesa a las y los jóvenes, colocándolos mucho más en el lugar de ejecutores que de víctimas de dicha violencia. Pero más allá de la atribución de responsabilidad, que sobre estos jóvenes se puede dar desde los diferentes sectores de la sociedad donde se origina la demanda, observamos una necesidad permanente de cuantificar, o por lo menos de poner en término de magnitudes relativas la intensidad de dicha violencia. Esta parte singular de la demanda por intervenir sobre la violencia, ya sea desde discursos de endurecimiento penal que piden mayor presencia policial y mayor castigo (Garland, 1990), o desde aquellos que se estructuran en torno al pleno ejercicio de los derechos humanos y la inclusión social, nos ha conducido a preguntar si es posible medir la violencia. ¿Qué información debe ser tomada como relevante a la hora de afirmar el aumento o disminución de la violencia?, ¿existe un desarrollo objetivo y autónomo de los hechos violentos que se pueda expresar en magnitudes relativas o, por el contrario, es efecto de un discurso producto de una "sensación" que varía en función del sector social que lo enuncie?

Inmediatamente nos detenemos en este punto: ¡es sólo un agrupamiento de hechos más o menos conexos o se inscriben en una secuencia, un proceso social de larga duración?, ¿cómo se nos presenta la información sobre los hechos de violencia que nos permita arrojar luz sobre estas cuestiones?

En este ensayo presentaremos algunos avances de la investigación que los autores llevamos adelante en torno a la temática de la violencia, en el marco de un proyecto dedicado a indagar las diferentes formas en que las y los jóvenes son atravesados por prácticas y situaciones donde la violencia se ejerce en sus mismos cuerpos. Esto último sobre la definición conceptual que concibe al cuerpo como un particular "territorio en que se expresan confrontaciones entre conjuntos de relaciones sociales" (Forte y Pérez, 2010, p. 12), punto nodal donde las tensiones que estructuran al capitalismo como formación socio-histórica toman su materialidad. Asimismo, para abordar la temática de la violencia tomamos como definición conceptual la otorgada por la Organización Mundial de la Salud (OMS), que la caracteriza como "El uso intencional de la fuerza o el poder físico, 


\section{2/ Perspectivas Metodológicas /19/Vol. II /Año 2017}

de hecho o como amenaza, contra uno mismo, otra persona o un grupo o comunidad, que cause o tenga muchas probabilidades de causar lesiones, muerte, daños psicológicos, trastornos del desarrollo o privaciones" (OMS, 2002, p. 3).

La concepción del cuerpo como territorialidad implica necesariamente entenderlo como producto de procesos históricos sociales de largo alcance y a la vez campo de confrontación de fuerzas sociales (Núnéz, 2012; Marín, 1996; Forte y Pérez, 2010). Desde el advenimiento de la Modernidad, el cuerpo fue consolidándose como objeto de gestión, y de las tecnologías de poder desplegadas a tal efecto (Foucault, 1987), bajo la forma en apariencia neutrales de las políticas públicas. El control sobre poblaciones socialmente peligrosas, moral y materialmente riesgosas, va instalando en los diferentes niveles del poder prácticas que buscarán disciplinar, ordenar, contener y eventualmente suprimir dichas fuentes de riesgo (Daroqui, López y García, 2012). La juventud se ha ido transformando cada vez con mayor frecuencia en una fuente de riesgo social -mucho más aún si está unida a la pobreza- y atravesada por dos discursos que reactualizan, paradójicamente, el estigma: uno de corte asistencialista en el cual se reconoce la vulnerabilidad de las y los jóvenes, que dispara una serie de dispositivos de promoción y protección de derechos que buscan "salvar" a dichos sujetos de la delincuencia, las drogas y el desempleo. Por otro lado, un discurso que estigmatiza y responsabiliza a las y los jóvenes por el aparente aumento de hechos delictivos, sensación de inseguridad y expansión del narcotráfico, creando articuladamente con el primero todo un cuerpo legal-jurídico de carácter punitivo que busca neutralizar esa fuente de riesgo social.

Este ensayo presenta la primera etapa del proyecto que refiere a la elaboración y análisis de una base de datos sobre las fuentes más visibles de información, registrando el contenido de todos los sitios web donde las diferentes agencias estatales y no estatales publican datos de acceso público sobre hechos de violencia referidos al aglomerado Mar del Plata/Batán. El recorte correspondiente a la franja etaria que elegimos se fue adaptando a la cantidad y calidad de la información disponible. Esta elección metodológica, en apariencia menor, fue consecuencia directa de las características propias de la información que fuimos encontrando, por el hecho de que la mayoría de los datos analizados están relacionados en mayor o menor medida con la conflictividad con la ley penal. En efecto, de 24 fuentes consultadas 20 corresponden a fuentes judiciales, policiales o relacionadas con el Sistema de Responsabilidad Penal Juvenil (SRPJ), lo que nos llevó a fijar al grupo etario objetivo entre los 15 y los 21 años de edad, correspondiente en su límite inferior con un año antes de la edad de punibilidad, que según la Ley 26061 es a partir de los 16 años, y en su límite superior con la categoría "jóvenes adultos", entre 18 y 21 años, que establece la Ley 12256 de Ejecución Penal. Esto no significa que exista una correspondencia entre este grupo etario y los grupos etarios de las fuentes. Muy por el contrario, existe una gran variabilidad a la hora de fijar la categoría "joven" y en muchas fuentes se toman hasta los 24 o incluso 26 años, lo que vuelve a veces incomparable dicha información.

\section{Análisis descriptivo de las fuentes disponibles de acceso público}

Acerca de la información publicada por la Procuración General de la Suprema Corte de Justicia de la Provincia de Buenos Aires, debemos advertir que refiere siempre a las 
María Belén Muñiz y Cristian Tibaldi / Aproximaciones analíticas al campo[...] 93 Investigaciones Penales Preparatorias (IPP), lo cual significa que son números que no hablan de personas sino de causas, en las cuales puede haber más de un imputado o, inversamente, un sujeto imputado en más de una causa.

En el caso del informe Caracterización de homicidios dolosos y robos con armas, estudio descriptivo de IPP, la información publicada sólo desagrega del total de la provincia tres grandes grupos de Departamentos Judiciales: Conurbano, Grandes (entre los que se encuentra el Depto. Judicial Mar del Plata) e Interior, con lo cual no es posible construir datos específicos para el territorio estudiado. Se puede señalar como dato relevante que para el año 2013, con una población 723.685 habitantes, para 89 IPP's iniciadas que involucraron a 91 fallecidos, la tasa (víctimas de homicidios dolosos consumados-HDC cada 100 mil habitamtes) fue de 12,57, superada sólo por Quilmes: 12,75. La inmediata inferior fue La Matanza, con 11,49.

De los informes publicados sobre el Fuero de Responsabilidad Penal Juvenil (FRPJ), el que más se acerca a nuestras necesidades es el referido a IPP FRPJ iniciadas por Bien J. y por Depto. Judicial, correspondiente al período 2012-2014. El resto de los informes, a saber: IPP FRPJ iniciadas por Depto. Judicial (2009-2014), IPP FRPJ iniciadas por Bien Jurídico Protegido total PBA (2009-2014) e IPP FRPJ iniciadas por Partido (2012) no contienen información suficientemente desagregada.

En relación al Ministerio de Seguridad de la Provincia de Buenos Aires, sólo nos provee de estadísticas criminales en informes presentados desde el 2010 hasta el 2012. Esta información provista por el Ministerio utiliza como fuente de análisis cuantitativo los datos contenidos en la base SIMP de la Procuración General de la Suprema Corte de Justicia de la Provincia, confrontándolos con los datos emanados de las bases de información del Ministerio de Justicia y Seguridad (desde el año 2013 separados en Ministerio de Seguridad y Ministerio de Justicia). Los datos son prácticamente los mismos que los publicados por la Procuración General, pero se completan los análisis con elaboración propia sobre registros del propio Ministerio. Pese a que esta información es de nuestra incumbencia, la misma no se encuentra lo suficientemente detallada y desagregada; vale decir, no es información completa ni exhaustiva al no encontrarse analizada con respecto a la edad ni al territorio. La única información que provee sobre el territorio consiste en separar el conurbano bonaerense del resto de la Provincia de Buenos Aires en relación tanto a la participación en las estadísticas criminales como en el núcleo de delitos vinculados a la seguridad ciudadana. Por otra parte, el Ministerio de Seguridad publica el informe Situación de las personas privadas de libertad en la Provincia de Buenos Aires. Esta consiste en un informe que abarca el periodo de Diciembre 2007 a Octubre 2011. Al igual que las estadísticas criminales, esta información toma como fuente a la Corte Suprema de Justicia de la provincia, por lo que toda la información es analizada sobre el total de la provincia salvo algunos pocos datos. Entre ellos, sólo encontramos información desagregada para la Unidad 15 de Mar del Plata-Batán, en lo que refiere a la cantidad de plazas habilitadas en el marco del programa "Casas por Cárceles" y la ocupación de las mismas al 15 de septiembre de 2011.

En lo que respecta al Centro Municipal de Análisis Estratégico del Delito, nos encontramos con que es el único organismo estatal que nos provee de información espe- 


\section{4/ Perspectivas Metodológicas /19/Vol. II /Año 2017}

cífica sobre la ciudad de Mar del Plata. Esta agencia estatal posee informes estratégicos de la ciudad en relación a robos y hurtos de automotores (2014-2015); violencia de género: análisis de denuncias penales (2014); informes sobre homicidios dolosos (20132014) y por último informes sobre tenencia de estupefacientes para consumo personal (2014). A su vez, nos provee de informes semanales y mensuales específicos de análisis criminal sobre el funcionamiento del Comando de Prevención Comunitaria (CPC) y de georreferencia del comportamiento delictual durante el año 2014 y 2015. Publican además una síntesis del análisis estratégico de las primeras 18 semanas (6 de junio al 9 de octubre de 2014) de funcionamiento del Comando de Prevención Comunitaria del partido de Gral. Pueyrredón. En relación a nuestro objeto de estudio, la única información de utilidad directa es la relacionada tanto con este último informe como con la tenencia de consumo de estupefacientes y la de homicidios dolosos, por ser los únicos datos que se encuentran relacionados con la edad. El Informe sobre las 18 semanas de funcionamiento del CPC nos brinda información sobre la cantidad de aprehendidos por esta fuerza menores de 18 ańos y el motivo de la aprehensión, comparando las semanas desde el 6 de junio al 9 de octubre del 2014. Con respecto al motivo de la aprehensión por robo con o sin arma de fuego y por hurto, observamos que en todos los casos el grupo de varones de más de 18 años fue el más numeroso. Salvo en la semana 3, en la que hubo una cantidad inédita, esto es, 32 aprehendidos, de los cuales 14 (43,7 \%) fueron varones menores de 18 ańos aprehendidos por robos con y sin arma de fuego. Pese a ello, en el resto del período la proporción de esta franja etaria ha sido más pequeña. En el caso del hurto es considerablemente mayor la cantidad de aprehendidos menores de 18 ańos varones, en varias semanas más que en el caso del robo. Es más notorio (aunque menor con respecto a la cantidad general) el involucramiento de mujeres -en mayor proporción la cantidad de mujeres mayores de 18 ańos-. Asimismo, en el caso de los aprehendidos por el CPC por averiguación de identidad o ilícito observamos, por la misma cantidad de semanas, que también sucede que los varones mayores de 18 años mantienen los niveles más altos. En cuanto a los menores de edad, se mantiene en importante menor proporción que los aprehendidos mayores, al tiempo que durante cuatro semanas no hubo aprehendidos menores. Por último, en cuanto a los aprehendidos por encubrimiento, si bien la mayoría son aprehendidos mayores de edad -como sucede en todos los motivos de aprehensión- llama la atención el número alto de aprehendidos menores de 18 años, muy superior a la media de todos los demás casos.

Por otro lado, tanto el informe sobre los procedimientos realizados por la Policía Bonaerense de Seguridad vinculados con los casos de infracción a la Ley 23.737 -tenencia por estupefacientes- durante el año 2014, como el Informe sobre homicidios dolosos (2013-2014), utilizan como fuentes de datos la base proporcionada por el CEPAID (Centro de Procesamiento de Análisis Informático Delictual del Ministerio de Seguridad de la Provincia de Buenos Aires). Entre el 1 de enero y el 31 de diciembre de 2014, el CEPAID reportó 1.035 casos que tenían relación directa con infracciones a la Ley 23.737. De esos casos, 756 fueron por tenencia para consumo personal; de estos últimos 666 tuvieron por objeto la sustancia estupefaciente marihuana; a su vez, en esos 666 casos fueron aprehendidas 1.075 personas por tenencia de marihuana, de los $111(10,33$ $\%)$ fueron varones menores de 18 años y $2(0,19 \%)$ fueron mujeres menores. Por último, el Informe de homicidios dolosos (2013-2014), además de tomar como punto de partida para su análisis los datos emanados del CEPAID, utilizaron como complemento 
María Belén Muñiz y Cristian Tibaldi / Aproximaciones analíticas al campo[...] 95 datos provenientes del Sistema Informático del Ministerio Público Fiscal (SIMP), datos de procedimientos del Comando de Prevención Comunitaria General Pueyrredón, con el relevamiento de su cobertura por los medios de comunicación y cifras parciales provenientes del sistema de salud. Entre el 1 de enero del 2013 y 31 de diciembre del año 2014, se registran 74 homicidios dolosos, con 76 personas fallecidas en el área del Municipio de General Pueyrredón, de los cuales más de un 90\% fueron hombres. En el año 2013 un $27 \%$ de las víctimas tenían entre 16 y 25 años de edad. Asimismo, el 50\% de las víctimas de homicidios dolosos ocurridos en 2013 tenían entre 16 y 35 años. En el año 2014, un 22\% de las víctimas tenían entre 16 y 25 años y un $47 \%$ perteneció a la franja etaria de 16-35 años.

La Secretaría de Niñez y Adolescencia de la Provincia de Buenos Aires (SNyA) publica información relevante por medio del Registro Estadístico Unificado de Niñez y Adolescencia (R.E.U.N.A.). Este sistema permite hacer consultas online sobre número de NNyA abordados anualmente por territorio (que indica el Servicio Zonal de Promoción y Protección de Derechos -SZPPD- en nuestro caso Mar del Plata); por motivo de la intervención; por organismo (el efector que solicitó intervención al SZPPD, es decir, por pedido de quién); por género y finalmente por edad. El sistema permite realizar cruces entre dichos ítems y solicitar información complementaria vía correo electrónico. Al día de publicación de este trabajo, la repartición no contestó los pedidos hechos por el equipo de investigación.

La información publicada permite un acercamiento a la cantidad de menores que pasan por el Sistema de Promoción y Protección de Derechos (SPPD), con la salvedad de que se registran las entradas al mismo pero no la evolución de cada caso; de modo que un niño o niña puede ser abordado una sola vez por algún operador, volver a la situación que originó la consulta, quedar asentada esa entrada en el sistema pero no tener un efecto real sobre el sujeto vulnerado. Esta situación es similar al caso de los datos de Procuración: se puede formar una IPP por un delito, pero no se puede saber cómo evoluciona esa causa, si fue archivada, si llegó a juicio, si hubo sobreseimiento o, por el contrario, se ejecutó una sentencia, cuántas medidas alternativas al encierro se solicitaron y cuántas se aplicaron, entre otras variables que permitirían conocer mejor.

La Municipalidad de General Pueyrredón dispone de una página web desde donde se puede ingresar al ítem Estadísticas. Allí sólo se reproducen datos copiados del INDEC y de la Dirección Provincial de Estadísticas del Ministerio de Economía de la Provincia de Buenos Aires, que en el ítem Seguridad replica datos del Ministerio de Justicia y Seguridad de la PBA, ya analizados arriba.

El Observatorio Social Legislativo, dependiente de la Honorable Cámara de Diputados de la PBA, publica desde el año 2010 el informe anual sobre adolescencia $\mathrm{La}$ adolescencia $M I D D E$. En dicha publicación existe un capítulo para la Dimensión Violencia contra NNA y otro para la Dimensión Justicia Penal. La información no está desagregada por partido, sino que agrupa el total de la PBA y son datos elaborados sobre cifras del Ministerio de Salud y Sistema SIMP del Ministerio Público Fiscal. A partir del 2014, publica el informe La niñez MIDDE, con las mismas fuentes de información y, por ende, los mismos niveles de desagregación insuficiente de categorías. 
El resto de las fuentes consultadas, como la Estadística de muertes en el Servicio Penitenciario, publicada por el Ministerio de Seguridad de la PBA, cifras del Ministerio de Salud de la Provincia de Buenos Aires, información de La Procuración Penitenciaria de la Nación junto con el Comité Contra la Tortura y el Grupo de Estudios sobre Sistema Penal y Derechos Humanos (Registro Nacional de casos de tortura y/o malos tratos del año 2012), son fuentes que eventualmente hacen referencia a alguna de las variables en estudio (territorio y edad), pero poco detallada y sin suficiente grado de desagregación.

\section{Consideraciones finales}

La mayoría de la información analizada no se encuentra actualizada, siendo prácticamente nula la información sobre 2015, al tiempo que prima una gran variabilidad en los límites temporales. A su vez, la mayoría de las fuentes se originan en agencias de control social penal, como el Poder Judicial y el Ministerio Público Fiscal, lo cual muestra el protagonismo que la dimensión legal-punitiva tiene por sobre otros aspectos de la violencia. Este factor puede tener como resultante la primacía de cifras enmarcadas en la relación conflictiva que los jóvenes tienen con la ley, relegándose el registro de cifras sobre procesos de violencia. Gran parte de los datos encontrados reflejan lo antedicho. Este profundo problema social -en lo que al registro de los hechos que lo conforman como proceso se refiere- se ha convertido paulatinamente en una mera tarea técnica encargada a personal con poca formación en el área metodológica, a la vez que el diseño estadístico se da profundamente ligado a las necesidades políticas del momento. Una de las mayores consecuencias de ello es la invisibilidad de los sujetos implicados en un hecho de violencia. La mayor parte de la información encontrada refiere a hechos, a datos presentados y analizados como una fotografía instantánea, dejando invisibilizado el conjunto de acciones que los cuerpos viabilizan, vale decir, las relaciones sociales que hay por detrás del hecho. Esto mismo lo cristaliza el análisis de las fuentes realizado con antelación. Sólo dos de las 24 fuentes analizadas -CeMAED y R.E.U.N.A.- nos provee información sobre las tres variables objeto de estudio: violencia, edad y territorio. Esto es, cierta información específica de un contexto social con particularidades propias, relacionando el hecho violento registrado con características del sujeto víctima y/o victimario. El resto de las fuentes construye las cifras de violencia como hechos puntuales y aislados de todo proceso social, los cuales permiten caracterizar los efectos de la violencia pero sin ahondar en las causas que la generan a nivel social e institucional.

La carencia de información confiable y comparable en el tiempo vuelve la publicación de estadísticas más un ejercicio de propaganda institucional que un registro útil para conocer la evolución -es decir, la manera en que se dan los cambios- de los procesos que instituyen relaciones sociales violentas. Entendemos sin embargo la importancia de comenzar por un diagnóstico de la realidad basado en datos estadísticos que confronten el ámbito de las sensaciones y especulaciones con hechos empíricos. Pero, al mismo tiempo, nos parece imprescindible comenzar a profundizar esta forma de construir y analizar la estadística, focalizando la mirada en el seguimiento del devenir punitivo, en este caso en la trayectoria de la violencia. Lo que proponemos entonces es comenzar a construir sistemas integrales de información, mapeos y rutas que abarquen todas las instancias por las cuales transita un joven protagonista de un hecho de violencia. 
María Belén Muñiz y Cristian Tibaldi / Aproximaciones analíticas al campo[...] 97

\section{Bibliografía}

- Daroqui, A., López, A. L. y García, R. (2012). Sujeto de castigos: hacia una sociología de la penalidad juvenil. Buenos Aires: Homo Sapiens

- Forte, G. y Pérez, V. (2010). El cuerpo, territorio del poder. Buenos Aires: Colectivo Ediciones/P.I.Ca.So.

- Foucault, M. (1987). Historia de la sexualidad III. La inquietud de sí. México, D. F.: Siglo XXI.

- Garland, D. (1990). Castigo y sociedad moderna. Un estudio de teoría social. México, D. F.: Siglo XXI.

- Marín, J. C. (1996). Conversaciones sobre el poder (Una experiencia colectiva). Buenos Aires: Archivo Chile.

— Núnez, A. (2012). Lo que el agua (no) se llevó. Política urbana: poder, violencia e identidades sociales. Buenos Aires: El Colectivo.

— Organización Mundial de la Salud (2002). Informe Mundial sobre la Violencia y la Salud. Ginebra. Recuperado de http://apps.who.int/iris/bitstream/10665/67411/1/ a77102_spa.pdf 



\section{Dossier}





\section{CUADERNOS DE TRABAJO}

CENTRO DE INVESTIGACIONES EN TEORÍAS Y PRÁCTICAS CIENTÍFICAS

ESPECIALIZACIÓN EN

METODOLOGÍA DE LA INVESTIGACIÓN CIENTÍFICA

SEGUNDA ÉPOCA N 03

Transformaciones en investigaciones y escrituras académicas

ISSN 1667-4995 / Agosto 2014

Publicación del Centro de Investigaciones en Teorías y Prácticas Científicas y de la Especialización en Metodología de la Investigación Científica del Departamento de Humanidades y Artes

Universidad Nacional de Lanús 
102/ Perspectivas Metodológicas /19/Vol. II /Año 2017 


\section{Presentación}

En este número 3 de Cuadernos de trabajo, encontramos tres escritos dedicados a temas de investigación y escritura académica. La preocupación por estos temas se vincula a la necesidad de evaluar los conocimientos adquiridos en los posgrados en escritos académicos ya que aparecen nuevos desafíos ante novedosas ofertas donde confluyen saberes interdisciplinarios y donde no hay una tradición a la que recurrir para legitimar estos saberes. La preocupación por estas transformaciones anima la investigación, sobre todo para repensar nuestras prácticas de investigación y escritura.

En el primer artículo Bendita tesis: tribulaciones personales e institucionales Cristina Ambrosini y Andrés Mombrú Ruggiero reflexionan sobre las características de los posgrados en la región, es decir, en Latinoamérica, en los últimos 20 años donde se registran tasas de egreso de posgrado muy inferiores a las de los países centrales. En nuestro país se refleja una situación acorde a la región. La reflexión acerca de las bajas tasas de egreso de posgrado se asocia a obstáculos psicológicos, sociales e institucionales donde "la falta de tiempo" y el "pluriempleo" de los alumnos parece ser la causa más mentada.

En este trabajo, luego de una mostración de la situación problemática, los autores, ambos profesores del Seminario de redacción de tesis de la Maestría en Metodología de la investigación científica de la UNLa y tutores para el acompañamiento en la escritura de tesis, defienden la idea de que no es la falta de tiempo la principal causa de abandono de tesis sino otras, sobre las que las instituciones pueden avanzar y planificar cursos de acción y entre las que se citan: falta de acompañamiento de las instituciones por ausencia de talleres o encuentros de tesistas, mal desempeño de los directores de tesis, falta de articulación entre las capacidades adquiridas en carreras de grado y requeridas para la escritura académica, falta de previsión de los posgrados para capacitar a sus alumnos en la escritura académica desde el inicio de los cursos junto a otros factores para contrarrestar la sensación de aislamiento y soledad que desmotiva para la escritura y en ocasiones frustra los intentos mejor intencionados de concluir la "bendita" tesis.

El artículo de Horacio Potel, La tesis imposible, enfoca la concepción de Jacques Derrida acerca de la escritura a partir de su posición "deconstruccionista", es decir, a partir de la crítica al logocentrismo y la aceptación de que ella convoca lo por-venir, lo imprevisible, lo que nunca termina de llegar ni de concluir en un estado definitivo y cerrado. Pareciera entonces que la tesis, en cuanto exigencia de una posición definitiva, apropiable, es una tarea imposible. Siguiendo las huellas de Husserll, se sostiene aquí que no hay un origen puro ni objetos no constituidos, no mediados ni deferidos por lo Otro. La imposibilidad de remitir la producción a un Sujeto autónomo, dueño de sus representaciones, a un autor original y a la unidad de un texto, problematiza todo logro, toda conquista al presentarse una tensión ineliminable entre la necesidad de "cerrar un sentido" y el carác- 
ter diseminante de todo sentido. En el artículo de Potel encontramos la idea derridiana donde nos advierte que en todo proceso de producción académica hay algo que se nos escapa, que no logra ser apresado completamente en una apropiación que resulta "imposible" pero que, artificiosamente, violentamente (en sentido simbólico) es necesario cerrar, como texto, a los fines de poder cumplir con los requerimientos académicos.

El artículo de Cecilia Pourrieux ¿Cómo investigar un problema que involucra a distintas disciplinas? (propuestas para la investigación en bioética) señala el carácter interdisciplinar de nuevas disciplinas, las que aparecen para contestar un problema pero al hacerlo se generan muchos otros problemas. Esta situación se ejemplifica a partir del caso de la bioética En sus debates intervienen perspectivas legales, científicas, sociales, éticas, políticas, entre otras. A partir de la historia de la bioética se puede afirmar que las actitudes reduccionistas o principistas encubren intereses espúreos que finalmente propician la vulneración de los derechos elementales de las personas. En estos temas, la confusión entre neutralidad valorativa y objetividad científica redunda en un "desvío distraccionista" destinado a evitar que el investigador incorpore aspectos económicos y políticos intervinientes, lo que distorsiona los debates. En estos casos, afirma la autora, la búsqueda de conocimiento por el conocimiento mismo aparece como un obstáculo más que como una meta lo que posiciona al investigador en una dimensión ético-política insoslayable.

Este tercer Cuaderno de trabajo compila, en estos tres artículos, temas de creciente interés para los posgrados: los presupuestos del proceso de investigación, sobre todo en caso de entrecruzamiento disciplinar donde el fantasma del reduccionismo está presente junto a la omisión del aspecto ético-político y el siempre complejo proceso de escritura de tesis que, en el caso de los posgrados, presenta una muy alta tasa de deserción y abandono no siempre adjudicable a la falta de dedicación de los autores Los dos artículos dedicados al tema se esfuerzan por mostrar que hay una amplia brecha donde las instituciones pueden planificar cursos de acción orientados a atender a aquellos obstáculos que son sistémicos, que exceden las posibilidades del tesista enfrentar y convocan a la búsqueda de estrategias innovadoras.

\section{Dra. Esther Díaz Dra. Cristina Ambrosini}




\title{
Bendita tesis: tribulaciones personales e institucionales
}

\author{
Cristina Ambrosini ${ }^{1}$ \\ Andrés Mombrú Ruggiero² \\ El contexto de los estudios de posgrado
}

Hacia la mitad del siglo XX, no era poco frecuente que alguien se presentara socialmente con una tarjeta en la que se podía leer: "Fulano de Tal, Bachiller Nacional"., o "Mengano de Cual, Perito Mercantil". La obtención de un título secundario era motivo de prestigio y reconocimiento, daba cuenta de que se trataba de una persona con "estudio", merecedora de mejores oportunidades en la vida. Algunos alcanzaban títulos universitarios: ingenieros, arquitectos, médicos, abogados. Como ocurre todavía hoy, estos últimos ostentando un título de doctor sin serlo. La denominación obtenida en forma consuetudinaria se remonta al principio Ilustrado para el cual alguien que conoce en profundidad un tema se manifiesta en carácter de docto; en estos casos, doctos en la ley y doctos en temas de salud. De cualquier manera hasta bien entrado el siglo XX los sectores que tenían acceso a la educación en general y a la educación superior eran muy restringidos. Por otra parte, aquellos saberes a los que se accedía eran preciados porque permitían el acceso a cierto estatus, pero además eran duraderos.

Aquellos conocimientos y destrezas que se adquirían duraban para toda la vida, e

1Cristina Ambrosini es Doctora en Filosofía por la UBA. Profesora regular del CBC de la UBA en la materia Introducción al pensamiento científico. Profesora regular de la UNLa en el área de ética, coordinadora académica de la Maestría en metodología de la Investigación Científica de la UNLa, dicta materias de posgrado. Autora de Del monstruo al estratega, Ética y juegos, Editorial Educando 2007, coautora con Rubén Padlubne de Ficciones posibles. Saberes filosóficos, semiológicos y científicos a través de la literatura, Biblos, 2014 y coautora con Carlos Asti Vera de Estructuras y procesos. Temas de Epistemología, Educando (2005) y de Argumentos y teorías. Aproximación a la epistemología, Educando (2009)

2 Andrés Mombrú Ruggiero es Dr. en Filosofía por la UNLa, Mg. y Especialista en Metodología de la Investigación Científica por la UNLa, Lic. En Filosofía por USAL, decente regular Asociado de la materia Metodología de las Ciencias Sociales, CBC, UBA; Titular de IPC UNLa, Profesor regular en Lógica Aplicada a la Investigación y Seminario de Redacción de Tesis y Coordinador Pedagógico en la Maestría en Metodología de la Investigación Científica en UNLa. Ha publicado numerosos libros y artículos en revistas de su especialidad, entre ellos: "Encrucijadas del Pensamiento, Análisis críticos del quehacer científico", con Sonia Durand, editorial Gran Aldea, 2004; "Filía (Filía) Uno de los posibles recorridos a través de la Filosofía de Occidente, con Carlos Rodríguez Murúa, Ed. Autor, 2011; Paralaje: Los giros y las controversias en el campo de la epistemología y sus consecuencias metodológicas en la investigación científica. Ediciones L.J.C. 2012; El Hacedor de Tesis en colaboración con Alejandro Marjetic, L.J.C. Ediciones, (reedición) 2013. 
incluso para la vida de la generación siguiente, por ello es que tanto en los oficios, como en las profesiones y en las disciplinas científicas, la trasmisión de los conocimientos era restringida dentro de las familias, del gremio o de la disciplina, seguramente como una herencia de la circulación del conocimiento en la Edad Media. Pero en la medida en que los conocimientos se incrementaban y al mismo tiempo decaía su valor, al ser sustituidos por otros, la lógica de su producción, circulación y uso se modificó dramáticamente. El mismo saber, convertido en mercancía respondía a la dinámica del vértigo de los mercados, era necesario sacarle el máximo provecho en el menor tiempo posible antes de que caducaran. Los imperativos de rápida obsolescencia que comenzaron a imponerse en los campos de la moda y la tecnología también se impusieron en la sociedad del conocimiento, la cual ve desbordada su capacidad crítica a causa del tsunami que produce la sociedad de la información. Más allá del hecho mismo de la información, del conocimiento, de los saberes y de las capacidades como mercancías, se encuentra, como en otros ámbitos de la producción el problema de la contaminación.

El viejo dicho, "el saber no ocupa lugar" es falso, y no nos referimos a las progresivamente arcaicas bibliotecas, ni a los a los crecientes terabyte, petabyte, exabyte, etc., conformadores de laberintos insondables de información, sino a la dificultad para diferenciar los conocimientos y saberes "significativos" para la vida de las personas de aquellos cuyo fin es el sostenimiento de las lógicas productivas a cualquier costo. Los conocimientos y saberes pertinentes para la realización de determinados proyectos personales y colectivos se ven "contaminados" por una enorme cantidad de requisitos externos, enajenantes, parasitarios de los primeros, que terminan consumiendo buena parte de la energía que debería estar destinada a los primeros. El mito de que el conocimiento es bueno por sí mismo ha impedido discriminar la finalidad a la que apunta. Disponer de recursos para algunas áreas y abandonar otras supone una decisión que facilitará ciertos desarrollos e impedirá otros. La decisión sobre que saberes fomentar y promover implica no sólo una decisión epistemológica, sino también política y ética. No sólo es importante saber, sino además saber qué se sabe y que consecuencias tienen esos saberes y su implementación sobre nuestras vidas. Lamentablemente el conocimiento que se promueve compulsivamente en la sociedad del conocimiento no apunta a la "sabiduría", ni siquiera como han supuesto muchos a partir de las tradiciones aristotélicas a la "felicidad", o más discretamente a la "realización" personal y social, sino que en la mayoría de los casos sigue apuntando a la supervivencia de muchos, mediante producciones genuinas o parasitarias y a la acumulación inaudita de riquezas por parte de unos pocos.

\section{Nuestro contexto general}

¿Qué ha impulsado a aquel Mengano o Perengano, bachiller o perito mercantil a tener un título universitario? ¿Qué ha motivado a aquel que ha obtenido un título de grado a obtener títulos de posgrado que van desde cursos de capacitación, pasando por especializaciones, maestrías, doctorados, hasta posdoctorados? Hoy causaría gracia cualquiera que se presente con una tarjeta que lo acredita como bachiller o perito mercantil, pero también, en situación similar, han caído los títulos de grado e incluso los de posgrado, ya que además esos títulos tienen que estar respaldados con producciones, publicaciones, asistencias a congresos, todos matemáticamente tabulados para la meritocracia que asigna reconocimientos y recursos. Se podría decir que el vértigo y la rápida obsolescencia de los 
conocimientos obliga a una formación permanente, pero el alto índice de fracaso y deserción muestran que la capacitación no pone en sintonía esfuerzo, recursos y resultados.

Alguien dijo sobre la tecnología que: "La tecnología viene a resolver una cantidad de problemas que antes del desarrollo tecnológico no teníamos”, se podría argumentar en contra que también ha resuelto problemas que sí teníamos y que los ha resuelto para muchos, pero lo que queda en entredicho es $L A$ TSSS el balance de problemas que ha resuelto en comparación con los que ha suscitado. Algo similar parece ocurrir con la investigación NO SE CREA científica que emana de la educación superior. Lo que se presenta como un hecho es que la posibilidad de mejoramiento (por lo NI SE DESTRUYE menos a mediano plazo) de las sociedades menos desarrolladas es apostar a la educación para la investigación y el desarrollo. $S O J O S E$ Lo que significa para esas sociedades un esfuerzo mucho mayor que para las del primer mundo. Numerosos estudios de CEPAL POSPONE ponen de manifiesto que en las últimas dos décadas la inversión en educación superior en América Latina ha producido un significativo incremento de esfuerzo de las personas y las familias tanto como del sector público y del privado en educación superior. El crecimiento de la matrícula ha crecido de 7 millones a 28 millones en las últimas dos décadas. Lo que ha cambiado entre la década de los 90 y la primera década del siglo XXI es el modelo político que impulsa las políticas en educación superior.

El neoliberalismo de los 90 apuntaba a una internacionalización y privatización de los servicios públicos, entre ellos la educación, en tanto que en la última década los proyectos integradores e inclusivistas de América Latina han dado mayor apoyo a las instituciones públicas y a la visión de la educación superior como un bien público social. De cualquier manera, según los especialistas, el promedio de inversión para la región es de aproximadamente el 1,5\% del PBI, lo cual resultaría insuficiente para atender a todas las demandas educativas y principalmente para sostener proyectos de investigación relevantes y sustentables. A esto debe sumarse otro dato importante. Según IESALC CINDA, 2005, ( Instituto para la Educación Superior de América Latina y el Caribe), las Ciencias Sociales, Empresariales y Jurídicas se llevan el $42 \%$ de la matrícula, en tanto que las ingenierías, industria y construcción el 14\%, educación y salud rondan el 10 $\%$ respectivamente, humanidades y arte el $6 \%$, otros el $2 \%$ y la agrícola (¿?) el $2 \%$. Se puede ver que sectores relevantes como el vinculado con el agro, por ejemplo, tienen una matrícula muy baja, para un sector productivo tan relevante, en tanto que las administrativas, de corte más burocrático son las de mayor matrícula y por lo tanto las que más recursos insumen. Estas deficiencias también se expresan en el muy bajo índice de publicaciones científicas, aproximadamente un 2,6\% de toda América Latina contra un $42 \%$ de Europa y un 31,8 de EE.UU.

Ahora bien, de los que realizan estudios de posgrado en América Latina y también en Argentina, sólo un $10 \%$ alcanza el título. ¿Quiere esto decir que se ha perdido un $90 \%$ de esos recursos, tanto por parte de los cursantes como por parte de las instituciones? Buena parte de las deserciones de ese $90 \%$ se dan muy cerca de haber finalizado los estudios, o incluso de haber concluido con ellos. Sin el título que se obtiene a partir de haber aprobado la tesis el reconocimiento institucional no se alcanza. Sin embargo, esto 
no quiere decir que los conocimientos y las capacidades adquiridas no se pongan en juego en los desempeños profesionales. Las mismas instituciones se benefician de disponer de personas capacitadas y formadas pero que no pueden acreditar esos conocimientos, eso se traduce en salarios inferiores para desempeños superiores. Esta situación surge de la siguiente ecuación: hay carreras largas (o que se hacen largas por distintos motivos), tanto en grado como en posgrado; para el ejercicio profesional de ciertas disciplinas no se requiere título o matrícula, la obtención del título se ve como lejana o inalcanzable, pero el ejercicio profesional es inmediato aunque se gane menos (o igual) que como titulado. Conclusión es más "negocio" trabajar aunque se gane menos que realizar el costoso esfuerzo de titularse. Para otros, como vimos, la titulación es imprescindible para la obtención de mejoras laborales. La realidad de los profesionales es que buena parte de las motivaciones para realizar posgrados no radican en el amor por el saber, sino en la expectativa, en algunos casos de mejorar los ingresos, en muchos, apenas en conservar el trabajo frente a la creciente competencia. Otro aspecto a tener en cuenta es que la misma práctica disciplinar obliga a una formación constante que se da mediante la práctica y los conocimientos que espontáneamente se adquieren a través de lecturas, cursos, inter-capacitación laboral. ¿Qué se busca en estos casos con la obtención de un título de posgrado? En ocasiones validar conocimientos que ya se poseen.

En los países centrales la situación parece ser la inversa en cuanto al promedio de

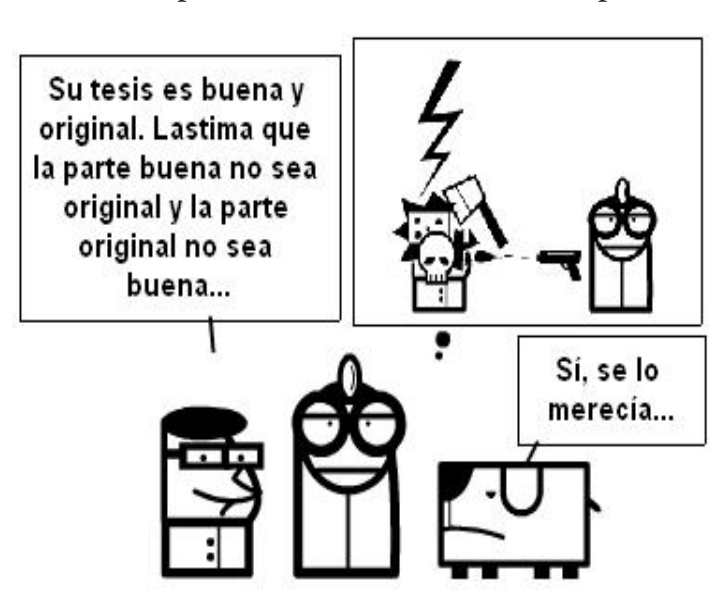
graduados, va del $50 \%$ al $90 \%$ de titulaciones. ¿Qué similitudes y diferencias encontramos entre estas dos realidades? En relación a los estudiantes no se puede dejar de tener en cuenta su condición sociocultural. En argentina el $90 \%$ de los estudiantes de posgrado estudian y trabajan y se encuentran motivados por expectativas económicas, esto no es ni bueno ni malo en sí mismo, pero determina que si los obstáculos o los resultados no satisfacen esas expectativas entonces es posible una mayor tasa de deserción, a diferencia que cuando las motivaciones son otras como por ejemplo la vocación. En nuestro país la edad promedio es entre los 25 y 30 años, pero se advierte un alto índice de quienes superan de 35 años. La mayoría de los estudios de posgrado son pagos. En los ámbitos privados son costosos, aunque en los públicos son mucho más accesibles. Para la gran mayoría de los cursantes los sistemas de becas consisten en restricciones o no pago de la matrícula y la cuota, esto sobre todo para los estudiantes que forman parte de una institución superior, son pocos los casos en que los estudiantes cobran becas lo suficientemente importantes como para realizar sus estudios sin trabajar.

En EEUU y Europa los estudios de posgrado, principalmente las maestrías se realizan a continuación de los estudios de grado. Los estudiantes prolongan su estatus universitario y su dependencia familiar. Esto también es posible por la duración de los posgrados, muchos de ellos menores de un año contra los dos o tres años que duran en la Argentina. 
El organismo principal para establecer la calidad educativa en Argentina es la CONEAU, (Comisión Nacional de Evaluación y Acreditación Universitaria). En la Resolución Ministerial 160/11 se establece la diferencia entre especializaciones, maestrías y doctorados. La especialización apunta a una profundización de los dominios en los desempeños profesionales. La maestría lo mismo pero con alcance profesional y/o académico. Mientras que la orientación profesional apunta a profundizar prácticas y saberes profesionales, la académica apunta a la formación para la investigación científica y los procedimientos metodológicos, en definitiva para la apropiación de herramientas para la producción de conocimiento en áreas disciplinares. En tanto que el doctorado exige la producción de aportes originales en un área específica. Estas definiciones nos ponen frente a un viejo problema que surge en la misma formación de grado, ¿una educación universitaria con un perfil profesional o académico? ¿ Una preparación para la práctica profesional o para la investigación científica? De hecho los estudiantes de grado transitan casi en forma conjunta, en los mismos claustros los dos tipos de orientaciones. No está mal que esto ocurra, pues la formación que excluye a estos grupos, como por ejemplo se practicó en algunas universidades de la URSS, desvincula la producción de conocimiento científico de las prácticas y los problemas concretos del resto de la sociedad. Esta situación hace que, en parte, se corra el peligro de no conseguir un perfil nítido para el cumplimiento de los propósitos de esas orientaciones.

Entendemos que en las carreras de corte profesional la formación se encuentra orientada principalmente para la práctica o desempeńo profesional, en tanto que, en las de corte académico el énfasis está puesto principalmente en la investigación. Ello implica modos de estudio, enfoques de problemas, didácticas diferentes. Las especializaciones no presentarían mayores dificultades cuando están llevadas adelante en sus áreas disciplinares específicas, aunque suelen producirse enfoques demasiado estrechos que no son capaces de revisarse a sí mismos a la luz de otras perspectivas epistemológicas y metodológicas. Por ello la importancia del desarrollo de la investigación interdisciplinaria incluso en sus pareas de formación. Pero, ¿qué pasa con las maestrías cuando los alcances profesionales y/o académicos toman más partido por la conjunción que por la disyunción? ¿Cómo se conjugan desde una perspectiva pedagógica y disciplinar estos dos universos? Se trata sin dudas de una situación conflictiva, pero de una conflictividad que merece ser encarada, ya que de su conjunción surge una dimensión relevante que aporta un plus valor a la formación de posgrado. En la actualidad un profesional no puede ser un mero aplicador de técnicas, para eso, cada vez más y de modo más eficiente están las máquinas y las computadoras. ¿Cuál es entonces la tarea más significativa de un profesional? Tomar decisiones. Por supuesto que tiene que tener un conocimiento técnico exhaustivo, pero su capacidad principal se manifiesta en la toma de decisiones, no sólo con respecto a esas técnicas, sino además en relación con ese universo cambiante que es su producción teórica disciplinar. Un profesional no está obligado a producir conocimientos como un científico, pero tiene la obligación de poder interpretar adecuadamente la producción teórica de su área. Un contador no es una calculadora, ni tampoco un creador de teorías económicas, pero debe poseer la capacidad para reflexionar sobre los que los cientistas sociales de su disciplina producen. Del mismo modo un científico debe estar al tanto de los diversos problemas que se producen en su campo a raíz de sus desarrollos teóricos. Entendemos que parte de los fracasos y la deserción en muchos posgrados es a causa de las dificultades para ensamblar armoniosamente estos dos universos. 


\section{Nuestro contexto particular}

El campo académico tampoco es homogéneo. Los modos de investigar y de comunicar los resultados de las investigaciones difieren, no solamente entre las ciencias naturales y sociales, sino también entre disciplinas próximas. Si bien la praxis científica implica

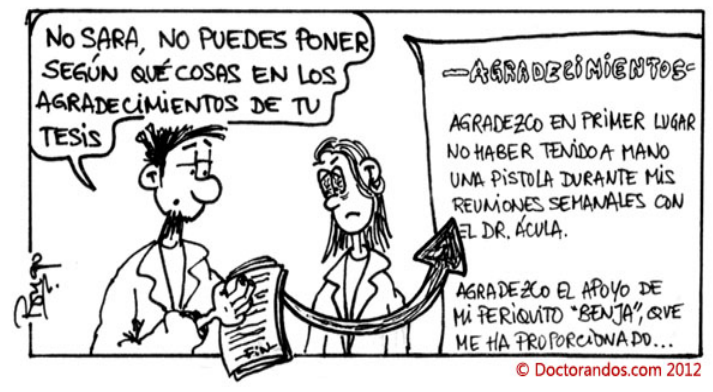
una dialéctica entre teoría y empiria, los sesgos teóricos y empíricos imponen diferentes modalidades, que a la postre generan prácticas y discursividades no siempre afines. Esta situación es común entre físicos teóricos y físicos experimentales, pero también entre antropólogos teóricos y antropólogos de campo. Los ámbitos de producción discursiva también son heterogéneos entre disciplinas y dentro de las mismas disciplinas, en relación con las prácticas disciplinares. Quienes trabajan en equipos de investigación están acostumbrados a la elaboración de informes y de "papers" que surgen como recorte de una tarea colectiva, que en general es un proyecto de investigación del que participan. En el campo de la filosofía y de las artes la tarea suele ser más solitaria, dando lugar a ensayos y artículos. Estas últimas formas de escritura también son una modalidad de comunicación en el ámbito profesional, la dificultad que plantean es que en ocasiones su carácter especulativo, o su modalidad periodística, impide distinguir la mera opinión (doxa, pareceres infundados) de los juicios fundados (episteme, fundados no sólo empíricamente y argumentalmente, sino integrando perspectivas de las epistemologías ampliadas). Pero algo tienen en común las distintas disciplinas en su instancia formativa, principalmente en el grado, y es que la escritura se limita la mayoría de las veces a responder preguntas, como en los exámenes abiertos, o a someterse a la modalidad de múltiple choice, en el que la escritura se encuentra ausente. En contadas ocasiones se piden monografías y en ellas se suele evaluar sus contenidos conceptuales, pero no el cumplimiento con esa forma de comunicación que es la escritura académica. Como señala Roberto Follari:

Y nos queda, lastbutnotleast, la cuestión de la escritura. Hoy los estudiantes no saben escribir. Mucho se ha dicho al respecto, y sin duda que la condición de posmodernización cultural, con el auge del mundo visual, es responsable estructural de esta situación. También las fallas en la educación de nivel primario y medio, y la falta de suficiente entrenamiento durante las carreras universitarias de grado. Es más: los alumnos muestran a veces dificultades de comprensión lectora, hasta cerca del final de sus licenciaturas. Todo esto hace que la tarea del director, a menudo se asimile a la de un corrector de estilo dentro de una editorial: corregir acentos, mayúsculas, comas, signos, palabras y construcción gramatical de frases.(Follari, 2001)

Entendemos que la dificultad en la escritura es sólo parte de la dificultad de comunicación. No sólo no se sabe escribir, tampoco se sabe hablar. El idioma se ha empobrecido, el conjunto de palabras que se usan se ha ampliado por un lado pero se ha restringido notablemente por otro, siempre haciendo alusión a grupos que deben al habla y a la escritura 
parte de su razón de ser. Hay más palabras, pero más pobreza gramatical y en consecuencia menor capacidad significativa. La pobreza de la palabra se convierte en pobreza del espíritu.

La tesis es un tipo particular de escritura que se diferencia de la monografía, el ensayo, el artículo, el informe o la ponencia. En la vida académica y por ende en los estudios de posgrado se dan todos estos tipos de escritura, es por ello que es necesario distinguirlos y manejarlos. Sin embargo, como hemos visto, a lo largo de la carrera de grado es escasa, por no decir nula, la formación para estos menesteres, incluso hay muchas carreras a las que se accede al título de grado sin la presentación de una tesis. Luego, cuando llega la hora de realizar un trabajo de esta naturaleza, suele reinar el desconcierto y la angustia, a causa de la necesidad de encarar una tarea para la que no se está preparado. Es que una tesis implica un tipo de escritura esencialmente académica, esto es, reflexiva, crítica, argumentativa; supone una dialéctica entre la teoría y la empíria, el manejo de procedimientos metodológicos específicos y propios anclados en sus fundamentos epistemológicos. En definitiva, una tesis es una investigación, una tarea propia de investigadores. Es por ello que les cuesta menos a aquellos que tienen a la investigación como parte de su "metier" cotidiano, pero les cuesta mucho más a los que se han formado sólo para ejercer una profesión. Este problema se agrava cuando los directores de tesis pueden ser idóneos en su área disciplinar, pero carecen de los conocimientos sobre formas de investigación, o aunque sean investigadores no tengan la capacidad de acompañar a su dirigido en el proceso de elaboración de la tesis. Otro problema a tener en cuenta es la dificultad para identificar las herramientas metodológicas que se condicen con el objeto de investigación y las elecciones epistemológicas del marco teórico. El problema se presenta como menos grave para maestrías orientadas en forma selectiva sobre un área disciplinar, ya que las elecciones metodológicas suelen ser propias y pertinentes; se complica mucho más cuando los concurrentes provienen de diferentes disciplinas y no aparece claridad en la pertinencia de la elección metodológica y epistemológica. Sumado a todos estos problemas se encuentra el específico de la escritura de la tesis. Esto sin tener en cuenta los debates epistemológico-metodológicos que atraviesan a todas las disciplinas.

Hasta tal punto la elaboración y presentación de la tesis se ha convertido en un obstáculo que la psicóloga Venezolana y Doctora en Ciencias Elizabeth Valarino, ha establecido las categorías de síndrome de TMT (Todo menos Tesis) y de TMI (Todo menos Investigación), ellos se expresan como:

[...] el concurso de trastornos, impedimentos, obstáculos, actitudes, sentimientos y conductas inadecuadas, ausencia o deficiencia en algunas destrezas o lagunas de conocimientos, que presentan o enfrentan los estudiantes, profesores y profesionales, cuando abordan la tarea de diseñar, planificar, desarrollar, escribir, supervisar y publicar trabajos de investigación o proyectos a largo plazo, como pueden ser trabajos de grado, tesis, trabajos de ascenso, artículos científicos, monografías, informes técnicos, reportes o similares, así como en la tarea de enseñar sobre dichos procesos. (Valarino, 1997, p. 255)

Entendemos que los motivos psicológicos concurren con otros de carácter social, cultural, económico, e institucional. Una manera de aproximarse a esta problemática 


\section{2/ Perspectivas Metodológicas /19/Vol. II /Año 2017}

consiste en analizar las dificultades que se presentan a la hora de la elaboración de la tesis, de encarar el proceso de investigación ordenando cada una de sus etapas y de plasmar en un documento escrito con claridad argumentativa cada una de las partes que darán forma "física" a esa unidad que es la tesis, en la instancia de lo que se da en llamar Taller de Tesis, Taller de Escritura de Tesis, Seminario de Tesis y otras denominación.

\section{No es bueno que el tesista esté solo}

Nuestra experiencia como docentes de Seminarios de redacción de tesis y lectores de tesis ya sea para orientación de alumnos y colegas o como jurados indica que entre las principales dificultades y obstáculos para la presentación de tesis de posgrado se señalan la desorientación y el aislamiento. En contra de la creencia firme de que es la falta de tiempo el principal motivo que lleva al abandono de las tesis, en nuestra experiencia a partir del contacto con tesistas hemos advertido que la principal desmotivación está dada por el desánimo que produce la falta de "acompañamiento" en el difícil momento de la escritura. En nuestra tradición cultural se supone que un escritor es como un navegante solitario que necesita estar apartado del mundo para poder concretar su tarea sin distracciones mundanas y sin la contaminación de ideas ajenas que afectarían la originalidad. En parte es cierto para el caso de la creación literaria donde la metáfora de la concurrencia de las "musas" inspiradoras se asocia a la intimidad de una voz interior, pero en el caso de la escritura académica se requiere la colaboración de muchas personas entre las que el director de tesis es una pieza fundamental sin desmerecer el aporte de profesores, colegas, amigos y familiares que pacientemente "contengan" al autor de la tesis en momentos de crisis.

En el último Seminario de redacción de tesis dictado en la Maestría en Metodología de la Investigación Científica de la UNLa, como parte del Examen final se administró un Cuestionario donde la primera pregunta fue ¿Por qué cree que no se termina una tesis? Recabaremos a modo de ejemplo algunas respuestas.

\section{Respuesta 1}

Coincido con Arnoux y otros (2004) que una tesis demanda "una extensión, un nivel de conceptualización original, un grado superior de integración de conocimiento y una capacidad de autoorganización y regulación del trabajo autónomo que solo pueden vehiculizarse por medio de un dominio escritor difícilmente obtenido en etapas anteriores". Habitualmente estas competencias necesarias para completar una tesis no se adecuan con la "ecuación personal", descripta por Mombrú (2013) es decir aquellas exigencias de tipo laboral y/o personal. Por eso, que se hace necesario el acompañamiento del director de la tesis y la interacción cooperativa con otros maestrandos.

\section{Respuesta 2}

Creo que un proceso de elaboración de tesis se ve atravesado por diferentes factores, por un lado los emocionales/personales, y por otro, los profesionales/disciplinares. Hay componentes que afectan a todo tesista emocionalmente, en tanto la dificultad que está asociada socialmente a la elaboración de una tesis y a la graduación en si a partir de la misma. Además, el tesista que se encuentra en ese proceso y enfrenta este desafío, está terminando un recorrido 
que amerita balances y cuestionamientos, saca a relucir inseguridades respecto de la manifestación pública (a sus pares) de sus propuestas y concepciones. Esto, sumado a los complejos tiempos personales y laborales de la actualidad, que impiden dedicarse exclusivamente a la realización de un estudio en la mayoría de los casos, complejizan la terminación de una tesis.

\section{Respuesta 3}

Considero que existen varias razones por las cuales no se termina una tesis. Una de ellas es el estado de aislamiento, de soledad, del tesista que no encuentra acompañamiento (tutorías o seminarios) ni instancias de dialogo e intercambio para llevar adelante su tarea. Otra razón es la falta de experiencia en la producción de este tipo de escrito puesto que, su gran mayoría, nunca ha leido, por ejemplo, una tesis. Este se relaciona con la ausencia de prácticas comunicativas especificas. También se puede mencionar que otra razón es la falta de tiempo que se relaciona con la ausencia de un cronograma tentativo y un plan personal donde se combinen los pasos y nuestro tiempo real dedicado a la producción de la tesis. La falta de tiempo y una mala organización personal del mismo provocan una discontinuidad de la tarea. Otra razón es el tiempo que el director de la tesis le dedica a nuestro trabajo y, a veces, la falta o ausencia de encuentros personales dedicados entre tesista y director para analizar el avance de nuestra producción.

\section{Respuesta 4}

Es sabido que la brecha entre la finalización de la cursada de los estudios de posgrado y la presentación de las tesis en muy grande. Considero que las causas son múltiples. Entre ella la presentación de la tesis es una trayectoria más solitaria que involucra autodisciplina por parte del alumno. Otro aspecto a considerar es la brecha entre la teoría y la práctica, la tesis implica llevar adelante un proyecto, responder a la buisqueda de conocimientos en relación a un problema real. Los tiempos concretos no son un aspecto menor los estudios de posgrado por lo general son realizados por personas dividen sus tiempos entre el trabajo, estudio, vida familiar y personal y el caso de las mujeres hay que considerar la crianza de los niños en las etapas de adultez temprana.

\section{Respuesta 5}

Creo que existen dos dificultades importantes a la hora de terminar una tesis, la primera es la falta de tiempo en exclusividad para dedicarse a ella, no existen becas accesibles para ello, y las múltiples actividades conspiran contra la finalización, la segunda es la falta de acompañamiento, la soledad, por mejor que sea un director de tesis, el problema principal es la falta de instancias intermedias durante la realización de la tesis, como talleres de apoyo entre alumnos, casi a modo de autoayuda, o instancias de encuentro con docentes de la maestría, etc., que permitan revitalizar o renovar las ganas de seguir incluso desde el lugar de ir (al lugar fisico) de la facultad.

\section{Respuesta 6}

Son varios los factores que imposibilitan la terminación de una tesis. Los mismos están vinculados de manera directa o indirecta con lo que particularmente denomino "Condiciones de posibilidad para "proveniente del sector público o privado, empresa o ámbito académico, ciencias biológicas o sociales, desarrollo del hábito de la escritura, etc., y del peso relativo de cada 
uno en el contexto de cada investigador. Por ejemplo no es lo mismo una persona que proviene de una universidad con experiencia en presentación de trabajos, que de la actividad profesional, ya que el primera está más favorecido por el entorno académico que el segundo. Otro de los condicionamientos para terminar la tesis se podría relacionar con recursos económicos, financieros e infraestructura (por ej. Laboratorios) identificado con la disciplina cientifica a la que pertenece el investigador. Es obvio que las provenientes de las ciencias biológicas son dependientes de estos recursos. En el pais existe una desigual distribución de estos recursos (hay excepciones) ya que coexisten universidades más provistas que otras de equipos, infraestructura y de cientificos o investigadores formados, con el tiempo suficiente para acompañar o dirigir tesis de post grado. Desde el punto de vista individual, creo que el tiempo es otro factor que influye dado que existe la necesidad de cumplir, primero, con las obligaciones laborales si uno no es investigador de carrera, cuyo ingreso es exclusivamente es producto exclusivamente de su actividad profesional y en segundo lugar si queda tiempo, dedicarse a la actividad de investigación.

En resumen, si se generara un ámbito más accesible para la investigación, especialmente para los tesistas de maestrías y doctorados, que implicara acompañamiento y que diera la oportunidad de consulta permanente, más las condiciones de infraestructura adecuadas (en función del tipo de tesis y que es factible de lograr con politicas explícitas orientadas a facilitar el trabajo de los mismos) se podria incentivar la conclusión de los trabajos de tesis en todo el territorio del país. No obstante reconociendo aún que desde el gobierno nacional se ha encarado una politica de fuerte apoyo a la investigación e innovación, es evidente que las mismas no hacen hincapié en esta problemática.

\section{Respuesta 7}

Para responder esta pregunta tendré en cuenta las experiencias vividas al compartir espacios con colegas de mi disciplina, son muchos los que han terminado el cursado de diferentes maestrias y la mayoría no han entregado la tesis, los problemas que se plantean son: falta de tiempo para poder dar continuidad al trabajo de investigación, sobre todo en la etapa de elaboración del informe; escasos recursos gramaticales que impiden una buena redacción y también un no reconocimiento de los errores cuando son marcados por el Director de Tesis o los profesores en las entregas de informes de avance he escuchado expresiones como "no lo entiendo y no me entiende, no sé qué quiere que escriba"; falta de incentivo, ya que en general, el terminar la tesis no le significará ningún cambio en relación a su jerarquia laboral; y sentimientos de que se está investigando algo que no tiene mucha importancia o que un enfermero no tiene capacidad para un trabajo tan profundo.

\section{Respuesta 8}

Creo que una mala planificación y la gran cantidad de horas que requiere la realización de una tesis son las principales trabas. Al planificar mal y al no cumplir con el cronograma inicial que el maestrando realiza, se genera una pérdida de interés a realizar tanto esfuerzo junto con la falta de obligatoriedad de presentar informes preliminares hacen que los tiempos se hagan demasiados largos perdiendo el hilo del proyecto.

\section{Respuesta 9}

Si bien es difícil generalizar al respecto, me parece que la problemática remite a dos cuestiones, el pluriempleo de los tesistas que demanda de ellos un esfuerzo desmedido y creo por 
otra parte que la tesis se debe empezar a escribir cuando uno está cursando y no cerrando la carrera; dejando al alumno en un umbral donde lo que queda a veces es soledad pura.

\section{Respuesta 10}

Entiendo que la problemática para la elaboración de un trabajo de tesis no tiene que ver con un factor específico, sino que más bien estamos ante la presencia de una problemática multifactorial. De todas maneras, desde mi óptica, el tiempo del que uno dispone asoma como el principal obstáculo (en términos de lo cotidiano y no del tiempo administrativo de entrega del que uno dispone). Considero que en gran porcentaje todos los que tienen la posibilidad de presentar un trabajo de tesis, tienen el bagaje académico suficiente para su elaboración. De todos modos es aqui donde las complicaciones laborales, familiares, etc., abortan la misión de finalizar el trabajo.

Otra problemática de mayor peso, refiere a la conjunción de la falta de entrenamiento del tesista para su elaboración, sumado a todas las dificultades con las que uno puede encontrarse cuando intenta plasmar una idea en un papel (inconvenientes para encontrar su propia voz). En esta instancia los directores de tesis, los cuales pueden cooperar para salir del "bache" en el cual uno se encuentra inmerso, en muchas ocasiones disponen aún de menos tiempo que el tesista, generando una interrupción en el flujo de comunicación entre ambos.

\section{Respuesta 11}

Uno de los inconvenientes surgen en la enseñanza en el pregrado: históricamente, en gran número de profesiones a lo largo del proceso formativo, se elimina la curiosidad y la duda sobre los saberes previos. El aprendizaje está basado en la repetición y el entrenamiento más que en la reflexión y en su reemplazo se apuntalan actitudes acriticas y conformistas, un no cuestionamiento a lo establecido. Al mismo tiempo generalmente se realizan análisis superficiales acerca de los procesos involucrados en la producción de conocimientos y las condiciones de su realización. Sumándole, ya en la instancia del trabajo final, un escaso o nulo conocimiento previo del tema propuesto para investigar.

En los posgrados encontramos, en gran parte, estudiantes con experiencia laboral en áreas en donde prevalecen los aspectos técnico y procedimentales, probablemente ninguna o escasa participación en equipos de investigación y un reducido número que acredita realizaciones por lo menos cercanas a lo cientifico. En forma conjunta, se identifican las limitaciones del tiempo disponible versus las expectativas en función de la tesis, y las posibilidades personales, profesionales y laborales. Esta situación es percibida inicialmente por el alumnado con temor por un lado (sustentado por el imaginario construido en torno a la investigación como actividad de "elegidos") y curiosidad. El reto es vencer el primero y aprovechar lo segundo en pos de producir una motivación tal que se mantenga a lo largo del proceso investigativo.

\section{Respuesta 12}

En mi experiencia personal he realizado una investigación sobre dificultades percibidas para la elaboración de la tesis en estudiantes de grado de la carrera de psicología de una Universidad privada y he observado que no se diferencian demasiado de lo que ocurre en posgrado. Entre los obstáculos percibidos, los más destacados eran: a) falta de formación en 
116/ Perspectivas Metodológicas /19/Vol. II / Año 2017

investigación, b) temor a no poder producir nuevos aportes, c) temor al manejo de la teoría, d) dificultades en la escritura y falta de acompañamiento del director.

Volviendo a las carreras de posgrado y buscando priorizar el factor de mayor peso, considero que en la formación universitaria no se transmite una "cultura de la investigación" siendo la consecuencia más inmediata de este déficit, la falta de realización de tesis de posgrado

\section{Respuesta 13}

De acuerdo a los conocimientos adquiridos en el módulo seminario de tesis, se pueden advertir problemáticas y dificultades que se presentan durante todo el proceso de desarrollo del plan de tesis, entre ellas se encuentran:

-Un intercambio de dialogo con el director poco fluido, que impide llevar adelante lo pasos del plan. Es común que los tesistas presenten un diálogo pobre con sus directores, aun cuando lo tienen y valoran, lo consideran insuficiente. Consideran que hay preguntas que no pueden plantearle al director, ya que estiman que solo deben hacerle consultas pertinentes a la investigación.

- Muchas veces el tesista no da a leer los avances al Director, y continua trabajando solitariamente, construyendo un argumento que aún no han sido revisados, por colegas, o personas pertinentes al tema en cuestión o que sepan de gramática, esto hace que los tiempos se extiendan cada vez más.

- Un inadecuado manejo del aparato crítico: suele advertirse en muchos trabajos una falta de criterios para expresar con cierta claridad, los objetivos y los puntos de anclaje de la investigación, diagnósticos que no están bien definidos.

- Falta de entrenamiento: es común que el alumno que inicia por primera vez un plan de tesis no posea una conceptualización sobre un discurso, ni sobre la escritura como práctica comunicativa especifica, ni sobre el campo académico pertinente en cuestión. También presentan un escaso entrenamiento en la escritura de textos académicos, por lo que se trata de un alumno que además de desconocer el producto que tiene que resolver, tampoco conoce las características del proceso que debe !levar a cabo para concretarlo.

- Dificultades en la conceptualización sobre el discurso, que obstaculiza la toma de decisiones adecuadas a la hora de redactar.

-Autonomia: la libertad que uno tiene para elaborar el plan, muchas veces perjudica la evolución de la misma, la autonomía juega en contra de la producción final. El investigador deja pasar lo tiempos pautados en la investigación, (lo dejo para más adelante, o lo termino la próxima semana o luego lo termino), obligando constantemente a replanificar los tiempos estimados de cada etapa.

\section{Algunas consideraciones como conclusión}

La "ecuación personal" a la que se hace referencia en una de las respuestas, representa no una situación individual aislada, sino el común denominador que más allá de las 
particularidades impone el contexto social, económico, laboral, familiar e institucional para el área de la UNLa, pero que entendemos que también tiene aspectos comunes con el resto del área latinoamericana. Hemos visto que el tiempo que se pueda dedicar a la producción de la tesis, en medio de exigencias laborales, familiares, institucionales no es el elemento que más conspira contra esa realización. Aunque no deja de ser importante se puede apreciar que afecta del mismo modo a los que presentan sus tesis y a los que no. ¿Qué elemento diferencial se puede apreciar en aquellos que arriban a la meta? Se puede concluir que la contención institucional, la buena capacitación de aquellos que deben orientar y acompañar a los alumnos, como tutores, consejeros, directores además de la disposición personal del tesista.

Se puede concluir que para modificar la alta tasa de ingresantes, mediana tasa de egresados y baja tasa de titulados, es necesario políticas proactivas de carácter institucional que tiendan ajustar las demandas y exigencias junto con los recursos materiales

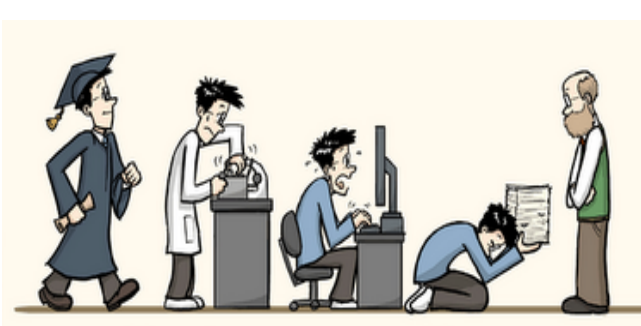

THE ORIGIN OF THE THESES y humanos que se requieren para llevar a buen término el proceso de producción de tesis. En muchas ocasiones no se trata de un problema de falta de recursos, sino de una adecuada administración de esos recursos. Hacer que los alumnos se titulen debe ser parte del proceso de formación. Suele observarse en la mayoría de las instituciones que hay una preocupación por dar contención a los alumnos en relación a que cuenten con cupos, docentes a cargo de materias, recursos bibliográficos y de las tics, apoyo económico a través de becas y subsidios, sin embargo, a la hora de finalizar las cursadas regulares y previo a la presentación de la tesis se advierte cierta orfandad en la que los tesistas quedan a la "deriva" para emprender una tarea que requiere un tiempo adecuado de aprendizaje. El seminario o taller de tesis muchas veces expone esta situación y trata de remediarla en la medida de la posible, pero no puede resolver hacia el pasado todo lo que no se hizo y hacia el futuro la suerte de acompañamiento que requieren los tesistas. En muchas ocasiones los directores de tesis pueden ser muy idóneos en su campo científico o profesional, pero se requiere más que eso para poder dirigir una investigación. No suele ser, en la mayoría de los casos, la extenuante y demandante tarea del director, cuando se encuentra llevada adelante adecuadamente, remunerada. Incluso muchas veces la buena voluntad de dirigir una tesis no se ve acompañada de la disponibilidad necesaria que ésta demanda.

Superar el cuello de botella de la elaboración y presentación de la tesis requiere de una toma de conciencia por parte de los tesistas de la tarea a realizar y de cómo deben ser ordenados los distintos pasos en el proceso de investigación a los efectos de no dilapidar esfuerzos y por parte de las instituciones la revisión en la implementación de recursos para la concreción de dicho proceso. No todo depende de la voluntad de los tesistas, ni de la contención institucional, pero ambos deben asistir a esa producción considerando el modo de generar prácticas y mecanismos qué, sin desmerecer la calidad de los resultados, contribuya a superar los obstáculos que se ponen en evidencia en todo momento en los claustros universitarios. 
118/ Perspectivas Metodológicas /19/Vol. II /Año 2017

\section{Bibliografía}

- Arnoux E: Escritura y producción de conocimientos en las carreras de postgrado (ed.)Buenos Aires, Santiago Arcos, 2009.

— Mombrú, A. Marjetic, A.: El hacedor de tesis, Ed. Pragma, Bs.As., 2002.

- Naishtat, F. y otros: Filosofía de la Universidad y conflicto de racionalidades. Colihue, Buenos Aires 2001.

- Wainerman,C.; Sautu, R.: La Trastienda de la Investigación, Bs.As., Ediciones Lumiere, 2001

\section{Bibliografía de la WEB}

— http://www.observatoriocts.org/files/.../formacion_de_postgrado. Formación de posgrado en América Latina - FINAL.pmd 28-10-2010

- http://repositorio.educacion.gov.ar:8080/dspace/bitstream/handle/123456789/109591 Anuario_de_Estadisticas_Universitarias_2010.pdf?sequen$\mathrm{ce}=1$

— http://www.coneau.gov.ar/CONEAU/index.php?option=com_content\&view=article\&id=92:normas-especificas-para-la-evaluacion-de-carreras-nuevas

- http://www.unrc.edu.ar/publicar/cde/05/Follari.htm

— http://www.comunicación y medios.com./Reflexión/Teorías /fin de siglo.htm. García Canclini: Comunicación fin de siglo. ¿Para dónde va nuestra investigación?

— http://www.scielo.org.ve/scieloOrg/php/Valarino, E. (2000/1997). Tesis a Tiempo. (2a. ed.). Barcelona, España: Grupo Editorial Carnero.

\section{Ilustraciones}

— Ilustración 1, p.2: http://www.escombrismo.blogspot.com.ar2012/03/01

— Ilustración 1, p.3: http://www.lunacreciente.blogspot.com.ar2006/12/01

- Ilustración 1, p. 6: http://www.doctorandos.com/agradecimientos-de-tesis $2012 / 14 / 12$

—Ilustración 1, p.11://http://www.phdcomics.com/comics/archive 2009/04/29 


\title{
La tesis imposible
}

\author{
Horacio Potel ${ }^{1}$
}

\begin{abstract}
Tras algunas observaciones amistosas sobre la conferencia que yo acababa de pronunciar, Jean Hyppolite añadía: «Aparte eso, verdaderamente no veo adónde va usted». Creo haberle contestado poco más o menos lo siguiente: «Si viese claramente, y por anticipado, adónde voy, creo realmente que no daría un paso más para llegar allí». Quizás pensé entonces que saber adónde se va puede indudablemente ayudar a orientarse en el pensamiento, pero no ha hecho jamás dar un paso, todo lo contrario. ¿Para qué ir adonde se sabe que se va y adonde se sabe uno destinado a llegar?
\end{abstract}

Jacques Derrida, El tiempo de una tesis

\section{Introducción}

En estas frases de Jacques Derrida, pronunciadas en su defensa de tesis, están expuestos los temas más importantes a la hora de mostrar la imposibilidad de la Tesis. La tesis es imposible, es imposible como acontecimiento, es decir como la llegada de lo otro, como invención del otro. Ya que para Derrida, una llegada programada, un acontecimiento programado, no es un acontecimiento. Es la repetición de lo mismo, la tesis programada, el programa de tesis es el filtro para impedir la llegada de lo nuevo. Pero la Tesis nunca llega.

\section{Trataremos de explicarlo mejor:}

Decir lo que la deconstrucción sea, es, claro, traicionarla, congelarla, asesinarla. Esto, desde ya, por supuesto, pasa con cualquier cosa: todo encasillamiento, encierra, encapsula, reduce, ya que supone una tarea de selección, de edición, en la que la totalidad e individualidad de "la cosa" -si es que algo así existe- necesariamente se pierde. Ahora bien, cuando la cosa a cercar, a limitar con un aparato conceptual, es la deconstrucción misma, la cuestión se vuelve paradójica: ya que la deconstrucción se empecina en mostrar que las cosas no tienen ni un significado definible ni una misión determinada. Que cada vez que se intenta definir una cosa, encerrarla en un casillero, la cosa misma se escapa y se escapa, porque lo que ocurre con las cosas no es algo que tenga que ver con el presente: el significado, la misión de las cosas, lo que ocurre con las cosas, siempre está por venir. La deconstrucción es una apasionada, amorosa, afirmación de lo por-venir. Esto quiere decir que lo que se afirma no es lo que es, lo que está, lo dado, lo presente, 1 Horacio Potel es Arquitecto y Licenciado en Filosofía por la Universidad de Buenos Aires. Se encuentra terminando su Tesis de Doctorado en Filosofía en la Universidad Nacional de Lanús. Es Profesor de Ética en la misma universidad. Ha publicado diversos textos, en la Argentina y en el exterior, donde trabaja algunos de los conceptos claves de Jacques Derrida, como herencia, diseminación, archivo, survie. 


\section{0/ Perspectivas Metodológicas /19/Vol. II /Año 2017}

eso que los enemigos de la esperanza suelen llamar "Lo Real". Lo que se afirma, por el contrario es lo por venir, y no lo por venir que algún día llegará, al fin de algún camino o como resultado de algún programa, de tesis por ejemplo. Lo por venir está siempre por llegar, lo que quiere decir que jamás se consumará en presente alguno. Lo por venir es lo que no se ve en ningún horizonte, lo monstruoso, lo imprevisible más allá del horizonte de lo mismo. La deconstrucción es una afirmación infinita, afirmación sin descanso ni meta, ni tesis final, de lo que está en construcción deconstruyéndose. La afirmación de lo otro que viene, la invención de lo otro, la promesa siempre renovada. Promesa originaria, pues si estoy constituido por lo otro, porque no soy el primero porque no hay primero, es la interpelación de lo otro lo primero, antes que cualquier pregunta, antes que cualquier teoría, antes que cualquier filosofía está lo otro, al que empiezo, antes de empezar y de ser, respondiendo: sí, sí.

Pero esto, el encasillamiento, es de alguna manera lo que nos pide el aparato de control académico, cuando nos exige tesis y artículos, es decir, tener por lo menos UNA posición firme que delimite y encierre en su cierre a la tesis, o a una tesis sobre Derrida. El cual, por cierto, también en ocasión de su defensa de tesis, decía: "La idea misma de presentación tética, de lógica posicional u oposicional, la idea de posición, [...] era una de las piezas esenciales del sistema sometido a un cuestionamiento deconstructor". ${ }^{2}$ Para Derrida "resumir o presentar conclusiones téticas" es imposible. Como ya dice en uno de sus trabajos juveniles: "Una de las tesis -hay más de una- inscritas en la diseminación es justamente la imposibilidad de reducir un texto en cuanto tal a sus efectos de sentido, de contenido, de tesis o de tema". ${ }^{3}$ Pareciera, entonces que una tesis, una posición sobre la deconstrucción, es una tarea condenada al fracaso, una tarea imposible. Pero he aquí que la deconstrucción es una incesante espera de lo imposible es decir de aquello cuya posibilidad está sostenida por su imposibilidad. Pues bien, como la lealtad pura es imposible, vamos a empezar con la traición impura, en nombre de una fidelidad infiel, para poder explicar tantas imposibilidades. Entonces lo mejor será que comencemos. Lo que no borra el dolor, ni el sentimiento de la traición; traición porque es imposible terminar, porque el contexto está siempre abierto, porque siempre está abierto el porvenir, y entonces jamás se podrá pronunciar la última palabra. Pero ese es, justamente, desde siempre el precio a pagar si se dice algo, la imposibilidad de decirlo todo, la certeza de estar en la incerteza, la impureza del perjurio, de la infidelidad, de la traición. Y a la vez, otra vez, a la vez, la traición, la infidelidad y el perjurio, es lo único que pude conservar el secreto, y el secreto es justamente lo que permite que nunca termine una tesis, un texto, una vida. Que nunca se cierre en una totalidad, que nunca baje a su tumba. Nada ni nadie termina nada ni nadie. Ni la muerte termina. Y entonces de nuevo lo único que se puede hacer es comenzar. Comenzar no para concluir nada, comenzar para inscribir la inconclusión, comenzar para sumar un trazo, un resto , algo que comienza ya como ruina y ceniza, y que justamente solo en tanto resto y ceniza abre el por-venir.

Comparemos la compulsión de tesis, esa obsesión por tener una posición, una estabilidad, un pensamiento original, con por ejemplo la avaricia.

2 Derrida, J., El tiempo de una tesis. Deconstrucción e implicaciones conceptuales, Proyecto A Ediciones, Barcelona, 1997, pp. 11-22. Texto presentado en la sesión de defensa de la tesis, basada en las obras publicadas de Derrida, que tuvo lugar en la Universidad de la Sorbonne, el 2 de junio de 1980, ante un tribunal formado por los profesores Aubenque, De Gandillac, Desanti, Joly, Lascault y Lévinas.

3 Derrida, J. «Hors libre», en La Diseminación, trad., J. Arancibia (mod.), Madrid, Fundamentos, 1997, p. 13. 
Afán de poseer para atesorar. Tal es una de las definiciones más usuales que suelen dar los diccionarios para hablar de la avaricia. Parecería entonces que el avaro es el incapaz de dar. Encerrado en sí mismo el avaro construiría una pared, un cerco, un búnker, una cripta en donde encerrar sus tesoros, en donde encerrar su sí mismo avaro, parecería... Pero, ahora bien, estos tesoros que atesora el avaro: ¿De dónde vienen? ¿De dónde sale eso que guarda con tanto afán?

Si el avaro no es el Dios de la ontoteología -hipótesis que hoy no abordaremos- es decir, si el avaro no es causa sui, inegendrado, completo, lleno, perfecto y puro, entonces esos tesoros deben haber sido obtenidos de otro lado que no sea la cripta, el búnker, el encierro del avaro; deben de proceder por tanto de allende las fronteras de su mismidad.

El avaro necesita, pues, de lo que está afuera de su encierro, más allá de sus fronteras, para poder ser así avaro, necesita de eso otro que no tiene, y lo necesita desde el primer momento. No es que sólo lo necesita para acrecentar su tesoro, necesita de lo otro para poder ser aún antes de ser avaro, necesita de lo que no tiene para tener, atesorar y no dar, o al menos intentar no dar. Necesita de lo otro, de lo que no es él para ser él, su avaricia necesita apropiarse de eso que no le pertenece, debe afanarse para que entre algo de lo otro en su más profunda mismidad para poder aspirar a ser él mismo. Es decir que el avaro está habitado desde siempre por lo que no le pertenece, por lo que él no es, por otro que es a la vez su riqueza y la segura fuente de su ruina.

La avaricia perfecta, la avaricia pura no puede entonces nunca constituirse, porque desde el primer momento está habitada por lo que no es, por un exceso que es justamente su contario pero al que está ligada de manera irreductible. Con lo cual ya se sentenció el fracaso de la avaricia. El avaro necesita tomar, apropiarse del otro, pero esa apropiación nunca puede ser completa, es necesario que la apropiación falle, que reste siempre algo de alteridad, para que el mecanismo de la avaricia pueda seguir funcionando.

La avaricia pura, si la hubiera, sería el cierre total en la totalidad del todo. El avaro se convertiría en el UNO, en el TODO, privado de toda alteridad, de toda diferencia, inmóvil a falta de espacio, incrustado en el instante sin tiempo de una eternidad eternamente presente, eternamente igual, eternamente la misma. El Todo es lo que no tiene exceso, el Todo no da. El avaro, ahogado, oprimido en su sí mismo, ya no sería ni siquiera un avaro; no tendría nombre, porque sería todos los nombres o la falta de todos ellos, ya que no hay nada que nombrar en el Todo. Avaro sin afán posible, ya que no podría apropiarse de ninguna alteridad, sin nada que atesorar porque no hay nada ni nadie que le pueda quitar ni dar nada. Porque la avaricia perfecta, o la totalización del Todo, sería a la vez que la muerte del avaro, la muerte del afuera, la muerte del otro -por el cual el avaro era-; el otro dejaría de ser otro para ser el mismo, o lo que es lo mismo, el mismo dejaría de ser el mismo para pasar a ser el otro, con lo cual ya no habría ni mismo ni otro: sólo Todo. Ni avaro ni tesoro: Todo.

Si pensamos el origen a la manera tradicional como origen simple, pues entonces no hay origen, ya que del uno como hemos visto, no sale nada. El Uno-Todo no da nada. Si 


\section{2/ Perspectivas Metodológicas /19/Vol. II / Año 2017}

el origen está contaminado por la alteridad entonces, como dice Derrida en su artículo sobre Freud: "Es el no-origen lo que es originario". Si en el origen están el mismo y el otro coimplicados, no puede haber primero, porque el primero necesita del segundo, para poder ser primero, pero entonces el segundo es la condición de posibilidad del primero, el retardo del segundo es lo que le permite al primero ser primero, pero entonces no lo es, como tampoco, claro está, y por los mismos motivos, no puede ser primero el segundo. Como decíamos hace un segundo si la plenitud, si la identidad no está dada, es necesario que algo supla la falta y este suplemento es originario. La repetición es originaria.

El otro entonces me antecede, me sucede, me constituye, me destituye, me acosa, me inventa. Y esta relación con lo otro es para Derrida, como sabemos, la Justicia. Y es la justicia la que nos impone el deber de abrir las fronteras, de romper con la avaricia en una hospitalidad incondicional ante la llegada del otro en cuanto otro. Como otro absoluto. Este deber (que lo otro siga siendo otro) es el que determina las condiciones para que sea posible lo que Derrida llama Acontecimiento, es decir la llegada del por-venir. Entonces para que las cosas ocurran, para que sigan dándose eventos, es preciso que lo otro reste, resista como otro. La paradoja aquí es que la llegada del acontecimiento, la hospitalidad incondicional, el don -de ser posibles- de presentarse algún día a la luz de la presencia terminarían con todo otro, como también vimos hace un instante. La llegada del Acontecimiento, si fuera posible, sería la detención de todo, la catástrofe última, pero tal cosa es imposible. No hay principio y no hay fin. El UNO es la cancelación de la sobrevida, que necesita siempre para darse del juego, del resto, del fracaso en la apropiación, del fracaso de la avaricia de una cierta indemnidad. El UNO es la Tesis, el cierre, el sentido, lo que por suerte nunca puede hacerse presente asegurando así el por-venir. Una cierta indemnidad de la alteridad absoluta, lo que Derrida llama a veces: lo indeconstruible, es decir el resto siempre resta. Es lo que siempre escapa en un proceso de apropiación, académico, por ejemplo.

La lectura de Husserl llevo a Derrida a sostener que no se puede acceder a las cosas mismas, es decir a una conciencia pura y a un objeto no constituido, mediado y diferido. No es extrańo que desde este planteo se piense el acceso a una alteridad radical como imposible. Y es que para Derrida, no puede haber un afuera puro limitando con un adentro puro: el afuera esta dentro del adentro, lo otro habita en el mismo, el mismo está en lo otro y el adentro está contaminado por el afuera, desde siempre. Exceder el discurso de la filosofía, que siempre se ha ceñido aasegurar el dominio del límite, no puede significar dar un paso fuera de la clausura. Pensar «Una clausura de la representación cuya forma no podía ser ya lineal, indivisible, circular, enciclopédica o totalizante» ${ }^{4}$ es pensar la supervivencia de los envíos. Porque la presencia es imposible, la re-presentación está clausurada, esto quiere decir que "no hay fuera de texto", ${ }^{5}$ si la survie es "todo aquello con lo que está entretejido de arriba abajo, el tejido de la existencia", no hay fuera de la sobrevida, lo que no quiere decir que la sobrevida o mejor las sobrevidas sean inmortales, no sólo por la finitud de la huella, como ahora veremos, si no sobre todo porque la sur-

4 «Envío», op.cit.

5 Derrida, J.: De la gramatología, trad. de O. del Barco y C. Ceretti, México D.F., Siglo XXI, 1998, p. 202. Cfr. p. 203: «Dentro de lo que se llama la vida real [...] nunca ha habido otra cosa que escritura; nunca ha habido otra cosa que suplementos, significaciones substitutivas que no han podido surgir sino dentro de una cadena de reenvíos diferenciales». 

vie jamás termina de constituirse: un texto, cualquier texto, oculta siempre su sentido, porque éste está siempre por venir, lo que también quiere decir que nunca puede llegar a un destino final, salvo que la huella desaparezca y que su tejido se pierda sin que nadie sepa nunca que se perdió, porque nunca se constituyó, nunca se encontró, eso perdido.

Si no hay presencia plena, no puede haber un "presente" el tiempo mismo no puede hacerse presente. No hay algo así como un "presente viviente" y no sólo por la imposibilidad de la presencia de constituirse como tal, sino porque como acabamos de ver: que la presencia nunca pueda llegar a estar presente hace que ésta deba desde siempre ya repetirse, re-presentarse en un suplemento, en un artefacto técnico. La vida, entonces, es habitada por la muerte, o la muerte es habitada por la vida desde siempre ya. Esta coimplicación originaria es la survie. Con lo cual no solo no podemos decir que seamos "vivos" o "muertos": somos fantasmas, sobrevivientes asediados por la vida y por la muerte; sino que también, y también esto es otra forma de decir lo mismo, no podemos decir que somos humanos o vivientes en general opuestos a máquinas; ${ }^{6}$ el suplemento de origen implica que la máquina está también desde siempre ya en la vida, con lo cual esta no puede pretender nunca estar desnuda o pura y ajena a la repetición, al retraso, a la muerte. Somos cyborg. Que la "vida" esté desde siempre coimplicada con la "muerte", significa también que la "vida" está desde siempre coimplicada con lo no maquinal, con el acontecimiento.

Que la survie no pueda empezar ni terminar no quiere decir que la survie sea infinita, la survie es indefinida. Toda huella es finita, toda huella debe poder perderse, desaparecer, no hay presencia sin huella ni huella sin muerte. "Una huella imborrable no es una huella, es una presencia plena, una sustancia inmóvil e incorruptible, un hijo de Dios, un signo de la parousíay no una semilla, es decir, un germen mortal". ${ }^{7}$

Lo que es imposible es la Muerte Absoluta, que de darse sería a la vez la Vida Absoluta. La conclusión de la Tesis, la presentificación del Mesías cerraría, envolvería en el círculo de lo mismo al tiempo y a la historia, sería el fin de la promesa y por tanto el fin de la esperanza, el fin del deseo, el fin de la pasión, el fin del futuro, el fin de la vida, el fin de toda sobrevida. La incondicional llegada del otro, de ser posible, sería la muerte del otro convertido por este acto en el Mismo, privado de toda diferencia; La Muerte, que es también lo imposible. La promesa mesiánica es una promesa que se rompería si se cumpliera, la posibilidad del Mesías es su imposibilidad. Para mantener la esperanza es necesario romper con toda esperanza determinada. Y seguir jugándose por lo imposible.

El resto es la condición de posibilidad del acontecimiento y la filosofía de Derrida es una filosofía del acontecimiento, entendiendo por tal: la donación de lo otro, que en tanto otro no puede ser lo mismo, y en cuanto don no puede ser lo dado, lo que implica la improgramabilidad del acontecimiento.

6 Cfr. De la gramatología, op. cit., p. 15: "Aún suponiendo que la teoría de la cibernética pueda desprenderse de todos los conceptos metafísicos -hasta del concepto de alma, de vida, elección, memoria- que anteriormente han servido para oponer la maquina al hombre, tendrá que conservar [...] la noción de escritura, de huella, de grama o de grafema. Incluso antes de ser determinado como humano [...] o como a-humano, el grama -o el grafema- dará así el nombre al elemento. Elemento sin simplicidad". El subrayado es nuestro.

7 «Freud y la escena de la escritura» en La escritura y la diferencia, op. cit., p. 315. 
¿Puede un sujeto responder de sí? Para hacerlo debería saber todo sobre sí, debería tener un "yo" que acompañe todas "sus" representaciones, debería ser capaz de totalizarse bajo un solo y único nombre, pero esta identidad consigo mismo está permanencia calculable, este encierro, si fueran posibles, haría imposible todo acontecimiento, tornando la decisión algo accidental que no cambia nada, que no abre nada. Si el acontecimiento es lo que viene sin ser previsto, predeterminado, pronosticado, el acontecimiento de la decisión no me pertenece, es "lo otro en mí, que decide y desgarra" ${ }^{8}$ Si la decisión está en mi(y estamos viendo cuántas dificultades conlleva este mí) si se encuentra bajo misaber y mi poder, si la decisión es para mí posible, si es una decisión que yo puedo tomar, siendo entonces el paso al acto de mis posibles, pues entonces no decido nada. Al pasar quiero mencionar que nos encontramos nuevamente con lo imposible como condición de posibilidad, la posibilidad de la decisión está sostenida en su imposibilidad. La decisión debe ser entonces una decisión pasiva, la decisión del otro en mí, decisión inconsciente que sin embargo no me libra de ninguna responsabilidad, ni de ninguna libertad. Ya que hay por venir, el contexto está siempre abierto porque acontece, si el contexto siempre está abierto entonces nunca puede ser del todo determinable. Que no se pueda saber nunca todo sobre algo, garantiza que en cada caso, me encuentre ante la necesidad de decidir lo indecidible, que no esté obligado por un cálculo o un programa sino entregado a la locura del instante, porque como dice Kierkegaard "El instante de la decisión es una locura", locura que nos arroja al desgarramiento de tener que elegir sin ninguna seguridad. La decisión como imposible debe ser indecidible. "Indecidible es la experiencia de lo que siendo extranjero, heterogéneo con respecto al orden de lo calculable y de la regla, debe sin embargo -es de un deber de lo que hay que hablar- entregarse a la decisión imposible". ${ }^{9}$ Indecidible no tiene nada que ver con indecisión, ni con parálisis.Lo indecidible es la condición de la decisión, del acontecimiento.

Lo contrario de la indecidibilidad no es la decisión sino lo calculable, lo programable, lo formalizable, lo computable. En este sentido decidir algo decidido no es decidir nada, es nuevamente asegurar el círculo de lo mismo. Sin el riego de esta indeterminación no habría lugar para el deseo y por tanto tampoco para el porvenir. Es entonces, para Derrida, el momento de ser fiel-infiel a la herencia de Kant, siguiendo hasta el extremo su propia lógica: para Kant una acción moral no debe solamente ser "conforme al deber", sino que debe ser llevada a cabo "por deber", "por puro deber". Muy bien, dice Derrida, pero la cosa no termina aquí; si yo actúo por puro deber, es decir, porque debo, no puedo afirmar que mi acción sea moral: en primer lugar dicha acción está determinada por un saber: yo sé lo que se debe hacer, cuento con una regla o un programa, una receta que me dice qué es lo que debo hacer. Y por otro lado si actúo porque debo, si el motivo de mi acción es una deuda, mi acción consiste en cancelar dicha deuda, en cerrar el círculo económico de un intercambio comercial, quedándome entonces encerrado en una totalización, en una reapropiación, que el acontecimiento de la decisión debería desbordar. La moralidad pura debe exceder todos los cálculos conscientes o inconscientes, todos los propósitos, todos los proyectos de restitución o de reapropiación. La decisión debe permanecer indecidible, nunca puede

8 Derrida, J.: Políticas de la amistad, trad. De Patricio Peñalver y Paco Vidarte, Madrid, Trotta, 1998, p. 87.

9 Derrida, J.: «Del derecho a la justicia», en Fuerza de ley. El «fundamento místico de la autoridad», Madrid, Tecnos, 1997, p. 55. 
decirse de ella que está presente y que es justa. En efecto: o fue tomada sin ninguna regla y nada permite entonces decir que es justa, o fue tomada de acuerdo con una regla que nada garantiza o bien en el caso de que la regla garantizara la justicia de la decisión ya no se trataría de una decisión sino de un cálculo. Con lo cual el fantasma de lo indecidible acosa a toda decisión deconstruyendo toda seguridad de presencia, toda buena conciencia, la existencia misma de la decisión en cuanto tal. El deber de lo indecidible pone en evidencia lo engańoso de basar una ética en el sujeto: "Sin duda la subjetividad de un sujeto, ya, no decide nunca sobre nada: su identidad consigo y su permanencia calculable hacen de toda decisión un accidente que deja al sujeto indiferente. Una teoría del sujeto es incapaz de dar cuenta de la menor decisión. [...] lo otro en mí que decide y desgarra. La decisión pasiva, condición del acontecimiento, es siempre en mí, estructuralmente, otra decisión, una decisión desgarradora como decisión del otro. Del otro absoluto en mí, del otro como lo absoluto que decide de mí en mî". ${ }^{10}$

Habíamos pensado terminar acá este escrito, ya que es un texto que habla sobre la imposibilidad de la tesis, sobre como no se puede escribir nunca todo sobre nada. Un texto que habla sobre la imposibilidad del fin y la deriva indefinida del sentido no debería encontrar de pronto un sentido al final del texto. Pero para seguir con las indicaciones académicas -indicaciones que se presentan como sí de exigencias "neutrales" se tratara, llenas de "buena fe" y avaladas por la palabra "método", trataremos acá de dar cierre, fin, sentido, resumen, es decir, todas esas cosas que está tradición no cuestionada de la Tesis, da por sentado que se encuentran tras un largo camino, al final del mismo, en una lógica teleológica que nos cansamos de recusar pero en la cual seguimos escribiendo como si fuera lo mismo como si no importara, como si la escritura fuera sólo un vehículo tosco, una herramienta o un ornamento que no hace a la survie del texto. En definitiva escribimos tesis contra el logocentrismo pero escribimos metafísicamente, bajo la metafísica del logocentrismo: que piensa que un texto no vale por sí mismo, que la "IDEA" está siempre más allá del texto, más allá de su concreta escritura. Entonces tendremos que hacer como si todo lo escrito no hubiera servido de nada, como si todo lo que se dijo sobre la imposibilidad del cierre y el fin, pudiera ser envuelto por una forma de escribir teleológica. El logocentrismo metafísico es el privilegio dado a la palabra viva, sobre la escritura técnica. Una ideología que para ocultar el valor de las normas, de los rituales burocráticos, de los formularios y las reglas de escritura, plantea el pensamiento como libre de toda estructura técnica, de toda pro-tesis. Así el plan de tesis, o el abstract, por ejemplo, deben decir lo que dirá la tesis antes de ser escrita y como la tesis comprende o debe comprender en sí misma la totalidad del sentido: el plan que planea la tesis es la mejor tesis; con lo que no se entiende la necesidad de escribirla. Según esta narrativa sabemos antes de escribir lo que vamos a decir, lo sometemos a la escritura concebida como un proceso de despliegue de esa totalidad que es la IDEA que vamos a manifestar para por fin terminar con el mejor resumen posible de esa IDEA que siempre, según este relato va a estar mejor en nuestro pensamiento que sometida a las reglas del aparato técnico de la escritura que justamente por estar hundido en lo técnico no puede jamás expresar en "verdad", en carne y hueso espirituales, el éter de las ideas.

10 Derrida, J., Políticas de la amistad, trad. De Patricio Peñalver y Paco Vidarte, Madrid, Trotta, 1998, pp. 86. 
El programa, el método es siempre protección contra el acontecimiento. Un programa perfecto programa perfectamente todo. Lo por hacer está ya hecho antes de hacerse, con lo cual no está por hacerse sino que se ha hecho. Los métodos académicos son programas burocráticos para reproducir las condiciones de la vida académica, sus jerarquías, sus pequeños privilegios.

Con esta teleología del sentido último hace pareja el mito del "autor", nosotros no comulgamos con la fe de esta creencia, no somos Dios, no hay nada de original en lo que escribimos, ya que no hay origen. La escritura se independiza del escritor desde el primer momento, escrita, ya no necesita de él, vive sin él. Se independiza desde siempre de su supuesto autor para devenir máquina productora, diseminante del sentido, separada de la conciencia y por tanto de las intenciones y de la plenitud del querer-decir de éste, y de cualquier otro que quiera erigirse en el dueño, o el restaurador de un supuesto sentido originario.

La unidad del texto, esta unidad que venimos cuestionando, asegurada supuestamente por la firma de un autor, necesita de la contra-firma del otro. Pero como todo otro, todo destinatario determinado, todo acto de lectura, se encuentra marcado por la misma muerte, la lectura no tiene fin, está siempre por venir, y por venir del otro. El cierre del sentido se vuelve así imposible. La escritura no pertenece al reino de la presencia, por el contrario es la condición de posibilidad de ésta. Al no pertenecer a la presencia no corresponde preguntarse por la esencia de la escritura, sino por la forma en que la escritura se inscribe, se marca, se traza y lo hace repitiendo, repitiéndose, iterándose. Diseminándose en una multiplicidad irreductible, la ausencia rompe el límite del texto, con lo cual queda impedido su totalización y su cierre, nunca acaba el querer-decir, la firma siempre está abierta a una nueva contrafirma. La herencia no termina. ¿'Terminamos? con Derrida:

"La fuerza reproductiva de la autoridad se conforma más fácilmente a declaraciones o tesis sedicentes revolucionarias en su contenido codificado con tal que se respeten los ritos de legitimación, la retórica y la simbólica institucional que desactiva y neutraliza todo lo que viene de otra parte. Lo irrecibible es aquello que, por debajo de las posiciones o las tesis viene a trastornar ese contrato profundo, el orden de esas normas, y que lo hace ya en la forma del trabajo, de la enseñanza o de la escritura”.11

\section{Bibliografía}

- Derrida, J.: «Del derecho a la justicia», en Fuerza de ley. El «fundamento místico de la autoridad», Madrid, Tecnos, 1997.

- Derrida, Políticas de la amistad, trad. De Patricio Peñalver y Paco Vidarte, Madrid, Trotta, 1998.

- Derrida, J.: De la gramatología, trad. de O. del Barco y C. Ceretti, México D.F., Siglo XXI, 1998.

- Derrida, J., El tiempo de una tesis. Deconstrucción e implicaciones conceptuales, Proyecto A Ediciones, Barcelona, 1997.

- Derrida, J. «Hors libre», en La Diseminación, trad., J. Arancibia (mod.), Madrid, Fundamentos, 1997

11 Derrida, J.: "El tiempo de una tesis: puntuaciones", op.cit, pp. 18. 


\title{
¿Cómo investigar un problema que involucra a distintas disciplinas? (propuestas para la investigación en bioética)
}

\author{
Cecilia Pourrieux ${ }^{1}$
}

\section{Introducción}

Numerosas son las transformaciones que ha experimentado el conocimiento en un sentido general, desde la clásica división griega del saber entre teórico y práctico. Los avances científicos -especialmente en el plano de las ciencias de la vida- se presentan a la reflexión en forma vertiginosa con problemas inéditos sobre los cuales es necesario debatir. La dinámica entre soluciones y problemas se ha exacerbado. Lo que se presenta en un momento como respuesta a un conflicto, genera en lo inmediato la aparición simultánea de nuevos problemas, distintos y urgentes.

Caracterizar el desarrollo de la ciencia para comprender el momento actual es algo que excede el objetivo de este trabajo. Nuestra meta se dirige a indagar quien debe abordar la investigación de algún campo del saber actual, cualquiera sea este, que a su vez es atravesado por otros tantos campos disciplinares. En este sentido, la integración y el debate entre diferentes tipos de saber son el sello distintivo de los tiempos actuales. La pregunta que se le plantea al investigador es ¿cómo investigar un problema que involucra a distintas disciplinas? Proponemos abordar este interrogante tomando a la investigación en bioética como paradigma investigativo. Esta elección responde al hecho de que ella misma es una disciplina relativamente nueva en la cual convergen distintos saberes. En sus debates intervienen no sólo perspectivas legales, científicas, sociales, morales, políticas sino otras tantas más. La interrelación entre ellas implica procesos complejos en la toma de decisiones respecto a nuevos conflictos, en donde se cuestionan normas y valores socialmente legitimados. Este diálogo entre múltiples disciplinas, involucra diferentes aspectos y en función de ellos es que vamos a mostrar dos posibles enfoques para analizar el problema:

1 Cecilia Pourrieux es egresada, docente e investigadora de la Universidad Nacional de Tucumán hasta el año 2008. Actualmente se desempeña como docente e investigadora en la Universidad Nacional de Lanús, en el Área Ética. Diplomada en estudios superiores en bioética, FLACSO, 2013. Último trabajo publicado: "Reproducción asistida: una mirada desde la bioética" del libro: Responsabilidad Profesional de los Médicos. Ética, Bioética y Jurídica. Civil y Penal. Tomo Il. Coordinador Dr. Oscar Ernesto Garay. Editorial, Edit. La Ley, Bs As, 2014. 
1) Epistemológico.

2) Histórico.

Ambos enfoques son complementarios y se presentan interconectados en la investigación. El abordaje histórico permite ir reconstruyendo el objeto de análisis para delimitar su ubicación en el plano epistemológico, en donde encontraremos una caracterización de la ciencia, alejada de una concepción aséptica o neutral del conocimiento. En las conclusiones se expondrá el carácter práctico y contextual de las investigaciones y la necesidad de introducir el debate entre las diferentes disciplinas.

\section{¿Disciplinar, interdisciplinar, transdisciplinar o multidisciplinar?}

De la modernidad a la actualidad, hay un proceso de especialización cada vez mayor que bien puede ser ejemplificado con la afirmación cartesiana de: "dividir cada una de las dificultades que examinare en tantas partes como fuese posible y en cuantas requiriese su mejor solución"(Descartes, 1980). Esta regla es un claro ejemplo del inicio de un proceso de división del conocimiento, que está a la base de toda disciplina y del problema de la interdisciplinariedad, (Peñuela Velásquez, 2005). Esto supone el siguiente obstáculo: a medida que se profundiza en el desarrollo y la comprensión de cada una de las partes, se aleja cada vez más de la comprensión del fenómeno como un todo. Este pareciera que fue el desarrollo del saber científico, ligado al concepto de disciplina, en donde paulatinamente, fue considerada como sinónimo de especialización. El debate de estos últimos años considera que esta fragmentación debe ser superada, para integrar todo aquello que una vez fue separado, pasando de lo disciplinar a lo interdisciplinario.

La cuestión central es la siguiente: ¿cómo se integran los distintos saberes frente a un problema inédito que se eleva sobre los pilares de aquellos campos clásicos del saber? Es así que surge el debate en torno a como se define la intersección de estos nuevos saberes: ¿son interdisciplinarios, transdisciplinares o multidisciplinares? Claramente la pregunta se origina en el terreno de la praxis y para ilustrarlo apelaremos a las distinciones que realiza Avenai Garrafa (2005) desde el ámbito de la bioética. Destaca en primer lugar que el error más frecuente es confundir suma con integración de disciplinas. Señala como primera medida que conviene distinguir la modalidad que puede tener en cada caso, esta integración. Un común denominador a la distinción entre multidisciplinariedad, interdisciplinariedad y transdisciplinariedad, es que todas tienden a rebasar los límites tradicionales de una sola disciplina, pero su delimitación parte claramente de objetivos distintos. Cuando un problema que tradicionalmente era abordado por una disciplina, trasciende los límites de ella y es analizado desde otras perspectivas, estamos en el terreno de la pluridisciplinariedad o-según su denominación actual- multidisciplinariedad. En este modo de integración, en lo que concierne a la bioética, el debate se enriquece con diferentes perspectivas, sin dejar de pertenecer al terreno médico. Un claro ejemplo de ello, puede ser la eutanasia, que en los debates bioéticos escucha las voces del derecho, la ética y no solo de la medicina. Pero, cuando el método de una disciplina se transfiere a otras tantas, estamos en el terreno de la interdisciplinariedad. Siempre en el terreno de la práctica, existen grados de aplicación. Garrafa ilustra estos grados de la siguiente manera: 
Cecilia Pourrieux / ¿Cómo investigar un problema que involucra a [...]/129

Por ejemplo, los métodos de la ingeniería genética (biología) transferidos a la medicina o al derecho, llevan al surgimiento de nuevas referencias con relación a las comprobaciones de la paternidad. Un segundo "grado epistemológico": la transferencia de métodos de la lógica dialéctica para la salud pública produce análisis diferenciados en la epistemología del derecho (justicia social). Y un tercer "grado de generación de nuevas disciplinas", (Garrafa, 2005, p.70) cuando varios conocimientos se juntan para crear otra disciplina, cuyo ejemplo está como que cortado al talle para la bioética.

La transdisciplinariedad, siguiendo al mismo autor, tiene como finalidad la unidad del conocimiento, esto es, comprender la realidad en su totalidad. De ahí su distinción con las dos modalidades anteriores, que no trascienden el ámbito disciplinar, a diferencia de ésta última que tiene como pretensión, de acuerdo al prefijo "trans", ir 'más allá de este campo, atravesar lo disciplinar, ubicarse 'entre ellas'. Es por esto mismo que muchos autores consideran que este modelo, es el adecuado para caracterizar la actividad de la bioética en la medida que trascendiendo los distintos saberes, sin reducir sus problemas a una sola disciplina, habita entre los intersticios conceptuales problematizando las distintas respuestas que brinda cada saber. Esta modalidad quizás sea difícil de concebir para una mentalidad forjada en los parámetros modernos en donde cada objeto está determinado por un campo del saber. Pero aquello que aparece difícil en el terreno de la especulación, en el ámbito de la praxis, aparece en forma necesaria y urgente. El mejor ejemplo de ello es lo que acontece en la bioética. En donde, antes que disputarse un objeto de conocimiento, el problema desborda los límites de lo conceptual. Es concreto. Necesita hundir sus raíces en la realidad porque en su resolución no están comprometidas categorías especulativas sino vidas humanas, la salud y la enfermedad, la posibilidad o no de una cura. Y en este terreno, urgen las soluciones. Esta necesidad, no acontece sólo en el ámbito de la bioética, sino en cada debate que pone en juego un curso de acción. Es por esto que para examinar estas cuestiones, se hace necesario examinar la historia y el contexto en el cual aparecen los problemas y se plantean las soluciones.

\section{De los principios al contexto}

Todo lo que mueve a los hombres tiene que pasar necesariamente por sus cabezas; pero la forma que adopte dentro de ellas depende en mucho de las circunstancias.

(Engel, 1975, p. 55)

La especie humana, desde siempre, se abocó a la tarea de comprender todo lo que existe. Pero no al modo de una pregunta abstracta, sino como una forma de resolver problemas concretos que le permitieran sobrevivir en este mundo. Numerosas son las teorías epistemológicas que giran en torno al debate de la dinámica actual del conocimiento. Un ejemplo de ello, es Barrow que en su libro Teoría del todo intenta explicitar el alcance y las posibilidades de encontrar una ley que pueda dar detalle del origen y la evolución, no sólo de este mundo, sino del universo todo.(Rieznik, 2005) El reduccionismo, por el contrario, se ubica en las antípodas de esta perspectiva y consiste en el intento de analizar las partes de un fenómeno determinado con la intención posterior de repro- 


\section{0/ Perspectivas Metodológicas /19/Vol. II /Año 2017}

ducir el conjunto. Las posiciones críticas al reduccionismo, señalan que el conocimiento científico no avanzó de esta manera, sino por el contrario, la historia nos demuestra que su desarrollo fue a través de la acción vinculante e integradora entre las diferentes áreas del saber. El esfuerzo metodológico apunta a investigar no sólo a cada elemento sino también los vasos comunicantes que existen entre ellos para poder abordar la realidad como una totalidad orgánica, (Rieznik, 2005). En el apartado anterior, además vimos que por el desarrollo mismo de los problemas, es necesario superar esta fragmentación del conocimiento. Los conflictos actuales, así lo demandan, dado que asistimos a un desarrollo como nunca antes se vio, de las capacidades humanas en su intento por entender y transformar la naturaleza. Y en ese esfuerzo los problemas con los que se encuentra el investigador son reales. En este apartado intentaremos demostrar la integración en una totalidad, del avance tecno-científico con el contexto social, económico, cultural y político. Lo primero en señalar será el carácter histórico de estos avances. En otras palabras, son construcciones humanas que acontecen a lo largo del tiempo. De ahí la necesidad de aproximarnos a ellas en términos de proceso, o sea como una materia sujeta a desarrollo histórico. Esta es justamente la base del materialismo que en la delimitación con el idealismo considera que la historia se desenvuelve en distintas fases sucesivas legitimadas en una época determinada y que, con el transcurso del devenir, indefectiblemente y por la misma dinámica de lo real, será reemplazada por formas nuevas:

[...] la gran idea cardinal de que el mundo no puede concebirse como un conjunto de objetos terminados sino como un conjunto de procesos en el que las cosas parecen estables, al igual que sus reflejos mentales en nuestras cabezas, los conceptos, pasan por un cambio ininterrumpido, por un proceso de devenir y desaparecer (Rieznik, 2005, p. 138).

Este punto de vista, cabe aclarar, no implica un determinismo en el cual el hombre es una hoja al viento llevada por fuerzas ajenas a él, ni una concepción mecanicista en la cual todo se resuelve en base al factor económico, puesto que la dinámica del conocimiento solo puede ser entendida poniendo en el centro a la acción humana, como motor y por lo tanto al hombre como agente de la historia.

Otro factor a tener en cuenta es que las investigaciones bio-tecno-científicas no se desenvuelven en un escenario ideal, sino en grupos sociales en los cuales conviven múltiples variables políticas y culturales, que además están atravesados por diferentes intereses económicos. Esto último merece una observación más detenida dado que es un problema que reviste distintos aspectos. En un sistema político y social en el cual las regulaciones parecieran regirse en base al valor del mercado ¿el conocimiento sale indemne de las generales de esta ley? Si bien desde hace ya tiempo que la neutralidad del conocimiento científico ha sido legítimamente cuestionada, importa ver qué papel desarrolla el investigador, en este marco en el cual conviven laboratorios e intereses empresariales, investigación y mercado. De ahí, la necesidad de contextualizar cada debate. En ese sentido y retomando como ejemplo a la bioética, vemos que ésta tiene la característica de introducir elementos polémicos que exigen ser debatidos en la sociedad.

Veamos brevemente los criterios con los que estos debates se desenvolvieron en la historia de esta disciplina. Por ejemplo: la teoría de los principios, en tanto fundamentación 
Cecilia Pourrieux / ¿Cómo investigar un problema que involucra a [...]/131 moral para la bioética, fue enunciada en 1979 por Tom Beauchamp y James Childress en su libro Principios de Ética Biomédica. Su predecesor fue el Informe Belmont producido por la Comisión Nacional para la Protección de Sujetos Humanos en la Investigación Biomédica $y$ de la Conducta, creada por el Congreso de los Estados Unidos en 1974. El objetivo era identificar los principios éticos básicos subyacentes en la conducta de las investigaciones y servir para desarrollar pautas y regulaciones administrativas (U.S.Congress, 1978). Esa primera comisión nacional de bioética fue propuesta en 1973 ante la fuerte tensión política de los defensores de los derechos civiles que reclamaban en torno a investigaciones realizadas en ese momento. En el libro de Beauchamp y Childress los principios serían cuatro: beneficencia, no maleficencia, autonomía y justicia. (Tealdi, 2005) Esta teoría de los principios, desempeñó un rol central en cada uno de los debates desarrollados en el seno de la bioética. Casi dos décadas después, estalla el escándalo por las investigaciones para reducir la transmisión perinatal del HIV, en donde se denuncia el tratamiento con placebo (aunque ya existía tratamiento para el HIV) de un grupo de control en África y República Dominicana. Los patrocinantes eran institutos de Estados Unidos, los cuales argumentaban en su defensa que "el no tratamiento" era el estándar local (Tealdi, 2005).

Desafortunadamente, ejemplos recientes como este abundan. La polémica que se desarrolla actualmente en torno a la ética de la investigación tiene este eje: la industria farmacológica, utiliza las investigaciones multicéntricas, en distintos países de América latina en especial, en las cuales busca la manera de acrecentar sus ganancias investigando en un marco regulatorio que les permite evadir la discusión en torno a los derechos humanos básicos. Vulnerando no solo los derechos de los sujetos de investigación sino de la accesibilidad de la población toda a esos medicamentos.

Tomando como ejemplo el debate en la bioética, la primera conclusión a la que arribamos es la siguiente: el debate en torno a la prevalencia de unos principios sobre otros, tal como ocurrió en la ética de la investigación, nos aleja de la realidad. Mientras tanto, los hechos son más que elocuentes: sujetos de investigación "usados" en países pobres para medicamentos que serán utilizados en países ricos; muertes maternas en ascenso por la práctica de aborto clandestino; uso privado con fines de comercialización en la investigación de distintas terapias génicas. En fin, los ejemplos abundan. Si acordamos que el objetivo de la investigación es el de no perder de vista los hechos y al mismo tiempo ubicarse en la posición de agente de los acontecimientos, urge entonces, buscar algunos criterios que contengan en sí la potencialidad de contextualizar el debate.

\section{Reflexiones finales}

Cuando se habla de contextualizar los problemas, se considera que es de la más urgente necesidad realizar un análisis en base a datos que provengan de la realidad social en cuestión. Para ilustrar esto, tomemos el caso en bioética de la polémica en torno a la política sanitaria aplicada a la salud reproductiva por un lado y la legalización del aborto por el otro. Estos problemas necesitan ser debatidos, por ejemplo, a la luz de las estadísticas de muerte materna, de embarazos adolescentes, etc. Estas variables son reales y permiten dirigir la polémica en base a datos concretos. De acuerdo al apartado anterior, podemos extraer varias conclusiones. Tomando en cuenta el dinamismo inherente a lo 


\section{2/ Perspectivas Metodológicas /19/Vol. II /Año 2017}

real, las investigaciones, deben redefinirse constantemente no solo en lo que respecta a sus problemas, sino también en cuanto a su método y los obstáculos que debe sortear. Por ejemplo, conviene revisar cómo va transformándose el objetivo de las investigaciones tecno-científicas a la luz de la aparición de los nuevos productos y las modificaciones que en ellas se suceden a raíz de su comercialización. Puede afirmarse que hasta finales del siglo XIX existe todavía la figura del investigador que, inmerso en su laboratorio, arriba a conocimientos que le permiten avanzar sobre un tema específico. Esta relación entre sujeto-investigador-estado es justamente la que sufrirá los principales cambios a comienzos del siglo XX. Tomemos como ejemplo las transformaciones de los objetivos de la industria farmacológica a medida que comienzan a insertarse los nuevos medicamentos en el mercado. Así, el estado por un lado y las empresas privadas por el otro, verán en estos avances, la posibilidad estratégica de aplicarlos con fines comerciales. Para un estado, pasa a ser una cuestión política importante en la medida en que aparece una nueva posibilidad de progreso económico. EEUU es un claro ejemplo de ello. Otro obstáculo frecuente a la hora de investigar es el de confundir neutralidad valorativa de las ciencias con objetividad científica. En el primer caso y tomando el contexto en el que estas se desenvuelven, sobran argumentos para cuestionarlas. Sin embargo, se puede considerar la objetividad científica en tanto actividad social "con las limitaciones del momento histórico que manifiesta. Su contenido está ligado a la capacidad del hombre de comprender los procesos de los cuales forma parte y en los cuales interviene". (Rieznik, 2005) En base a esto, afirmamos que el escenario en el cual se desenvuelven las investigaciones científicas, no es el de un laboratorio aséptico. Un investigador, para no caer en una desvío distraccionista, debe incorporar en su análisis todos los elementos que permitan comprender que los debates actuales se desarrollan en un marco social y político atravesado de fuerzas antagónicas en constante tensión. Incorporando a los mismos la existencia de intereses económicos y políticos que podrían llevar a la distorsión de cualquier debate. Finalmente, apelaremos a la bioética para mostrar a modo de ejemplo, el vínculo existente entre los problemas que hunden sus raíces en la realidad, una disciplina (que puede ser cualquiera) y los objetivos que debe plantearse todo investigador:

No es casual que la bioética haya surgido en momentos en que la racionalidad, la ciencia, los estados, la democracia y la economía no cumplieron sus promesas. Las de que iba a haber salud para todos en el año 2000 por ejemplo, o las de constituir organismos internacionales que aseguraran la paz, o las de garantizar la alimentación a todos los hombres o poner al alcance de todo el que quisiera los instrumentos para el conocimiento y la creación. La tarea de la bioética es la de no olvidar esos compromisos que la humanidad tiene con sus componentes y recordarlos en todas las circunstancias en que estén en peligro, en todas las circunstancias en que la vida siga siendo el precio de la justicia. (Pfeiffer, 2002)

Para concluir, el conocimiento por el conocimiento mismo no debería ser concebido como una meta en la investigación. Más bien constituye un obstáculo que desvía la conciencia. Por el contrario, desde este espacio proponemos que cada investigador oriente su producción en base a un compromiso con la humanidad, no en un sentido abstracto, sino encarnada en la figura de cada hombre. 
Cecilia Pourrieux / ¿Cómo investigar un problema que involucra a [...]/133

\section{Bibliografía}

— Descartes, R., "Discurso del Método" en Obras escogidas. Editorial Charcas, Bs As, 1980.

- Peñuela Velásquez, A,: "La transdisciplinariedad. Más allá de los conceptos, la dialéctica" en Andamios v. 1 no 2, México, 2005. http://www.scielo.org.mx/scielo. php?pid=S1870-00632005000300003\&script=sci_arttext\#notas

- Garrafa, V.: "Multi-inter-transdisciplinariedad, complejidad y totalidad concreta en bioética" en: Estatuto epistemológico de la bioética. Garrafa, Kotow y Saada. UNAM, México, 2005.

- Engels F., Plejánov G.: Ludwig Feuerbach y el fin de la filosofia clásica alemana. P. 55. Ed. Siglo XXI, Cuadernos del Pasado y el Presente, 1975.

- Rieznik, P: El mundo no empezó en el 4004 antes de Cristo. Marx, Darwin y la ciencia moderna. (Prefacio) Editorial Biblos, Buenos Aires, 2005.

— Tealdi, J.C.: "Los principios de Georgetown" en V.Garrafa, A.Saada, M.Kottow (coords), Estatuto Epistemológico de la Bioética, México, Universidad Nacional Autónoma de México-UNESCO, 2005, p.35-54.

- Tealdi, J.C. "Etica de la investigación: el principio y el fin de la bioética". Summa Bioética.-Organo de la Comisión Nacional de Bioética-, México, Año I, Número Especial, Septiembre de 2003, p.69-72.

- Pfeiffer; M. L., "El ser humano como objeto. Ciencia y ética”. Revista Jurídica de Buenos Aires. Bioética y Derechos Humanos, Buenos Aires, 2006.

— Pfeiffer, M. L., "Bioética ¿para qué? En Cuadernos de Ética No 30 Buenos Aires, 2002.

— Jungues, R., "El Estatuto espitemológico de la bioética" http://www.unesco.org.uy/ shs/fileadmin/templates/shs/archivos/TrabajosLibres-Bioetica/16.\%20El\%20estatuto\%20espistemologico.pdf 
134/ Perspectivas Metodológicas /19/Vol. II /Año 2017 


\title{
La escritura académica y su evaluación (una experiencia con estudiantes de ingeniería a partir de un tema de geometría analítica)
}

\author{
Vicente Messina ${ }^{1}$, Gloria Cittadini' ${ }^{2}$ Carlos Pano $^{3}$ \\ vrmessi@gmail.com
}

\section{Resumen}

En este trabajo narramos una actividad de escritura académica realizada por estudiantes de ingeniería y su evaluación. Para ello elegimos un capítulo de un texto universitario que trata sobre secciones cónicas. Describimos el contexto y el trabajo de los alumnos. Caracterizamos la noción de trabajo práctico y su aplicación a este caso. Señalamos el concepto de evaluación seguido. Especificamos los aspectos de un escrito académico en el marco de alfabetización académica y su evaluación en los escritos de los alumnos. Presentamos los resultados. El desarrollo de la actividad estuvo mediado por el aula virtual. Sostenemos que la práctica de la escritura académica aporta a una mejor formación de los ingenieros.

Palabras clave: alfabetización académica - escritura académica - evaluación - geometría analítica - entropía.

\footnotetext{
1 Licenciado en Enseñanza de las Ciencias por la Universidad Nacional de General San Martín Especialista y maestrando en Metodología de la Investigación Científica por la Universidad Nacional de Lanús. Profesor Adjunto en Álgebra y Geometría Analítica e investigador en la Facultad Regional Buenos Aires de la Universidad Tecnológica Nacional.

2 Licenciada en Tecnológia Educativa. Profesora Titular Ordinaria en Álgebra y Geometría Analítica e investigadora en la Facultad Regional Buenos Aires de la Universidad Tecnológica Nacional.

3 Licenciado en Ciencias Matemáticas. Profesor Titular Ordinario de Probabilidad y Estadística e investigador en la Facultad Regional Buenos Aires de la Universidad Tecnológica Nacional. Profesor Titular de Estadística en la Facultad de Psicología de la Universidad de Buenos Aires.
} 


\section{Abstract}

This work is devoted to narrate the academic writing activity done by engineering students, as its assessment. Therefore, the chosen text was about conic sections. The context where the experience was realized and the student's work was described. The concept of the task, as well as its application was characterized. The followed assessment concept was indicated. Then, the academic writing's aspects were evaluated in the academic literacy framework. The results were presented. The virtual campus made possible the activity's development. From the work it is concluded that the practice of academic writing contributes to a better engineer's formation.

Keywords: academic literacy - academic writing - evaluation - analytic geometry - entropy.

\section{Introducción}

Todas las instituciones educativas (desde el jardín de infantes hasta la Universidad) son responsables de que las personas comprendan mensajes cada vez más complejos de la mejor forma posible. Es por eso que la alfabetización no debería ser considerada privativa de la escuela primaria sino establecerse como un proceso de aprendizaje permanente, en especial porque el vínculo de los adultos con la lengua escrita es mayormente de resistencia a su uso y de dificultad para abordarla de manera placentera y correcta (Castedo, 1995).

Como docentes de Álgebra y Geometría Analítica para carreras de Ingeniería, y en el marco del Proyecto de Investigación Alfabetización académica en entornos virtuales de aprendizaje y evaluación innovadora con función pedagógica (2013), en el cual participamos, hemos realizado, con estudiantes de la materia, una experiencia de escritura académica. El objetivo fue realizar una actividad de alfabetización académica en un entorno virtual de aprendizaje. Este trabajo reporta los resultados obtenidos.

La escritura de los alumnos en la universidad está ligada a la lectura y a la comunicación oral. Los estudiantes producen escritos a partir de la lectura de la bibliografía que leen, de la escucha de lo trasmitido por los docentes y de las interacciones que ocurren en el aula entre ellos y con el profesor. En el caso de la experiencia, los escritos que les pedimos se sustentaron principalmente con la lectura de un capítulo de libro recomendado. También pudieron rescatar ideas del foro virtual al que pudieron acceder.

La escritura académica requiere de la lectura reflexiva del texto elegido, no para reproducirlo sino para iniciar el desarrollo de la propia argumentación. Se trata de un trabajo mental de comprender y ordenar las ideas expuestas en el texto y de cotejarlas con las propias. La escritura académica precisa planificación, es decir, formulación de objetivos que pueden modificarse mientras se escribe en virtud de la aparición de nuevas ideas. Necesita transformación, "transformación supone el acceso a la memoria semántica, encontrar la palabra que expresa la idea, colocar la palabra en la frase y leer lo que 
Vicente Messina , Gloria Cittadini y Carlos Pano / La escritura académica y [...] 137 está saliendo" (Bruning, Schraw, Norby y Ronning, 2005, p. 345). Necesita también de revisión para hacer las correcciones y modificaciones que se consideren apropiadas, lo que implica la reorganización y reescritura de lo hecho.

La escritura académica es un modo de apropiarse y transformar el conocimiento que favorece el análisis crítico sobre el propio saber. La palabra escrita no sólo expresa el pensamiento sino que su producción lo desarrolla y le da consistencia. Para agregarle valor, resulta preciso escribir con conciencia retórica, esto es, anticipar el efecto del propio texto sobre el lector. Formar a los estudiantes en escritura académica es una manera de alfabetizar en la Universidad. Su práctica es una actividad cognitiva donde el estudiante construye un nuevo conocimiento, combinando lo que ya sabe sobre un tema con el conocimiento que posee sobre los procesos del discurso y sus objetivos.

La Alfabetización Académica, de acuerdo con Thaiss, Bräuer, Carlino, Grabocsik-Willians y Sinha (2012) y Carlino (2005), permite apropiarse de algunas de las formas de razonamiento instituidas en la cultura discursiva de una disciplina científica o tecnológica. No es un enfoque que pretende remediar deficiencias en la formación previa, sino que implica que cada una de las cátedras esté dispuesta a abrir las puertas de la disciplina que enseña. Abrir las puertas de Álgebra y Geometría Analítica nos encamina en la dirección de mejorar los aprendizajes de la asignatura.

\section{Contexto}

La actividad que describimos se desarrolló en un curso de Álgebra y Geometría Analítica, asignatura que se cursa en forma anual, con una carga horaria de cinco horas semanales. El curso contó con 61 alumnos que comenzaban su formación universitaria, habían cursado y aprobado el Seminario Universitario de Ingreso que se imparte en la Facultad durante los meses de febrero y marzo. Ellos cursaban por primera vez materias del primer nivel de la Facultad Regional Buenos Aires de la Universidad Tecnológica Nacional. La Universidad Tecnológica Nacional fue creada en 1959 y desde ese año han egresado más de 30.000 profesionales de las distintas carreras de grado. Una de sus características principales es la de ser la única Universidad del país en priorizar la enseñanza y el aprendizaje de las distintas ingenierías. Otra es su carácter federal, dado que está integrada por 29 Facultades Regionales que se encuentran distribuidas por todo el país. Esto implica que los sistemas productivos regionales están en permanente relación con la Universidad, generando un intercambio académico a nivel nacional. El alumnado que cursa las distintas ingenierías en todas estas Regionales es aproximadamente de 70.000 alumnos que equivale a más del $50 \%$ de todos los estudiantes de ingeniería del país. A pesar de esta masividad, la Universidad considera importante que la razón entre la cantidad de alumnos y la cantidad de docentes por curso permita una relación docente-alumno personalizada. Desde su origen está comprendida en la concepción asociativa universidad-trabajo. En lo concreto, esto se traduce en horarios de clase compatibles con la actividad laboral, clases teórico-prácticas de tipo seminario o taller. Respecto a la asignatura Álgebra y Geometría Analítica, cabe aclarar que ésta es común a todas las especialidades de las carreras de Ingeniería, junto con otras asignaturas de ciencias básicas que se imparten en el mismo nivel. El contenido medular del curso consiste en una introducción al Álgebra Lineal y al tratamiento de la Geometría Analítica desde un enfoque vectorial. 


\section{8/ Perspectivas Metodológicas /19/Vol. II /Año 2017}

En el curso donde fue desarrollada la experiencia, las clases presenciales abordaron los temas propios del programa. La actividad de escritura académica se gestionó a través del aula virtual, allí estuvieron instalados los materiales y allí también los alumnos dejaron sus producciones. Las consultas se resolvieron a través del foro del aula virtual. Los alumnos contaron con computadora o facilidad para utilizar una máquina. Pudieron acceder a internet tanto en la Universidad como en sus domicilios, así como también al aula virtual asignada al curso. La clase estuvo a cargo de dos profesores: la profesora titular y el jefe de trabajos prácticos. Los dos docentes participaron en cada clase presencial y tuvieron a su cargo el desarrollo de la experiencia que describimos en el marco del proyecto antes mencionado.

\section{Sobre los trabajos prácticos}

Los trabajos prácticos son un instrumento cuyo objetivo es relacionar la teoría con la práctica y que exige a los alumnos comprensión y análisis de los conceptos puestos en juego por el docente. De acuerdo con Steiman (2008), "Consideramos al trabajo práctico como una propuesta de interpretación y fundamentación teórica que parte de una situación problemática global que contextualiza a cada una de las tareas a realizar" (Steiman, 2008, pp 85-86). Éste análisis y comprensión implica que los alumnos deban interactuar con sus conocimientos previos, con los contenidos explicados, con la lectura de los textos sugeridos; les exige saber qué es lo que saben, pero teniendo simultaneamente en cuenta conciencia de lo que no saben. Para la resolución del trabajo práctico deben usar en forma integrada sus conocimientos y habilidades adquiridas, apelando en algunos casos a la creatividad. Los trabajos prácticos se pueden resolver de manera individual o grupal, en el aula o fuera de ella, o en un contexto virtual. Cualquiera sea el caso, los mismos contribuyen a la construcción de los conocimientos específicos de la asignatura.

Según Doyle (1981), la forma de pensar del alumno está condicionada por las tareas que se le solicitan. Los docentes guían el aprendizaje de los alumnos al diseñar e implementar tareas académicas; en el desarrollo de estos diseños, el profesor reflexiona sobre los contenidos, la organización, la secuencia de las actividades, su adecuación al curso y puede prever las posibles interacciones en el aula. Doyle (1982) señala además la tipología de tareas académicas de acuerdo con los procesos cognitivos: tareas de memoria, actividades de rutina o procedimientos, tareas de comprensión, tareas de opinión. A nuestro entender, se deberían agregar tareas de creación. Es posible diseñar trabajos prácticos en los cuales los alumnos deban hacer análisis e interpretaciones cada vez más profundos. Esta profundización requiere demandas cognitivas que la acompañen.

Los trabajos prácticos usualmente propuestos en la asignatura Álgebra y Geometría Analítica están pensados para que el alumno desarrolle un cierto entrenamiento en resolver ejercicios, utilizando la fórmula adecuada o siguiendo los pasos convenientes para llegar a la respuesta correcta. Estos trabajos prácticos se sirven del lenguaje de la asignatura, de modo tal que obligan al alumno a tratar de comprenderlo. No ofrecen posibilidades de profundizar, pues se limitan a los contenidos que están estipulados en el programa y a los objetivos de la asignatura. No contienen ejercicios integradores y 
Vicente Messina, Gloria Cittadini y Carlos Pano / La escritura académica y [...] 139 muchos de los ejercicios están destinados a que el estudiante memorice fórmulas, procedimientos y propiedades. No están elaborados para que el alumno trabaje con sus pares. Cuando el alumno se encuentra frente a un ejercicio, intuye que debe descubrir cuál es el procedimiento correcto para encontrar la respuesta.

\section{1. El diseño de los trabajos prácticos para la experiencia}

Para el diseńo de los trabajos prácticos, preparamos una serie de preguntas y ejercicios que el alumno pudiera responder a partir de la lectura del capítulo elegido. Elaboramos cinco trabajos prácticos. En cada uno de estos se indica cuál es la sección del capítulo que abarca los contenidos necesarios para la realización del trabajo, los objetivos a lograr y las pautas de lectura y escritura que el alumno debe seguir para el desarrollo del escrito pedido.

A través de estas actividades, buscamos que el alumno pueda precisar por escrito los conceptos leídos, emplear los procedimientos expuestos en la resolución de los ejercicios, utilizar el lenguaje formal de las matemáticas y valorar su rigurosidad. También buscamos que pueda apelar a representaciones gráficas utilizando el software que le indicamos. Asimismo, nos interesa que pueda adquirir un manejo adecuado del vocabulario del tema, dándole a los términos el significado que les corresponde en el espacio contextual de las cónicas.

\subsection{Texto propuesto a los alumnos para su lectura}

El texto elegido es el capítulo 3: "Secciones Cónicas", del libro Nociones de Geometría Analítica y Álgebra Lineal, escrito por Kozak, A., Pastorelli, S., Vardanega (2007). La elección de este capítulo se debe al tratamiento que los autores hacen del tema. Este tratamiento nos permite ubicar la mencionada sección del libro al comienzo de la cursada de Algebra y Geometría Analítica y de forma paralela al curso presencial. Circunstancia que podía facilitar la realización de la experiencia.

El libro seleccionado está en la bibliografía de la asignatura. Tiene la particularidad de que los autores son docentes de distintas Regionales de la Universidad Tecnológica Nacional. Sigue los temas del programa, la presentación es clara en un nivel adecuado para los alumnos que comienzan en una carrera de ingeniería. Cada capítulo comienza con la presentación de un problema de aplicación no resuelto, referido a los contenidos de ese capítulo. El libro tiene abundantes ejemplos con su solución, ejercicios propuestos sin la respuesta, una autoevaluación con sus respuestas y un glosario de términos al final de cada capítulo.

\subsection{El trabajo de los alumnos}

Los alumnos desarrollaron la experiencia en sus domicilios y en el aula virtual, usando recursos de la tecnología actual. Las clases presenciales estuvieron dedicadas a la enseñanza y al aprendizaje de los temas propios de la materia. "En definitiva, los entornos virtuales de aprendizaje permiten aprender sin coincidir en el espacio ni en el tiempo y asumen las funciones de contexto de aprendizaje que en los sistemas de formación pre- 
sencial desarrolla el aula" (Duart, Sangrá, 2001, p. 31). La llegada masiva de las TIC ha significado para la sociedad una evolución que la educación, como factor de movilidad social, debe acompañar. Freire (2009) señala que "la educación, como proceso basado en conocimiento, comunicación e interacciones sociales se ha visto afectada de forma radical por la emergencia de la cultura digital", la cual a su vez, "ha transformado a sus actores, profesores y estudiantes provocando la necesidad de cambios en las propias instituciones educativas" (Freire, 2009, p. 2). Además, el aula virtual como ámbito de resolución de la actividad favorece el aprendizaje colaborativo. Este aprendizaje en entornos virtuales implica dejar el protagonismo docente y estimular la participación activa, elaborada, profunda, libre de prejuicios, reflexionada entre los alumnos. Esta participación despierta la curiosidad e imaginación, y se presenta como contracara al hecho de que el alumno, en el desarrollo de las tareas en forma virtual, deba enfrentarse solo al estudio, produciéndole una sensación de aislamiento y soledad que puede ser causa de abandono. Esta interacción promueve una construcción social del conocimiento y una visión más amplia del aprendizaje, dejando paulatinamente los enfoques tradicionales y generando verdaderas comunidades de autoconocimiento de acuerdo con Pérez-Mateos (2010).

Los alumnos trabajaron en cada trabajo práctico durante dos semanas. Para facilitarles la lectura y escritura del trabajo, les proporcionamos pautas orientadoras que, como parte de las consignas, acompañan a cada trabajo práctico. Hubo un foro de consultas habilitado para cada trabajo práctico, dedicado a la interacción entre los alumnos, moderado por los docentes. Los docentes utilizaron también el foro para evacuar las dudas planteadas. Las devoluciones a los alumnos de los trabajos evaluados se realizaron a través del espacio de retroalimentación de la plataforma Moodle.

\section{Sobre la evaluación}

La evaluación en la universidad constituye por lo general una parte diferenciada y puntual del proceso educativo. Se implementa en instancias formales planificadas al finalizar unidades temáticas, consistiendo en exámenes parciales y finales, de manera común escritos y separados del proceso de enseñanza y de aprendizaje (Alvarez Méndez, 2003). Desde esta perspectiva, la evaluación cumple la función social e institucional de acreditar saberes y habilidades. Esta acreditación se caracteriza por dos puntos: el primero desvincula el examen del desarrollo de la enseńanza y el aprendizaje, mientras que el segundo desvirtúa la relación del alumno con el docente, sobre todo cuando uno estudia para aprobar y el otro enseña lo que se va a evaluar (Díaz Barriga, 1992).

Las evaluaciones centradas en la medición presuponen que la puntuación en una prueba tiene el mismo significado para todos los individuos y que es "objetiva y neutral". Desde la perspectiva constructivista, nosotros construimos el mundo de acuerdo con nuestros valores y percepciones. El sujeto cognitivo es un constructor activo de sus estructuras de conocimiento. Se evoluciona de un estado cognitivo a otro. Cada uno de los autores que han aportado a esta corriente -como Piaget, Vigotsky, Maturana, Ausubel, Novak, von Glaserfeld, Bruner- tratan de explicar la construcción de ciertas estructuras a partir de otras diferentes. Coherentes con este enfoque, piensan en una "puntuación verdadera", marcando la dificultad de establecer una medición cuantitativa objetiva de los conocimientos del estudiante. Así, tenemos que adherir a Sverdlick (2012) cuando expresa: 
Vicente Messina, Gloria Cittadini y Carlos Pano / La escritura académica y [...] 141

[...] ya nadie dude de que aun definiendo operacionalmente las claves de corrección "la nota" puede diferir si la corrección la efectúan personas diferentes, o incluso la misma persona en diferentes en momentos o días distintos; la mística de la "objetividad" y de la "neutralidad" continúa vigente. [...] En efecto, la lógica positivista que aun prima en la escuela tiene su expresión en la demanda de criterios y parámetros de evaluación 'objetivos', lo que equivale a que sean "neutros" y "verdaderos". Esta idea, asentada en la ilusión de neutralidad o de ecuanimidad de una evaluación "objetiva", supone que existe un valor de verdad por fuera de la construcción que están haciendo los actores en el momento de la evaluación. (Sverdlick, 2012, pp. 150, 151)

De acuerdo con Mateo y Olmo (2008), el presupuesto implícito en lo que se denomina psicometría clásica está en suponer que existe un constructo que explica la naturaleza de la conducta humana, que se puede definir con precisión y por tanto es posible construir una prueba que nos permita capturar su esencia y medirla. Los modelos conductistas dieron soporte teórico a un universo de pruebas denominadas objetivas. Por ello, buscar significados objetivos en las prácticas escolares, sabiendo que el evaluador aporta su subjetividad durante el proceso de evaluación, no es conducente. Esta subjetividad está integrada por supuestos previos acerca del objeto a evaluar y por sus supuestos teóricos e ideológicos. En tal sentido, el evaluador que renuncia a buscar objetividad prefiere el concepto de "intersubjetividad", donde la validación de la información se genera a través de estrategias que permiten a los evaluadores y a los evaluados la posibilidad de acordar o disentir sobre los resultados de la evaluación. En este caso se posee consciencia de que el conocimiento es una construcción social y por lo tanto intersubjetiva, que refleja acuerdos, legitimando así al producto que se obtenga.

\section{1. La evaluación alternativa}

Darling-Hammond (2014) señala que, para muchas personas, la evaluación alternativa se define más facilmente por lo que no es. Cualquier procedimiento que aplique instrumentos cuyo diseño implique un intento de percibir, captar, discernir el rendimiento en forma distinta de las formas clásicas planteadas por la psicometría -es decir, pruebas de elección múltiple o alguna de las pruebas objetivas centrada en la medición y el control de los resultados- se puede considerar como una evaluación alternativa. Desde esta perspectiva, la evaluación alternativa abarca una amplia gama de actividades donde se espera que el alumno construya una respuesta original, en lugar de reconocer una respuesta potencialmente correcta de una lista predeterminada. Las actividades pueden ir desde completar una frase con unas pocas palabras hasta la escritura de un ensayo o el análisis de una investigación de laboratorio donde el alumno participa en forma activa y no sólo como observador.

La evaluación alternativa se presenta como un paradigma de cambio respecto a los modelos de medición, privilegiando la parte integral del proceso enseñanza y de aprendizaje. Por supuesto, las evaluaciones acreditativas pueden usarse para el aprendizaje, pero el interés de la evaluación alternativa está en que la valoración es parte esencial 
del proceso pedagógico. Asimismo, el alumno es participante activo en la construcción de significado, hasta el punto en que su inserción refleja una valoración de las normas de rendimiento y la necesidad de la metacognición en el aprendizaje (Gipps y Stobart, 2003). De acuerdo con Darling-Hammond (2014), el desempeńo de los estudiantes se juzga con criterios pre-establecidos, basados en el discernimiento humano, y apunta a la evaluación de conocimientos complejos y de alto nivel de pensamiento que tengan relación con contextos reales. Se dice que la evaluación alternativa es autentica cuando las tareas que el alumno ejecuta tienen como contexto situaciones del mundo real. Como señalan Mateo y Olmo (2008), cuando aparece un nuevo término, casi al mismo tiempo surgen variaciones en su significado. Este es el caso de la evaluación alternativa, que considera como sinónimos los terminos evaluación alternativa, autentica y de ejecución. La evaluación auténtica y la de ejecución no son lo mismo. Para que una evaluación sea autentica las tareas que deben desarrollar los alumnos deben estar asociadas a la vida real. En la de ejecución, esta condición no es imprescindible.

En definitiva, la evaluación basada en ejecuciones (performance based assessment) y la auténtica son dos modalidades dentro del denominado enfoque alternativo, donde la evaluación de ejecución requiere que los estudiantes, en un momento concreto, justifiquen, construyan, realicen un producto o solución a partir de pautas determinadas (Gips y Stobart, 2003). Siguiendo esta misma línea, Khattri y Sweet (como se cita en Mateo y Olmo, 2008), señalan que adoptar el enfoque de la evaluación de ejecución involucra los siguientes pasos a realizar por los estudiantes: estructurar las tareas objeto de evaluación, aplicar información previa, construir respuestas y explicar el proceso que los ha llevado a una determinada respuesta.

\section{La evaluación de las producciones escritas de los alumnos que participaron en la experiencia}

En la evaluación en los exámenes escritos de matemática, el profesor atiende habitualmente a los razonamientos y a los resultados obtenidos, no reparando en otros aspectos de la escritura.

En nuestra experiencia pretendimos hacer una evaluación más amplia de la escritura académico-matemática. Les planteamos a los estudiantes un trabajo que los responsabilizaba de su propio aprendizaje y buscamos generar hábitos de revisión y control de los propios procesos. La evaluación de estos trabajos necesitó mecanismos que hagan evidentes los distintos aspectos de la escritura académica, además de una participación docente diferente. Esta evaluación obliga a que los docentes encargados deban actuar como co-evaluadores, consensuando no sólo los criterios para dirimir la calidad de un escrito matemático, sino para conocer la destreza del estudiante al momento de comunicar por escrito.

Se trató de evaluar los escritos de los alumnos derivados de la lectura del capítulo antes mencionado, teniendo presente que el tema no fue tratado en las clases presenciales. Los escritos respondieron a las demandas docentes. Estas fueron de dos tipos: 
Vicente Messina , Gloria Cittadini y Carlos Pano / La escritura académica y [...] 143

- Respuestas a preguntas

- Resoluciones de ejercicios

El procedimiento de evaluación consta de los siguientes elementos:

1. Para cada pregunta o ejercicio el equipo docente construyó una respuesta modelo.

2. Hay aspectos a considerar para señalar las fallas, relacionadas con la escritura académica, que los escritos contienen.

3. Hay una escala para clasificar los escritos, cuyas categorías se definen por el grado de afinidad con el modelo construido por el equipo.

4. Las fallas señaladas concurren para clasificar las respuestas con la escala.

5. Los escritos son corregidos por dos docentes y la calificación (clasificación) surge del acuerdo entre ambos.

\section{1. La respuesta modelo}

Para cada pregunta o ejercicio el equipo construyó una respuesta modelo. Esta respuesta será obviamente correcta, estará convenientemente fundamentada, ordenada en su presentación y explicada.

Los aspectos considerados y acordados por el grupo de investigación para la evaluación de los escritos son:

- Argumentación

- Cierre

- Coherencia

- Cohesión

- Gramática

- Presentación

- Semática

- Tema

- Representación

En el proceso de corrección nos interesa detectar las fallas que el estudiante-escritor comete en los aspectos señalados. Para eso, a continuación describimos las fallas a considerar en los distintos aspectos:

Argumentación: el escrito a evaluar contiene razonamientos inadecuados, desarrolla demostraciones incorrectas, formula argumentos inapropiados, carece de explicaciones.

Cierre: en el escrito no se definen ni explican símbolos o términos que son utilizados en el trabajo.

Coherencia: en el escrito faltan títulos o subtítulos cuando debieran estar. Se omite la transcripción de la pregunta o del enunciado del ejercicio. No se señala la o las respuestas. Falta la presencia de un hilo conductor que le otorgue unidad al texto producido. 
144/ Perspectivas Metodológicas /19/Vol. II /Año 2017

Cohesión: el escrito presenta partes desconectadas, no tiene conexión lógica entre algunos enunciados ni entre párrafos verbales y gráficos o tablas. Carece de conectores adecuados.

Gramática: el escrito contiene faltas de ortografía, oraciones mal construidas o mal enlazadas, o hace un empleo incorrecto de los signos de puntuación.

Presentación: el trabajo debe respetar las normas de presentación: título, subtítulo, apellido y nombre, curso al que pertenece, fecha de entrega, tipo y tamaño de letra.

Semántica: el escrito presenta un uso incorrecto de los términos, en particular de los términos técnicos o confude el significado de las palabras.

Tema: el escrito no responde a la pregunta o desacuerda con el enunciado del ejercicio.

Representación: el escrito omite nombres globales en las tablas de datos y gráficos, y en sus partes constitutivas. Exhibe un tratamiento inadecuado de las expresiones algebraicas o las locuciones simbólicas.

\subsection{La escala}

Para evaluar las respuestas de los alumnos usamos una escala ordinal. Las clases de la escala son:

- respuesta correcta

- respuesta próxima a la correcta

- respuesta próxima a la incorrecta

- respuesta incorrecta

- respuesta en blanco

Se asignó a cada respuesta un valor numérico a los fines de conformar una nota para cada ejercicio, como se indica en la tabla $\mathrm{N}^{\circ} 1$.

\begin{tabular}{|l|c|}
\hline \multicolumn{1}{|c|}{ Respuesta } & Nota \\
\hline Respuesta correcta & $\mathbf{4}$ \\
\hline Respuesta próxima a la correcta & $\mathbf{3}$ \\
\hline Respuesta próxima a la incorrecta & $\mathbf{2}$ \\
\hline Respuesta incorrecta & $\mathbf{1}$ \\
\hline Respuesta en blanco & $\mathbf{0}$ \\
\hline
\end{tabular}

Tabla $\mathbf{N}^{\circ}$ 1. Asignaciones de valores numéricos a las respuestas

\section{Consideramos:}

- correcta toda respuesta que guarda relación de semejanza con la respuesta modelo.

- próxima a la correcta a una respuesta con más partes afines al modelo correcto que partes contrarias al mismo. 
Vicente Messina, Gloria Cittadini y Carlos Pano / La escritura académica y [...] 145

- próxima a la incorrecta a una respuesta con menos partes afines al modelo correcto que partes contrarias al mismo.

- incorrecta, a una respuesta que, en todas sus partes, resulte contraria al modelo.

- respuesta en blanco en el caso que no haya respuesta.

Si bien los resultados a que lleguen los estudiantes hacen, desde el punto de vista de la matemática, a la calidad de los escritos, no son determinantes para la clasificación. Un resultado matemáticamente incorrecto no será clasificado como 1 (respuesta incorrecta) si no hay fallas en los aspectos considerados o las hay en una cantidad no significativa. De manera similar, un resultado matemáticamente correcto no será clasificado como 4 (respuesta correcta) si hay fallas en los aspectos considerados en una cantidad significativa.

\subsection{La corrección de los escritos}

De los escritos de los alumnos que participaron de la experiencia elegimos ocho al azar. Las condiciones materiales en que se realizó la experiencia no nos permitieron considerar, para este artículo, la totalidad. Todos los escritos surgieron a partir de la lectura del capítulo del texto indicado más arriba.

Cada escrito es corregido por dos docentes. Si ambos coinciden en la asignación de la clase de la escala, esta queda como definitiva; en caso contrario, interactuarán para resolver por consenso, con convencimiento mutuo, la asignación.

La lectura y evaluación de las producciones de los alumnos están afectadas por las concepciones que el docente-investigador tiene sobre la evaluación y estas son puestas en juego en la tarea. El procedimiento de evaluación de los escritos, por parejas docentes participantes del proyecto, con criterios establecidos y con respuestas modelo que utilizamos en la experiencia, hace que ese equipo deba discutir, reflexionar, analizar, acordar. Es un procedimiento que no busca la objetividad, pero como se obligan a consensuar mediante el análisis y la reflexión conjunta, a la luz de los criterios establecidos, la calificación que se consiga será una construcción intersubjetiva y por lo tanto con legitimidad.

\subsection{Definición de la matriz de fallas}

La matriz de un alumno da cuenta de las fallas que surgen en los distintos aspectos de cada ejercicio. Hay nueve aspectos a considerar y quince ejercicios en la totalidad de los trabajos prácticos.

Cuando un alumno en el ejercicio i-ésimo incurre en por lo menos una falla del aspecto j-ésimo lo indicamos con 1 (uno) y lo denotamos éxito, caso contrario lo indicamos con 0 (cero) y lo señalamos como fracaso. Esta información para cada alumno define una matriz de quince filas por nueve columnas. Es una matriz de unos y ceros, con lo cual se tienen así 135 variables dicotómicas. 
En la tabla $\mathrm{N}^{\circ} 2$ presentamos la matriz correspondiente al alumno A. Habiendo agregado una columna con la nota arriba definida y una fila con la suma por columnas que denominamos vector de éxitos por aspectos.

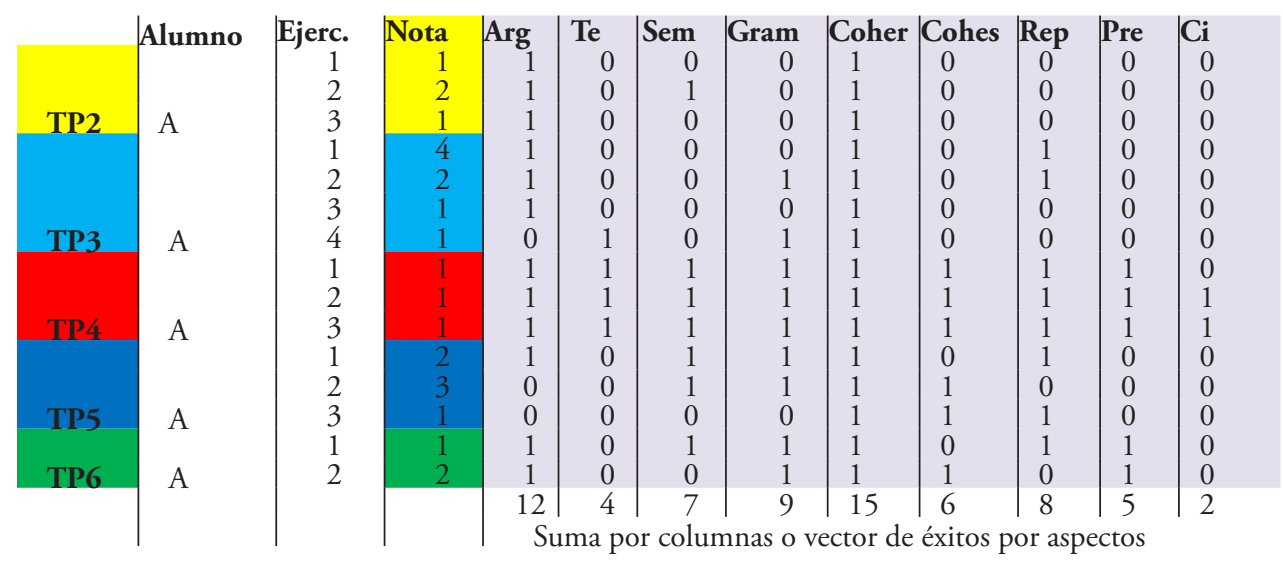

Tabla No2. Matriz de fallas del alumno A

Es posible mostrar la evolución de cada alumno en sus escritos, a través de la variable nota transformada, en función de la sucesión temporal de trabajos prácticos. La nota transformada estará constituida por cada una de las notas obtenidas en cada ejercicio del trabajo práctico correspondiente. Para calcular el valor asignado a la variable se sumaron las notas obtenidas por el alumno en cada ejercicio del trabajo práctico y esa suma se dividió por cuatro veces la cantidad de ejercicios del trabajo práctico. Así, la nota transformada queda independiente de la cantidad de ejercicios del trabajo práctico. Hallamos la nota transformada para los ocho alumnos y calculamos el coeficiente de correlación lineal, entre el número de trabajo práctico (indicador del tiempo) y la nota transformada para cada alumno, obteniendo los valores mostrados en la tabla $\mathrm{N}^{\circ} 3$.

\begin{tabular}{|l|c|c|c|c|c|c|}
\hline & TP2 & TP3 & TP4 & TP5 & TP6 & $\begin{array}{l}\text { Coeficiente de } \\
\text { correlación lineal R }\end{array}$ \\
\hline Alumno A & 0,33 & 0,50 & 0,25 & 0,50 & 0,38 & 0,1212 \\
\hline Alumno B & 0,75 & 0,44 & 0,58 & 0,67 & 0,88 & 0,4574 \\
\hline Alumno C & 0,67 & 0,63 & 0,75 & 0,92 & 0,50 & 0,6481 \\
\hline Alumno D & 0,75 & 0,81 & 0,58 & 0,92 & 0,88 & 0,4293 \\
\hline Alumno E & 0,67 & 0,44 & 0,75 & 0,67 & 0,88 & 0,6392 \\
\hline Alumno F & 0,42 & 0,50 & 0,25 & 0,33 & 0,33 & 0,0000 \\
\hline Alumno G & 0,67 & 0,5 & 0,58 & 0,42 & 0,88 & 0,2998 \\
\hline Alumno H & 0,33 & 0,69 & 0,42 & 0,50 & 0,50 & 0,4004 \\
\hline
\end{tabular}

Tabla $N^{\circ} 3$. Coeficiente de correlación lineal para cada uno de los ocho alumnos

Se puede observar que los coeficientes de correlación lineal son no negativos. Esto indica que en el transcurso de la experiencia la nota transformada fue en aumento. Puede considerarse que la evolución de los escritos académico-matemáticos de los alumnos fue 
Vicente Messina , Gloria Cittadini y Carlos Pano / La escritura académica y [...] 147 mejorando en los sucesivos trabajos prácticos de la experiencia. Otro indicador que nos permite apreciar la dispersión de la distribución de éxitos de un alumno en los aspectos es el concepto de entropía.

\section{5. Entropía}

En Garcia Mayoraz (1989), leemos que entropía es un término de origen griego, viene de la palabra tropee, que significa transformación o cambio. Desde el punto de vista termodinámico, es una medida de la transformación de la energía. Fue creado en 1876 por el físico alemán Rudolf Claussius (1822-1888). Permite cuantificar los valores de transformación de la energía, calculando las variaciones de entropía entre dos estados de un sistema que evoluciona entre ellos. Ludwig Boltzmann (1844-1906) logró llegar al concepto de entropía partir de la teoría atómica y la probabilidad, preguntándose sobre los factores que afectan a la probabilidad de que una molécula se mueva con cierta velocidad. Según su teoría, un sistema que evoluciona espontáneamente de un estado de menor probabilidad a otro de mayor probabilidad, es decir, mayor desorden, mayor entropía y el estado más desordenado es el estado más probable. A finales de la década del cuarenta, Claude E. Shannon (1916-2001) propone una teoría que mide la cantidad de información contenida en un mensaje. Se puede calcular un valor promedio de información como la cantidad media de información por símbolo de la fuente, expresándose como $\mathrm{H}$.

$$
\mathrm{H}=-\mathrm{p}_{1} \ln \mathrm{p}_{1}-\mathrm{p}_{2} \ln \mathrm{p}_{2}-\ldots-\mathrm{p}_{\mathrm{k}} \ln \mathrm{p}_{\mathrm{k}}
$$

En una distribución de frecuencias, la entropía se calcula con la fórmula anterior reemplazando las probabilidades $\mathrm{p}_{\mathrm{i}}$ por las frecuencias relativas correspondientes. De acuerdo con Reuchlin (1976), esta noción de dispersión de una distribución nominal podrá ser mayor cuanto mayor es el número de clases. Para un número fijo de clases, será mayor si las observaciones se reparten igualmente sobre todas las clases en lugar de concentrarse sólo en algunas. Se puede explicitar y cuantificar esta noción definiendo y calculando la entropía de la distribución de éxitos en los aspectos. La entropía para los ocho alumnos se muestra en la tabla $\mathrm{N}^{\circ} 4$.

\begin{tabular}{|l|l|l|l|}
\hline Alumno A: 2,07 & Alumno B: 1,74 & Alumno C: 1,90 & Alumno D: 1,89 \\
\hline Alumno E: 2,00 & Alumno F: 1,87 & Alumno G: 1,72 & Alumno H: 1,90 \\
\hline
\end{tabular}

Tabla $N^{\circ}$ 4: Valores de entropía de los escritos de los ocho alumnos

Se observa que el alumno G, que obtuvo menor entropía, tiene una mayor concentración de éxitos en algunos de los aspectos, y que el alumno A, con la máxima entropía, tiene éxitos repartidos entre todos los aspectos. Con lo cual podemos concluir que al alumno $\mathrm{G}$ es conveniente que revise los aspectos donde se concentran el mayor número de éxitos. En cambio al alumno A será necesario que ponga atención en todos los aspectos. En el gráfico $\mathrm{N}^{\circ} 1$ se muestra las distribuciones de éxito estos dos alumnos. El alumno A tiene en sus escritos más éxitos que el alumno G. Se puede observar mayor dispersión en A que en G. 


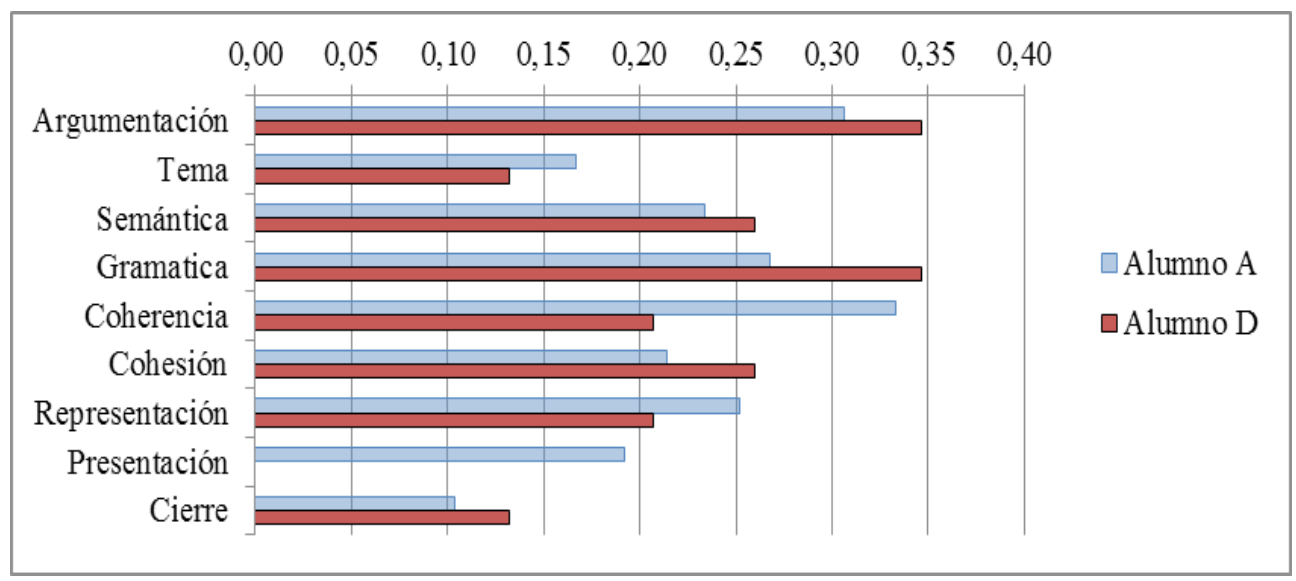

Gráfico $\mathrm{N}^{\circ}$ 1: Dispersión de éxitos, por aspectos, en dos alumnos

\section{Reflexiones finales}

Este estudio, llevado a cabo a principios del año 2015, permitió observar los escritos de alumnos de ingeniería que recién comenzaban su formación. Nos encontramos con escritos que muestran cuáles alumnos tienen dificultas para comunicar sus ideas. Nos consta el poco uso que hacen los estudiantes de los textos recomendados. Por eso, entendemos que, como docentes universitarios, debemos ocuparnos de la escritura académica, proponiendo actividades dirigidas a su práctica. El objetivo de la experiencia consistió en poner en función una actividad de alfabetización académica para propender al mejoramiento del aprendizaje de las secciones cónicas. En la experiencia que contamos, los alumnos autónomamente leyeron y escribieron, siguiendo determinadas pautas, sobre un tema de la geometría analítica que deben dominar. Habremos de generar actividades de escritura de textos académicos en álgebra lineal y geometría analítica que abran caminos al aprendizaje sólido en la compleja red de conceptos que los constituyen y que preparen a los estudiantes para poder profundizarlos y aplicarlos. Sostenemos que los estudiantes alfabetizados académicamente serán ingenieros capaces de enfrentar con solvencia los desafíos de la vida profesional y adaptarse con comodidad a los cambios sociales y tecnológicos que ocurren con una rapidez cada vez mayor.

\section{Bibliografía}

— Álvarez Méndez, J. M. (2003). La evaluación a examen. Ensayos críticos. Buenos Aires: Miño y Dávila.

- Bruning, R., Schraw, G., Norby, M. y Ronning, R. (2005). Psicología cognitiva y de la instrucción (4ta. ed.). Madrid: Pearson Prentice Hall.

— Carlino, P. (2005). Escribir, leer y aprender en la universidad. Una introducción a la 
Vicente Messina , Gloria Cittadini y Carlos Pano / La escritura académica y [...] 149 Alfabetización Académica. Buenos Aires: Fondo de Cultura Económica de Argentina.

- Castedo, M. L. (1995). "Construcción de lectores y escritores". Lectura y vida, 16(3), pp. 5-24.

- Darling-Hammond, L. (2014). Next generation assessment. Moving beyond the bubble test to support $21^{\text {st }}$ century learning. San Francisco: John Wiley and Sons.

- Díaz Barriga, A. (1992). Didáctica. Aportes para una polémica. Buenos Aires: Aique.

- Doyle, W. (1981). "La investigación sobre el contexto del aula: hacia un conocimiento básico para la práctica y política de formación del profesorado”. Revista de Educación, 277, pp. 29-42. Recuperado el 07/04/2016 de http://www.mecd. gob.es/dctm/revista-de-educacion/articulosre277/re2770200503.pdf?documentI$\mathrm{d}=0901 \mathrm{e} 72 \mathrm{~b} 813 \mathrm{c} 3054$

- Doyle, W. (1982). Academic work. National Commission on Excellence in Education. Washington: Department of Education. Recuperado el 09/05/2016 de la base de datos ERIC.

- Duart, J.M. y Sangrá, A. (2001). Aprender en la virtualidad. Barcelona: Gedisa.

- Freire, J. (2009). Monográfico "Cultura digital prácticas creativas en educación". Revista de Universidad y Sociedad del Conocimiento. Recuperado el 10/06/2015 de http://www.raco.cat/index.php/Rusc/article/viewFile/129749/179184

- Garcia Mayoraz, J. (1989). Entropía y Lenguajes. Buenos Aires: Hachette.

- Gipps, C. y Stobart, G. (2003). Alternative Evaluation. En Kellaghan, T. y Stufflebean, D. (Eds.). International Handbook of Educational Evaluation (pp. 549-573). Dordrecht, The Netherlands: Kluwer Academic Publishers.

- Kozak, A. M., Pastorelli, S. y Vardanega, P. (2007). Nociones de geometría analítica y álgebra lineal. Buenos Aires: McGraw-Hill Interamericana.

- Mateo, J. y Olmo, F.M. (2008). La evaluación alternativa de los aprendizajes. Barcelona: Ediciones Octaedro.

- Pérez-Mateo Subirà, M. (2010). La dimensión social en el proceso de aprendizaje colaborativo virtual: El caso de la UOC. Comprender y abordar la dimensión social en el trabajo en grupo virtual. Universitat Oberta de Catalunya. Recuperado de http://www.tdx.cat/bitstream/handle/10803/37113/tesi_mperezmateo1.pdf;jsessionid=F5DDD10BA07494D7DE1095F43B2218EB.tdx1? sequence $=1$. Recuperado el 01/03/2015.

— Pano, C., Cittadini, G., Pustilnik, I., Sara, A. y Messina, V. (2013). Alfabetización académica en entornos virtuales de aprendizaje y evaluación innovadora con función pedagógica. Proyecto con asiento en Universidad Tecnológica Nacional Regional Buenos Aires, reconocido por el código 25/C138 en el ámbito del Programa de Incentivos a los Docentes Investigadores.

— Reuchlin, M. (1976). Compendio de estadística: Método conceptual. Madrid: Pablo del Rio Editores.

- Steiman, J. (2008). Más didáctica (en la educación superior). Buenos Aires: UNSAM Edita.

— Sverdlick, I. (2012). ¿Qué hay de nuevo en evaluación educativa? Políticas y prácticas en la evaluación de docentes y alumnos. Propuestas y experiencias de autoevaluación. Noveduc: Buenos Aires.

— Thaiss, C., Bräuer, G., Carlino, P., Ganobcsik-Williams, L. y Sinha, A. (2012). Writing programs worldwide. Profiles of academic writing in many places. Recuperado de http://wac.colostate.edu/books/wpww/ 
150/ Perspectivas Metodológicas /19/Vol. II /Año 2017 


\section{Reseñas}


152/ Perspectivas Metodológicas /19/Vol. II /Año 2017 
MOMBRÚ, ANDRÉS. Metodologías y Epistemologías de la Investigación. Fundamentos epistemológicos y técnicas de investigación de algunas de las propuestas metodológicas de las ciencias en general y de las ciencias sociales en particular, LJC Ediciones, Avellaneda, 2017.

En cierta oportunidad, quien suscribe estas líneas le preguntó a Andrés Mombrú cuanto tiempo le demandó llevar adelante el plan de trabajo que finalmente se terminaría convirtiendo en Philia y Sophía para una metacrítica de la epistemología. Reflexiones sobre ideas y prácticas (2013), su tesis de doctorado. "Cuarenta años", replicó tajante. Con esa respuesta daba a entender que tal tesis era el fruto maduro de toda una vida consagrada al estudio, a la reflexión y a la docencia de la filosofía en general, y de la filosofía de la ciencia, la epistemología y la metodología en particular.

Respecto de su nueva obra, Metodologias y Epistemologias de la Investigación. Fundamentos epistemológicos y técnicas de investigación de algunas de las propuestas metodológicas de las ciencias en general y de las ciencias sociales en particular (LJC Ediciones, Avellaneda, 2017), Mombrú bien podría decir exactamente lo mismo: que se trata de un desarrollo superador de trabajos de reflexión anteriores como Ciencia y Sociedad (con Berta Stolior et al.), Metacritica y filosofia de la ciencia (con Graciela Bosch, 2002), Encrucijadas del pensamiento (con Sonia Durand, 2003), Nueva Bitácora. Perspectiva critica de la producción cientifica (2009), y Paralaje: Los giros y las controversias en el campo de la epistemología y sus consecuencias metodológicas en la investigación científica (2012), al tiempo que de una revisión crítica de todos ellos.

No obstante, este nuevo libro introduce importantes novedades en cuanto a sus contenidos respecto de aquellos que lo precedieron, ya que una de las finalidades explícitas para las que se lo concibió fue responder a las modificaciones más recientes de las currículas y programas universitarios y, por lo tanto, adaptarse a las necesidades de formación académica de los estudiantes.

Si tuviéramos que caracterizar a Metodologías y Epistemologías de la Investigación por la negativa, lo primero que diríamos es que no nos encontramos en presencia de un manual de metodología, de una de esas obras que se proponen enseñar a sus lectores qué es y en qué consiste $e l$ método científico. No pretende Andrés Mombrú convertirse en una de las tantas Doñas Petrona que abundan en el ámbito de la metodología. No hallará el lector en el libro una suerte de recetario que le indique cómo se cocina y sirve la mesa de la investigación científica, sino un trabajo de reflexión crítica, un espacio en el que las diferentes tradiciones que dan fundamento a diversas líneas de investigación se discuten y se polemizan.

Metodologías y Epistemologías de la Investigación no es, por tanto, un libro de perfil técnico, aun cuando parte del reconocimiento de que toda investigación científica tiene una dimensión técnico-instrumental sin la cual la producción de conocimiento en el terreno de las ciencias fácticas resulta imposible. De hecho, el extenso artículo que cierra el libro - "Procesos de investigación y enfoques cuanticulatitativos y cualicuantitativos en las ciencias sociales" - está consagrado íntegramente a la discusión, reflexión y exposición de los aspectos metodológicos más directamente operativos. 


\section{4/ Perspectivas Metodológicas /19/Vol. II /Año 2017}

En él encontramos diferentes tipos y diseños de investigación presentados esquemáticamente, así como también un muestrario de técnicas y de herramientas conceptuales que en la investigación social son usuales para construir información/datos -encuesta, censo, focus group, observación participante, entrevista estructurada, entrevista en profundidad, entre otras-y para procesarlos/analizarlos -construcción de matrices de datos, elementos básicos de estadística descriptiva, herramientas gráficas para la presentación de datos, rudimentos de análisis semiótico, etcétera-. A lo largo del artículo, Andrés Mombrú enfatiza la idea de que las metodologías no proporcionan herramientas neutras que sean garantías del conocimiento, motivo por el cual lo técnico aparece siempre supeditado a alguna estrategia de fundamentación metodológica, y éstas a su vez sólo cobran sentido a partir de un determinado posicionamiento epistemológico.

El primado de lo epistemológico es un denominador común de todos los artículos que conforman el libro. Pero no de una epistemología fría, formal, logicista y descarnada, sino de una que hace hincapié en las influencias extracientíficas que tiene toda actividad de investigación. Desde la óptica de Mombrú, si el conocimiento no existe en abstracto sino siempre como producto social, tampoco tiene sentido una reflexión epistemológica y metodológica sobre las formas de producción y validación del conocimiento que disocie a la ciencia de sus condicionamientos sociales, políticos, culturales, económicos y éticos. Tal disociación no puede ser sino una ficción.

Otro hilo conductor que atraviesa transversalmente el libro es la intención -manifiesta ya desde su propio título- de romper con toda forma de monismo epistemológico. En su lugar, dice Andrés Mombrú, "pretendemos presentar un panorama amplio y plural que dé cuenta de algunas de las propuestas más relevantes - entre las que también se encuentran varios monismos- por su incidencia en los ámbitos científicos y académicos, pero principalmente considerando los múltiples problemas a los que se enfrentan las ciencias sociales en relación tanto a la producción de sus saberes, cuanto a los conflictos sociales en los que se encuentran inmersos". Asimismo, Metodologias y Epistemologías de la Investigación se propone como un intento de superación de ciertas oposiciones maniqueas que dividen artificiosamente a la metodología de las ciencias sociales: epistemologías ortodoxas vs. epistemologías heterodoxas, metodologías cualitativas vs. metodologías cuantitativas, enfoques teóricos objetivistas vs. enfoques teóricos subjetivistas, entre otros pares de presuntos opuestos.

Puestos a hacer un racconto a vuelo de pájaro de los artículos que conforman el libro, el panorama es el que siguiente:

"Perspectivas históricas, sociales y éticas de la producción científica" tiene como punto de partida la idea de que la ciencia es una producción histórica y social. Tras un repaso de las características que distinguen al conocimiento científico y que lo diferencian de otras tantas maneras de producir conocimiento, se reflexiona acerca de cómo diferentes formaciones histórico-sociales dieron lugar a diferentes maneras de concebir y de practicar la ciencia. En este sentido, se propone un recorrido por diferentes momentos históricos de la ciencia que parte del momento original en la Antigüedad Clásica, continúa luego en la Edad Media, y culmina en la Modernidad con el surgimiento de la sociedad burguesa y del modelo de ciencia experimental que la 
caracteriza. El artículo finaliza con dos apartados que trabajan la relación entre ciencia y tecnología, y entre ciencia y ética.

"Criterios para la clasificación de las ciencias" problematiza los fundamentos epistemológicos vinculados a la operación de clasificar, y presenta críticamente los sistemas de categorías que resultan de clasificar las ciencias por su objeto de estudio, por sus enunciados, por sus métodos, y por sus fines.

"Lenguaje y ciencia del lenguaje" hace una introducción general a nociones de lingüística y la semiótica, y reflexiona sobre las principales características del lenguaje científico y de los enunciados que lo conforman.

En "Lógica y argumentación" se presentan no solamente los rudimentos de lógica clásica usuales en cualquier libro del tipo del que aquí nos ocupa, sino que hay lugar también para la lógica cuantificacional o de predicados, la lógica de clases, y las falacias no formales.

"Epistemologías y metodologías; ideas y prácticas en la investigación científica" aborda el problema del método en la filosofía y la ciencia modernas, a partir de un recorrido que toma como puntos de partida al racionalismo y al empirismo renacentistas y que finaliza en las posturas que en el siglo XX se convirtieron en la ortodoxia de la metodología: el empirismo lógico y el hipotético-deductivismo -las características de esta última corriente en particular serán trabajadas pormenorizadamente en el artículo "Dos ejemplos de la Filosofía Tradicional de la Ciencia: Hempel y Popper"-. Tal recorrido hace escalas en el criticismo kantiano del siglo XVIII, y en la emergencia y consolidación de la filosofía positivista en el siglo XIX.

En "Las ciencias sociales y sus particularidades epistemológico-metodológicas" y en "Consideraciones en torno al carácter específico de las ciencias sociales" se discute el carácter específico tanto del dominio que estudian las ciencias sociales como de los problemas epistemológicos, metodológicos e ideológicos que estas enfrentan. El segundo de los artículos mencionados problematiza los enfoques de fundamentación epistemológica usuales en el campo de la investigación social: naturalismo, comprensivismo y teoría crítica.

La reacción que cobró forma en el campo epistemológico durante la segunda mitad del siglo XX frente a la ortodoxia aparece trabajada en "Tres ejemplos de la Nueva Filosofía de la Ciencia: Kuhn, Lakatos y Feyerabend”.

"Las polémicas en el ámbito de las epistemologías y sus consecuencias metodológicas", como su nombre lo indica, aborda una serie de controversias generatrices de posicionamientos encontrados en el terreno de la investigación social. En él, se trabaja la polémica entre visiones historicistas y antihistoricistas, entre enfoques cientificistas y anticientificistas, y entre holismo e individualismo metodológico, entre otras. Asimismo, se problematizan los principales ejes del debate Popper-Adorno y, en el ámbito de la epistemología argentina, del debate Klimovsky-Varsavsky. 
156/ Perspectivas Metodológicas /19/Vol. II /Año 2017

Cierra el libro el ya mencionado artículo - "Procesos de investigación y enfoques cuanticulatitativos y cualicuantitativos en las ciencias sociales".

Metodologías y Epistemologias de la Investigación se trata, en síntesis, de un libro de introducción a la a la epistemología y a la metodología concebido fundamentalmente para un lectorado de estudiantes universitarios, pero también para todos aquellos que quieran tener una aproximación crítica a las controversias que existen respecto de la/s manera/s en que la ciencia produce y valida el conocimiento, e indagar en diferentes estrategias de construcción de la investigación científica.

Javier Andrés Piñeiro 


\section{ALONSO, MANUEL; AMBROSINI, CRISTINA; BERALDI, GASTÓN. Bestiario epistemológico. Metáforas zoomórficas y de otras entidades en la enseñanza de las ciencias y la epistemología. Buenos Aires, Editorial de la Facultad de Fi- losofía y Letras de la UBA, 2017.}

El pensamiento nos acostumbra al juego de las oposiciones: desde los griegos, al mito se opone el logos, la episteme (ciencia) se diferencia claramente de la doxa (opinión) y el conocimiento de la fantasía. En este juego opositivo, a la ciencia le corresponde el polo de un saber mejor fundamentado que el resto de los saberes y, en la versión positivista, un tipo de conocimiento fundamentado racionalmente, objetivo e imparcial. En el otro polo, la literatura es el terreno de la fantasía, de la imaginación, de la exploración sobre otros mundos posibles que, siendo ficticios, son visionarios y anticipan, en algunas oportunidades, lo que luego ocurrirá.

En este Bestiario, que presentan tres profesores del Ciclo Básico Común de la Universidad de Buenos Aires, la oposición, la tensión y el antagonismo son el leitmotiv de este zoológico. Debemos recordar que el Ciclo Básico Común de la Universidad de Buenos Aires, creado en 1985, intentó desde su inicio, ser un "espacio democrático de cambio e innovación pedagógica basado en una enseñanza básica, común y transdisciplinaria”, bajo la convicción de que el encuentro entre disciplinas, en un espacio común de formación académica, se puede enriquecer el trabajo de los docentes en beneficio de los futuros profesionales y científicos. Con esto se espera que la interdisciplina ocurra en el inicio y no en el final de una carrera disciplinar.

Este Bestiario compila parte de la tarea inter-cátedras que se lleva a cabo entre las materias Biología e Introducción al Pensamiento Científico y es el resultado de una línea de investigación sostenida a lo largo de estos últimos años donde convergen la epistemología, la ética, la biología y la enseńanza en ciencias naturales. Estos recursos metafóricos están orientados, según nos dicen los autores, a mostrar al conocimiento científico como una construcción a través de la elaboración de teorías y modelos históricamente situados con sus implicancias sociales y bioéticas.

Como señala desde el Prólogo el Dr. Héctor Palma, uno de los principales referentes de la valoración cognitiva de las metáforas científicas en nuestros medios académicos, durante siglos se ha considerado a las ciencias como el ejemplo más acabado y pleno de un lenguaje referencialmente preciso, formalizado, y como el resultado de procedimientos algorítmicos claramente pautados y controlados; y del otro lado a la literatura o al discurso retórico, como el campo de la asociación libre, la falta de límites lógicos y formales, de la mera intuición y creatividad sin rigurosidad racional, apelando a todo tipo de artimañas semánticas, incluidas las metáforas. Tender puentes entre estas dos esferas separadas y antagónicas del discurso es también una de las intenciones de los autores. Para ello recurren a otras metáforas, el puente y la muralla, tomadas de la obra del Dr. Ricardo Maliandi, donde se muestra el antagonismo entre el cambio y la permanencia, entre la conquista del futuro frente a la necesidad de preservar el pasado, lo ya conquistado. La aplicación de esta tensión en el campo de las metáforas para tipificar los conceptos epistemológicos, indica que estos recursos pueden ser transitados como puentes, para propiciar nuevos significados, o pueden ser vistos como obstáculos en el sentido de 


\section{8/ Perspectivas Metodológicas /19/Vol. II /Año 2017}

"obstáculos epistemológicos" ya explorados por Gastón Bachelard. Otra polaridad que atraviesa el Bestiario es la que puede ubicarse entre lo animal y lo humano asociados a la polaridad, a su vez, entre lo racional y lo irracional. Otra oposición que recorre y da sentido a esta revisión de metáforas es, la ya señalada en la obra de Thomas Kuhn, entre la revolución y la normalidad; entre la ruptura y la continuidad.

El libro se divide en dos partes. En la Parte I los autores recorren sus marcos teóricos, sus autores de referencia en la valoración de las metáforas como figuras que pueden tener un valor cognitivo en el lenguaje científico. Aquí se admite que las metáforas no son solamente formas subsidiarias de un lenguaje que luego debe ser "traducido" a otro lenguaje original, neutro y transparente, sino que ellas tienen un valor epistémico, y son constitutivas en la producción de conocimiento que realizan los científicos y luego apropian los estudiantes. En apoyo a esta idea se señala básicamente el aporte de Héctor Palma en cuanto a la valoración positiva de las metáforas científicas pero también se recurre a Paul Ricoeur.

En cuanto a la noción de "tensión" y "agonismo" se recurre en varios pasajes a Miguel de Unamuno. En la Parte II se presentan los animales en pares antagónicos, donde se pueden encontrar: La abeja lógica vs. La mosca estética como símbolos que señalan dos actitudes: el seguimiento estricto de los procedimientos deductivos frente a la actitud de entregarse al azar y la improvisación como nota vital que logra superar así los obstáculos en los que queda prisionera la abeja lógica. El par de animales antagónicos que se presentan luego de estos dos insectos epistemológicos son: El pavo inductivista, habitante de los Manuales de epistemología en los que se formaron generaciones de científicos y El cisne negro, presentado por Nassim Niklas Taleb, el filósofo libanés que representa en esta rara avis la actitud refutacionista de Karl Popper que, en oposición al inductivista quien confía en la constancia y regularidad de los acontecimientos, espera siempre la irrupción de lo altamente improbable, que se prepara para reorientar su investigación y romper las reglas transitadas hasta el momento. El pato-conejo, instalado en la epistemología a partir de los años 30' del Siglo XX, representa la ambigüedad siempre presente en las interpretaciones del mundo. Como dice Kuhn, lo que antes de la revolución eran patos, serán conejos después. En este sentido representa el pato-conejo la contrafigura de El gallo del positivismo, que se niega a admitir otra realidad que la de los "hechos" y en nombre de la objetividad y la imparcialidad se entroniza como verdad consagrada. El camello y El león riente son símbolos tomados de los animales de Nietzsche, que representan también personajes antagónicos donde el primero es obediente y carga con los pesos, transita el desierto, mientras el segundo representa la actitud del espíritu libre, todavía reactivo a los valores consagrados, todavía incompleto en su transformación hacia la ingenuidad del creador pero ya habitante de un mundo donde la risa es posible para confrontar con lo consagrado también como "serio". En paralelo con estas dos figuras nietzscheanas, El gato de Cheschire junto al Conejo Blanco tomados de Lewis Carroll parece simbolizar de este modo la actitud irónica y burlona del gato frente a las reglas impuestas por la Reina de Corazones. El Conejo Blanco, como contratara, representa la actitud servil y sumisa frente al poder imperante y el acatamiento a las reglas. El ornitorrinco es aludido por Umberto Eco para señalar los límites de todo sistema clasificatorio en su libro Kant y el ornitorrinco. Este símbolo muestra los límites de los sistemas clasificatorios y con ello los límites de nuestro lenguaje para inventar categorías universales. 
El gatopardo inverso nos da la nota característica de los procesos revolucionarios: la preocupación por mostrarse en continuidad con el paradigma hegemónico cuando está provocando su ruptura. Otras entidades como el humo del progreso, el árbol de la vida y el fantasma teleológico muestran la vigencia del positivismo y del creacionismo aún después de la revolución darwiniana.

Como nos dicen los autores, este Bestiario fue motivado, en solidaridad con la tradición iniciada por Esopo y La Fontaine para "aprender" algo de los animales y sacar alguna moraleja. También en solidaridad con otras obras geniales como Los viajes de Gulliver, Alicia en el país de las maravillas o el Zarathustra de Nietzsche, donde las caracterizaciones zoomórficas expresan el discurso de la racionalidad en el límite entre una animalidad humana y no humana, para tomar en broma la moralina que esconden las fábulas tradicionales.

El recurso a estas figuras resulta pertinente frente a un público de estudiantes nóveles, que no está totalmente en condiciones de acceder al tema propuesto de un modo puramente conceptual. La mediación de estos "animales" no pretende allanar las distancias entre los modelos científicos y la "supuesta" realidad que representarían sino que constituyen un modo más de hacer el intento de comprender la producción científico-tecnológica.

Como se dijo ya en el inicio, una de las actitudes destacadas en el libro es la de "tender puentes". La publicación del mismo libro es el resultado de esta actitud ya que la Facultad de Filosofía y Letras de la UBA es la editora de este libro que sirve de material de estudio para los estudiantes del Ciclo Básico Común de la UBA. Un rasgo de solidaridad y colaboración que merece ser destacado. También podemos advertir, en favor de la presentación de este Bestiario, la conveniencia de concebirnos como "animales" que más allá de la capacidad racional, tenemos compromisos de solidaridad y respeto con el resto de los seres vivos, con los que formamos una comunidad en tanto habitantes de un único y frágil planeta. 
160/ Perspectivas Metodológicas /19/Vol. II /Año 2017 